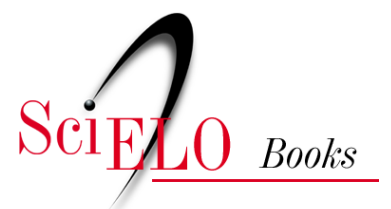

\title{
Vigilância alimentar e nutricional para a saúde Indígena
}

\author{
Denise Cavalcante Barros \\ Denise Oliveira e Silva \\ Silvia Ângela Gugelmin \\ (orgs.)
}

\section{SciELO Books / SciELO Livros / SciELO Libros}

BARROS, D.C., SILVA, D.O., and GUGELMIN, S.Â., orgs. Vigilância alimentar e nutricional para a saúde Indígena [online]. Rio de Janeiro: Editora FIOCRUZ, 2007, 254 p. Vol. 2. ISBN: 978-857541-589-4. Available from: doi: 10.7476/9788575415894. Also available in ePUB from: http://books.scielo.org/id/c9fjf/epub/barros-9788575415894.epub.

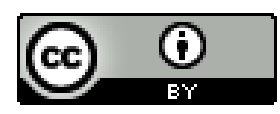

All the contents of this work, except where otherwise noted, is licensed under a Creative Commons Attribution $\underline{4.0 \text { International license. }}$

Todo o conteúdo deste trabalho, exceto quando houver ressalva, é publicado sob a licença Creative Commons Atribição 4.0. 


\section{Vigilância Alimentar e Nutricional para a Saúde Indígena}




\section{Fundação Oswaldo Cruz - Fiocruz}

PRESIDENTE

Paulo Marchiori Buss

VICE-PRESIDENTE DE ENSINO, INFORMAÇÃO E COMUNICAÇÃO

Maria do Carmo Leal

\section{Editora Fiocruz}

DIRETORA

Maria do Carmo Leal

EDITOR EXECUTIVO

João Carlos Canossa Mendes

EDITORES CIENTÍFICOS

Nísia Trindade Lima

Ricardo Ventura Santos

CONSELHO EDITORIAL

Carlos E. A. Coimbra Jr.

Gerson Oliveira Penna

Gilberto Hochman

Lígia Vieira da Silva

Maria Cecília de Souza Minayo

Maria Elizabeth Lopes Moreira

Pedro Lagerblad de Oliveira

Ricardo Lourenço de Oliveira
Escola Nacional de Saúde Pública Sergio Arouca

DIRETOR

Antônio Ivo de Carvalho

\section{Educação a Distância}

COORDENADORA GERAL

Lúcia Maria Dupret

ASSESSORAS PEDAGÓGICAS

Henriette Santos

Suely Guimarães Rocha 


\section{Vigilância Alimentar e Nutricional para a Saúde Indígena}

Denise Cavalcante Barros

Denise Oliveira e Silva

Silvia Ângela Gugelmin

Organizadoras
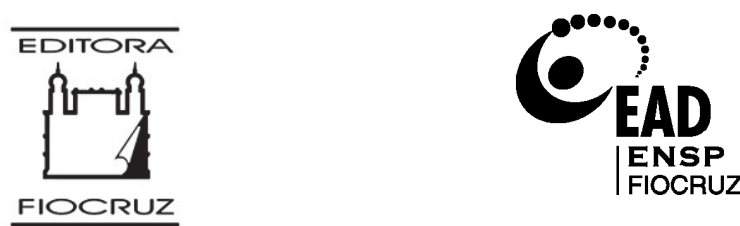
Copyright (C) 2008 dos autores

Todos os direitos de edição reservados à Fundação Oswaldo Cruz/Editora e EAD

Tiragem da edição: 700 exemplares

ISBN: 978-85-61445-06-5

EDITORA ASSISTENTE DA CO-EDIÇÃO

Christiane Abbade

SUPERVISÃO EDITORIAL

Jonathas Scott

Maria Leonor de M. S. Leal

REVISÃO METODOLÓGICA

Henriette Santos

Suely Guimarães Rocha
REVISÃO E NORMALIZAÇÃO

Alda Maria Lessa Bastos

Maria Auxiliadora Nogueira

Sonia Kritz

CRIAÇÃO E PROJETO GRÁFICO

Jonathas Scott

EDITORAÇÃO ELETRÔNICA

Quattri Desenhos

ILUSTRAÇÃO E TRATAMENTO DE IMAGEM

Quattri Desenhos

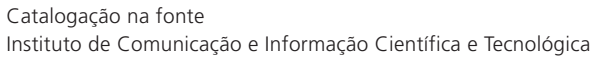

F981v Fundação Oswaldo Cruz. Escola Nacional de Saúde Pública Sergio Arouca. Educação a Distância

Vigilância Alimentar e Nutricional para a Saúde Indígena,

2./ Fundação Oswaldo Cruz. Escola Nacional de Saúde Pública Sergio Arouca. Educação a Distância; Organizado por Denise Cavalcante Barros, Denise Oliveira e Silva e Silvia Ângela Gugelmin. - Rio de Janeiro : Editora FIOCRUZ, 2008.

256 p. il., tab., graf.

1.Vigilância Nutricional. 2.Estado Nutricional. 3.Diagnóstico. 4.Antropometria. 5.Sistemas de Informação. 6.Saúde Indígena. 7.Educação a Distância. I.Barros, Denise Cavalcante (org.). II.Silva, Denise Oliveira e (org.). III.Gugelmin, Silvia Ângela (org.). IV.Título.

CDD - 22.ed. -371.35

2008

\section{Editora Fiocruz}

Avenida Brasil, 4036 - Sala 112

Manguinhos - CEP 21040-361 - Rio de Janeiro - RJ

Tels.: (21) 3882-9039 ou 3882-9041

Telefax: (21) 3882-9006

www.fiocruz.br/editora
Educação a Distância da Escola Nacional de Saúde Pública Sergio Arouca

Rua Leopoldo Bulhões, 1480

Prédio Professor Joaquim Alberto Cardoso de Melo Manguinhos - CEP 21041-210 - Rio de Janeiro - RJ Tel.: (21) 2598-2996

www.ead.fiocruz.br 
O mais importante e bonito,

do mundo, é isto:

que as pessoas não estão sempre iguais,

ainda não foram terminadas

- mas que elas vão sempre mudando.

Guimarães Rosa 


\section{Autores}

\section{Alessandra Bento Veggi David}

Nutricionista, com doutorado em Saúde Coletiva pelo Instituto de Medicina Social, Universidade do Estado do Rio de Janeiro.

\section{Aline Diniz Rodrigues Caldas}

Nutricionista, com especialização em Administração na área de Saúde Pública pela Escola Nacional de Saúde Pública Sergio Arouca, da Fundação Oswaldo Cruz (ENSP/Fiocruz).

\section{Denise Cavalcante Barros (organizadora)}

Nutricionista; doutoranda da Escola Nacional de Saúde Pública Sergio Arouca, da Fundação Oswaldo Cruz (ENSP/Fiocruz); tecnologista em Saúde Pública da Fiocruz; coordenadora do Centro Colaborador em Alimentação e Nutrição da Região Sudeste; coordenadora do curso de Vigilância Alimentar e Nutricional - modalidade a distância.

\section{Denise Oliveira e Silva (organizadora)}

Nutricionista, com doutorado em Ciências da Saúde pela Universidade de Brasília; pesquisadora adjunta da Fundação Oswaldo Cruz (Fiocruz); coordenadora de cursos de pós-graduação no campo da Segurança Alimentar e Nutricional, na Fiocruz de Brasília e na Escola Nacional de Saúde Pública Sergio Arouca (ENSP), com destaque para a coordenação do curso Vigilância Alimentar e Nutricional - modalidade a distância.

\section{Geila Cerqueira Felipe}

Nutricionista; assistente da direção do Instituto de Nutrição Annes Dias, da Secretaria Municipal de Saúde do Rio de Janeiro.

\section{Juliana Paulo e Silva}

Nutricionista; especialista em Nutrição Materno-Infantil pelo Instituto de Nutrição da Universidade do Estado do Rio de Janeiro.

\section{Maurício Soares Leite}

Nutricionista, com doutorado em Saúde Pública pela Escola Nacional de Saúde Pública Sergio Arouca, da Fundação Oswaldo Cruz (ENSP/Fiocruz); professor adjunto da Universidade Federal de Santa Catarina.

\section{Silvana Granado Nogueira da Gama}

Enfermeira, com doutorado em Saúde Pública pela Escola Nacional de Saúde Pública Sergio Arouca, da Fundação Oswaldo Cruz (ENSP/Fiocruz); pesquisadora titular da ENSP na área de Epidemiologia.

\section{Silvia Ângela Gugelmin (organizadora)}

Nutricionista, com doutorado em Saúde Pública pela Escola Nacional de Saúde Pública Sergio Arouca, da Fundação Oswaldo Cruz (ENSP/Fiocruz); professora adjunta do Instituto de Nutrição da Universidade do Estado do Rio de Janeiro. 


\section{Sumário}

Prefácio

Apresentação

Tiagnóstico nutricional na atenção à saúde

1. Bases para o diagnóstico nutricional

Denise Cavalcante Barros

2. Antropometria

Denise Cavalcante Barros, Geila Cerqueira Felipe, Juliana Paulo e Silva

3. Diagnóstico nutricional individual 75

Denise Cavalcante Barros, Silvia Ângela Gugelmin, Mauricio Soares Leite,

Alessandra Bento Veggi David

\section{II}

\section{Diagnóstico nutricional coletivo}

4. Construção do fluxo de dados

Denise Oliveira e Silva, Aline Diniz Rodrigues Caldas

5. Análise e interpretação dos dados.

Silvana Granado Nogueira da Gama, Denise Oliveira e Silva

6. Divulgação dos resultados

Denise Oliveira e Silva, Denise Cavalcante Barros

7. Uso dos dados e informações para o planejamento de ações e intervenções...

Denise Oliveira e Silva

Siglas 


\section{Prefácio}

Os progressos alcançados pela ciência nutricional perdem sua importância se não forem traduzidos em ações concretas. Por esse motivo, é um enorme prazer prefaciar um livro tão bem escrito, prático e relevante, que faz uma ponte entre os mais recentes avanços da pesquisa e o desafio de melhorar as condições nutricionais da população.

Mais relevante ainda é o fato de ser este livro especificamente direcionado à população indígena, com a qual nosso país tem uma enorme dívida histórica. Priorizar as comunidades indígenas com ações médicosanitárias é uma estratégia essencial para reduzir as enormes iniqüidades sociais que afligem a saúde dos brasileiros.

O livro é organizado de uma forma lógica, cobrindo tanto a avaliação nutricional de indivíduos quanto de comunidades. Seu enfoque direcionado ao ciclo vital abrange todas as faixas etárias, da concepção até a terceira idade. Coerentemente com a transição nutricional que atravessamos, os autores abordam com igual ênfase as duas faces perversas da desnutrição: tanto os déficits de crescimento ou subnutrição quanto o sobrepeso e a obesidade.

Tenho me dedicado ao estudo da evolução do estado nutricional por meio de estudos de coortes, em que indivíduos são acompanhados desde o nascimento até a idade adulta. Fico feliz em observar que os principais avanços obtidos por esse tipo de estudo de coortes já estão incorporados nesta publicação.

Quero salientar dois pontos fundamentais. O primeiro é a ênfase na importância do crescimento saudável no período pré-natal e durante os dois primeiros anos de vida. Resultados de nossos estudos confirmam ser 
este o período mais crítico para a nutrição humana. Conforme afirma o dito popular, "é de menino que se torce o pepino". O baixo peso ao nascer e a subnutrição nos dois primeiros anos de vida não apenas afetam a morbimortalidade de crianças, mas têm um impacto permanente sobre o capital humano. Crianças bem nutridas se tornam adultos mais altos e fortes, mais inteligentes, que atingem maior escolaridade e que têm maior renda na idade adulta do que crianças subnutridas. Na geração seguinte, os filhos de meninas bem nutridas já nascem com maior peso do que os filhos de meninas subnutridas. Esses benefícios são independentes da situação socioeconômica familiar dessas crianças. O crescimento inadequado entre a concepção e os dois anos de idade, portanto, traz danos irreversíveis para a saúde humana.

O segundo destaque neste livro, apoiado por nossos achados recentes, é sua ênfase na prevenção do sobrepeso e da obesidade. Paradoxalmente, a pior combinação possível para uma criança é padecer de subnutrição intra-uterina ou nos dois primeiros anos de vida, e em seguida ganhar peso rapidamente - principalmente a partir de cerca de quatro anos de idade e na adolescência. Essas crianças são "programadas" no início de suas vidas para se tornarem indivíduos pequenos e, ao ganharem peso, apresentam um aumento dramático no risco de doenças cardiovasculares e de diabete na idade adulta. Esse problema parece ser particularmente importante em alguns grupos étnicos, entre os quais se incluem os indígenas das Américas.

A vigilância nutricional é essencial para garantir os direitos humanos, reduzir as iniqüidades sociais e atingir a saúde para todos. É também um componente fundamental do desenvolvimento econômico, pois crianças desnutridas não alcançam seu potencial de contribuir para as comunidades em que vivem. Um texto rigoroso e prático como o deste livro, dirigido especificamente a um grupo populacional tão importante, embora historicamente excluído, traz uma contribuição fundamental para construir um país mais saudável e igualitário.

Cesar G. Victora

Médico, doutor em Epidemiologia pela London School of Hygiene and Tropical Medicine. Atualmente é professor emérito da Universidade Federal de Pelotas, consultor e perito em Nutrição da World Health Organization, e consultor do Conselho Nacional de Desenvolvimento Científico e Tecnológico. 


\section{Apresentação}

A proposta de construção do Sistema de Vigilância Alimentar e Nutricional (Sisvan) para a Saúde Indígena responde à demanda por informações em nível nacional sobre as condições alimentares e nutricionais dos povos indígenas no Brasil, que são a base para o estabelecimento de políticas e ações de intervenção alimentar e nutricional.

A partir de 2003, o componente Saúde Indígena do Projeto Vigisus II, da Fundação Nacional de Saúde (Funasa) - acordo entre o Governo do Brasil e o Banco Mundial -, visando vencer o desafio da ausência de informações, estabeleceu um subcomponente para a implantação do Sisvan no âmbito da Política Nacional de Saúde Indígena. O principal objetivo do Sistema é subsidiar ações, políticas e programas para a melhoria das condições nutricionais dos povos indígenas.

Uma das estratégias para a implantação do Sisvan na saúde indígena foi a criação do Curso Vigilância Alimentar e Nutricional para Saúde Indígena, uma parceria entre a Funasa/Projeto Vigisus II e a Escola Nacional de Saúde Pública Sergio Arouca (ENSP), da Fundação Oswaldo Cruz. O Curso visa a formação de mão-de-obra especializada para o desenvolvimento das ações de vigilância nutricional indígena em todos os Distritos Sanitários Especiais Indígenas (DSEI) do país.

A publicação do livro Vigilância Alimentar e Nutricional para a Saúde Indígena faz parte da estratégia de formação de profissionais envolvidos com saúde indígena. O volume 1 está centrado na discussão da realidade contemporânea dos povos indígenas no Brasil, especificamente em seus aspectos epidemiológicos, demográficos, alimentares e sociais. Nele é explorada a contextualização do perfil de morbimortalidade da população indígena, com destaque para os conhecimentos instrumentais que 
possibilitam ao leitor desenvolver um olhar critico em relação ao diagnóstico nutricional e ao Sisvan.

Esse sistema implica a reunião de diversas áreas de conhecimento. Nesse processo temos verificado que a epidemiologia, os sistemas de informação e vigilância à saúde e as estratégias para informar, comunicar e educar, são pressupostos que apóiam o planejamento dessa ação. Assim surge a construção do volume 2 do livro Vigilância Alimentar e Nutricional para a Saúde Indígena.

Este livro foi escrito por autores com ampla experiência em vigilância alimentar e nutricional, e com contribuições importantes para a saúde e a nutrição indígena. Teve como ponto de partida o material didático do Curso Vigilância Alimentar e Nutricional oferecido regularmente pela Educação a Distância/ENSP. O objetivo foi readequar o conteúdo, revisando e ampliando-o conforme o perfil dos profissionais que atuam na saúde indígena, a fim de possibilitar ao leitor desenvolver o diagnóstico nutricional individual e coletivo.

O livro Vigilância Alimentar e Nutricional para a Saúde Indígena, volume 2, é composto por duas partes: "Diagnóstico Nutricional na Atenção à Saúde" e "Diagnóstico Nutricional Coletivo". Os conteúdos apresentados em cada parte terão uma abordagem diferenciada. No decorrer dos capítulos, intercalamos atividades didáticas com o texto, de forma a reforçar o conhecimento adquirido nesse processo e facilitar o desenvolvimento do conjunto de ações previstas para a implantação/implementação do Sisvan no nível local.

A Parte I, "Diagnóstico Nutricional na Atenção à Saúde", é constituída por três capítulos e tem como objetivo consolidar as bases teóricas para a realização do diagnóstico nutricional na atenção básica, com destaque para a avaliação antropométrica nas diferentes fases da vida. Pretende oferecer aos leitores possibilidades de ampliação de seus conhecimentos no sentido de subsidiá-los na realização do diagnóstico nutricional.

"Bases para o Diagnóstico Nutricional" contempla os conceitos importantes e imprescindíveis para fazer um diagnóstico nutricional, seja ele individual ou coletivo. No nível individual, a pessoa é o foco da investigação e no nível coletivo, o foco passa a ser uma determinada população, que será estabelecida com base nos objetivos do estudo que se pretende realizar. Os diversos fatores que interferem no Estado Nutricional (EN) 
e as diversas formas de fazer um Diagnóstico Nutricional (DN) também serão abordados nesse Capítulo.

Em seguida, o Capítulo "Antropometria”, método de realização do DN mais utilizado nos serviços de saúde, aprofunda o estudo das técnicas e dos procedimentos usados nas medições antropométricas.

"Diagnóstico Nutricional Individual" aborda as ferramentas necessárias para fazer o DN em cada fase do curso de vida: infância, adolescência, idade adulta, gestação, terceira idade, pois cada uma apresenta particularidades que serão exploradas detalhadamente.

A Parte II deste livro, "Diagnóstico Nutricional Coletivo", é formada por quatro capítulos. O objetivo dessa unidade é discutir a dimensão coletiva do Sisvan a fim de gerar informações que contribuam na orientação das ações propostas pelos técnicos e/ou gestores, permitindo a reorganização dos serviços e, conseqüentemente, melhorando a qualidade da assistência prestada à saúde.

Para contextualizar o conteúdo teórico com a realidade da implantação do Sisvan nos DSEI, incluímos a leitura da Norma Técnica sobre Vigilância Alimentar e Nutricional nos DSEI, elaborada pela Funasa em parceria com a Fundação Oswaldo Cruz, como estratégia de orientação para a discussão do fluxo de dados. Esse material oferece um modelo de entrada de dados baseado em formulários específicos para o Sisvan, tanto para a coleta como para a consolidação.

Assim, nessa parte do livro são apresentadas as etapas de organização do fluxo de dados, que pressupõe: (1) construção do fluxo de dados; (2) análise e interpretação de resultados, baseados no uso de ferramentas estatísticas e epidemiológicas; (3) divulgação dos resultados; e (4) uso dos dados e informações para o planejamento de ações e intervenções. Ao final, esperamos que o leitor saiba construir um fluxo de dados, saiba tratar, analisar e interpretar as informações, e apoiar o planejamento para a escolha de ações e intervenções de forma participativa.

Ainda existem diversos limites e desafios na construção do Sisvan para a Saúde Indígena: a incorporação da "atitude de vigilância" como uma rotina básica de todos os integrantes da equipe multidisciplinar de saúde; a discussão de sistemas de informação e da vigilância a saúde para a população indígena; e o reconhecimento de que os sistemas devem ser 
integrados. A solução desses e de outros desafios que se colocam cabe a todos nós, pois fazemos parte de uma iniciativa inovadora na Saúde Indígena e precisamos atuar como protagonistas desse processo, agentes de mudanças e de transformação.

Este livro representa mais um avanço da parceria entre a Fiocruz e a Equipe Vigilância Alimentar e Nutricional/Projeto Vigisus II/Funasa, na construção e consolidação da vigilância alimentar e nutricional para a Saúde Indígena e na concretização dos princípios básicos do Sistema Único de Saúde (SUS) para os povos indígenas brasileiros.

As Organizadoras 


\section{Diagnóstico nutricional na atenção à saúde}




\section{Bases para o diagnóstico nutricional}

Denise Cavalcante Barros

Neste Capítulo, vamos discutir os princípios fundamentais, isto é, os conhecimentos essenciais que orientam a adequada utilização das técnicas estabelecidas para a realização do diagnóstico nutricional de indivíduos e coletividades.

Nosso objetivo é o de desenvolvermos, juntos, uma boa base teóricoprática para a realização do diagnóstico nutricional em seu trabalho. Desta forma você produzirá informações confiáveis e úteis para a tomada de decisão quanto a ações que visem melhorar a situação de saúde e nutrição da população atendida.

Os princípios básicos da realização do diagnóstico nutricional, tanto para o indivíduo quanto para uma coletividade, são os mesmos e, por isso, iniciamos nossos estudos refletindo sobre a definição de diagnóstico nutricional.

\section{O que é um diagnóstico nutricional?}

Um diagnóstico clínico é definido como conhecimento ou determinação de uma doença pelos sintomas e/ou mediante exames diversos, tais como radiológicos, laboratoriais, físicos etc. (FERREIRA, 1986).

A partir desse conceito, percebemos que, para realizar um diagnóstico, precisamos conhecer a sintomatologia da doença e o que a determina, ou seja, os determinantes de uma situação ou um problema. A partir 
Diagnóstico nutricional é a identificação e determinação do estado nutricional do indivíduo, elaborado com base em dados clínicos, bioquímicos, antropométricos e dietéticos, obtidos quando da avaliação nutricional e durante o acompanhamento individualizado (CONSELHO FEDERAL DE NUTRICIONISTAS, 2005).
Estado Nutricional (EN) é a condição resultante do equilíbrio entre o consumo alimentar e o gasto energético do organismo. Relacionase ao estado de saúde do indivíduo e com a capacidade do organismo em utilizar adequadamente os nutrientes (ENGSTROM et al., 2002). da detecção e do conhecimento dessa situação e de suas causas, necessitamos também saber qual a sua extensão para, então, pensarmos na intervenção.

O diagnóstico que nos interessa no momento é o nutricional e refere-se ao conhecimento do efeito do(s) problema(s) "alimentação-nutrição" que acomete $(\mathrm{m})$ indivíduos ou populações. Ao realizarmos esse diagnóstico, estamos, na verdade, querendo identificar a situação de nutrição de uma pessoa ou de um grupo. O que nos interessa realmente é saber se há, qual é, e como se comporta um problema que pode interferir negativamente na saúde das pessoas. Respondidas essas questões, teremos subsídios para propor ações que busquem solucionar o problema encontrado, seja para o indivíduo seja para o coletivo.

Em resumo: quando nos propomos a realizar um diagnóstico nutricional, quer individual quer coletivo, a intenção, na verdade, é conhecer um problema que nos interessa em particular, preferencialmente encontrando respostas para as seguintes questões:

1. Que condições levam ao seu aparecimento? (determinantes)

2. Como se identifica o problema individualmente? (diagnóstico individual)

3. Qual a extensão do problema, ou seja, sua magnitude, quais as tendências no tempo, distribuição geográfica, grupos populacionais de maior risco? (perfil ou diagnóstico coletivo)

4. Como podemos solucioná-lo nas esferas coletiva e individual? (intervenção)

Para que todos esses passos sejam dados de forma segura, é preciso, antes de tudo, conhecer bem as técnicas e os instrumentos adequados para realizar um diagnóstico nutricional.

Utilizando corretamente esses instrumentos e técnicas, você terá dados confiáveis e eles serão a base para toda e qualquer ação de promoção, recuperação e manutenção da saúde e nutrição de indivíduos e coletividades. Falaremos sobre essas ações mais adiante.

Ao realizar um diagnóstico nutricional, estaremos, então, conhecendo o estado nutricional das pessoas. Você sabe o que é estado nutricional? 
Estado nutricional é a situação de nutrição de um indivíduo. Ele é diretamente determinado pela relação entre a quantidade de alimentos ingerida (o combustível do nosso corpo) e a quantidade de energia que nosso organismo despende para o desempenho de suas diversas funções e atividades do dia-a-dia. O que queremos dizer é que o EN sofre influência direta tanto da "ingestão de alimentos", quanto do "gasto energético" do corpo. Ou seja, se há um desequilíbrio entre ingestão e gasto, o EN de uma pessoa estará comprometido de alguma forma.

Vejamos:

Se sua ingestão alimentar é suficiente para repor toda a energia que seu organismo consome, há um equilíbrio.

Se sua ingestão alimentar é menor do que o gasto energético, seu organismo está em desequilíbrio, isto é, em déficit nutricional, podendo causar desnutrição ou outra carência nutricional.

E, ainda, se sua ingestão alimentar é maior do que seu gasto energético, haverá um excesso, podendo causar obesidade, diabetes, hipertensão, entre outros distúrbios nutricionais.

Figuras 1, 2 e 3 - Relação entre consumo alimentar e gasto energético

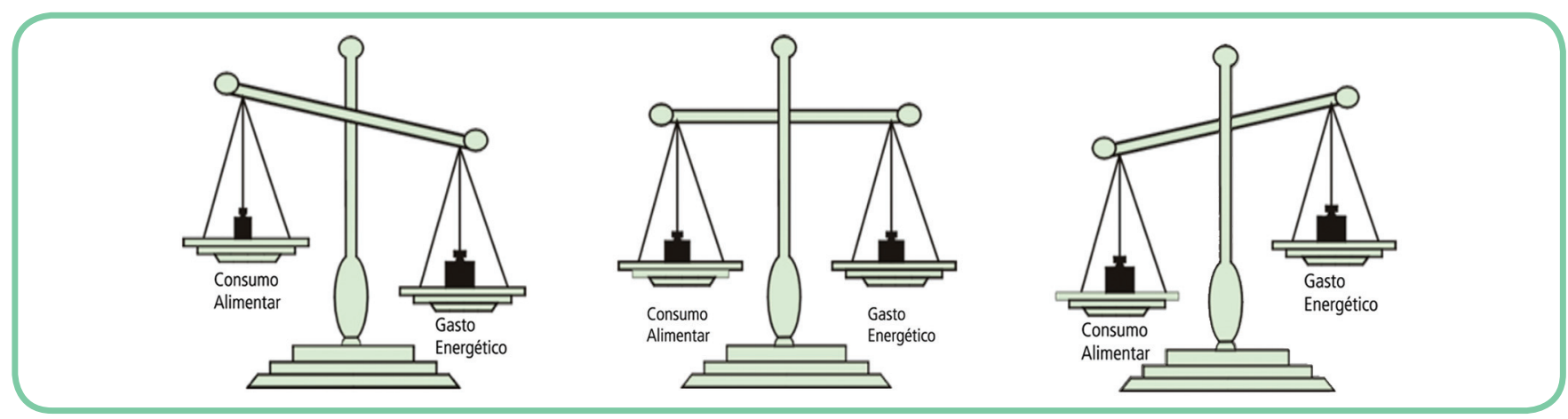

Fonte: Engstrom et al. (2002).

\section{Para refletir}

Observando as Figuras 1, 2 e 3, o que você acha que cada situação pode causar ao indivíduo? 
Necessidades nutricionais referem-se à quantidade de nutrientes suficiente para atender a necessidade de quase todos os indivíduos saudáveis em um determinado estágio de vida e gênero (FISBERG et al., 2005).
Os temas produção de alimentos, diversidade alimentar, sazonalidade e reciprocidade são abordados no Capítulo 7 do livro Vigilância Alimentar e Nutricional para a Saúde Indígena, volume 1, de Denise Cavalcante Barros, Denise Oliveira e Silva e Silvia Ângela Gugelmin (2007).
Para ser considerada adequada, isto é, equivalente ao gasto energético, a ingestão alimentar deve corresponder às necessidades nutricionais individuais. Essas necessidades são estabelecidas com base em vários fatores, tais como:

- fase do curso da vida (infância, adolescência, gestação etc.);

- atividade física;

- doenças que aceleram o metabolismo (por exemplo, febre, infecções).

Outro fator que contribui para a determinação do estado nutricional de um indivíduo é a utilização biológica do alimento consumido, ou seja, como o organismo aproveita os nutrientes que compõem esses alimentos. Essa utilização pode sofrer influência, por exemplo, de algumas patologias que interferem nesse processo.

Consumo ou ingestão alimentar, gasto energético, utilização biológica de nutrientes são fatores que compõem a "dimensão biológica" da determinação do estado nutricional de um indivíduo. Nessas situações, a intervenção deve ser imediata, mas nem sempre o problema é facilmente resolvido, pois outras questões de cunho mais abrangente podem estar interferindo. Queremos dizer com isso que não são somente os fatores biológicos que influenciam o estado nutricional.

A ingestão alimentar a que nos referimos anteriormente pode também ser denominada de consumo alimentar, e o sentido do termo "consumo", aqui utilizado, está relacionado à quantidade e à qualidade do alimento ingerido por uma pessoa. No entanto, esse termo pode ter um sentido muito mais abrangente. Consumo alimentar também está relacionado com a produção de um alimento, sua oferta e sua aquisição, ou seja, com o "acesso" a ele.

Para ter acesso aos alimentos, é preciso que eles estejam disponíveis às pessoas. Por exemplo: que sejam produzidos nas roças, coletados no mato, doados ou trocados pelo sistema de reciprocidade, estejam à venda no mercado regional. É necessário, ainda, que sua produção seja suficiente para atender a demanda da população, dependendo, então, das condições ambientais, da degradação do solo, do ciclo sazonal.

Assim, o acesso está relacionado a questões que extrapolam a dimensão biológica. Ele é influenciado por fatores socioeconômicos, políticos, ambientais e culturais. Por exemplo: um indivíduo pode estar com anemia porque sua ingestão de alimentos ricos em ferro é insuficiente. A ingestão insuficiente pode ter origem no fato de que, na região onde 
mora, os alimentos ricos em ferro (carnes, feijão, rapadura) não estão disponíveis no ambiente ou no mercado e, conseqüentemente, o acesso a eles está prejudicado. Também pode acontecer de o alimento estar disponível no mercado, mas o indivíduo não ter recursos financeiros para adquiri-lo, ou até não ter o hábito de consumi-lo.

\section{Para refletir}

Você conhece ou já vivenciou no seu trabalho com povos indígenas alguma situação parecida com o que acabamos de citar? Relate-o.

A partir desses exemplos, podemos observar como os fatores sociais interferem no estado nutricional dos indivíduos. Esses fatores compõem a "dimensão social" da determinação do EN. Outros fatores, tais como o acesso aos serviços de saúde, a falta de saneamento básico etc., também contribuem nesse processo. No entanto, sabemos que essas questões são de difícil resolução, pois demandam estratégias de intervenção mais amplas, profundas e quase sempre de longo prazo.

É importante lembrar que o conceito de EN foi construído sob os preceitos da biomedicina ou da medicina ocidental e pode ser insuficiente para descrever a realidade indígena.

\section{Para refletir}

O que a(s) comunidade(s) indígena(s) com a(as) qual(quais) você trabalha pensa $(\mathrm{m})$ sobre estado nutricional e como ela(s) o define $(\mathrm{m})$ ? A definição é diferente entre as comunidades?

Como você faria um diagnóstico nutricional nas comunidades em que trabalha? Quais seriam os métodos que você utilizaria? Por quê?

\section{O que é necessário para fazer um diagnóstico nutricional?}

Como vimos anteriormente, fazer um diagnóstico implica:

1. saber o que o determina;

2. identificar o problema;

3. saber qual sua extensão (sua magnitude, tendências no tempo, distribuição geográfica, grupo de maior risco);

4. propor intervenções.
Os conceitos de saúde-doença dos povos indígenas brasileiros; a construção do corpo; noções de natureza e fisiologia indígena são abordados no Capítulo 2 do livro Vigilância Alimentar e Nutricional para a Saúde Indígena, volume 1, de Denise Cavalcante Barros, Denise Oliveira e Silva e Silvia Ângela Gugelmin (2007). 
Para cumprir essas etapas é preciso, antes de tudo, conhecer os métodos disponíveis e recomendados pela Organização Mundial da Saúde (OMS) e identificar alguns conceitos importantes que são necessários para você fazer um diagnóstico nutricional (WORLD HEALTH ORGANIZATION, 1995).

Os métodos para avaliação nutricional são classificados em dois grupos: diretos e indiretos, e a sua escolha deve se dar de acordo com os objetivos do seu estudo.

Os métodos diretos expressam objetivamente as manifestações biológicas de um desequilíbrio nutricional. As ferramentas usadas são os exames clínicos, bioquímicos e antropométricos.

Os métodos indiretos explicam os determinantes da situação de nutrição de indivíduos e/ou coletividades. As ferramentas utilizadas para se conhecer a causalidade do problema nutricional são informações sobre a situação socioeconômica e de consumo alimentar de indivíduos/coletividades, bem como taxas que expressam sua situação de saúde.

O Quadro 1 apresenta um resumo desses métodos.

Quadro 1 - Métodos utilizados para realização do diagnóstico nutricional

\begin{tabular}{|c|c|}
\hline Métodos diretos & Métodos indiretos \\
\hline $\begin{array}{l}\text { CLínICO: } \\
\text { Exame físico para identificação de sinais e } \\
\text { sintomas de carências nutricionais. } \\
\text { Por exemplo: presença de edema na } \\
\text { gravidez; identificação de manchas } \\
\text { brancas acinzentadas (Bitot) nos olhos para } \\
\text { investigação de hipovitaminose A. }\end{array}$ & $\begin{array}{l}\text { INQUÉRITO SOCIOECONÔMICO: } \\
\text { Busca compreender as causas do EN, no âmbito social. } \\
\text { Por exemplo, ocupação: é a atividade } \\
\text { efetivamente desenvolvida pelo chefe da família. } \\
\text { Veja o caso de Alcides, que trabalha em sua roça } \\
\text { e no período de colheita foi contratado como } \\
\text { ensacador; essa é a sua ocupação atual. Portanto, } \\
\text { saber apenas qual é a profissão de uma pessoa } \\
\text { não indica se está realmente atuando nela. }\end{array}$ \\
\hline $\begin{array}{l}\text { BIOQUÍMICO: } \\
\text { Exame laboratorial para identificar carências } \\
\text { específicas de micronutrientes. } \\
\text { Por exemplo: valor de hemoglobina para avaliar } \\
\text { presença de anemia. }\end{array}$ & $\begin{array}{l}\text { ESTATÍSTICAS VITAIS: } \\
\text { Retratam o perfil de saúde e nutrição de uma } \\
\text { população. } \\
\text { Por exemplo, tamanho da família: conhecer o } \\
\text { número de pessoas que compõem uma família } \\
\text { pode nos dar uma pista de como é a distribuição } \\
\text { intrafamiliar dos alimentos. }\end{array}$ \\
\hline $\begin{array}{l}\text { ANTROPOMÉTRICO (antropometria): } \\
\text { Exame das medidas do corpo para avaliar o } \\
\text { crescimento e o desenvolvimento. } \\
\text { Por exemplo, peso gestacional: para } \\
\text { avaliar se a gestante está ganhando peso } \\
\text { adequadamente, conforme o esperado para seu } \\
\text { tempo de gravidez, e, com isso, identificar se o } \\
\text { bebê está se desenvolvendo bem. }\end{array}$ & $\begin{array}{l}\text { CONSUMO ALIMENTAR: } \\
\text { Visa avaliar a ingestão de alimentos e bebidas e/ } \\
\text { ou o comportamento do consumo de alimentos. } \\
\text { Por exemplo, recordatório de } 24 \text { horas para } \\
\text { identificar o tipo, a quantidade e a qualidade de } \\
\text { alimentos e bebidas consumidos nas últimas } 24 \\
\text { horas. }\end{array}$ \\
\hline
\end{tabular}


Alguns desses métodos podem ser utilizados tanto no diagnóstico de indivíduos quanto no de coletividades. A escolha do método irá depender dos objetivos do estudo a ser desenvolvido. Vários dados obtidos com a aplicação desses métodos já são conhecidos e utilizados por grande parte dos profissionais da saúde.

\section{Qual é o método utilizado para avaliar o estado nutricional na atenção à saúde?}

Uma vez que, no Brasil, o Sistema de Vigilância Alimentar e Nutricional foi incorporado principalmente pelo setor saúde, o método antropométrico tem sido o mais utilizado, sendo recomendado em todas as publicações do Ministério da Saúde. Visto que o Sisvan Indígena também foi ou está sendo implementado pelo setor saúde, vamos enfatizar, neste livro, o uso do método antropométrico.

\section{Para refletir}

Em sua opinião, por que a antropometria é o método mais usado no setor saúde?

No entanto, os estudos nacionais de perfil nutricional vêm demonstrando mudanças referentes ao aumento do ganho de peso na população, em geral como um reflexo do estilo de vida e padrão alimentar dos dias atuais (ENGSTROM, 2007). Assim, a preocupação dos pesquisadores/ gestores vem aumentando cada vez mais, com o sentido de realizar estudos sobre consumo alimentar, seja da população como um todo ou para grupos populacionais específicos.

Com o objetivo de oferecer algumas informações e abrir caminhos que possam facilitar a realização de estudos sobre consumo alimentar, optamos pela apresentação sucinta desse método. A intenção é proporcionar um primeiro contato para muitos de vocês e estimular a reflexão sobre a importância deste tipo de estudo e como ele pode contribuir para a escolha de possíveis intervenções.

\section{- Método do consumo alimentar}

O método do consumo alimentar tem por finalidade obter, da forma mais precisa possível, informações quantitativas e/ou qualitativas sobre a ingestão de alimentos e bebidas e de práticas alimentares individuais e/ ou da população. Essas informações têm uma reconhecida importância
A história do Sisvan no Brasil é abordada no Capítulo 6 do livro Vigilância Alimentar e Nutricional para a Saúde Indígena, volume 1, de Denise Cavalcante Barros, Denise Oliveira e Silva e Silvia Ângela Gugelmin (2007). O tema antropometria, por sua vez, será melhor detalhado nos Capítulos 2 e 3 do presente volume.

As mudanças no perfil nutricional da população brasileira são discutidas no Capítulo 5 do livro Vigilância Alimentar e Nutricional para a Saúde Indígena, volume 1, de Denise Cavalcante Barros, Denise Oliveira e Silva e Silvia Ângela Gugelmin (2007)

Práticas alimentares referemse aos modos como os povos se alimentam e, em termos mais amplos, às atividades relacionadas à alimentação. Este conceito está descrito nos Capítulos 5 e 7 do livro Vigilância Alimentar e Nutricional para a Saúde Indígena, volume 1, de Denise Cavalcante Barros, Denise Oliveira e Silva e Silvia Ângela Gugelmin (2007). 
Epidemiologia é tradicionalmente definida como o estudo da distribuição e determinação das doenças e outros agravos à saúde, que pode também ser classificada como Epidemiologia descritiva e Epidemiologia analítica, respectivamente (SZKLO \& JAVIER NIETO, 2007).
O Capítulo 1 do livro Vigilância Alimentar e Nutricional para a Saúde Indígena, volume 1, de Denise Cavalcante Barros, Denise Oliveira e Silva e Silvia Ângela Gugelmin (2007), apresenta a discussão da sociodiversidade indígena no Brasil No Capítulo 7 do referido livro a sociodiversidade é retomada, quando tratamos da alimentação indígena. para o diagnóstico indireto do estado nutricional de indivíduos e populações, pois contribuem para a complementação de estudos clínicos e epidemiológicos, para a formulação e orientação de políticas de produção e comercialização de alimentos, e para o planejamento e avaliação de programas de intervenção nutricional (VASCONCELLOS, 2007).

A medição do consumo alimentar é sempre uma estimativa que poderá - ou não - retratar, de forma mais precisa, a ingestão real do indivíduo e/ou da população. Não é uma tarefa simples conhecer o que um indivíduo come, especialmente quando nos referimos à sociodiversidade dos povos indígenas brasileiros.

Além da diversidade, encontramos outras dificuldades na execução de um inquérito alimentar, tais como: sistemas numéricos, idiomas e noção de porcionamento diferentes daqueles que estamos acostumados a usar, memória; variação diária no consumo; cansaço, incômodo e interferência na conduta alimentar; hábito de comer e preparar determinados alimentos, que não serão explicitadas no momento de uma entrevista ou de uma consulta, devido à vergonha ou ao embaraço, entre outras.

A decisão de fazer um estudo sobre consumo alimentar deve acontecer após a escolha do "melhor" método a utilizar. Nesse caso, devemos sempre considerar:

- o objetivo do estudo;

- a população a ser estudada;

- a reprodutibilidade do método;

- os recursos disponíveis; e

- os aspectos custo-efetividade.

Com base nos itens anteriormente citados teremos condições de escolher um dentre os métodos de avaliação do consumo alimentar individual e/ou coletivo, os quais podem ser classificados como retrospectivos e prospectivos, caracterizando o período de tempo em que as informações são obtidas. Os métodos de inquéritos dietéticos usados para a investigação do consumo alimentar são: recordatório 24 horas; história alimentar; questionário de freqüência alimentar; registro alimentar e análise de duplicata das porções (FISBERG et al., 2005). 
A título de exemplo, quando a intenção é caracterizar a ingestão habitual, os métodos de memória (freqüência alimentar e recordatório dietético) são as melhores opções; já para a avaliação da ingestão atual, os dados são mais bem obtidos por meio de registro alimentar, pesagem dos alimentos ou duplicata das porções.

Assim, a escolha do método depende do tipo de estudo que o pesquisador irá realizar, pois a avaliação do consumo de um dia específico é muito pobre para estimar a ingestão média de um indivíduo. Se o interesse da análise é caracterizar a dieta desse indivíduo, será necessário maior número de observações, o que difere da avaliação de um grupo de pessoas (PENNINGTON, 1991).

Outros fatores, como o número de pessoas investigadas e de entrevistadores disponíveis, a capacidade de compreensão dos indivíduos avaliados, o número de dias necessários para identificar o consumo de um determinado nutriente e o tempo para a coleta dos dados dietéticos - se a avaliação se refere ao consumo habitual de um período de tempo do passado presente ou mais antigo - também influenciam na escolha do método. Considerando esses aspectos ainda na fase do planejamento, a ocorrência de erros poderá ser controlada ou minimizada, tornando o estudo mais preciso (WILLET, 1998; FISBERG et al., 2005).

Portanto, avaliar o consumo alimentar de um indivíduo ou de uma população não é uma tarefa fácil. São muitos métodos disponíveis e há erros inerentes a cada método e forma de análise que precisam ser controlados. É importante considerar a representatividade da população, dos dias da semana e do número de dias necessários para obter a ingestão de um determinado nutriente. Por isso, se nos dispusermos a trabalhar com esse método, precisaremos aprofundar nosso conhecimento nessa área e, se necessário, solicitar ajuda de pessoas com experiência em estudos de consumo alimentar. Se resolvermos fazer um estudo sem esse conhecimento prévio, os resultados possivelmente não representarão a realidade do grupo ou do indivíduo estudado.

A avaliação do consumo de alimentos de um indivíduo ou de uma população implica um conhecimento detalhado dos diversos métodos existentes, de sua utilização e formas de análise dos dados. Enfim, apesar de ser útil, não é de fácil aplicação. Por exemplo: não é recomendável usar apenas um recordatório de 24 horas para avaliar a ingestão habitual de

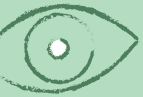

Sugerimos a seguintes leituras para o aprofundamento do tema consumo alimentar:

- Inquéritos alimentares: métodos e bases científicas, de Regina Mara Fisberg e colaboradores (2005):

- Avaliação nutricional de coletividades, de Francisco de Assis Guedes Vasconcelos (2007). 
Precisão, também denominada reprodutibilidade ou confiabilidade, refere-se à consistência dos resultados quando a medição ou exame se repete (PEREIRA, 2000).

Este conceito será discutido mais profundamente no Capítulo 3, deste livro. energia e carboidratos de um indivíduo. Para conhecermos seu consumo habitual, precisaríamos aplicar 31 dias de recordatórios para o mesmo indivíduo, e isso é impraticável na rotina diária de um serviço de saúde ou em um estudo (BASIOTIS et al., 1987). Por isso, as informações sobre consumo alimentar geralmente são apresentadas para grupos de pessoas e são colhidas por meio de pesquisas científicas. Tomando o mesmo exemplo anterior do consumo de energia e carboidratos quando avaliamos grupos de indivíduos, a precisão parece melhorar aumentando-se o número da amostra. Em uma amostra típica de 10 a 20 pessoas, estima-se que aproximadamente três dias de recordatório sejam necessários para avaliar a ingestão de energia.

Por isso a antropometria é amplamente utilizada nos serviços de saúde. Ela é um método de menor custo, se comparado aos demais, fácil, simples de aplicar e não apresenta riscos ou danos à saúde. Ela é capaz de dar respostas imediatas do estado nutricional e faz parte da rotina dos serviços de saúde, não importando seu nível de abrangência e atuação. É um método que traduz muito bem as dimensões corporais, tem correlação significativa com as condições de nutrição e saúde, e pode ser utilizado para realizar o diagnóstico nutricional tanto de indivíduos quanto de coletividades. Em nível coletivo, permite a triagem de grupos de risco nutricional, apontando as prioridades de atenção do serviço de saúde (ENGSTRON, 2002; VASCONCELOS, 2007).

Para refletir

Você já teve alguma experiência significativa de utilização do diagnóstico de consumo alimentar em seu serviço? Qual sua análise sobre o fato?

\section{Como transformar dados em informação?}

Após a aplicação dos métodos diretos e indiretos de diagnóstico nutricional, vamos obter dados importantes que poderão ser utilizados para o diagnóstico nutricional. Alguns desses dados, chamados também de variáveis, são coletados e registrados diariamente nos serviços de saúde; contudo, se analisados isoladamente não terão utilidade alguma. Para que eles sejam transformados em uma informação, é preciso agrupá-los a outros, formando um índice. Aí sim, analisando o peso em relação à idade, por exemplo, essa informação será capaz de nos dizer muita coisa. 
Portanto, para sistematizarmos as idéias, temos:

- Variável - é o dado isolado, por exemplo, peso, altura, idade etc.

- Índice - quando relacionamos uma ou mais variáveis.

- Indicador - medida qualitativa ou quantitativa que descreve uma determinada situação do problema nutricional, compreendendo limites de normalidade ou adequação (pontos de corte).

Como o próprio nome sugere, o indicador tem por objetivo informar a ocorrência e revelar as características do problema encontrado; no nosso caso, de um problema nutricional. Para tanto, faz-se necessário estabelecer limites de normalidade, denominados também de pontos de corte. Como exemplo de indicador, podemos citar o peso ao nascer. $\mathrm{O}$ peso do recém-nascido pode indicar se ele sofreu desnutrição durante a gestação. Nesse exemplo, o limite de normalidade é $2.500 \mathrm{~g}$, ou seja, crianças nascidas com peso abaixo de $2.500 \mathrm{~g}$ são de baixo peso e, por isso, necessitam de atenção especial, pois são consideradas de risco.

Estudamos vários conceitos indispensáveis para realizar os diagnósticos nutricionais, individuais ou coletivos. Vamos retomar os mais importantes?

1. Diagnóstico nutricional - tem o objetivo de conhecer o(s) problema(s) de nutrição que acomete $(\mathrm{m})$ indivíduos ou populações. Ao realizar um diagnóstico nutricional, buscamos, além de saber o que o está determinando, identificar o problema, qual sua extensão para então intervir sobre ele.

2. Estado nutricional (EN) - é a situação de nutrição de um indivíduo. Tem relação direta com ingestão alimentar e gasto energético. Quando essa relação está em equilíbrio, podemos dizer que o EN do indivíduo é normal, mas quando há um desequilíbrio, pode estar ocorrendo um excesso ou um déficit nutricional.

3. Necessidades nutricionais - quantidade de nutrientes necessária para cada indivíduo, determinada por estudos científicos.

4. O EN sofre interferência direta de diversos fatores que podem ser biológicos - dimensão biológica -, ou sociais - dimensão social.

5. Para fazer um diagnóstico nutricional, utilizamos os métodos diretos e/ou indiretos; podemos usar um tipo de método em complementação ao
No Capítulo 3 aprofundaremos o conhecimento sobre indicadores para avaliação do estado nutricional de cada fase do curso de vida. No Capítulo 5 novamente trabalharemos o tema transformação do dado em informação. 
O tema modelo causal e determinação do estado nutricional também é tratado no Capítulo 4 do livro Vigilância Alimentar e Nutricional para a Saúde Indígena, volume 1, de Denise Cavalcante Barros, Denise Oliveira e Silva e Silvia Ângela Gugelmin (2007). outro. Esses métodos podem ser empregados para o diagnóstico tanto individual quanto coletivo; a escolha irá depender dos objetivos da investigação/estudo que se pretende realizar.

6. Variável - dados isolados, tais como peso, altura, idade, sexo, idade gestacional etc.

7. Índice - para construir um índice, utilizamos duas ou mais variáveis e as comparamos entre si. Por exemplo: peso para idade, peso para altura, altura para idade, peso para idade gestacional etc.

8. Indicador - informa que um problema está ocorrendo e revela suas características, por meio da comparação com os pontos de corte previamente estabelecidos.

9. Pontos de corte - limites de normalidade, estabelecidos por estudos científicos.

\section{PARA CONSOLIDAR SEUS CONHECIMENTOS}

Com base na leitura deste primeiro Capítulo, "Bases para o diagnóstico nutricional", e em seu conhecimento sobre modelos causais para desnutrição infantil, reveja seus conceitos sobre a determinação do estado nutricional na infância. Reflita a respeito dessa questão em sua realidade e pense:

- Como você construiria um modelo causal para sua população?

- Quais seriam os possíveis determinantes a serem contemplados na construção de um modelo causal em sua realidade?

\section{Referências}

BARROS, Denise Cavalcante (Org.). Sisvan: instrumento para o combate aos distúrbios nutricionais na atenção à saúde: a antropometria. Rio de Janeiro: SDE/ENSP/Fiocruz, 2005.

BARROS, Denise Cavalcante (Org.); SILVA, Denise Oliveira e (Org.); GUGELMIN, Silvia Ângela (Org.). Vigilância alimentar e nutricional para a saúde indígena, 1. Rio de Janeiro: Fiocruz/ENSP/Educação a Distância, 2007.

BASIOTIS, P. P. et al. Number of days of food intake records required to estimate individual and group nutrient intakes with defined confidence. Journal of Nutrition, v. 177, n. 9, p. 1638-1641, Sept. 1987. 
CONSELHO FEDERAL DE NUTRICIONISTAS (Brasil). Resolução CFN n. 380/2005. Brasília, 2005.

Disponível em: <http://dtr2004.saude.gov.br/nutricao/documentos/resolucao_cfn_380.pdf>. Acesso em: 24 abr. 2007.

ENGSTROM, E. M. (Org.) Sisvan: instrumento para o combate aos distúrbios nutricionais em serviços de saúde: o diagnóstico nutricional. Rio de Janeiro: CECAN/ENSP/Fiocruz, 2002.

Situações e determinantes de saúde e nutrição da população brasileira. In: BARROS, Denise Cavalcante (Org.); SILVA, Denise Oliveira e (Org.); GUGELMIN, Silvia Ângela (Org.). Vigilância alimentar e nutricional para a saúde indígena, 1. Rio de Janeiro: Fiocruz/ENSP/Educação a Distância, 2007.

FERREIRA, A. B. H. Novo dicionário da língua portuguesa. 2. ed. Rio de Janeiro: Nova Fronteira, 1986.

FISBERG, R. M. et al. Inquéritos alimentares: métodos e bases científicas. Rio de Janeiro: Manole, 2005.

PENNINGTON, J. A. T. Methods for obtaining food consumption information. In: MACDONALD, I. Monitoring dietary intakes. New York: Springer-Verlog, 1991.

PEREIRA, M. G. Aferição dos eventos. In: Epidemiologia: teoria e prática. 4. reimpr. Rio de Janeiro: Guanabara Koogan, 2000.

SZKLO, M.; JAVIER NIETO, F. Epidemiology beyond the basics. Maryland: Aspen Publication. 2007.

VASCONCELOS, F. A. G. Avaliação nutricional de coletividades. 4. ed. Florianópolis: Ed. da UFSC, 2007.

WORLD HEALTH ORGANIZATION. Physical status: the use and interpretation of antropometry. Geneva, 1995. (Who technical report series, 854)

WILLET, W. Nature of variation in diet. In: Nutritional epidemiology. Oxford: Oxford University Press, 1998. p. 33-49. 


\section{Antropometria}

Denise Cavalcante Barros

Geila Cerqueira Felipe

Juliana Paulo e Silva

Neste Capítulo vamos aprofundar o estudo da antropometria, método que iremos utilizar para determinar o estado nutricional (EN) dos indivíduos. A antropometria é aplicada nos serviços de saúde e, como já dissemos, é um método prático e amplamente aceito pela população.

A antropometria tem como objetivo mensurar as medidas corporais. Existem vários tipos de medidas antropométricas e cada uma cumpre um objetivo. São elas:

- Peso - estima a massa corporal. O peso é a medida mais sensível às alterações nutricionais, isto é, a perda de peso é o primeiro sinal de que há algo errado - probabilidade de existência de alguma patologia.

- Altura - estima a dimensão linear do corpo. Modificações na altura são mais lentas: uma restrição alimentar de longo prazo pode ocasionar diminuição da velocidade de crescimento.

- Perímetros - estimam a dimensão linear de segmentos corporais. Os diversos tipos de perímetro são: cefálico, torácico, braquial, de cintura, abdominal, de quadril e de coxa.

- Pregas cutâneas - estimam a quantidade de gordura corporal subcutânea. Os diversos tipos são: bicipital, tricipital, subescapular, suprailíaca, de coxa, abdominal e de panturrilha.

Como já vimos anteriormente, uma medida isolada não nos dará nenhuma informação útil.

De que adianta saber, por exemplo, que Leonardo pesa 50, $60 \mathrm{ou} 100 \mathrm{~kg}$ ?

Adotamos neste livro o termo altura para medições de um modo geral. Existem termos específicos para a medida realizada na posição deitada (comprimento) e de pé (estatura), o que será discutido mais adiante, na página 54 deste Capítulo. 
O Índice de Massa Corporal é calculado a partir da fórmula: IMC: $\frac{\text { peso }(\mathrm{kg})}{\text { altura }^{2}}$

Se as medidas antropométricas não forem tomadas com extremo cuidado e precisão, todo diagnóstico nutricional (individual e coletivo) estará, com certeza, seriamente prejudicado, podendo trazer conseqüências graves.
Essa variável (peso) deverá ser associada a outra (altura, por exemplo) para que possamos obter uma informação mais concreta, um índice.

Podemos construir vários tipos de índice, mas o Ministério da Saúde (MS), baseado em diversos estudos, já estabeleceu quais deverão ser utilizados nacionalmente com a finalidade de realizar o diagnóstico nutricional de acordo com as diferentes fases do curso de vida e sexo (BRASIL, 2004):

- crianças menores de 5 anos - peso para idade; altura para idade;

- escolares - altura para idade e peso para idade;

- adolescentes, adultos e idosos - Índice de Massa Corporal (IMC);

- gestantes - IMC pré-gestacional, IMC para idade gestacional.

Estabelecidos os índices, os resultados obtidos por intermédio das medidas antropométricas serão comparados com aqueles da população de referência, ou com pontos de corte específicos para cada caso (os citados no parágrafo anterior). Este tema será discutido com maior profundidade mais adiante.

Quais as conseqüências da falta de qualidade na coleta das medidas antropométricas?

Partindo do pressuposto de que o objetivo do diagnóstico nutricional é conhecer um problema para tentar solucioná-lo, se a técnica para obter os dados principais (coleta) para o desencadeamento do processo (diagnóstico nutricional) estiver incorreta, conseqüentemente o resultado não será verdadeiro. Por exemplo: Eliana levou sua filha Luciane, de um ano e meio, à unidade de saúde, pois a criança estava com febre há dois dias. O profissional da saúde, além de pesar a menina com roupa, esqueceu-se de calibrar a balança antes. Esses procedimentos geraram um erro no peso e Luciane teve como adequado o resultado do seu diagnóstico nutricional, apesar de estar com desnutrição. Dessa forma ela não foi encaminhada para a consulta de orientação alimentar, já que o critério de prioridade no atendimento era justamente o estado nutricional. Outro problema foi em relação à medicação prescrita para controlar a febre, pois a dosagem recomendada para crianças está relacionada com o peso e, provavelmente, foi calculada de forma errada.

O exemplo de Luciane nos mostra que é fundamental o conhecimento detalhado das técnicas e dos equipamentos utilizados para a tomada das medidas antropométricas. 


\section{O método antropométrico}

Como definição, a antropometria é a "medição das variações nas dimensões físicas e na composição global do corpo humano, em diferentes idades e distintos graus de nutrição" (VASCONCELOS, 2007, p. 32).

Para obter medidas confiáveis e de qualidade, devemos conhecer muito bem os equipamentos e as técnicas de medição, entendendo qual é a sua finalidade, a que faixa etária se destina, suas vantagens e desvantagens. Para isso, é recomendado que todo profissional envolvido com essas técnicas participe de capacitações, se possível semestrais. Essas capacitações são muito importantes, pois permitem a atualização sobre novos métodos e técnicas e também evitam a cristalização de vícios desenvolvidos na rotina de um serviço, conforme demonstra o texto a seguir.

\section{PADRONIZAÇÃO DE MEDIDAS}

Como já foi dito anteriormente, para obter medidas de qualidade é preciso realizar capacitações periódicas, a fim de garantir uma medida precisa e exata. Para um melhor entendimento desses dois termos, vamos adaptar os conceitos de ambos para o nosso objetivo:

- Precisão (reprodutibilidade): comparação de duas medidas repetidas, realizadas no mesmo indivíduo pelo mesmo profissional. Assim, após passar pela padronização, o profissional deverá ter a habilidade de repetir uma medição na mesma pessoa, com uma variação mínima entre os resultados encontrados.

- Exatidão: comparação das medidas realizadas pelo profissional e pelo capacitador no mesmo indivíduo (o valor verdadeiro). Assim, após passar pela padronização, o profissional deverá ter a habilidade de obter um resultado o mais próximo possível do valor verdadeiro. 0 valor verdadeiro aqui considerado é a medição realizada pelo capacitador, pois se supõe que este tenha maior competência técnica para obter o valor real ou o mais próximo do real.

Para exemplificar os dois conceitos vamos observar duas situações:

1. Lurdes, enfermeira com 10 anos de experiência, pesou Lucas, uma criança de um ano e dois meses, e encontrou os seguintes resultados:

$1^{\text {a }}$ pesagem: $9.420 \mathrm{~g}$

$2^{\text {a }}$ pesagem: $9.420 \mathrm{~g}$ 
0 resultado demonstra que Lurdes foi precisa, pois conseguiu repetir o mesmo valor em duas pesagens consecutivas, com uma variação mínima.

2. Solange, Maria e Raquel, auxiliares de enfermagem em período de treinamento, pesaram a mesma criança, Lucas, de um ano e dois meses, logo em seguida. Os resultados encontrados foram:

\begin{tabular}{lcc} 
Nome & $1^{\mathrm{a}}$ pesagem & $2^{\mathrm{a}}$ pesagem \\
\hline Solange & $9.420 \mathrm{~g}$ & $9.420 \mathrm{~g}$ \\
Raquel & $9.400 \mathrm{~g}$ & $9.400 \mathrm{~g}$ \\
Maria & $9.400 \mathrm{~g}$ & $9.470 \mathrm{~g}$ \\
Lurdes (valor verdadeiro) & $9.420 \mathrm{~g}$ & $9.420 \mathrm{~g}$
\end{tabular}

0 resultado demonstra que Solange, além de ser precisa, também foi exata na sua pesagem, pois, comparando as medidas, ela conseguiu chegar ao peso real de Lucas.

Porém, pode ocorrer de a pessoa ser precisa e não ser exata, como é o caso da Raquel. Nas duas pesagens ela atingiu o mesmo valor ( $9.400 \mathrm{~g})$, contudo não era o peso real de Lucas. E também é possível encontrar pessoas que não são exatas e nem precisas. Esse é o caso de Maria.

Esse exemplo evidencia a importância da padronização das medidas para capacitar os profissionais, de modo a avaliar e corrigir os principais erros de medição. Tudo isso pode parecer irrelevante, mas imagine que em uma unidade de saúde, onde há manutenção periódica dos equipamentos, dois profissionais meçam um adulto em dias diferentes, tendo como resultado valores conflitantes. Isso gerará um diagnóstico errado e poderá afetar o indivíduo que está recebendo atenção naquela unidade de saúde!

Portanto, para que não ocorra esse tipo de erro, os profissionais responsáveis pelas medições devem valorizar sua atividade e realizar capacitações periódicas.

Pesar e medir são atividades de rotina nos serviços de saúde, e por serem relativamente simples, a maioria das pessoas se julga apta a realizá-las. Porém, o profissional deverá, antes de tudo, estar sensibilizado, de modo que valorize esse trabalho. Ele deverá valorizar os dados obtidos, pois estes servirão de base para a determinação do perfil nutricional e de saúde, bem como para possíveis intervenções individuais e/ou coletivas. Estar sensibilizado significa estar ciente da importância dos dados e tecnicamente capacitado para a realização dessas medidas. 


\section{Para refletir}

O que você observa na rotina de pesagem e medição em seu serviço (esta rotina existe, quem faz, como ela é realizada etc.?)

Os profissionais da saúde estão sensibilizados para a importância deste momento, na produção de dados confiáveis?

O que é possível fazer para melhorar esta rotina?

Entendemos ser este procedimento, por vezes, estressante, cansativo e monótono, principalmente em duas situações: quando realizado com crianças, já que, freqüentemente, elas choram e se irritam; e quando o profissional que realizará a consulta exerce muita pressão sobre os responsáveis pelas medições.

Mas nem tudo depende do profissional. Para obter medidas de qualidade, precisamos também de equipamentos e local apropriados para a realização das aferições de peso, estatura/comprimento e perímetros, utilizados na consulta. Por isso é importante conhecer os equipamentos e realizar sua constante manutenção, conforme recomendações apresentadas no texto a seguir.

\section{MANUTENÇÃO DOS EQUIPAMENTOS}

Além de conhecer os equipamentos e as técnicas antropométricas, não podemos esquecer da importância da manutenção dos equipamentos, a fim de evitar erros causados por problemas ou defeitos dos mesmos.

A balança normalmente gera mais erros por falta de manutenção ou calibração. Para evitar possíveis problemas ao adquirir esse equipamento, a unidade de saúde deve solicitar a realização de um exame (calibração) pelos órgãos responsáveis por esse serviço. São eles: o Instituto de Pesos e Medidas (Ipem) e o Instituto Nacional de Metrologia, Normalização e Qualidade Industrial (Inmetro). Procedimentos de regulagem de balanças e/ou conserto podem ser realizados por uma firma idônea, ficando a critério da unidade de saúde a sua contratação.

0 período de regulagem das balanças depende do volume de atendimento e de sua utilização na unidade de saúde. Entretanto, essa regularidade não deve ultrapassar o período de um ano.

Para a manutenção dos antropômetros em madeira, é importante observar se estão localizados em lugar seco, pois existe o risco de empenar com a umidade local, gerando erros na medição. A parte móvel do antropômetro também

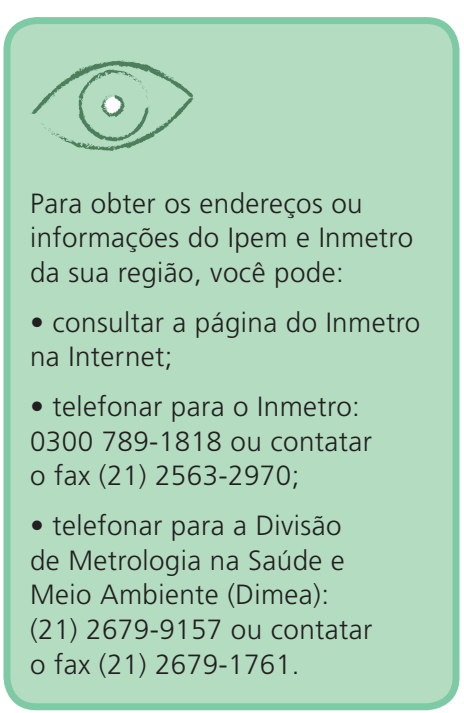


Poderemos montar estas "salas" em outros locais?

Sim! Devemos encontrar o melhor local para a realização dos procedimentos de pesagem e medição, tentando cumprir ao máximo as determinações sugeridas.

O importante é termos um espaço de confiança para pesar e medir!

Não esqueça! pode ocasionar erros na medição quando não mantém o ângulo reto na base da régua. Os parafusos devem ser verificados constantemente. Para evitar esses problemas é recomendada a sua substituição por antropômetros de alumínio ou outro metal resistente.

Recomenda-se que o antropômetro horizontal e a balança pediátrica sejam apoiados em bancada de mármore ou madeira fixada em parede. 0 antropômetro vertical deve ser fixado em parede lisa e sem rodapé, e, assim como para a balança plataforma, o piso/chão que servirá de apoio para o equipamento e/ou indivíduo deve ser plano e regular.

No caso do uso de fita métrica comum, deverá ser observado seu desgaste, pois tende a se esgarçar, alterando assim o valor das medidas.

Precisamos também de um local reservado e adequado para a realização desses procedimentos e sua escolha deve ter base no bom senso. Em muitas ocasiões, teremos que entender que o improviso não significa inadequação para as medidas antropométricas.

Sabemos que a realidade nas aldeias indígenas, nos pólos-base e distritos é muito adversa. Por exemplo, nas aldeias muitas vezes o profissional realizará as medidas antropométricas no lado de fora das casas e/ou apoiará os equipamentos no chão, que pode ser de terra batida e irregular; não terá paredes ou bancadas para apoiar os equipamentos, entre outros detalhes. No entanto, na maioria dos distritos poderá haver sala específica para isso e deveremos partir das recomendações ideais e adaptá-las, ao máximo, para conseguirmos obter a melhor informação possível e maior conforto para o usuário. Vejamos a seguir as recomendações mínimas para esse local (BARROS, 2005).

- ser um espaço suficiente para permitir liberdade de movimentos, onde o profissional e o usuário do serviço de saúde possam se locomover sem dificuldades. O MS recomenda uma área mínima de $16 \mathrm{~m}^{2}$ para postos de saúde e $25 \mathrm{~m}^{2}$ para centros de saúde;

- ter iluminação clara, para uma boa visibilidade dos números;

- possuir temperatura ambiente normal, sem o desconforto do calor e do frio excessivos, sendo que este último pode vir a superestimar o valor da medida, pelo fato de as crianças não tirarem toda a roupa ato necessário para a medição; 
- ser um local arejado, mas não sujeito a fortes correntes de ar, o que contribui para o desnivelamento no caso da balança mecânica;

- ter piso plano, para evitar possíveis acidentes;

- possuir parede ou qualquer outra superfície lisa, em ângulo reto com o piso, para servir de base para os equipamentos. É fundamental que esses equipamentos estejam posicionados de forma a permitir um fluxo adequado, facilitando a realização da pesagem, da medição, bem como a movimentação do profissional e do paciente dentro da sala;

- ter espaço para troca de roupa.

Recomendamos que os procedimentos de aferição do peso e da altura sejam iniciados meia hora antes da primeira consulta, para evitar possíveis erros na tomada das medidas. Porém, cada serviço de saúde deve levar em consideração a demanda de usuários, o número de salas e de profissionais que realizarão as medições, de modo que estes não fiquem sobrecarregados e possam realizar sua atividade com maior tranqüilidade.

A antropometria não é uma simples ação de pesar e medir. É preciso ter "atitude de vigilância", isto é, um olhar atento para o estado nutricional, permitindo uma ação precoce, quando verificada alguma alteração.

Agora que você já sabe a importância da aferição correta das medidas antropométricas e está consciente da necessidade de capacitações periódicas, os passos a seguir serão:

1. saber qual equipamento é mais utilizado para cada tipo de medida (peso, altura e perímetros);

2. conhecer cada equipamento;

3. entender como fazer a antropometria na prática.

Vamos começar pelas medidas mais utilizadas - peso e altura -, nas diferentes faixas etárias e, depois, ver as medidas que servem para complementar o diagnóstico nutricional.

\section{Medição do Peso}

A massa corporal (peso) é a variável antropométrica mais conhecida e utilizada nos serviços de saúde. É tão importante que influencia desde o cálculo de dosagem de medicamentos e orientações nutricionais até a
Ao realizarmos medições antropométricas na aldeia, precisamos ter cuidado redobrado! Devemos observar sempre se o local em que estamos trabalhando tem piso plano para acomodar a balança digital e o estadiômetro/ antropômetro. Se estivermos trabalhando com balança de campo, devemos buscar um batente de porta ou um galho de árvore resistente e seguro, que permitam pendurar a balança com o visor de leitura à altura da visão do profissional.

A "atitude de vigilância nutricional" é um conceito detalhado no Capítulo 6, do livro Vigilância Alimentar e Nutricional para a Saúde Indígena, volume 1, de Denise Cavalcante Barros, Denise Oliveira e Silva e Silvia Ângela Gugelmin (2007). 
definição do estado e perfil nutricional dos usuários, com o objetivo de planejar, implementar e avaliar os programas de saúde.

O equipamento utilizado para a aferição da massa corporal é a balança. Existem vários tipos, sendo as principais:

- pediátrica ou pesa-bebê: utilizada para crianças de 0 até dois anos;

- plataforma: pesa adultos e crianças maiores de dois anos;

- de campo: assim denominada porque é portátil e foi idealizada para utilização em atividades externas ao serviço de saúde.

Foto 1 - Balança pediátrica mecânica

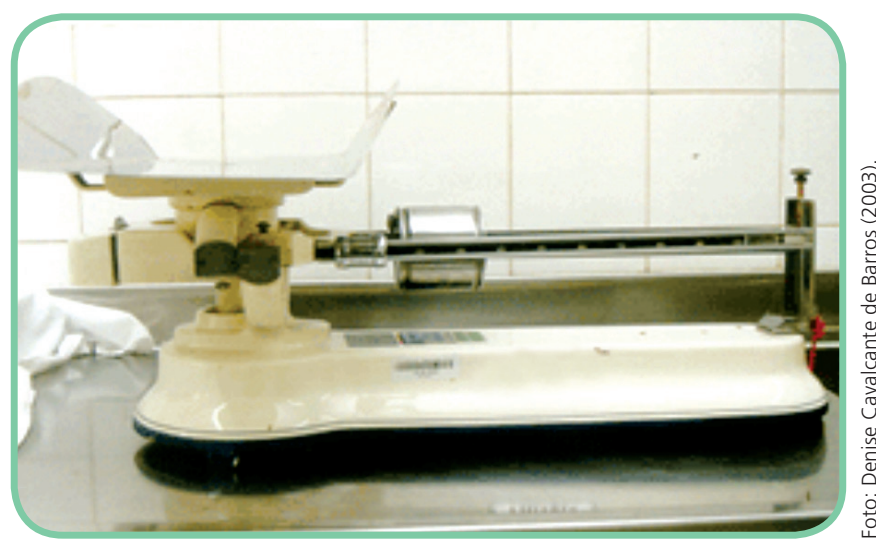

Foto 3 - Balança de campo digital

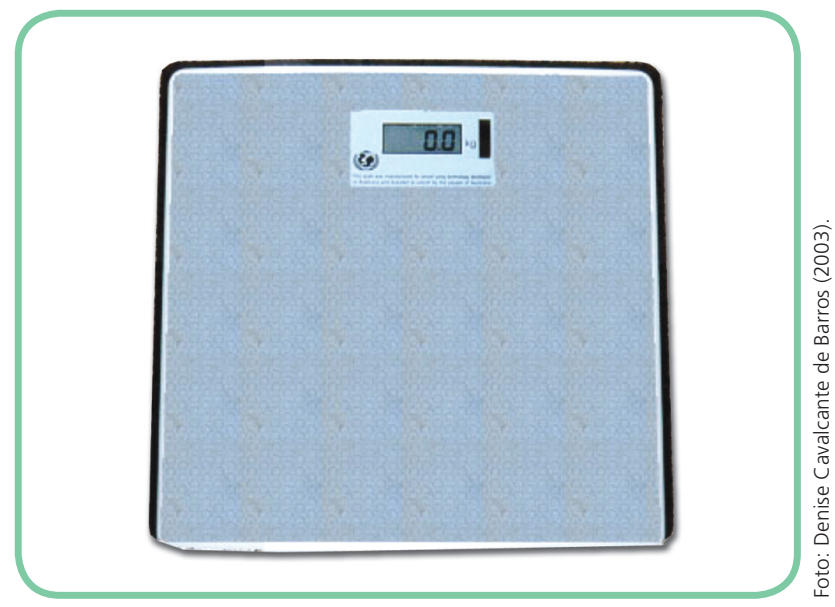

Foto 2 - Balança de campo criança

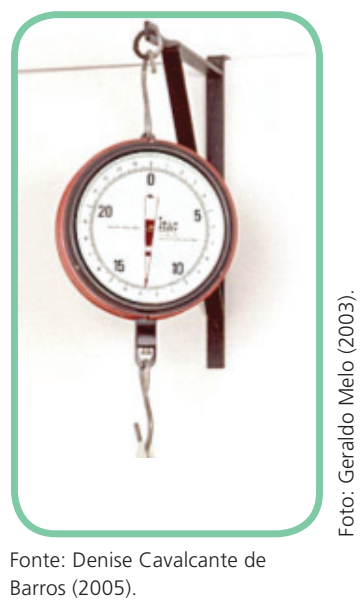


Foto 4 - Balança mecânica adulto

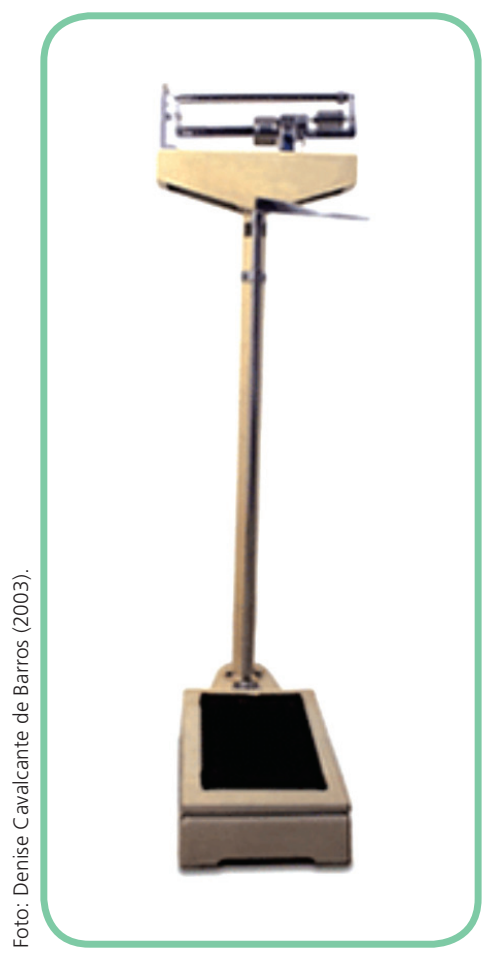

Foto 5 - Balança eletrônica adulto

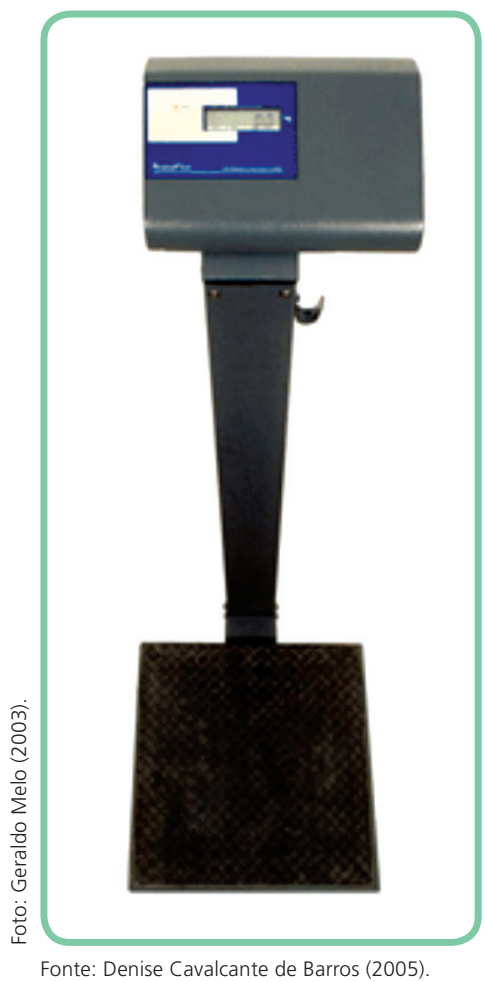

Com certeza você já deve ter visto e até utilizado esses equipamentos no seu local de trabalho. Vamos conhecer, com detalhes, seus componentes. Porém, não basta conhecer somente o equipamento com que iremos trabalhar; é preciso aprender as técnicas de medição do peso. Esse procedimento parece ser simples, mas se não for adequadamente aplicado poderá causar problemas; por isso, preste muita atenção!

\section{Técnicas de medição do peso de crianças menores de dois anos}

Nessa faixa etária, a balança indicada é a pediátrica (mecânica ou eletrônica), pois até a idade de dois anos as crianças ainda não conseguem ficar eretas quando estão paradas. A seguir apresentamos alguns equipamentos e seus componentes. 
Foto 6 - Balança pediátrica mecânica

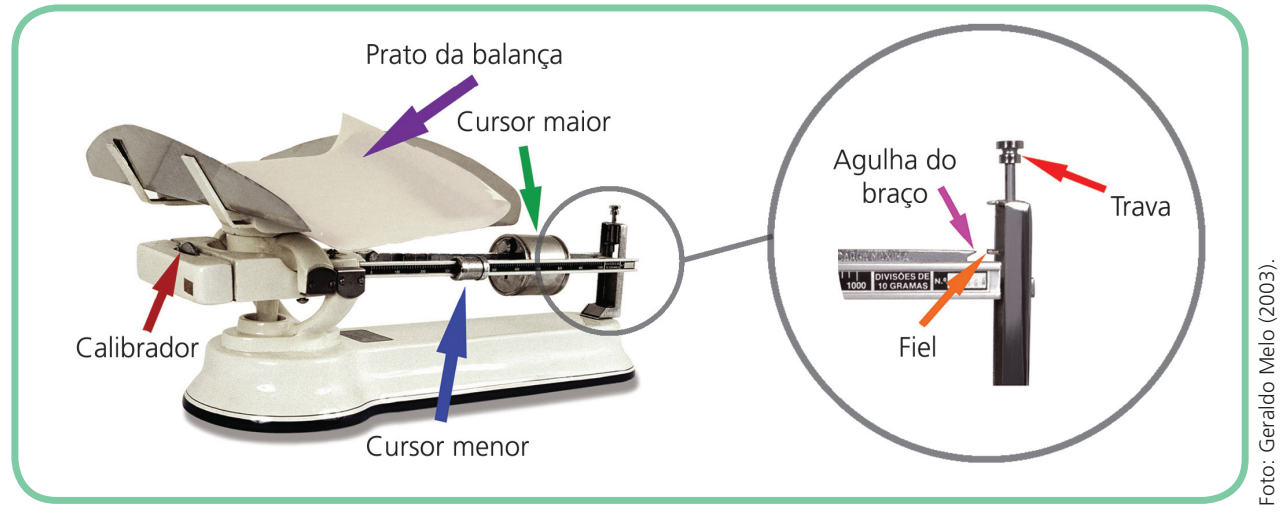

Fonte: Denise Cavalcante de Barros (2005).

Foto 7 - Balança pediátrica eletrônica

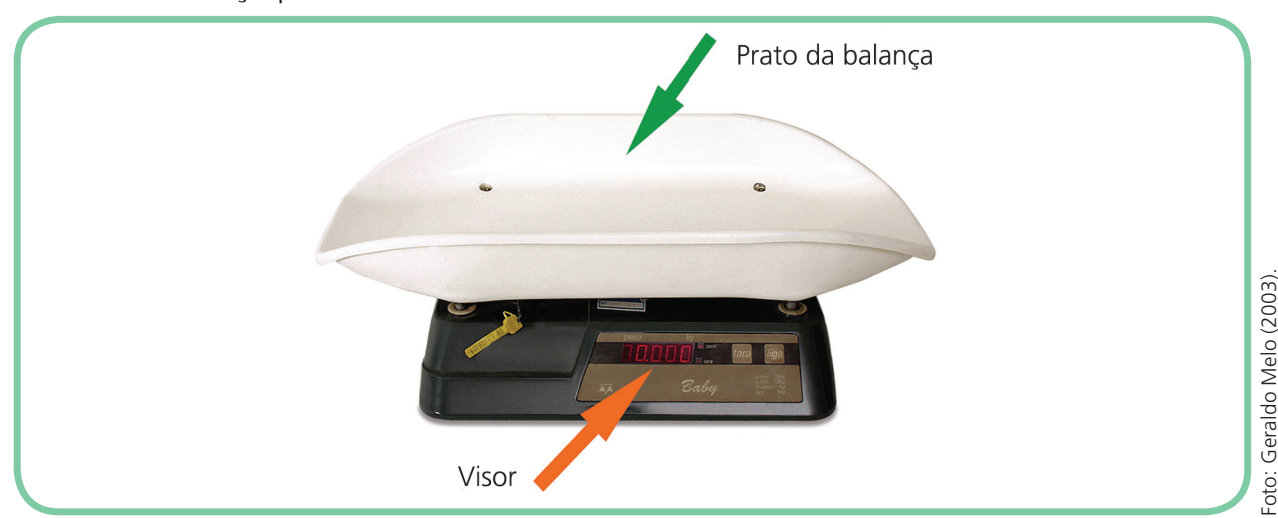

Fonte: Denise Cavalcante de Barros (2005).

Agora, vamos às técnicas utilizadas!

\section{Para refletir}

Como você ou sua equipe executa a tarefa de pesar uma criança menor de dois anos? Relate cada etapa realizada durante a pesagem.

As crianças devem ser pesadas sentadas ou deitadas, despidas (sem fraldas, roupas e sapatos), e não devem estar apoiadas na parede, nem segurando na mãe ou no profissional. Uma variação de peso, mesmo que pequena, fará grande diferença na avaliação da criança, principalmente nos casos de desnutrição.

São muitos detalhes e alguns parecem desnecessários, mas, pelo contrário, para obter dados confiáveis, devemos seguir cada passo, sem esquecer nenhum. 
É importante lembrar que, para as crianças menores de dez anos, utilizamos como instrumento para marcação do peso o gráfico de crescimento da Caderneta de Saúde da Criança (BRASIL, 2007), para acompanhar o seu crescimento e desenvolvimento. O profissional deve marcar no gráfico, a cada mês, o peso da criança e explicar à mãe a evolução nutricional do seu filho, tendo um olhar atento para que nenhuma criança deixe de ter o seu estado nutricional avaliado pelo serviço.

Veremos, a seguir, os passos da medição do peso nos diferentes equipamentos disponíveis nos serviços de saúde.

\section{- Balança pediátrica mecânica}

Os passos dessa pesagem são os seguintes:

1. Antes de colocar a criança na balança, verificar se está travada. Em caso positivo, destravá-la.

2. Verificar se está calibrada (a agulha do braço e o fiel devem estar na mesma linha horizontal). Caso contrário, é preciso regulá-la. Como? Utilizando o calibrador. Gire-o lentamente até que as agulhas fiquem niveladas.

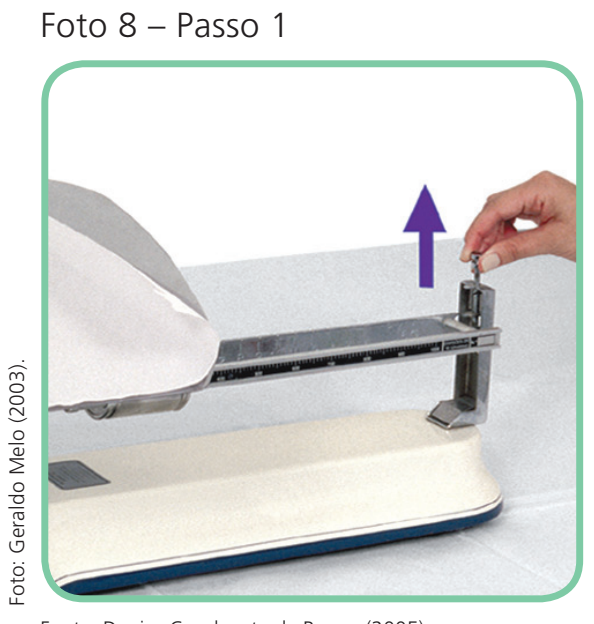

Fonte: Denise Cavalcante de Barros (2005).

Foto 9 - Passo 2

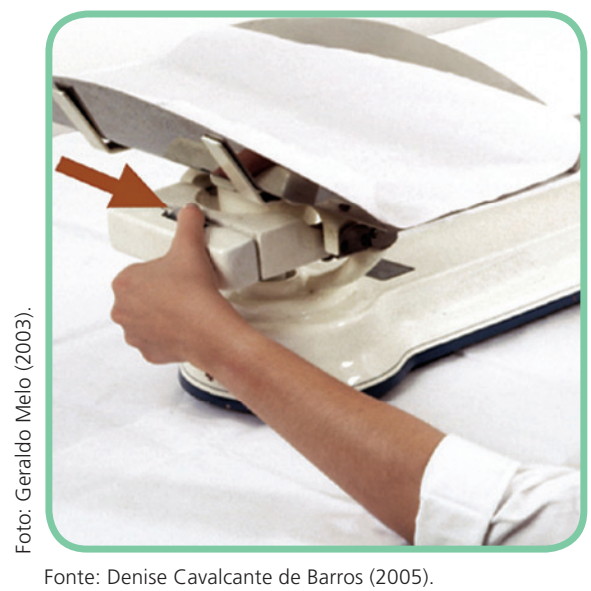

Fonte: Denise Cavalcante de Barros (2005).
O diagnóstico nutricional de crianças e o uso da Caderneta de Saúde da Criança serão discutidos detalhadamente no Capítulo 3 deste livro, "Diagnóstico Nutricional Individual".
O passo "calibrar a balança" é imprescindível e deve ser realizado antes de cada pesagem.

3. Após estar certo de que a balança está calibrada, ela deve ser novamente travada. Só depois disso a criança deve ser pesada.

4. Colocar a criança despida no centro da balança, sentada ou deitada, de modo que o peso fique distribuído igualmente sobre o prato do equipamento. Destravar a balança, mantendo a criança parada o maior tempo possível nessa posição. 
Foto $10-$ Passo 3

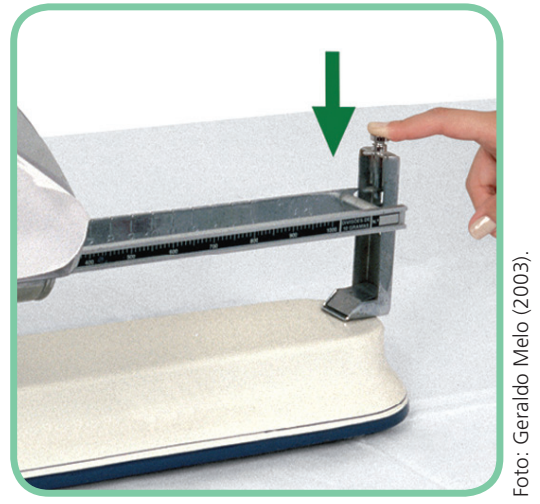

Fonte: Denise Cavalcante de Barros (2005).
Foto 11 - Passo 4

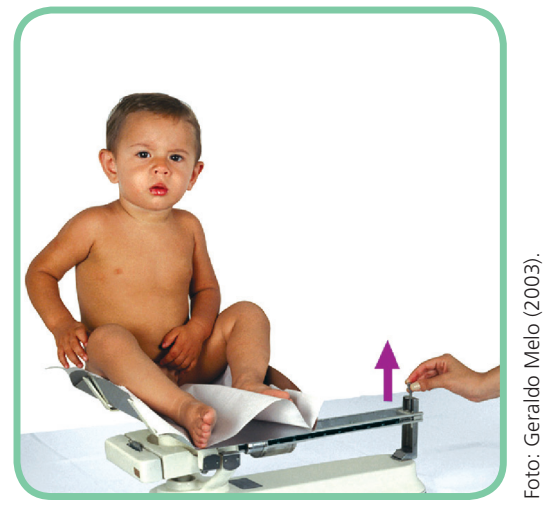

Fonte: Denise Cavalcante de Barros (2005).

5. Mover os cursores sobre a escala numérica: primeiro, o maior - quilos - e, depois, o menor - gramas -, até que a agulha do braço e o fiel estejam nivelados (após mover os cursores, esperar a agulha do braço da balança ficar na mesma linha horizontal do fiel).

6. Travar a balança para evitar que sua mola se desgaste, assegurando o bom funcionamento do equipamento.

7. Realizar a leitura de frente para o equipamento, com os olhos no mesmo nível da escala, a fim de visualizar melhor os valores apontados pelos cursores.

Fotos 12,13 e $14-$ Passo 5

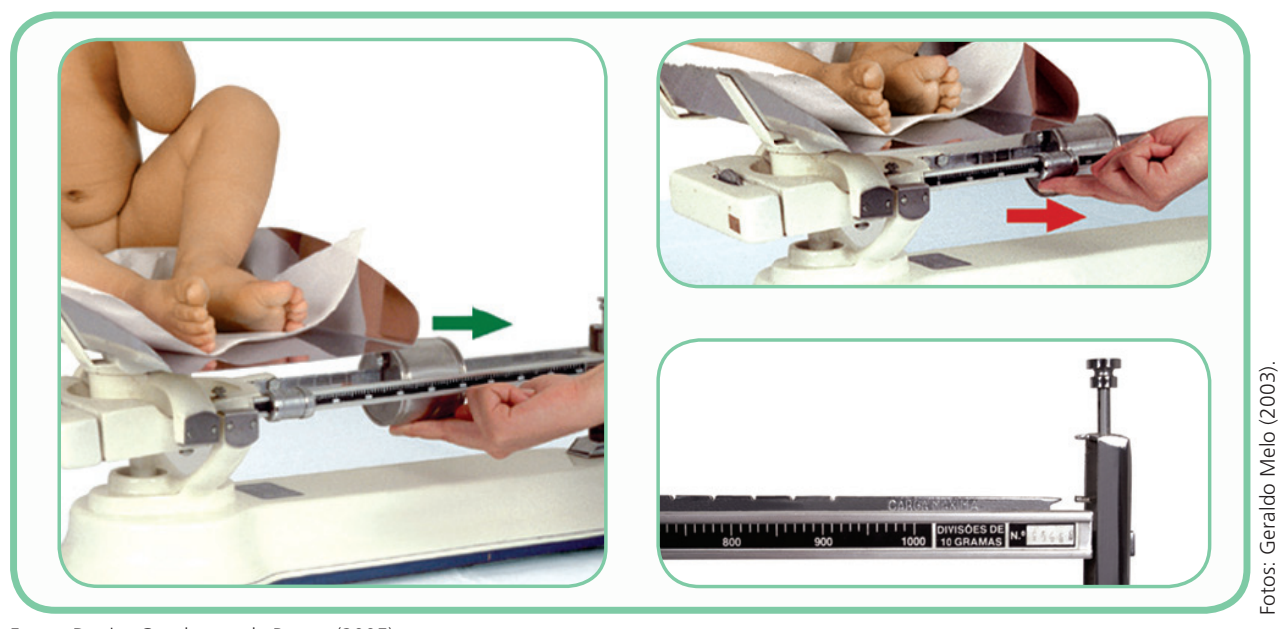

Fonte: Denise Cavalcante de Barros (2005). 
Foto 15 - Passo 6

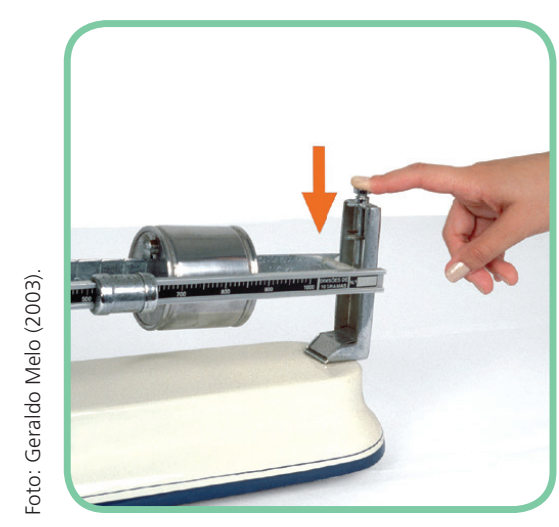

Fonte: Denise Cavalcante de Barros (2005).

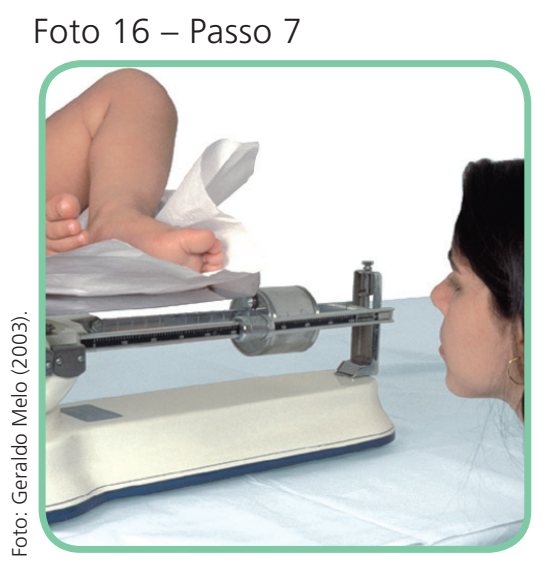

Fonte: Denise Cavalcante de Barros (2005).

8. Anotar o peso no prontuário ou na ficha de registro.

9. Retirar a criança da balança e retornar os cursores ao zero na escala numérica.

10. Marcar o peso na curva do gráfico de crescimento da Caderneta de Saúde da Criança.

Foto 17 - Passo 8

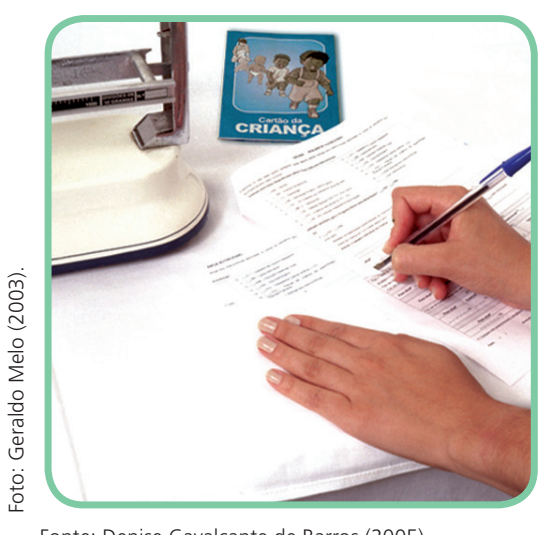

Fonte: Denise Cavalcante de Barros (2005).

\section{Foto 19 - Passo 10}

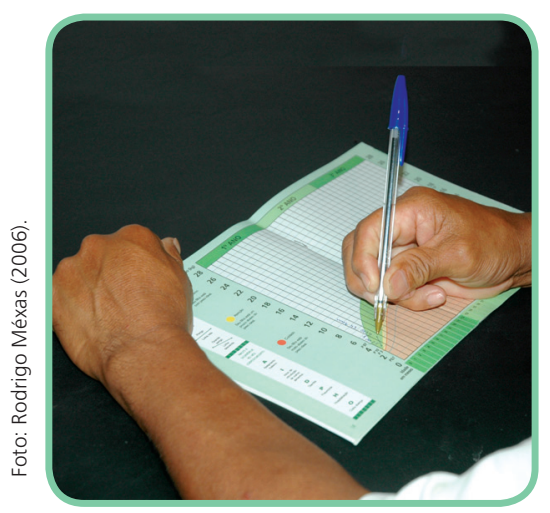

Foto 18 - Passo 9

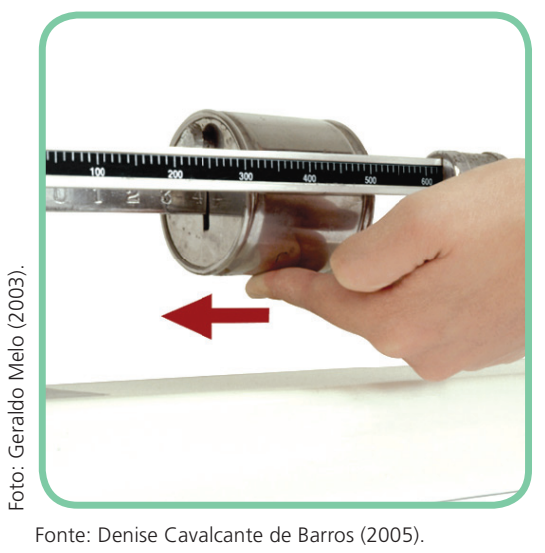

Fonte: Denise Cavalcante de Barros (2005). 
Ao utilizar a balança pediátrica, eletrônica ou mecânica, coloque um protetor (papel descartável ou fralda) antes de apoiar a criança. Essa é uma medida de higiene que evitará possíveis contaminações por doenças infectocontagiosas. Não esqueça de "zerar" ou calibrar a balança antes de apoiar a criança sob o protetor.

\section{- Balança pediátrica eletrônica}

Se a balança que você utiliza for a eletrônica, os passos serão mais simples, mas não menos importantes. São eles:

1. Ligar a balança antes de colocar nela a criança. Esperar até que o visor mostre o número zero.

2. Colocar a criança despida no centro do prato da balança, sentada ou deitada, de modo que o peso fique bem distribuído. Manter a criança parada o maior tempo possível nessa posição.

3. Aguardar que o valor do peso esteja fixado no visor e realizar a leitura.

4. Anotar o peso no prontuário ou na ficha de registro e retirar a criança da balança.

5. Marcar o peso na curva do gráfico de crescimento da Caderneta de Saúde da Criança.

6. Verificar no visor se o valor retornou ao zero.

É importante destacar que as balanças eletrônicas apresentam inúmeras vantagens. Por exemplo: variação de apenas $\log$ (a mecânica tem uma variação de $100 \mathrm{~g}$ ); facilidade de leitura; maior praticidade no manuseio do equipamento, proporcionando maior agilidade no procedimento de pesagem e, conseqüentemente, maior conforto para o cliente e menor possibilidade de erro. Entretanto, sabemos que na realidade a maioria das unidades de saúde possui apenas a balança mecânica, devido ao custo elevado da eletrônica, à sua maior fragilidade e à necessidade de uso de eletricidade, pilhas ou baterias.

\section{- Balanças de campo/mecânica}

Esse tipo de balança é muito utilizado em visitas domiciliares, campanhas de vacinação, inquéritos, pesquisa de campo etc.

Ela é composta dos seguintes itens: escala numérica, uma corda e um suporte com aberturas para encaixar as pernas. Esse suporte pode ser uma sacola de pano, de material descartável ou até uma cesta. 
A instalação dessa balança é diferente das demais. Ela deverá ser pendurada (pela corda, gancho ou suporte em metal) em algum local resistente (viga de madeira ou porta), a uma altura razoável do chão, de modo que a criança, ao ser colocada no suporte, não toque o piso. Ao mesmo tempo, deve permitir uma boa visualização da escala, ou seja, esta precisa ficar na altura dos olhos do profissional/agente de saúde.

Vamos então aos procedimentos para a aferição do peso das crianças com balanças de campo. Os passos são os seguintes:

1. Montar a balança e pendurá-la em local resistente, numa altura onde a criança não coloque os pés no chão e a escala numérica esteja na linha de visão do profissional.

2. Com o suporte pendurado na escala, colocar o ponteiro na posição zero, ou seja, calibrar a balança.

3. Travar a balança.

4. Com a ajuda da mãe e/ou do responsável, colocar a criança despida no suporte, deitada ou sentada.

5. Destravar a balança.

6. Ler o peso registrado e anotá-lo no prontuário ou na ficha de registro.

7. Retirar a criança do suporte com a ajuda da mãe e/ou do responsável.

8. Marcar o peso na curva do gráfico de crescimento da Caderneta de Saúde da Criança.

Assim como acontece com a balança mecânica (ver itens anteriores), antes de cada aferição deve-se verificar se a balança está calibrada, a fim de evitar erros.

Além disso, é fundamental que o profissional tenha muita calma e paciência, pois essa é uma atividade diferente na rotina da comunidade. Os pais geralmente ficam ansiosos, e as crianças assustadas e nervosas. Conversar com os pais e a criança explicando o procedimento facilitará a medição.
A escolha do local de instalação deve ser cuidadosa para que não haja riscos de queda da criança. É comum pendurar as balanças em galhos de árvore. O profissional deve ter certeza de que o galho é firme e não apresenta risco de quebrar com o peso da criança! 


\section{Técnicas de medição do peso de crianças maiores de dois anos e adultos}

Para medir o peso de crianças maiores de dois anos e adultos, a balança utilizada é a do tipo plataforma, encontrada também nas versões mecânica e eletrônica, com uma variação do peso de $100 \mathrm{~g}$.

Os procedimentos de aferição do peso são semelhantes aos descritos anteriormente. Os adultos devem ser medidos com o mínimo de roupa possível e sempre sem sapatos. As crianças devem estar, de preferência, despidas ou no máximo de calcinha/cueca, sempre sem sapatos, e não devem estar apoiadas na parede, segurando a mãe ou o profissional.

Foto 20 - Balança plataforma mecânica

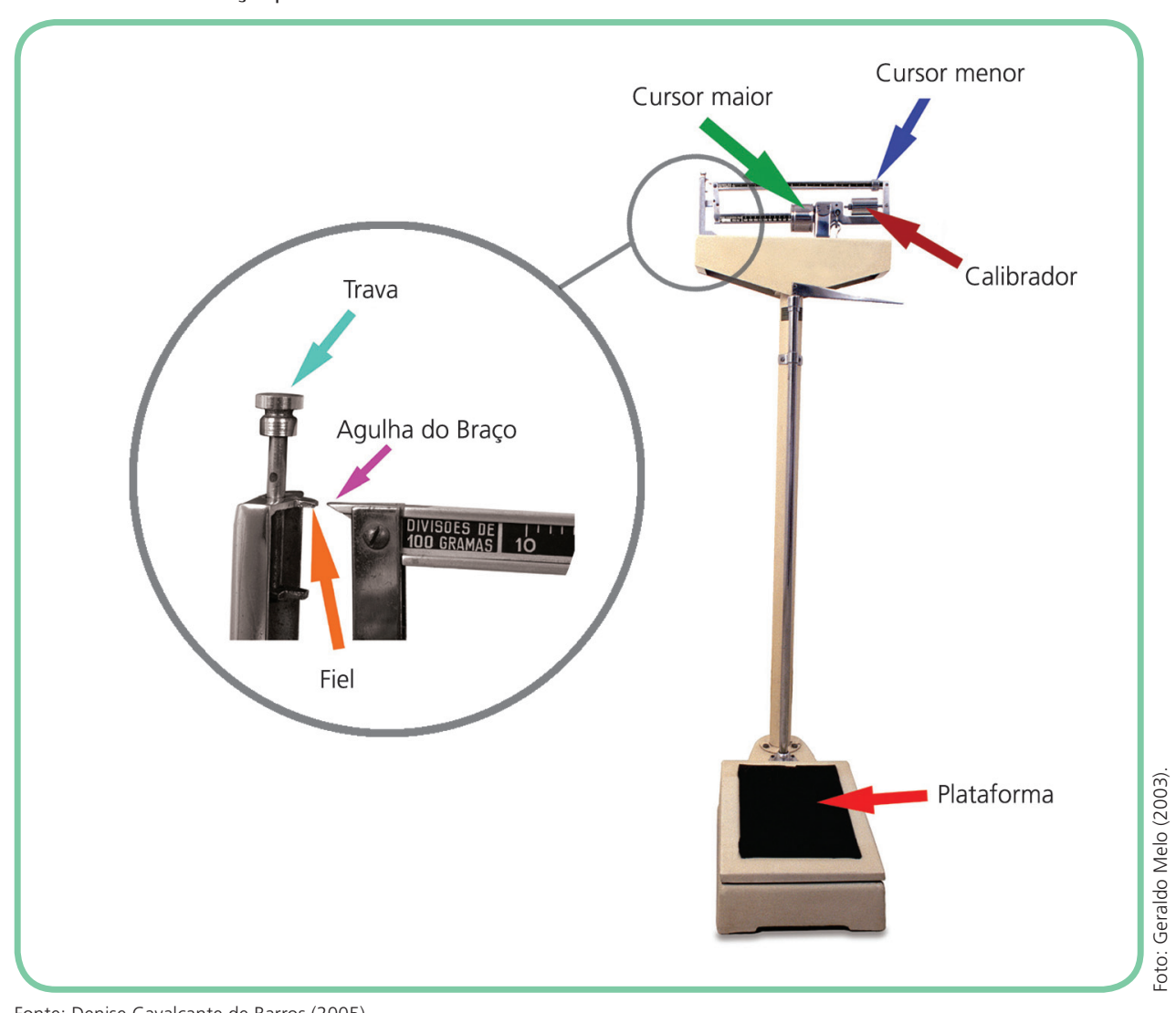

Fonte: Denise Cavalcante de Barros (2005). 
Foto 21 - Balança plataforma eletrônica

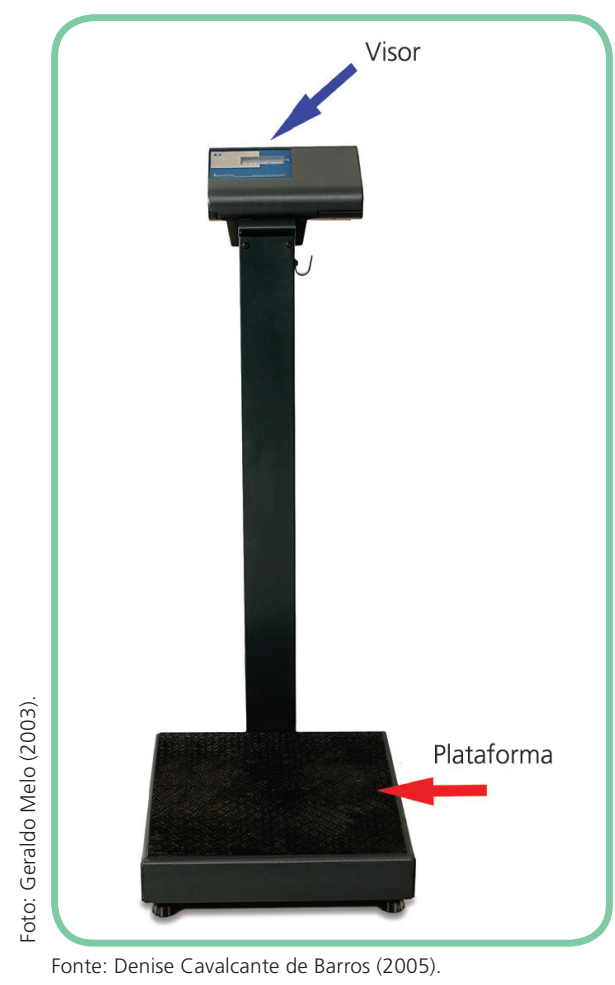

Foto 22 - Balança de campo eletrônica

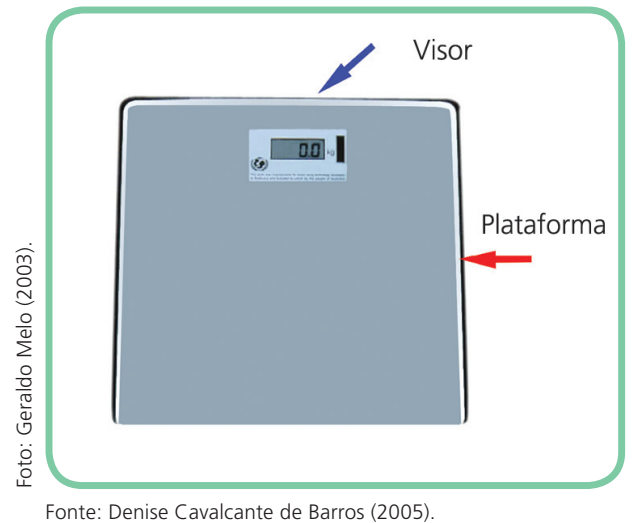

É importante lembrar que, para as crianças de até dez anos de idade, utilizamos, para marcação do peso, a Caderneta de Saúde da Criança. Mas isso será abordado no próximo capítulo.

\section{- Balança plataforma mecânica}

Os passos para aferição do peso de crianças maiores de dois anos e adultos estão descritos a seguir.

1. Antes de colocar a criança/o adulto na balança, verificar se ela está travada.

Foto 23 - Passo 1

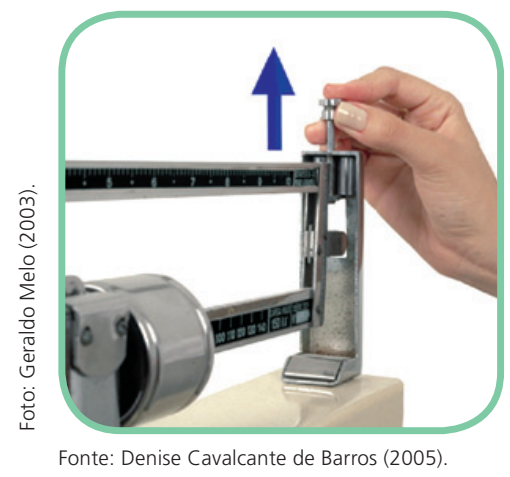


2. Destravar a balança e verificar se ela está calibrada. Caso contrário, é preciso calibrá-la. Como? Utilizando o calibrador. Gire-o leve e lentamente até que as agulhas estejam niveladas. Após estar certo de que a balança está calibrada, ela deve ser novamente travada, para só depois posicionar a criança/o adulto para a pesagem.

Fotos 24 e 25 - Passo 2

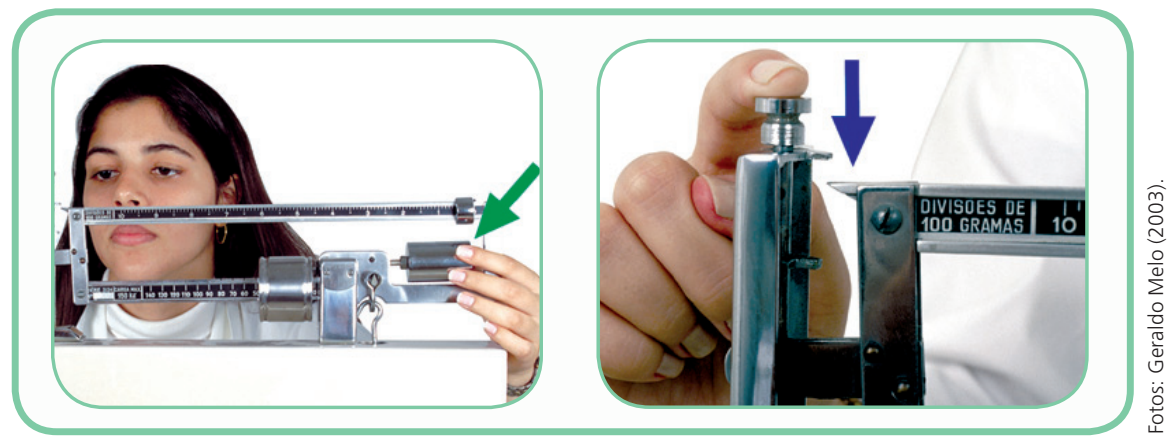

Fonte: Denise Cavalcante de Barros (2005).

3. Posicionar a criança/o adulto de costas para a balança, no centro do equipamento, descalço, com o mínimo de roupa possível, ereto, com os pés juntos e os braços estendidos ao longo do corpo.

4. Manter a criança/o adulto parado nessa posição.

Foto 26 - Passo 3

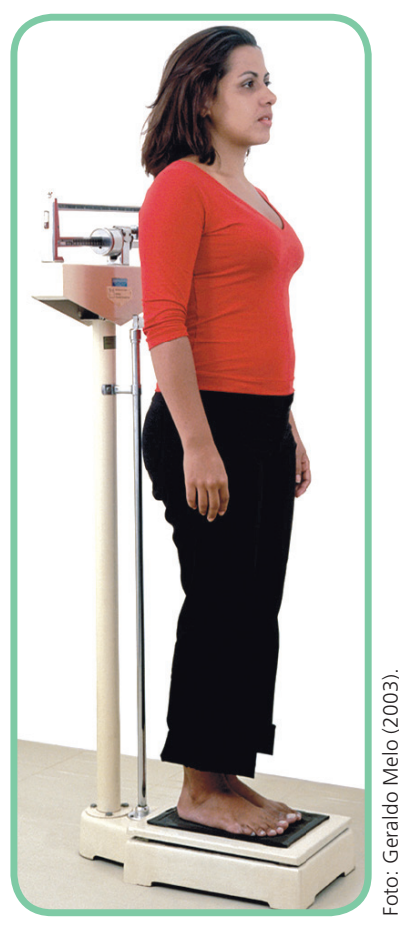

Fonte: Denise Cavalcante de Barros (2005).
Foto 27 - Passo 4

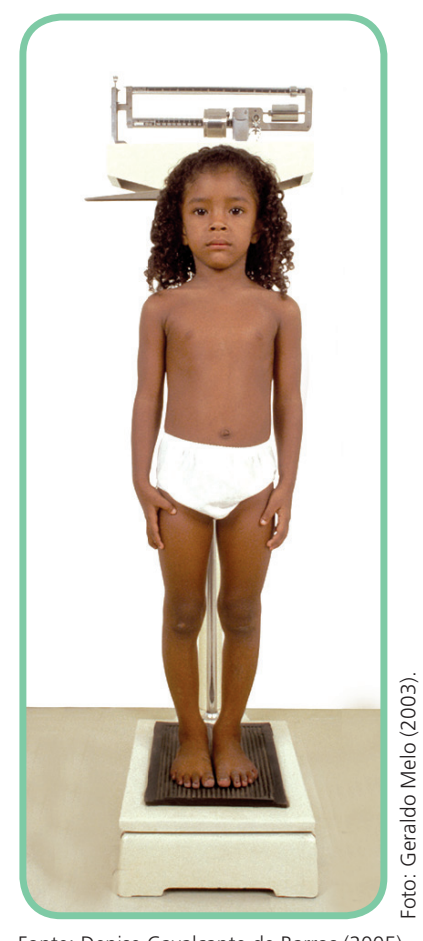


5. Destravar a balança.

6. Mover os cursores sobre a escala numérica: primeiro, o maior - quilos - e, depois, o menor - gramas -, até que a agulha do braço e o fiel estejam nivelados.

7. Travar a balança para evitar que sua mola desgaste, assegurando o bom funcionamento do equipamento.

Foto 28 - Passo 5

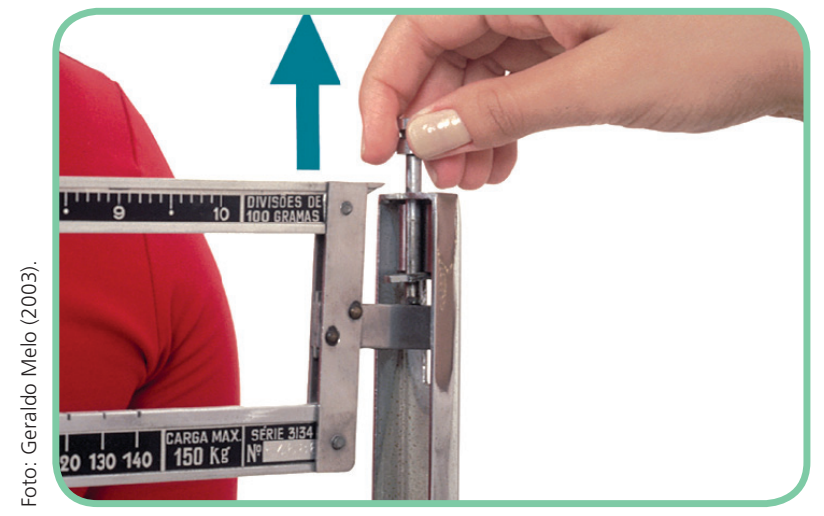

Fonte: Denise Cavalcante de Barros (2005)

Fotos 29, 30 e 31 - Passo 6

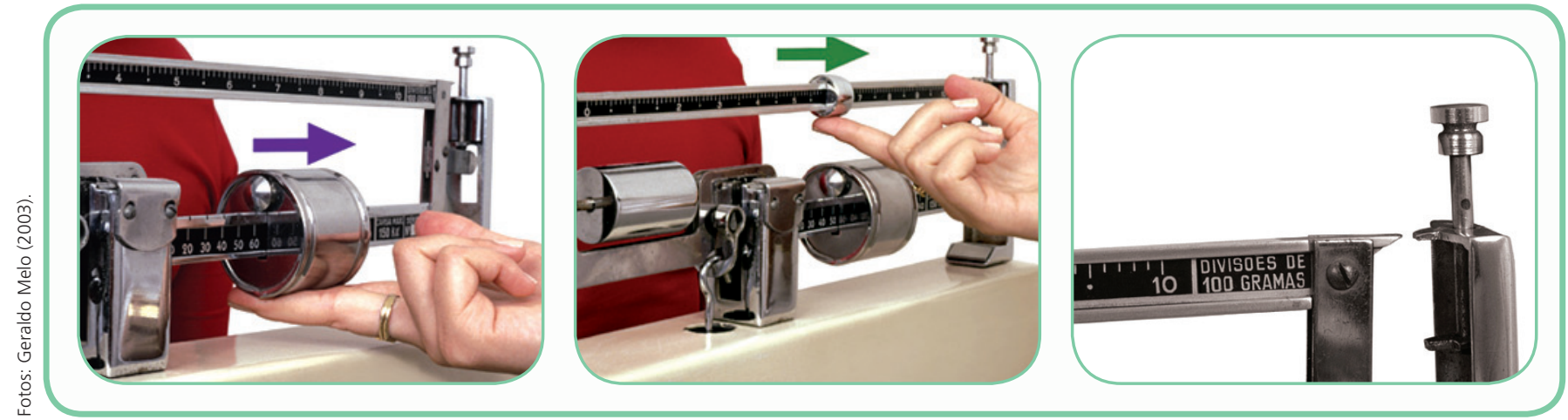

Fonte: Denise Cavalcante de Barros (2005).

Foto 32 - Passo 7

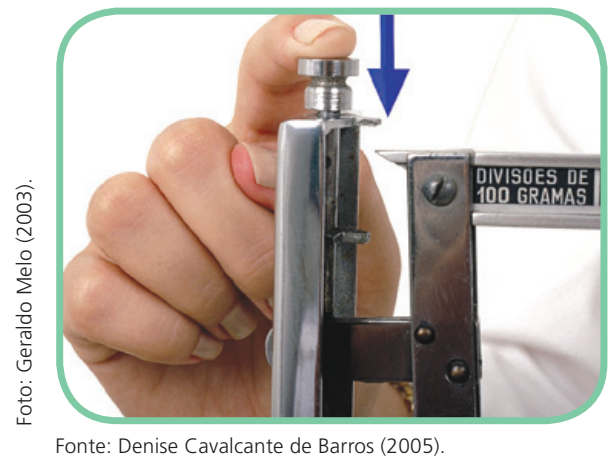


A balança digital é muito utilizada em pesquisas de campo. Destinada a qualquer faixa etária, apresenta inúmeras vantagens, tais como: é portátil, facilitando o transporte; funciona também com pilhas ou baterias, dispensando eletricidade; é de fácil leitura e manuseio; possui variação de peso de $10 \mathrm{~g}$.

Os procedimentos de uso são simples e muito parecidos com os das balanças eletrônicas existentes nos serviços de saúde.
8. Realizar a leitura de frente para o equipamento a fim de visualizar melhor os valores apontados pelos cursores.

9. Anotar o peso no prontuário ou na ficha de registro.
Foto 33 - Passo 8

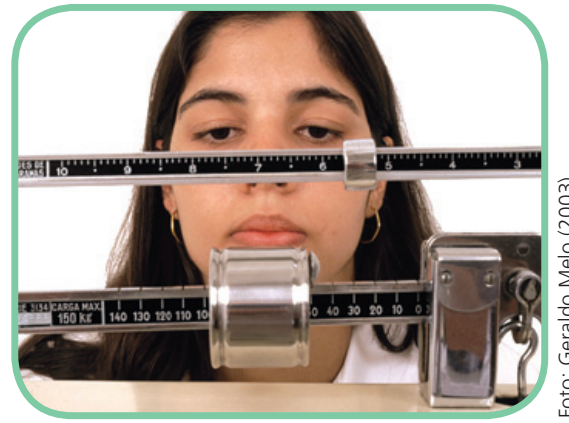

Fonte: Denise Cavalcante de Barros (2005).
Foto 34 - Passo 9

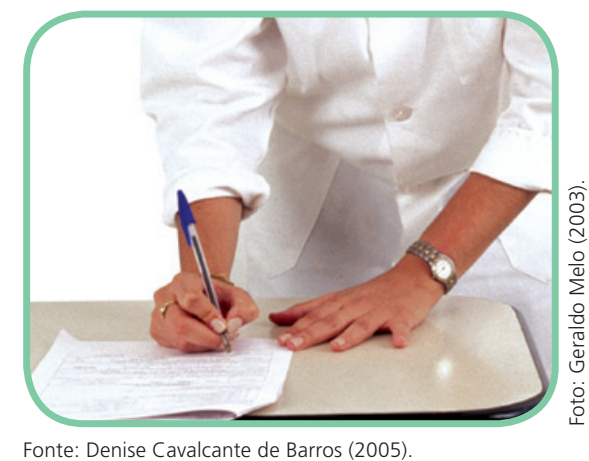

Fonte: Denise Cavalcante de Barros (2005).
10. Retirar a criança/o adulto da balança.

11. Retornar os cursores ao zero na escala numérica.

12. Anotar o peso da criança (se tiver até dez anos de idade) na curva do gráfico de crescimento da Caderneta de Saúde da Criança.
Foto 35 - Passo 10

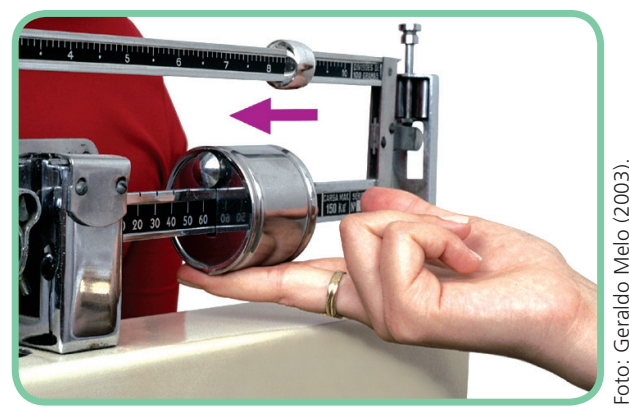

Fonte: Denise Cavalcante de Barros (2005).
Foto 36 - Passo 11

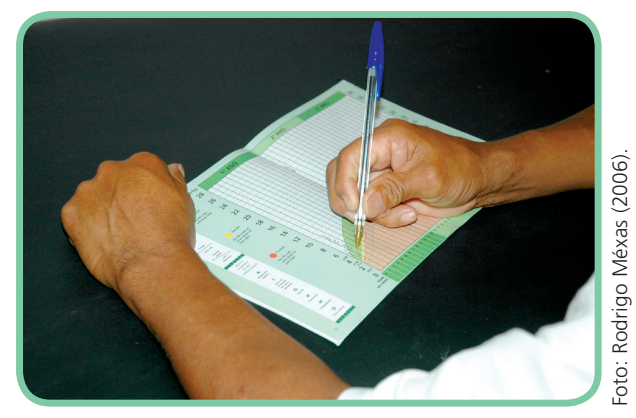

- Balança plataforma ou de campo eletrônica/digital

Os passos são:

1. Ligar a balança antes de posicionar nela a criança/o adulto e esperar que o visor mostre o número zero. 
2. Posicionar a criança/o adulto de costas para a balança, no centro do equipamento, descalço, com o mínimo de roupa possível, ereto, com os pés juntos e os braços estendidos ao longo do corpo.

3. Manter a criança/o adulto parado nessa posição.

4. Realizar a leitura após o valor estar fixado no visor.

5. Anotar o peso no prontuário ou na ficha de registro.

6. Retirar a criança/o adulto da balança.

7. Anotar o peso da criança (se tiver até dez anos de idade) na curva do gráfico de crescimento da Caderneta de Saúde da Criança

8. Verificar se o visor voltou a marcar zero.

\section{RECOMENDAÇÕES PARA AFERIÇÃO DO PESO}

Evite pesar a pessoa com roupa e depois descontar o peso por estimativa. Essa atitude certamente acarretará variações consideráveis de peso.

Pesar a mãe com a criança no colo e depois descontar seu peso é um procedimento não recomendado, pois geralmente induz a erros na obtenção da medida.

No entanto, há exceção para o caso dessa medição ser realizada em balanças eletrônicas fabricadas para este fim. Essas balanças funcionam da seguinte forma: a mãe sobe na balança eletrônica e o agente de saúde "zera" o equipamento na opção tara. Quando aparecer o zero no visor, o profissional acomoda a criança no colo da mãe. 0 número que aparecer no visor, agora, corresponde ao peso da criança e esse é o valor a ser registrado.

\section{Medição da altura}

Medir um indivíduo consiste em avaliar, principalmente nas crianças e adolescentes, se o potencial de crescimento está sendo alcançado de acordo com o previsto para sua idade e sexo.

Saber quanto uma pessoa mede é importante, pois esse dado servirá de base para a determinação do crescimento linear do indivíduo, refletindo a dimensão linear do corpo - sua altura. 
Embora se use o termo altura para designação do crescimento linear, existem termos específicos para as medições feitas nas posições deitada e em pé. Para as realizadas com o indivíduo deitado e de ventre para cima, o termo usado é comprimento, sendo utilizado para crianças de até dois anos de idade, pois elas ainda não conseguem ter firmeza suficiente para, em pé, manterem-se eretas. Para crianças maiores de dois anos de idade e adultos, a medição é realizada em pé e o termo específico é estatura.

Como o MS utiliza o termo altura na Caderneta de Saúde da Criança, adotaremos o termo altura para nos referirmos a essa medida de uma forma mais geral e comprimento/estatura nos casos específicos, segundo faixa etária.

Para refletir

A medição da altura é feita em seu serviço?

Em que momento e como ela é realizada?

A medição do comprimento das crianças menores de dois anos requer muita paciência por parte dos profissionais, já que elas ficam assustadas e se mexem muito, dificultando a aplicação das técnicas corretas. Não é difícil encontrarmos valores conflitantes, como se a criança tivesse "encolhido"; para que isso não ocorra no seu trabalho, a nossa dica é: tenha muita atenção!

O equipamento utilizado para menores de dois anos é o antropômetro horizontal ou infantômetro ou, ainda, pediômetro. Para maiores de dois anos e adultos são utilizados o antropômetro vertical ou estadiômetro, e a trena. Na ausência desses equipamentos, pode-se utilizar a fita métrica como instrumento de medição, desde que adotando os cuidados necessários recomendados nesta Parte I do livro.

O antropômetro horizontal deve estar apoiado em uma superfície firme e plana. No caso do estadiômetro, trena ou fita métrica, a superfície da parede deve ser plana, sem rodapé, de preferência que o chão seja liso e sem elevações. A criança/adulto deve estar descalço, com o mínimo de roupas e sem enfeites, rabo de cavalo ou tranças no cabelo.

Agora vamos conhecer os instrumentos e as técnicas de medição em cada instrumento! 


\section{Técnicas de medição do comprimento de crianças menores de dois anos}

\section{- Antropômetro horizontal}

Foto 37 - Antropômetro horizontal

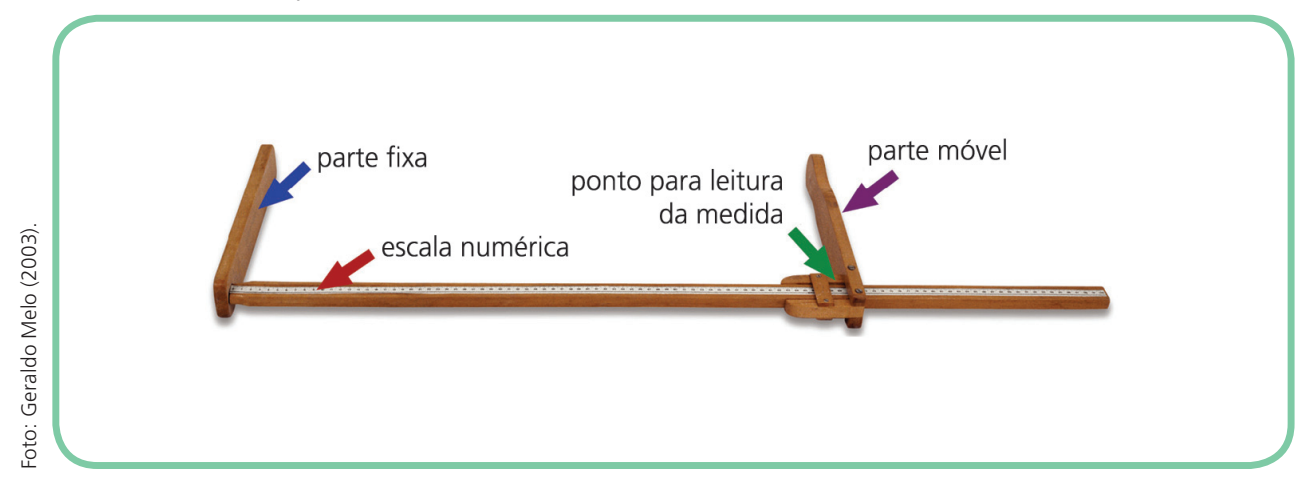

Fonte: Denise Cavalcante de Barros (2005)

Os passos para a medição do comprimento são os seguintes:

1. Deitar a criança no centro do equipamento, descalça e com a cabeça livre de adereços. Lembre-se de que o antropômetro deve estar apoiado em uma superfície plana, firme e lisa.

2. Com a ajuda da mãe ou de outra pessoa, manter a cabeça da criança apoiada firmemente contra a parte fixa do equipamento. O pescoço deve ficar reto, isto é, o queixo não pode encostar no peito; os ombros, as nádegas e os calcanhares devem estar totalmente em contato com a superfície onde está apoiado o antropômetro; os braços permanecem estendidos ao longo do corpo.

Foto 38 - Passo 1

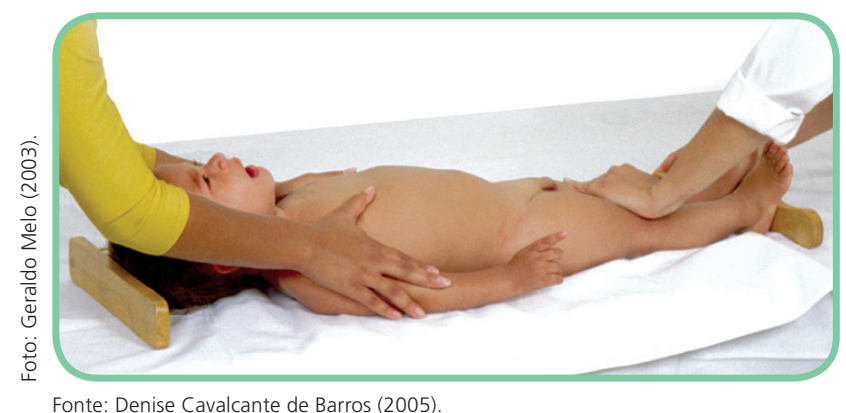

Fonte: Denise Cavalcante de Barros (2005)
Foto 39 - Passo 2

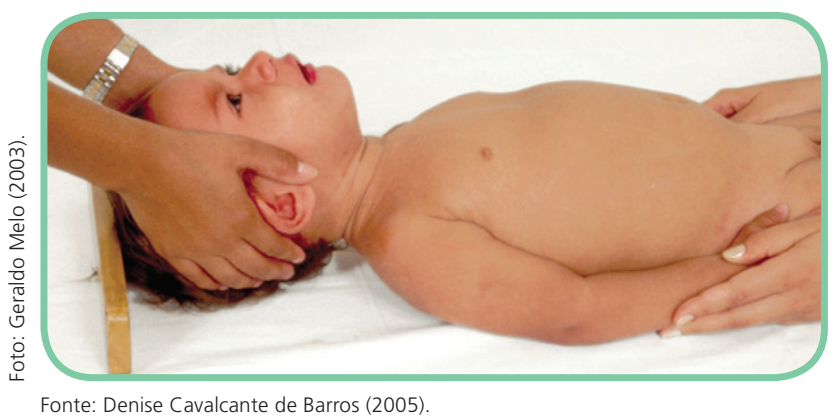


3. Pressionar cuidadosamente, com uma das mãos, os joelhos da criança para baixo, de modo que as pernas fiquem estendidas.

4. Manter os pés unidos, fazendo um ângulo reto com as pernas. Levar a parte móvel do antropômetro até as plantas dos pés, tomando cuidado para que não se mexam.

5. Realizar a leitura do comprimento quando estiver seguro de que a criança não se moveu da posição indicada.

6. Anotar o resultado no prontuário ou na ficha de registro.

7. Retirar a criança do antropômetro.

8. Anotar o comprimento na curva do gráfico de crescimento da Caderneta de Saúde da Criança.

Foto 40 - Passo 3

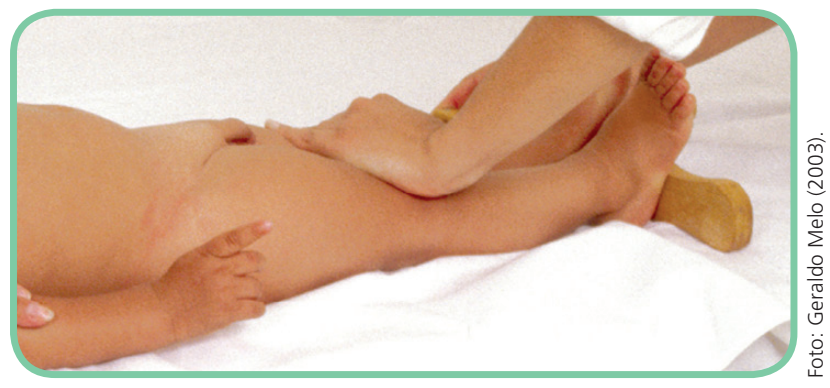

Fonte: Denise Cavalcante de Barros (2005).

Foto 42 - Passo 5

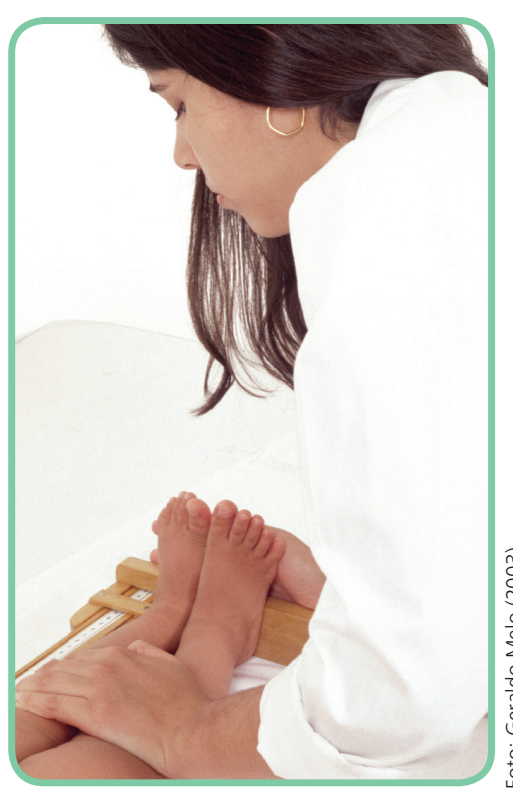

Fonte: Denise Cavalcante de Barros (2005).
Foto 41 - Passo 4

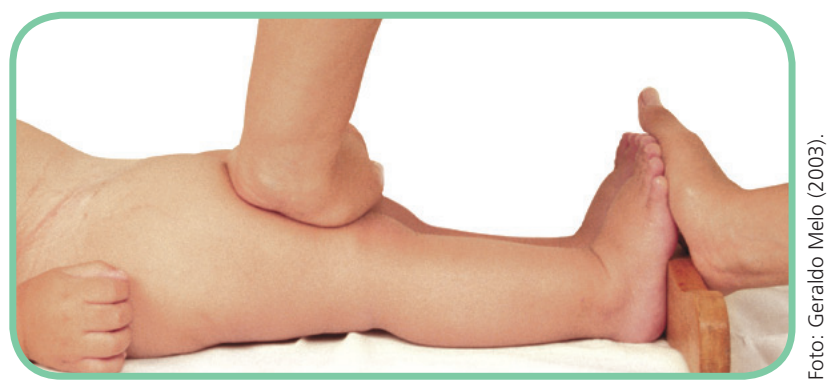

Fonte: Denise Cavalcante de Barros (2005).

Foto 43 - Passo 6

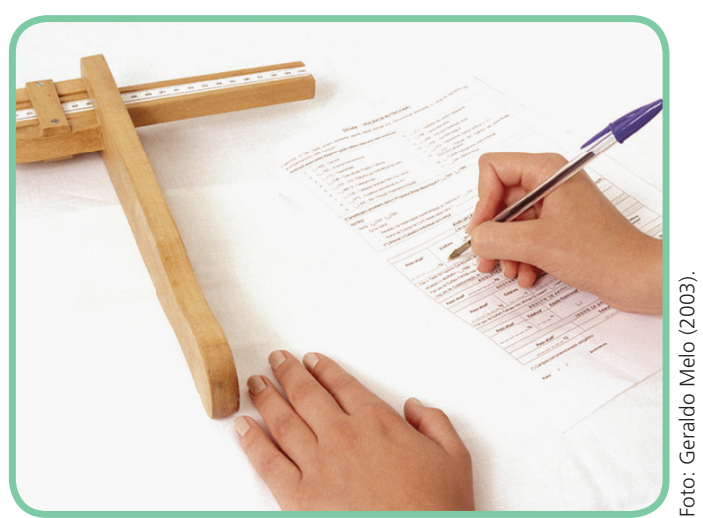

Fonte: Denise Cavalcante de Barros (2005). 


\section{- Antropômetro horizontal transportável}

Esse é o instrumento que deverá ser escolhido para a coleta da medida do comprimento das crianças na aldeia. Para que a sua utilização seja adequada, é importante observar o local onde o equipamento será colocado. Ele deve ser apoiado sobre uma mesa firme e lisa ou no chão, em local plano e liso, tendo o cuidado de forrar essas superfícies com um pano ou uma toalha.

Os passos são os seguintes:

1. Deitar a criança sobre o equipamento.

2. Colocar a criança paralelamente à escala numérica do equipamento. Com a ajuda da mãe ou de outra pessoa, o profissional deverá mantê-la com a cabeça apoiada firmemente contra a parte fixa do equipamento e com o pescoço reto (o queixo não deve encostar no peito); os ombros, as nádegas e os calcanhares devem estar totalmente em contato com a superfície onde está apoiado o corpo da criança; os braços permanecem estendidos ao longo do corpo.

3. Pressionar cuidadosamente, com uma das mãos, os joelhos da criança para baixo, de modo que as pernas fiquem esticadas. Manter os pés unidos, fazendo um ângulo reto com as pernas.

4. Levar a parte móvel do antropômetro até a planta dos pés, tendo cuidado para que não se mexam.

5. Realizar a leitura do comprimento quando estiver seguro de que a criança não se moveu da posição indicada.

6. Anotar o resultado no prontuário ou na ficha de registro.

7. Retirar a criança do equipamento.

8. Anotar o comprimento na curva do gráfico de crescimento da Caderneta de Saúde da Criança.

\section{- Fita métrica}

Os mesmos cuidados ao se utilizar o antopômetro horizontal devem ser observados com o uso da fita métrica, resguardando-se as peculiaridades do instrumento. Ressaltamos que esse instrumento somente deverá ser utilizado na impossibilidade do uso do antropômetro horizontal. Nestes casos, usar fita métrica preferencialmente metálica, ou de fibra de vidro 
inelástica e flexível, pois as de tecido tendem a esgarçar e, com isso, acabam alterando a medida.

Os passos são os seguintes:

1. Fixar a fita métrica em uma superfície plana, firme e lisa, onde seja confortável para deitar a criança.

2. Colocar a criança paralela à fita métrica e com a ajuda da mãe ou de outra pessoa o profissional deve mantê-la com a cabeça apoiada firmemente contra uma superfície fixa e com o pescoço reto, isto é, o queixo não deve estar encostado ao peito; os ombros, as nádegas e os calcanhares devem estar totalmente em contato com a superfície onde está apoiado o corpo da criança; e os braços devem permanecer estendidos ao longo do corpo.

3. Manter ombros, nádegas e calcanhares totalmente em contato com a superfície onde está apoiada a fita métrica. Os braços devem permanecer estendidos ao longo do corpo.

4. Pressionar, cuidadosamente, com uma das mãos, os joelhos da criança para que permaneçam estendidos.

5. Manter os pés unidos, fazendo um ângulo reto com as pernas.

6. Colocar uma régua, esquadro ou material equivalente na planta dos pés, tendo cuidado para que eles não se mexam.

7. Realizar a leitura, uma vez que esteja seguro de que a criança não se moveu da posição indicada.

8. Anotar o resultado na ficha de registro.

9. Retirar a criança.

10. Anotar o comprimento da criança na curva do gráfico de crescimento da Caderneta de Saúde da Criança. 


\section{Técnicas para medição da estatura de crianças maiores de dois anos e adultos}

São diversos os modelos de equipamentos usados para a medição da estatura. A seguir, apresentamos três modelos comumente utilizados em unidades de saúde e pesquisas de campo.
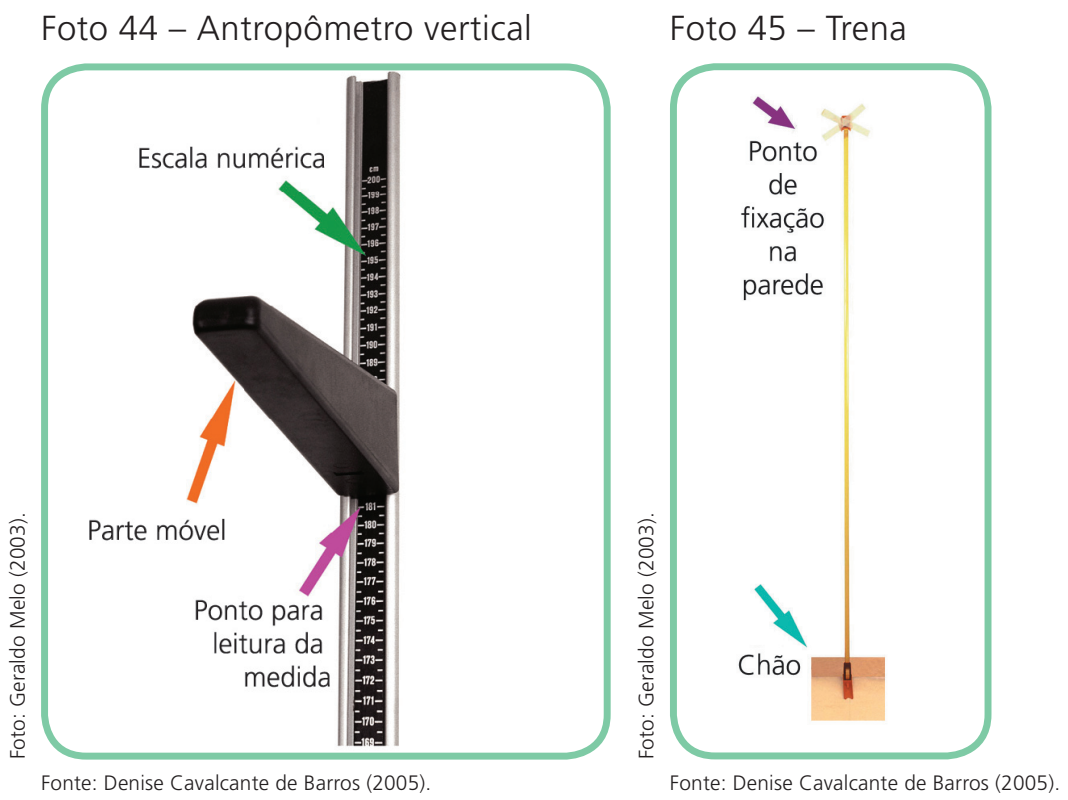

Fotos 46 e 47 - Antropômetro transportável: altura exata e altura exata com criança

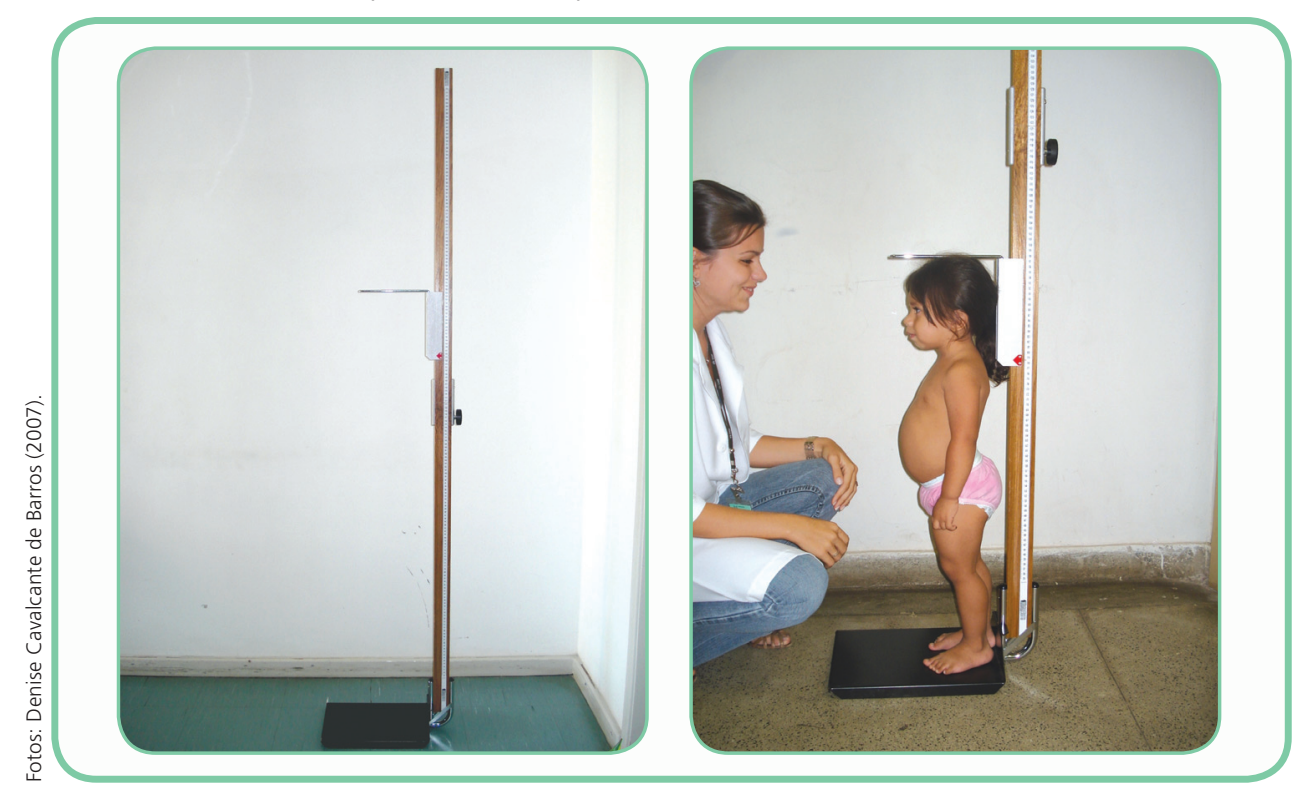

Apresentamos detalhadamente os passos para a medição da estatura nos diferentes equipamentos. 


\section{- Antropômetro vertical}

Os passos são:

1. Posicionar a criança ou o adulto descalço no centro do equipamento, com a cabeça livre de adereços.

2. Colocar a criança ou o adulto de pé, ereto, com os braços estendidos ao longo do corpo, com a cabeça erguida, mirando um ponto fixo na altura dos olhos. Os calcanhares, os ombros e as nádegas devem estar em contato com o antropômetro ou a parede.

3. Fazer com que os ossos internos dos calcanhares se toquem, bem como a parte interna dos joelhos. Os pés devem ficar unidos, fazendo um ângulo reto com as pernas.

4. Abaixar a parte móvel do equipamento, fixando-a contra a cabeça, com pressão suficiente para comprimir o cabelo. Retirar a criança ou o adulto quando tiver certeza de que não houve movimentação.

5. Realizar a leitura da estatura sem soltar a parte móvel do equipamento.

6. Anotar o resultado no prontuário ou na ficha de registro.

7. Anotar a estatura da criança (se tiver até dez anos de idade) na curva do gráfico de crescimento da Caderneta de Saúde da Criança.

\section{- Trena}

Esse instrumento é muito utilizado também em atividades de pesquisa, atividades de campo, por ser prático, portátil e leve.

Os passos para a medição são os seguintes:

1. Posicionar a haste da trena, que serve de esquadro, no chão, e, sem movê-la do lugar, suspender em linha reta o pequeno suporte plástico no qual a fita está fixada, desenrolando-a até que a linha vermelha do visor do esquadro esteja posicionada no valor $200 \mathrm{~cm}$ da escala. Fixar o suporte plástico na parede de forma que não se mova.

2. Posicionar a criança ou o adulto descalço, abaixo da haste móvel da trena, no centro do equipamento, com a cabeça livre de adereços.

3. Colocar a criança ou o adulto de pé, ereto, com os braços estendidos ao longo do corpo, com a cabeça erguida, olhando para um ponto fixo na altura dos olhos. Os calcanhares, os ombros e as nádegas devem estar em contato com a parede. 
4. Fazer com que os ossos internos dos calcanhares se toquem, assim como a parte interna dos joelhos. Os pés devem estar unidos, fazendo um ângulo reto com as pernas.

5. Abaixar a parte móvel da trena, fixando-a contra a cabeça, com pressão suficiente para comprimir o cabelo.

6. Retirar a criança ou o adulto quando tiver certeza de que não houve movimentação.

7. Realizar a leitura da estatura sem soltar a parte móvel do equipamento.

8. Anotar o resultado no prontuário ou na ficha de registro.

9. Anotar a estatura da criança (se for maior de 10 anos) na curva do gráfico de crescimento da Caderneta de Saúde da Criança.

\section{- Fita métrica}

Na medição da estatura com fita métrica, os mesmos passos e cuidados ao se utilizar a trena devem ser observados, resguardando-se as peculiaridades do instrumento, em particular no que se refere aos passos 1 (fixar o limite inferior da fita no chão e o superior a $200 \mathrm{~cm}$ do mesmo) e 5 (utilizar um esquadro, régua ou material equivalente para apoiar contra a cabeça da criança/do adulto, tornando possível a aferição da medida).

Deve-se usar fita métrica preferencialmente metálica ou de fibra de vidro inelástica e flexível, pois as de tecido tendem a esgarçar e, com isso, acabam alterando a medida.

\section{Outros métodos para estimar estatura}

No caso de pessoas acamadas, com dificuldades de locomoção, e deficientes físicas, pode-se também estimar a estatura com base nas seguintes medidas:

\section{- Envergadura}

Para essa estimativa é utilizada uma fita métrica inelástica em que se mede a distância entre as extremidades dos dedos médios (maior), de ambas as mãos, com os braços estendidos lateralmente, nivelando os ombros. É importante ajustar a fita métrica na altura do ombro do indivíduo.

A envergadura corresponde, aproximadamente, à estatura do indivíduo.
Não se recomenda o uso de aparelhos de medição da estatura acoplados a balanças, pois estes não fornecem medidas exatas, ocasionando erros no resultado. É necessário que no mínimo quatro pontos da parte posterior do corpo - cabeça, costas, nádegas e calcanhares - estejam tocando na superfície plana (antropômetro ou parede). 
Fotos 48, 49, 50, 51 e 52 - Envergadura
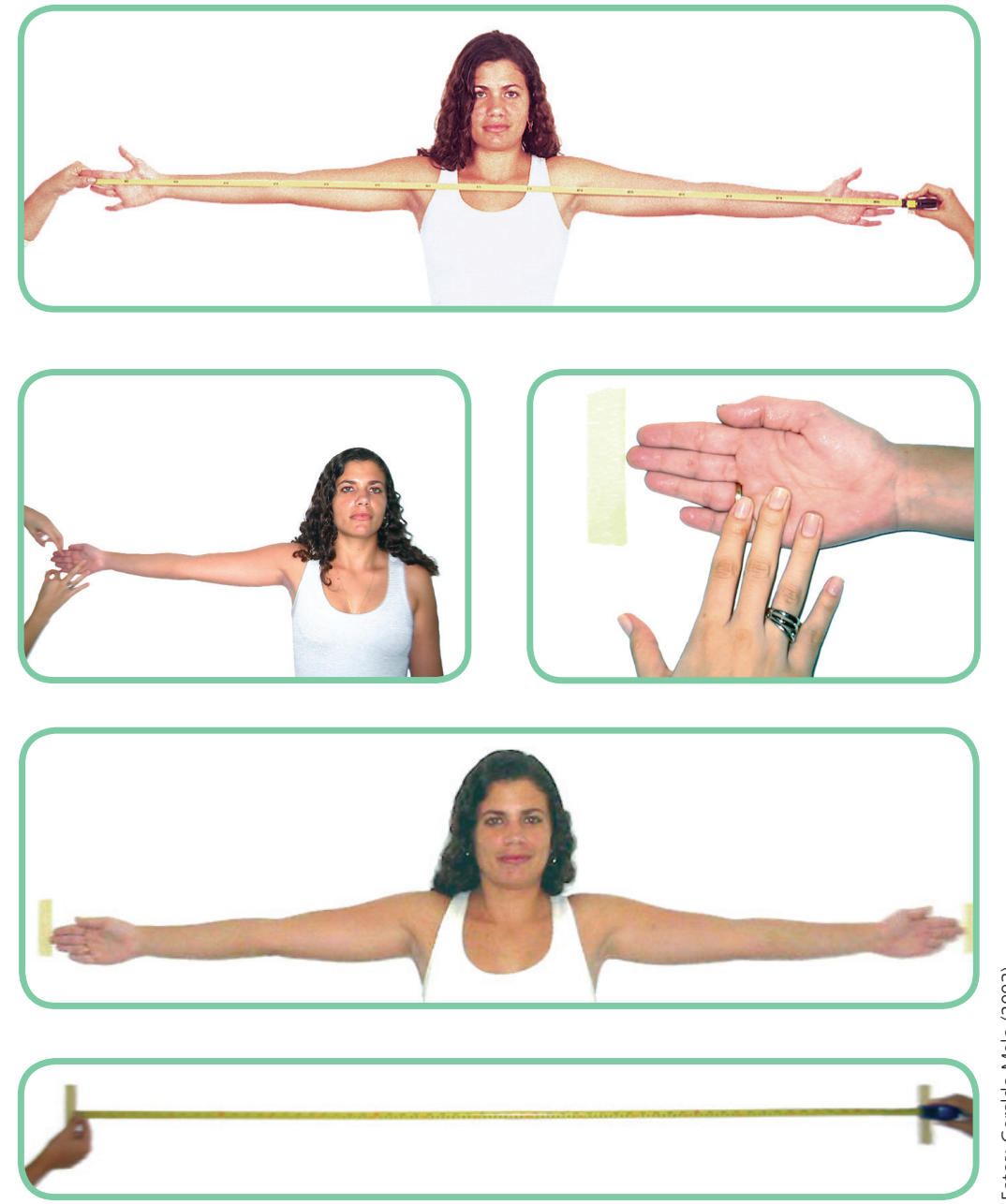

Fonte: Denise Cavalcante de Barros (2005).

\section{- Altura do joelho}

É utilizado um calibrador ou uma fita métrica inelástica, em que se mede a distância do calcanhar do pé esquerdo até a patela do joelho. O indivíduo deve estar com o joelho flexionado a $90^{\circ}$. São necessárias duas medidas sucessivas, e a diferença entre elas não deve ultrapassar o limite de $0,5 \mathrm{~cm}$. Essa medida é aplicada numa fórmula que serve para estimar a estatura dos indivíduos (GIBSON, 1990):

- homens: $(2,02 \times$ altura do joelho em $\mathrm{cm})-(0,04 \times$ idade em anos $)+64,19$

- mulheres: $(1,83 \times$ altura do joelho em $\mathrm{cm})-(0,24 \times$ idade em anos $)+84,88$ 
Foto 53 - Altura do joelho

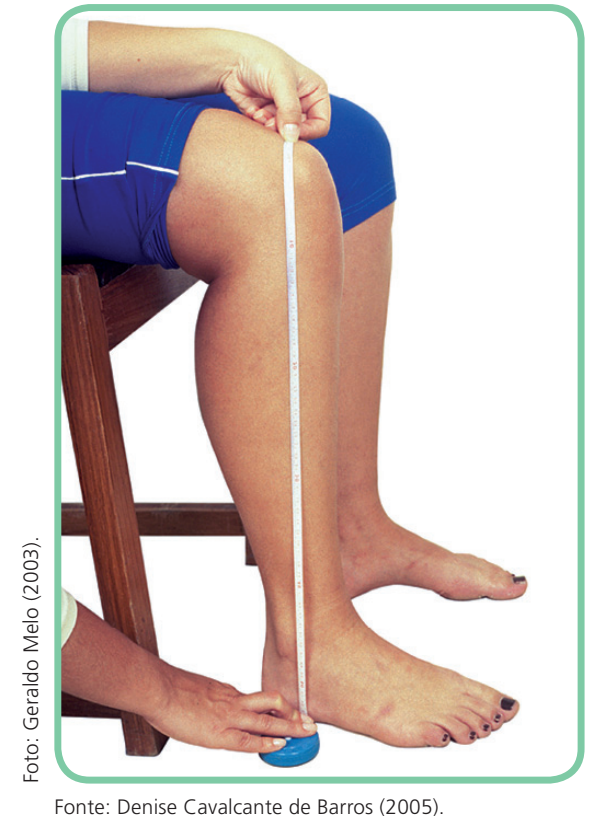

Fonte: Denise Cavalcante de Barros (2005).

O resultado da fórmula será aproximadamente o valor da estatura do indivíduo.

Como já foi dito no início deste Capítulo, até aqui você estudou as medidas mais comuns e rotineiramente utilizadas (peso e altura), os equipamentos utilizados, bem como os procedimentos técnicos para cada um deles. A seguir, iremos conhecer as demais medidas antropométricas usadas como medidas complementares para o diagnóstico nutricional: perímetros e dobras cutâneas, suas aplicações, os equipamentos utilizados e técnicas de mensuração.

\section{Medidas complementares}

Mencionamos anteriormente que a antropometria foi incorporada nos serviços de saúde para avaliação do estado nutricional devido a sua relativa simplicidade e seu baixo custo operacional. O MS recomenda o uso de medidas mais simples, como o peso e a altura, para facilitar a rotina dos profissionais, mas existem diversas medidas antropométricas que podem ser realizadas para a avaliação da estrutura e da composição corporal. 


\section{Perímetros}

O instrumento utilizado para tomar essa medida é a fita métrica. Utilizar, de preferência, uma fita métrica de fibra de vidro, inelástica e flexível, com precisão de $0,1 \mathrm{~cm}$ e largura de $0,7 \mathrm{~cm}$, no máximo. A fita comum não deve ser utilizada, pois não apresenta as características citadas.

Foto 54 - Fita métrica

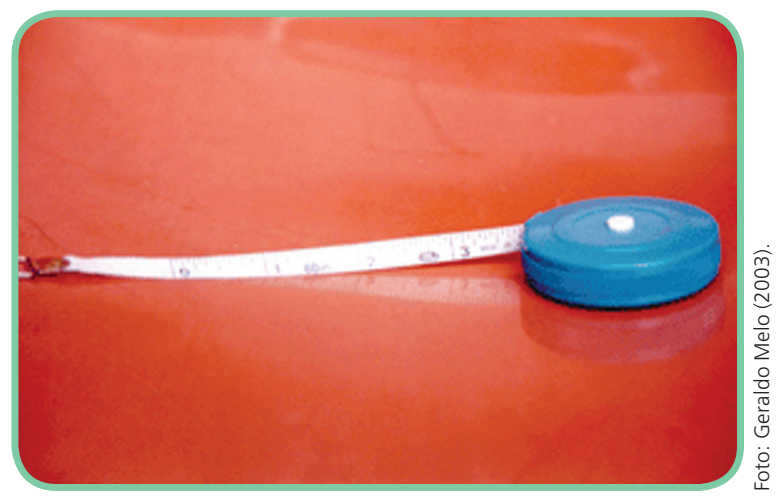

Fonte: Denise Cavalcante de Barros (2005).

Para que essas medidas sejam de qualidade, é preciso realizá-las duas vezes e o valor a ser utilizado será a média entre elas. A diferença entre as duas medidas não deve ultrapassar os limites aceitáveis; caso contrário será necessário repetir o par de medidas (Tabela 1).

Tabela 1 - Limites aceitáveis para medidas duplicadas

\begin{tabular}{l|c} 
Perímetro & Limites $(\mathrm{cm})$ \\
\hline Cefálico & 0,2 \\
\hline Torácico & 1,0 \\
\hline Braquial & 0,2 \\
\hline Cintura & 1,0 \\
\hline Quadril & 1,0 \\
\hline
\end{tabular}

Fonte: Lohman; Roche; Martorell (1988).

\section{Perímetro cefálico}

Essa medida é muito utilizada em pediatria e tem o objetivo de acompanhar o crescimento da cabeça/cérebro das crianças, servindo para diagnosticar casos de microcefalia, macrocefalia ou hidrocefalia. Na avaliação nutricional, essa medida, em relação à idade, pode ser utilizada para o diagnóstico da desnutrição crônica, que às vezes interfere no retardo do 
crescimento, na redução do número de células do cérebro e na diminuição da circunferência cefálica. É recomendada para avaliação de crianças menores de dois anos, em razão do rápido crescimento do crânio.

Foto 55 - Perímetro cefálico

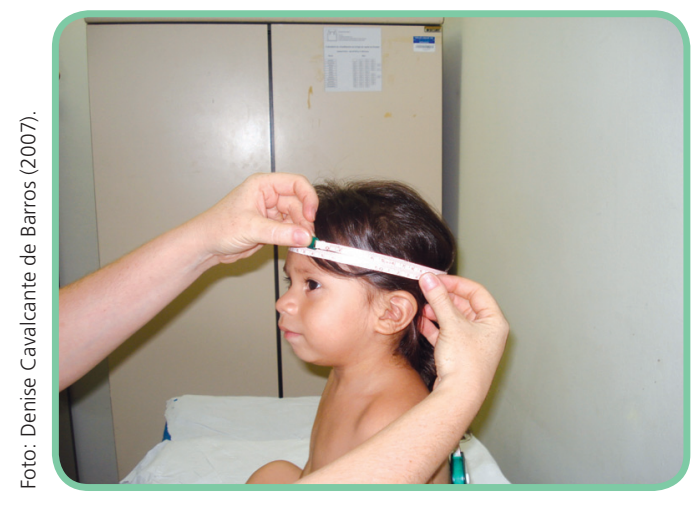

O perímetro cefálico pode ser avaliado em percentis, em que o perímetro adequado situa-se numa faixa de normalidade entre o percentil 10 e o 90 (Tabela 2).

Tabela 2 - Valores de referência de perímetro cefálico $(\mathrm{cm})$ de crianças de 0 a 36 meses, por sexo e idade

\begin{tabular}{l|l|l|l|l|l|l|l|l|l|l} 
Meninos & \multicolumn{1}{l}{$\begin{array}{l}\text { Idade } \\
\text { (meses) }\end{array}$} & \multicolumn{1}{l}{ Meninas } \\
\hline P5 & P10 & P50 & P90 & P95 & & P5 & P10 & P50 & P90 & P95 \\
\hline 32,6 & 33,0 & 34,8 & 36,6 & 37,2 & 0 & 32,1 & 32,9 & 34,3 & 35,5 & 35,9 \\
\hline 34,9 & 35,0 & 37,2 & 39,0 & 39,6 & 1 & 34,2 & 34,8 & 36,4 & 37,8 & 38,3 \\
\hline 38,4 & 38,9 & 40,6 & 42,5 & 43,1 & 3 & 37,3 & 37,8 & 39,5 & 41,2 & 41,7 \\
\hline 41,5 & 42,0 & 43,8 & 45,6 & 46,2 & 6 & 40,3 & 40,9 & 42,4 & 44,1 & 44,6 \\
\hline 43,5 & 44,0 & 45,8 & 47,5 & 48,1 & 9 & 42,3 & 42,8 & 44,3 & 46,0 & 46,4 \\
\hline 44,8 & 45,3 & 47,0 & 48,8 & 49,3 & 12 & 43,5 & 44,1 & 45,6 & 47,2 & 47,6 \\
\hline 46,3 & 46,7 & 48,4 & 50,1 & 50,6 & 18 & 45,0 & 45,6 & 47,1 & 48,6 & 49,1 \\
\hline 47,3 & 47,7 & 49,2 & 51,0 & 51,4 & 24 & 46,1 & 46,5 & 48,1 & 49,6 & 50,1 \\
\hline 48,0 & 48,4 & 49,9 & 51,7 & 52,2 & 30 & 47,0 & 47,3 & 48,8 & 50,3 & 50,8 \\
\hline 48,6 & 49,0 & 50,5 & 52,3 & 52,8 & 36 & 47,6 & 47,9 & 49,3 & 50,8 & 51,4 \\
\hline
\end{tabular}

Fonte: Adaptada de Hamil et al. (1979 apud Barros, 2005).

Como proceder à medição do perímetro cefálico?

1. Colocar a criança sentada ou deitada.

2. Retirar qualquer objeto que possa alterar a medida, desde enfeites de cabelo a tranças ou outros penteados. 
3. Manter-se de frente para o lado esquerdo da criança, e colocar o marco zero da fita na lateral da cabeça dela.

4. Posicionar a fita na região frontal da cabeça da criança, acima das sobrancelhas e na parte posterior, na região occipital (osso localizado na base do crânio). Procurar sempre o maior diâmetro da cabeça, sem incluir as orelhas.

5. Observar se a fita está posicionada no mesmo nível em toda a cabeça, passando sobre a região mais saliente do occipital. Para isso, é necessária a ajuda de um assistente.

6. No momento do ajuste da fita, ela deve ser comprimida sobre o cabelo da criança, para se obter uma medida mais próxima da real circunferência cefálica. Fazer duas medidas e registrar a média entre elas.

7. Realizar a leitura.

8. Anotar o valor da medida no prontuário ou na ficha de registro.

9. Anotar o perímetro cefálico da criança na curva do gráfico de perímetro cefálico da Caderneta de Saúde da Criança.

\section{Perímetro torácico}

Essa medição é empregada em crianças e adultos. É uma das medidas mais utilizadas na infância, período no qual a relação entre Perímetro Torácico (PT) e Perímetro Cefálico (PC) resultará no indicador PT/PC, que auxilia na avaliação do diagnóstico nutricional.

Do nascimento até o sexto mês de vida, os perímetros cefálico e torácico são aproximadamente iguais, resultando numa relação $\mathrm{PT} / \mathrm{PC}=1$. Dos seis meses aos cinco anos de idade, uma relação normal entre PT/PC é sempre maior que 1 . Uma relação $\mathrm{PT} / \mathrm{PC}<1$, dos seis meses aos cinco anos, é indicativa de Desnutrição Protéico Calórica (DPC), na medida em que o perímetro torácico não se desenvolve em função da atrofia dos músculos torácicos e da redução do tecido gorduroso (VASCONCELOS, 2007). 
Foto 56 - Perímetro torácico

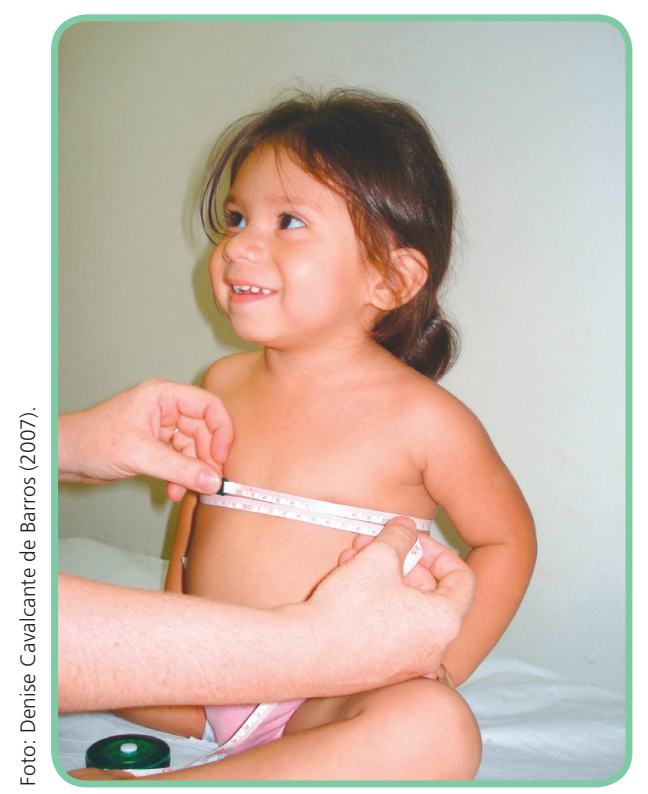

Os passos para a medição do perímetro torácico são os seguintes:

1. Colocar a pessoa em pé ou sentada. Caso esteja em pé, seus pés devem ficar afastados, fazendo paralelas com os ombros.

2. Mantê-la com o tórax despido.

3. Afastar os braços do tórax, a fim de facilitar o acesso ao local para ajuste da fita métrica e, logo depois, retorná-los à posição normal, junto à lateral do corpo.

4. Colocar a fita horizontalmente, ao redor da pessoa, no maior diâmetro do tórax, em geral na altura dos mamilos.

5. Manter-se de frente para a pessoa, segurando o ponto zero da fita métrica em sua mão direita e, com a mão esquerda, passar a fita por trás da pessoa.

6. Verificar se a fita está em posição horizontal em todo o tórax, bem ajustada, mas sem comprimir o corpo. Para isso, o ideal é ter um assistente.

7. Pedir para a pessoa inspirar e em seguida expirar totalmente.

8. Realizar a leitura.

9. Anotar o valor da medida no prontuário ou na ficha de registro.

O PC e o PT podem ser analisados em relação à idade, utilizando a referência de Jelliffe (1968), reproduzida por Vasconcelos (2007, p. 62). 
Tabela 3 - Valores de referência dos perímetros cefálico e torácico para ambos os sexos, segundo idade em meses

\begin{tabular}{c|c|c}
\hline Idade em meses & Perímetro cefálico $(\mathrm{cm})$ & Perímetro torácico $(\mathrm{cm})$ \\
\hline 0 & 35,0 & 35,0 \\
\hline 3 & 40,4 & 40,0 \\
\hline 6 & 43,4 & 44,0 \\
\hline 12 & 46,0 & 47,0 \\
\hline 18 & 47,4 & 48,0 \\
\hline 24 & 49,0 & 50,0 \\
\hline 36 & 50,0 & 52,0 \\
\hline 48 & 50,5 & 53,0 \\
\hline 60 & 50,8 & 55,0 \\
\hline
\end{tabular}

Fonte: Vasconcelos (2007).

\section{Perímetro braquial}

O Perímetro Braquial (PB) é utilizado para avaliação das áreas de gordura e livres de gordura (ossos e músculos) do braço, em crianças, adolescentes, adultos, gestantes e idosos. Tem sido empregado para obtenção do diagnóstico nutricional somente quando o objetivo é fazer uma "triagem" da clientela, ou quando os equipamentos para pesar e medir não estão disponíveis (VASCONCELOS, 2007).

As limitações dessa medida são muitas, tais como a falta de precisão, de exatidão e a inexistência de padrões de referência adequados para a população brasileira. Entretanto, o MS (BRASIL, 2004) propõe um valor mínimo aceitável de $12,5 \mathrm{~cm}$ para crianças de seis a 30 meses, e de $13,5 \mathrm{~cm}$ para crianças de 31 a 60 meses.

Fotos 57, 58 e 59 - Etapas da medição

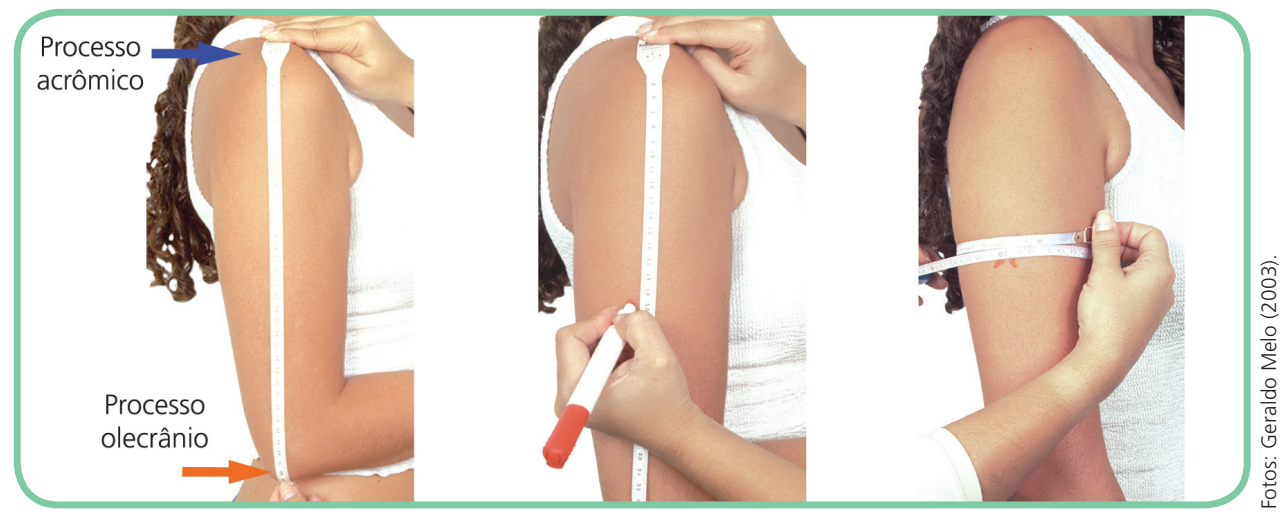

Fonte: Denise Cavalcante de Barros (2005). 
Os passos para a medição do perímetro braquial são os seguintes:

1. Colocar a criança ou o adulto com o braço direito - despido e dobrado junto ao tronco, formando um ângulo de $90^{\circ}$, com a palma da mão voltada para cima.

2. Localizar o extremo do ombro (processo acrômico) e o extremo do cotovelo (processo olecrânio).

3. Marcar um traço (com caneta) no local correspondente à metade da distância dessas duas medidas (ponto médio).

4. Reposicionar o braço da criança ou do adulto, de forma que fique estendido ao longo do tronco, com a palma da mão voltada para dentro.

5. Colocar a fita métrica horizontalmente ao redor do braço.

6. Verificar se a fita está no mesmo nível em todas as partes, de modo que não fique nem frouxa, nem apertada.

7. Realizar a leitura.

8. Anotar o resultado obtido na ficha de registro ou no prontuário.

\section{Perímetro da cintura}

É uma medida aproximada de massa de gordura intra-abdominal e gordura total do corpo. É utilizada na avaliação da distribuição de gordura em adultos, visto que algumas complicações, como as doenças metabólicas crônicas, estão associadas à deposição da gordura abdominal (OLINTO et al., 2004).

Por ser uma medida simples, prática e com uma correlação entre distribuição de gordura e a saúde do indivíduo, seu uso é recomendado para triagem inicial dos indivíduos com risco aumentado de doenças relacionadas à obesidade. Para a avaliação dessa medida, utilizamos a recomendação da WHO (WORLD HEALTH ORGANIZATION, 1997), que indica os pontos de corte em relação ao sexo, para o risco de complicações metabólicas associadas à obesidade.

Tabela 4 - Valores de perímetro da cintura que denotam risco de complicações metabólicas associadas à obesidade

\begin{tabular}{l|c|c}
\multicolumn{1}{l|}{ Risco } & Risco Aumentado \\
Homem & $>94 \mathrm{~cm}$ & $>102 \mathrm{~cm}$ \\
\hline Mulher & $>80 \mathrm{~cm}$ & $>88 \mathrm{~cm}$ \\
\hline
\end{tabular}

Fonte: World Health Organization (1997). 
Foto 60 - Etapas da medição

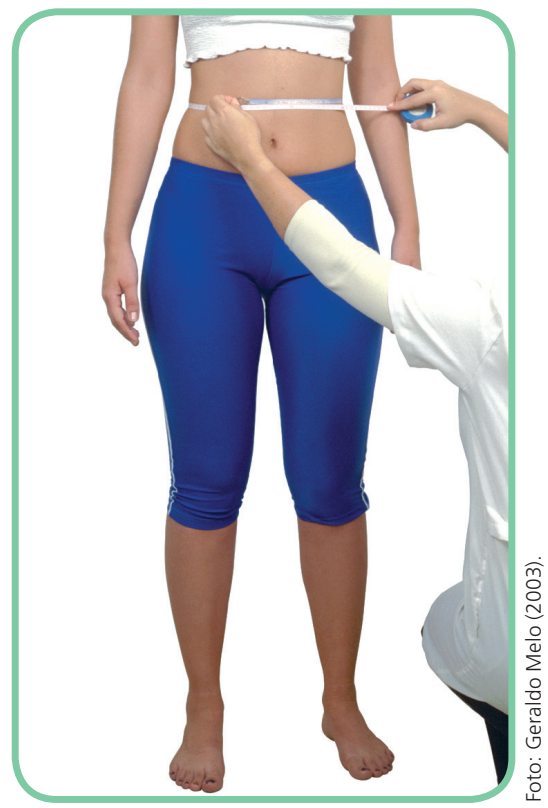

Fonte: Denise Cavalcante de Barros (2005).

Os passos para medição do perímetro da cintura são os seguintes:

1. Colocar a pessoa de pé, ereta, com abdômen relaxado, braços estendidos ao longo do corpo e os pés separados numa distância de 25 a 30cm.

2. Afastar a roupa, de forma que a região da cintura fique despida. A medida não deve ser feita sobre a roupa ou cinta.

3. Manter-se ao lado da pessoa, segurando o ponto zero da fita métrica em sua mão direita e, com a mão esquerda, passar a fita por trás da pessoa, em posição horizontal, ao redor da cintura, sem comprimir o tecido. A fita deve ficar posicionada no ponto médio entre a margem inferior da última costela e a parte superior da crista ilíaca, em um plano horizontal. Cada ponto anatômico deve ser apalpado e marcado, e o ponto médio, determinado com uma fita (WORLD HEALTH ORGANIZATION, 1995, p.430).

4. Verificar se a fita está no mesmo nível em todas as partes da cintura; não deve ficar larga, nem apertada.

5. Pedir para que a pessoa inspire e, em seguida, expire totalmente.

6. Fazer a leitura da medida antes que a pessoa inspire novamente.

7. Anotar o valor da medida no prontuário ou na ficha de registro. 


\section{Perímetro do quadril}

Para uma melhor avaliação, relaciona-se a circunferência da cintura com a circunferência do quadril, já que os homens tendem a depositar mais gordura no abdômen e as mulheres no quadril. A relação cintura/quadril indica um aumento de risco, quando esta relação é maior que 0,95 para homens e 0,80 para mulheres (WORLD HEALTH ORGANIZATION, 1997).

Os passos para a realização dessa medida são:

1. Colocar o adulto, com o mínimo de roupas possível, em pé, ereto, com os braços ao longo do corpo e com os pés juntos.

2. Manter-se ao lado da pessoa, de forma que sua visão fique na direção da extensão máxima dos glúteos.

3. Colocar a fita métrica horizontalmente ao redor do quadril, na área de maior diâmetro, sem comprimir a pele.

4. Verificar se a fita está em posição horizontal e no mesmo nível em todas as partes, de modo que não fique nem frouxa, nem apertada.

5. Realizar a leitura.

6. Anotar o valor da medida no prontuário ou na ficha de registro.

\section{Perímetro da panturrilha}

É uma medida recomendada para a avaliação da massa muscular em idosos por ter maior precisão, nesta faixa etária, em relação às outras de uso mais comum.

Trata-se de uma medida alternativa para pacientes que não deambulam, com cifose, ou ainda que andam de modo inclinado, comprometendo a aferição da estatura.

É uma medida utilizada junto com outros três valores para obtenção do peso corporal. Segundo Chumlea et al. (1988), para estimar o peso são necessários os valores de Altura do Joelho (AJ), Perímetro Braquial (PB) e Dobra Cutânea Subescapular (DCSE).
Cifose é um desvio postural com aumento anormal da concavidade posterior da coluna vertebral. Geralmente ocasionada pela má postura e condicionamento físico insuficiente. 
Os passos são os seguintes:

1. Colocar o indivíduo em pé, ereto, com os pés separados aproximadamente $20 \mathrm{~cm}$, de forma que o peso seja distribuído uniformemente. Caso o indivíduo esteja acamado, colocá-lo sentado com as pernas soltas, sem encostar no chão. Entretanto, se o indivíduo não conseguir ficar sentado, deve-se flexionar o joelho ao ângulo de $90^{\circ}$.

2. Posicionar a fita métrica horizontalmente na área de maior diâmetro da panturrilha.

3. Verificar se a fita está em posição horizontal e no mesmo nível em todas as partes, de modo que não fique nem frouxa, nem apertada.

4. Realizar a leitura.

5. Anotar o valor da medida no prontuário ou na ficha de registro.

Foto 61 - Perímetro da panturilha

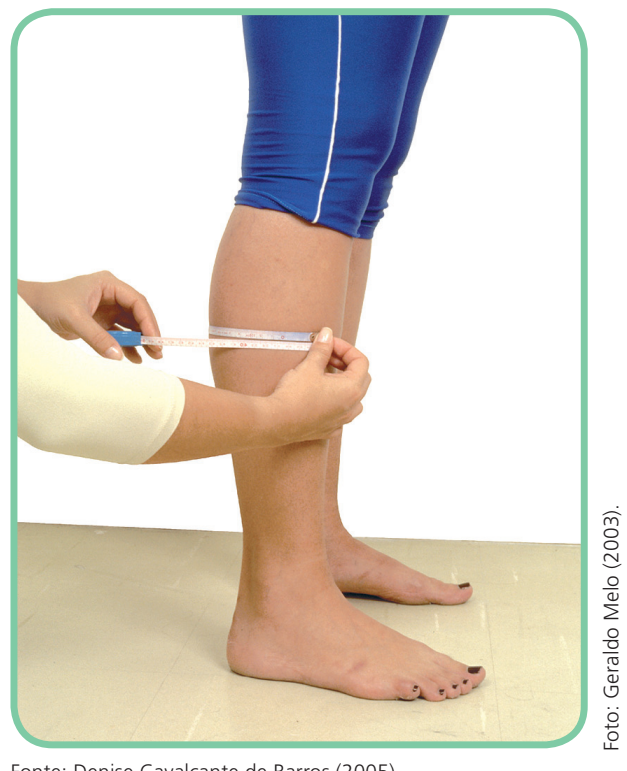

Fonte: Denise Cavalcante de Barros (2005).

Equação para estimar o peso corporal:

- Peso (mulheres) $=$ $(1,27 \times C P)+(0,87 \times A J)+(0,98 \times P B)+(0,4 \times D C S E)-62,35=$ peso em $\mathrm{kg}$

- Peso (homens) $=$ $(0,98 \times C P)+(1,16 \times A J)+(1,73 \times P B)+(0,37 \times$ DCSE $)-81,69=$ peso em $\mathrm{kg}$ 


\section{Para refletir}

Pense na sua experiência. Quais são as maiores dificuldades encontradas em sua trajetória profissional para fazer o diagnóstico nutricional?

\section{PARA CONSOLIDAR SEUS CONHECIMENTOS}

Que tal assistir a um vídeo sobre o tema discutido neste Capítulo?

Para relaxar, saia um pouco da frente do texto e assista ao vídeo Antropometria, disponível na página eletrônica da Fiocruz/CICT/DCS/vídeo saúde.

Depois, procure realizar as atividades propostas a seguir.

1. Analise o vídeo a que assistiu, identificando aspectos positivos e negativos sobre as técnicas utilizadas, os equipamentos e a relação profissional/paciente.

2. Verifique, em seu local de trabalho, os equipamentos disponíveis e as condições de manutenção dos mesmos. Descreva o que foi encontrado e elabore uma proposta de conserto ou manutenção, conforme o caso.

3. Observe, na sua unidade de saúde, a pesagem e medição de seis pessoas, nas seguintes faixas etárias:

- duas crianças menores de dois anos;

- duas crianças maiores de dois anos;

- dois adultos.

a) 0 que você observou?

b) As pesagens e as medições estão sendo feitas corretamente? Em caso negativo, liste as falhas encontradas e proponha as correções devidas.

4. Elabore uma proposta para a capacitação dos colegas de trabalho sobre "Como realizar um diagnóstico nutricional".

\section{Referências}

BARROS, Denise Cavalcante (Org.). Sisvan: instrumento para o combate aos distúrbios nutricionais na atenção à saúde: a antropometria. Rio de Janeiro: SDE/ENSP/Fiocruz, 2005. 
BRASIL. Ministério da Saúde. Vigilância alimentar e nutricional - SISVAN: orientações básicas para a coleta, o processamento, a análise de dados e a informação em serviços de saúde. Brasília, 2004. 120 p. (Série A. Normas e manuais técnicos).

Ministério da Saúde. Secretaria de Atenção Básica. Caderneta de saúde da criança. Brasília: 2007.

CHUMLEA, W.C. et al. Prediction of body weight for nomambulatory elderly from anthropometry. Journal of the American Dietetic Association, v. 88, n. 5, p. 564-568, 1988.

GIBSON, R. Principles of nutritional assessment. New York: Oxford University Press, 1990.

HAMILL, P. V. V. et al. Physical growth: National Center for Health Statistics Percentiles. Americam Journal of Clinical Nutrition, v. 32, p. 607-629, 1979.

JELLIFFE, D. B. Evoluación del estado de nutrición de la comunidad. Genebra: OMS, 1968.

LOHMAN, T. G.; ROCHE, A. F.; MARTORELL, R. Anthropometric standardization reference manual. Champaign, IL: Human Kinetics, 1988.

OLINTO, M. T. A. et al. Waist circunference as a determinant of hypertension and diabetes in Brazilian women: a population based study. Public Health Nutrition, v. 7, n. 5, p. 629-635, 2004.

VASCONCELOS, F. A. G. Avaliação nutricional de coletividades. 4. ed. Florianópolis: Ed. da UFSC, 2007.

WORLD HEALTH ORGANIZATION. Physical status: the use and interpretation of anthropometry. Geneva, 1995. (WHO technical report series, 854).

Obesity: preventing and managing the global epidemic: Report of WHO Consultation on Obesity. Geneva, 1997. 


\title{
3. Diagnóstico nutricional individual
}

\author{
Denise Cavalcante Barros \\ Silvia Ângela Gugelmin \\ Mauricio Soares Leite \\ Alessandra Bento Veggi David
}

Neste Capítulo, vamos nos dedicar ao estudo teórico e prático do diagnóstico individual para cada fase do curso de vida. Para tanto, a técnica de diagnóstico utilizada será a antropometria. As fases do curso de vida a serem estudadas estão apresentadas na seguinte ordem:

- crianças - zero a 10 anos;

- adolescentes - 10 a 19 anos;

- gestantes;

- adultos - 20 a 59 anos;

$\checkmark$ idosos - a partir de 60 anos.

Quais são os grupos contemplados pelo Sistema de Vigilância Alimentar e Nutricional (Sisvan)?

Segundo a Coordenação Geral das Políticas de Alimentação e Nutrição (CGPAN/MS), todos os grupos podem e devem ser contemplados no Sisvan (BRASIL, 2004a). Podemos iniciar a implantação do sistema por um grupo específico, por exemplo, crianças, e depois ampliar para as outras fases. A escolha depende da prioridade social e/ou biológica, da estrutura do serviço e da capacitação dos profissionais. O Sisvan nacional tem enfocado, principalmente, crianças menores de cinco anos e gestantes, devido a sua vulnerabilidade social e biológica.
As técnicas utilizadas para as medidas antropométricas são abordadas no Capítulo 2, "Antropometria", deste livro. 
Assistência integral à saúde da criança compreende a abordagem global da criança, contemplando todas as ações de saúde adequadas para prover resposta satisfatória na produção do cuidado, não se restringindo apenas às demandas apresentadas. Compreende, ainda, a integração entre todos os serviços de saúde, da atenção básica à atenção especializada, com o acompanhamento de toda a trajetória da criança pelos serviços de saúde.

\section{Crianças}

Na elaboração de políticas públicas de saúde, o grupo das crianças tem sido considerado prioritário por apresentar uma característica importante: a grande vulnerabilidade biológica. Até os cinco anos, a atenção à saúde e à nutrição deve ser acompanhada bem de perto, pois essa ainda é uma fase em que o organismo está em formação, sendo mais suscetível a doenças.

Ao longo das últimas décadas, o MS vem investindo e priorizando a assistência à clientela materno-infantil, e o resultado tem-se mostrado positivo. Em 1984, com a criação do Programa de Assistência Integral à Saúde da Criança, mudou a lógica da atenção à saúde. A doença deixou de ser o foco da assistência, de modo que a criança passou a ser vista de forma integral. Com essa nova lógica, a melhoria da situação de saúde teve maior visibilidade e trouxe repercussões importantes para o crescimento e desenvolvimento das crianças brasileiras (BRASIL, 2004b). Mas é importante assinalar que referimo-nos aqui às crianças não-indígenas. Mais adiante, veremos o que pode ser dito sobre as crianças indígenas.

As pesquisas nacionais têm apontado para uma significativa melhora na situação de saúde das crianças brasileiras, na redução da mortalidade infantil - com destaque para o declínio da mortalidade por diarréias, infecções respiratórias e doenças imunopreveníveis -, na erradicação da poliomielite e na redução da desnutrição protéico-calórica. Cabe ressaltar que esses resultados se apresentam de forma diferente nas diversas regiões do país e também nas áreas urbana e rural. Nas regiões Norte e Nordeste e zonas rurais, prioritariamente, é preciso maior investimento e dedicação, pois os resultados ainda são considerados insatisfatórios (MONTEIRO, 2000).

A queda da taxa de mortalidade infantil se deu basicamente pela melhoria do acesso aos serviços de saúde e saneamento básico, assim como por meio da implantação das ações básicas de saúde da criança, que são:

- Terapia de Rehidratação Oral (TRO) - visa ao combate à diarréia.

- Controle das Infecções Respiratórias Agudas (IRA).

- Monitoramento do crescimento e desenvolvimento - será amplamente discutido neste Capítulo.

- Incentivo ao aleitamento materno e orientação para o desmame.

- Controle das doenças imunopreveníveis (vacinação). 
Outras ações, voltadas para o atendimento pré-natal e o parto, também se mostraram importantes na redução da taxa de mortalidade infantil. Um fator que contribuiu foi a queda na taxa de fecundidade, isto é, as mulheres estão tendo menos filhos.

Mas o que pode ser dito sobre as crianças indígenas?

No que se refere a esse segmento da população brasileira, não se pode afirmar, com segurança, que o mesmo tipo de tendência teve lugar, embora em alguns casos haja evidências de redução da mortalidade infantil e das prevalências de desnutrição infantil; em outros, contudo, os dados disponíveis apontam para a persistência de indicadores amplamente desfavoráveis. A escassez de dados epidemiológicos para os povos indígenas dificulta a identificação de tendências e mesmo o delineamento dos perfis de saúde.

Apesar disso, as pesquisas têm apontado para um perfil de saúde de modo geral precário, caracterizado por níveis elevados de morbidade e mortalidade, e onde prevalecem as doenças infecciosas, parasitárias e respiratórias (GARNELO; MACEDO; BRANDÃO, 2003; SANTOS; COIMBRA JÚNIOR, 2003).

Segundo a Funasa (FUNDAÇÃO NACIONAL DE SAÚDE, 2006), em 2005 a Taxa de Mortalidade Infantil (TMI) média nos 34 Distritos Sanitários Especiais Indígenas (DSEI) correspondia a 53,11 óbitos por mil nascidos vivos. Cabe assinalar, mais uma vez, a grande variação desses coeficientes entre as comunidades indígenas. Por exemplo: as taxas de mortalidade infantil médias variaram entre 9,71 (DSEI Potiguara - Paraíba) a 174,89 (DSEI Alto Rio Juruá - Acre) óbitos por mil nascidos vivos.

O fato é que, a despeito dessa grande amplitude de valores, constata-se que as taxas encontradas são geralmente superiores àquelas observadas entre as crianças não-indígenas das mesmas regiões. Esses números demonstram claramente as desigualdades em saúde que separam o contingente indígena do não-indígena no Brasil.

Uma vez contextualizada a situação de saúde da população infantil, podemos pensar em como fazer o diagnóstico nutricional das crianças. Vamos começar pelo estudo do diagnóstico em recém-nascidos.
A invisibilidade epidemiológica e demográfica dos povos indígenas é amplamente discutida nas Partes I e III do livro Vigilância Alimentar e Nutricional para a Saúde Indígena, volume 1, de Denise Cavalcante Barros, Denise Oliveira e Silva e Silvia Ângela Gugelmin (2007). 


\section{Recém-nascidos}

A avaliação do peso da criança imediatamente após o nascimento é o primeiro momento em que se faz o diagnóstico nutricional. O peso ao nascer retrata as condições de crescimento intra-uterino, podendo refletir problemas nutricionais durante a gravidez. Fazer esse diagnóstico é importante, pois a avaliação do peso ao nascer permite uma intervenção precoce. Segundo a Organização Mundial de Saúde (WORLD HEALTH ORGANIZATION, 1995), a classificação dos recém-nascidos conforme o peso ao nascimento é feita como mostra o Quadro 1.

Quadro 1 - Classificação do peso ao nascer segundo WHO (1995)

\begin{tabular}{|c|l|}
\hline Peso ao nascer & Classificação \\
\hline$<1.500 \mathrm{~g} *$ & Muito baixo peso \\
\hline$<2500 \mathrm{~g}$ & Baixo peso \\
\hline$\geq 2500 \mathrm{~g} \mathrm{e}<3000 \mathrm{~g}$ & Peso insuficiente \\
\hline$\geq 3000 \mathrm{e}<4000 \mathrm{~g}$ & Peso adequado \\
\hline$\geq 4000 \mathrm{~g}$ & Peso excessivo ou macrossomia \\
\hline
\end{tabular}

* Essas crianças são consideradas como de altíssimo risco.

As crianças que nascem com peso menor do que $2.500 \mathrm{~g}$ são consideradas de Baixo Peso ao Nascer (BPN). Elas devem ter atenção especial e individualizada, pois o risco de contrair doenças e de morrer é muito grande. As causas do BPN podem ser inúmeras, entre elas a prematuridade, o hábito de fumar, hipertensão materna, doenças infecciosas crônicas, intervalo interpartal menor que dois anos, gestação múltipla, partos cesáreos indicados precocemente e a má nutrição da mãe durante a gestação (BRASIL, 2000a). As conseqüências podem ser graves para a saúde da criança, com repercussões em seu desenvolvimento, não só físico mas também intelectual.

Para fazer uma melhor avaliação do peso ao nascer, é importante conhecer a Idade Gestacional (IG), ou seja, o tempo transcorrido entre a concepção e o parto. É preciso saber quanto tempo durou a gestação, que normalmente é de cerca de 40 semanas. Assim, dependendo desse tempo, o recém-nascido será considerado como mostra o Quadro 2, a seguir:

Quadro 2 - Classificação do recém-nascido segundo idade gestacional

\begin{tabular}{|l|l|}
\hline Classificação & Idade gestacional \\
\hline Pré-termo (prematuro) & Quando o nascimento ocorrer antes de 37 semanas de gravidez \\
\hline A termo & Quando o nascimento ocorrer entre 37 e 42 semanas de gravidez \\
\hline Pós-termo & Quando o nascimento ocorrer após 42 semanas de gravidez \\
\hline
\end{tabular}


Exemplo:

- Filho de Mariana - PN = 2.950g; IG= 39 semanas - Peso adequado, a termo

Filho de Judite $-\mathrm{PN}=2.360 \mathrm{~g} ; \mathrm{IG}=38$ semanas - Baixo peso, a termo

Filho de Cleusa - PN = 1.480g; IG = 30 semanas - Muito baixo peso, prematuro

- Filho de Rita - PN = 3.820g; IG = 43 semanas - Peso adequado, pós-termo.

As causas do BPN são diferentes nos casos de crianças prematuras ou a termo. Observando o exemplo, podemos concluir que entre os prétermos o ganho de peso foi inadequado devido ao nascimento antes da data prevista (por diversos motivos, não relativos à nutrição mãe-filho). Provavelmente, esse recém-nascido teria alcançado o peso se completasse o prazo de 37 a 42 semanas de gestação. Na criança a termo, com baixo peso, ocorreu um Retardo do Crescimento Intra-Uterino (RCIU), sinal provável de má nutrição materna. Essas crianças são classificadas como Pequenas para Idade Gestacional (PIG). As crianças nascidas pré-termo, que não tiveram a velocidade de crescimento intra-uterino alterada, atingirão mais facilmente o peso e a altura adequados à idade, do que aquelas nascidas a termo e com RCIU (INSTITUTE OF MEDICINE, 1990).

A avaliação nutricional do recém-nascido pode ser feita também por intermédio de outras medidas antropométricas, como os perímetros cefálico e torácico.

\section{PARA PRATICAR - DIAGNÓSTICO NUTRICIONAL DE RECÉM-NASCIDOS}

1. Relate como é realizado o diagnóstico nutricional dos recém-nascidos nas aldeias e proponha ações que facilitem esse diagnóstico.

2. Faça o diagnóstico nutricional dos seguintes casos, identificando também se a criança é pré-termo, a termo ou pós-termo:

- Beatriz - nasceu com 38 semanas de gestação e com $2.785 \mathrm{~g}$.

- Bianca - nasceu com 35 semanas de gestação e com $2.000 \mathrm{~g}$.

- Pedro - nasceu com 43 semanas de gestação e com 3.850g.
As técnicas para a medição dos perímetros cefálico e torácico estão apresentadas no Capítulo 2, "Antropometria", deste livro. 
Para melhor compreensão do diagnóstico nutricional realizado nas crianças recém-nascidas, resumimos no Quadro 3 os passos a serem seguidos.

Quadro 3 - Passos para o diagnóstico de recém-nascidos

\begin{tabular}{|c|l|}
\hline Passos & Ações \\
\hline 1 & $\begin{array}{l}\text { Pesar o bebê nas primeiras seis horas de vida (é importante garantir balanças em número suficiente e aferidas, além de } \\
\text { técnica de pesagem adequada). }\end{array}$ \\
\hline 2 & $\begin{array}{l}\text { Registrar o valor em prontuário e na ficha que será entregue à mãe na data da alta da maternidade (Declaração de Nascido } \\
\text { Vivo). Se disponível, preencher e entregar a Caderneta de Saúde da Criança. }\end{array}$ \\
\hline 3 & Avaliar a idade gestacional e realizar o exame físico do bebê, para complementar o diagnóstico. \\
\hline 4 & $\begin{array}{l}\text { Crianças com BPN devem receber atenção diferenciada, devendo ser garantido acompanhamento prioritário subseqüente nos } \\
\text { serviços de saúde. }\end{array}$ \\
\hline 5 & Intervenção adequada para BPN. O incentivo ao aleitamento materno é fundamental! \\
\hline
\end{tabular}

\section{Crescimento é o processo} dinâmico e contínuo que engloba o desenvolvimento físico do corpo, a substituição e a regeneração de tecidos e órgãos humanos. Nota: esse processo é considerado um dos melhores indicadores de saúde da criança, em razão de sua estreita dependência de fatores sociais e ambientais, tais como alimentação, ocorrência de doenças, cuidados gerais e condições de vida no passado e no presente (BRASIL, 2007a).

Desenvolvimento é o aparecimento e aperfeiçoamento de funções como a linguagem, a habilidade motora, as funções cognitivas, a maturidade psíquica e outras (BRASIL, 2007a).

\section{Crianças menores de cinco anos}

A ação básica de saúde que envolve o monitoramento do crescimento e do desenvolvimento das crianças é fundamental para o acompanhamento de sua saúde e nutrição. Essa é uma prática comum entre os profissionais da saúde que trabalham com essa clientela, seja qual for o nível de atenção à saúde.

Crescimento e desenvolvimento não são sinônimos! O primeiro refere-se ao aumento do tamanho do corpo; o segundo, ao aperfeiçoamento das atividades realizadas pela criança, tais como andar, sentar etc.

De modo geral, o crescimento é um processo dinâmico e contínuo que ocorre desde a concepção até o final da vida. É considerado um dos melhores indicadores de saúde da criança, uma vez que sofre influência direta dos fatores ambientais, tais como alimentação, patologias, condições de habitação e saneamento básico, assim como o acesso aos serviços de saúde, cuidados gerais e higiene.

A velocidade de crescimento pós-neonatal é particularmente elevada nos dois primeiros anos de vida, com declínio gradativo e pronunciado até os cinco anos de idade. A partir daí até os 10 anos, mantém-se constante, com leve aumento ao final do período.

O acompanhamento periódico do ganho de peso permite a avaliação do progresso individual da criança, identificando aquelas de maior risco 
de morbimortalidade e sinalizando precocemente a desnutrição. Esta é considerada a causa básica da instalação ou do agravamento de grande parte dos problemas de saúde infantil.

Para acompanhar e avaliar o crescimento e o desenvolvimento infantil, e fazer o registro da vacinação, o MS propõe o uso da Caderneta de Saúde da Criança (BRASIL, 2005a). Esse instrumento está em processo de implantação, pois o Cartão da Criança passou por uma revisão e foi transformado na Caderneta da Criança, em 2005, incorporando a avaliação de crianças até sete anos. Essa transformação visou a reforçar a promoção da vigilância à saúde integral da criança. Em 2006, uma nova Caderneta passou a ser adotada pelo Ministério da Saúde, na qual o acompanhamento do crescimento e desenvolvimento foi ampliado para crianças até 10 anos de idade. No mesmo ano de 2006, foram apresentadas as novas curvas de crescimento lançadas pela OMS e o novo calendário vacinal, com a inclusão da vacina para rotavírus. Assim, algumas unidades de saúde ainda utilizam o Cartão da Criança, enquanto outras fazem uso da Caderneta da Criança.

A avaliação antropométrica no Cartão era e ainda pode ser realizada por meio da utilização do gráfico do peso para a idade para crianças menores de cinco anos. Na última versão da Caderneta, a avaliação ocorre por meio da utilização dos gráficos de: Perímetro Cefálico (crianças menores de dois anos), Peso-Idade (crianças de zero a cinco anos), Altura-Idade (crianças de zero a cinco anos) e Estatura e Peso-Idade (crianças entre cinco e 10 anos).

Apresentamos a seguir a Caderneta de Saúde da Criança publicada em 2006 e daremos destaque especificamente à seção referente ao acompanhamento do crescimento. Para conhecer com detalhes a caderneta e compreender sua utilização você pode acessar as informações na página eletrônica já indicada.

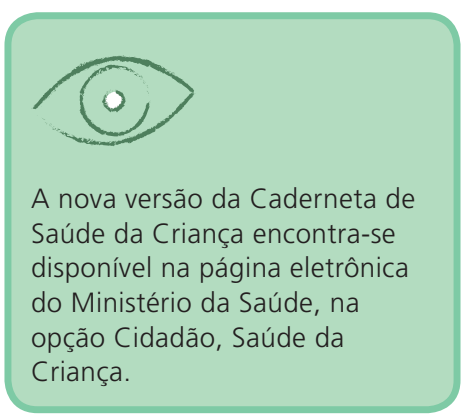


Figura 1 - Caderneta de Saúde da Criança

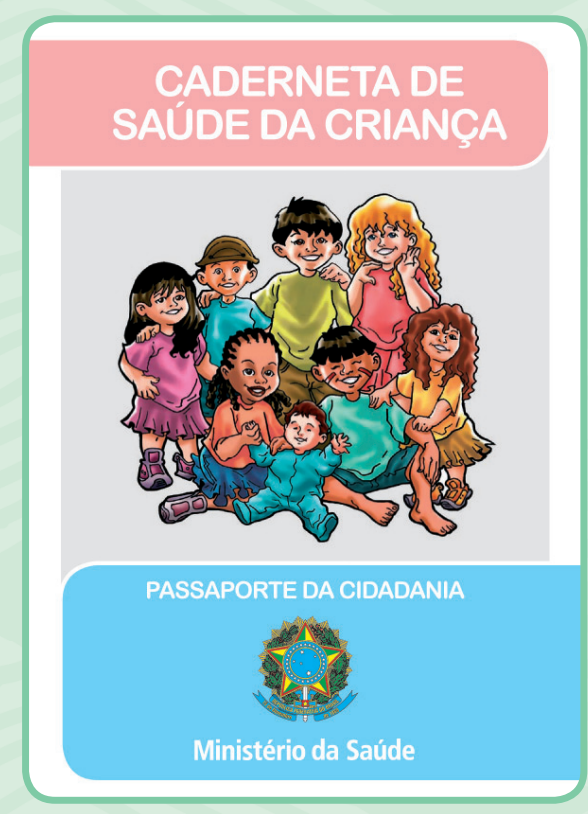

A Caderneta de Saúde da Criança é um instrumento importante no acompanhamento da saúde de cada criança. É um retrato de sua vida até os 10 anos de idade. Quando usada de forma correta e total, permite a visualização integral do seu estado de saúde e nutrição.

Essa caderneta traz as informações já contempladas no Cartão da Criança, acrescidas de outros dados também importantes: as condições de saúde do recém-nascido, a gravidez, o parto e o puerpério, orientações importantes sobre alimentação, gráficos de perímetro cefálico por idade, espaço para anotações de peso e altura.

Apresenta ainda dicas e orientações sobre a saúde auditiva, visual e bucal, prevenção de acidentes, o caminho esperado para o desenvolvimento global, espaço para anotações de intercorrências clínicas, tratamentos efetuados, suplementação preventiva de ferro e de vitamina A e o calendário básico de vacinação.

Você provavelmente encontrará, em seu dia-a-dia, versões distintas do Cartão da Criança e da Caderneta de Saúde da Criança, elaboradas em diferentes épocas pelo Ministério da Saúde, ou mesmo por outras instituições. Como o formato e os dados disponíveis no instrumento podem variar bastante, ele deve ser cuidadosamente examinado para evitar erros em seu preenchimento.
A Caderneta de Saúde da Criança é destinada a acompanhar o crescimento de crianças que nasceram dentro do tempo considerado normal de gravidez. Como já citamos anteriormente, o prematuro é aquele que nasceu com menos de 37 semanas de gestação. Como ele não completou seu crescimento, irá fazê-lo fora da barriga da mãe. Por isso, tanto o peso ao nascer como a velocidade de crescimento dessas crianças são 
diferentes das crianças nascidas a termo. Assim, a Caderneta de Saúde da Criança deve ser usada para os prematuros, desde que levando em conta essas ressalvas. Ou seja, o profissional deve corrigir a idade cronológica da criança até dois anos de idade, utilizando a seguinte fórmula:

Idade corrigida $(I C)=$ Idade cronológica (em semanas) (40 semanas - idade gestacional do nascimento prematuro)

Essa correçãopossibilitará um prognóstico e uma conduta mais adequada à idade real da criança.

É importante destacar que agora a caderneta propõe o monitoramento do crescimento infantil por meio de seis gráficos, específicos por sexo - perímetro cefálico de zero a dois anos de idade; peso para idade de zero a dois anos; comprimento para idade de zero a dois anos; peso para idade de dois a cinco anos; estatura para idade de dois a cinco anos - e um gráfico distinto por sexo, mas que engloba dois índices: peso para idade e estatura para idade para crianças de cinco a 10 anos. Os valores de referência utilizados são aqueles compilados pelo Estudo Multicêntrico, realizado pela Organização Mundial de Saúde (WORLD HEALTH ORGANIZATION, 2006) para crianças de até cinco anos de idade, e pelo National Center of Health Statistics (NCHS), em 1977, para crianças maiores. Os gráficos foram construídos tendo por base a avaliação por percentis (NATIONAL CENTER FOR HEALTH STATISTICS , 1977).

\section{DEFINIÇÃO DOS PERCENTIS DA CADERNETA DE SAÚDE DA CRIANÇA}

No primeiro Cartão da Criança, elaborado em 1984, e na Caderneta de Saúde da Criança de 2005, as curvas de peso para idade correspondiam aos dados compilados pelo NCHS, em 1977/78, e adotados pela Organização Mundial da Saúde (WORLD HEALTH ORGANIZATION, 1995) como referência internacional. No cartão, a curva superior correspondia ao percentil 90 e a inferior, ao percentil 10. A criança cujo peso para idade estivesse entre essas duas curvas era considerada como de crescimento normal e, portanto, seguindo o caminho da saúde. Aquela com peso para idade abaixo do percentil 10 era considerada como apresentando déficit de crescimento e tinha diagnóstico presumível de desnutrição energético/protéica. 0 critério adotado para usar o percentil 10 como ponto de corte inferior foi baseado na proposta do professor Carlos Augusto Monteiro,
A discussão sobre idade gestacional foi realizada no item recém-nascido neste capítulo. 
do Departamento de Nutrição da Faculdade de Saúde Pública da Universidade de São Paulo (BRASIL, 2002).

A seleção do ponto de corte depende de vários fatores, como o grau de sensibilidade e especificidade que se quer dar ao diagnóstico. Este, por sua vez, é determinado em função da prevalência da desnutrição na população considerada e de cada situação específica (programas existentes, diagnósticos de crianças acompanhadas nos serviços de saúde etc.).

A elaboração do segundo Cartão da Criança, em 1997, foi resultado da mudança do perfil epidemiológico das crianças brasileiras, apontada nos resultados da Pesquisa Nacional de Demografia e Saúde, 1996 (BRASIL, 2002). A pesquisa revelou, em crianças menores de cinco anos, uma redução de quase $20 \%$ na prevalência de baixo peso para idade em relação à registrada em inquérito anterior, à Pesquisa Nacional sobre Saúde e Nutrição (PNSN), de 1989. Demonstrava-se que a prevalência de desnutrição no país havia diminuído muito, e não se justificava mais utilizar o percentil 10 como ponto de corte inferior da curva de crescimento no Cartão da Criança.

Por isso, o MS adotou o percentil 3 como ponto de corte inferior. Foi então impresso o novo cartão, com três curvas: percentil 97, percentil 10 e percentil 3. As crianças cujo peso para idade encontrava-se entre os percentis 10 e 3 eram consideradas como de risco, critério que lhes permitia continuar como clientela dos programas de suplementação alimentar, juntamente com aquelas que apresentavam valores iguais ou inferiores ao percentil 3, consideradas como baixo peso.

Em 2001, com a atualização das Normas Técnicas para o Acompanhamento do Crescimento e Desenvolvimento, foi acrescentada mais uma curva ao Cartão da Criança: o percentil 0,1. A inclusão teve como objetivo a compatibilização do cartão com o instrumento de capacitação da Atenção Integrada às Doenças Prevalentes na Infância (AIDPI), permitindo uma gradação nos déficits de peso para idade: peso baixo (valor entre os percentis 3 e 0,1 ) e peso muito baixo (valor igual ou inferior ao percentil 0,1 ), para melhor orientação alimentar e acompanhamento de crianças com alto risco.

A Área Técnica de Saúde da Criança e Aleitamento Materno revisou o Cartão da Criança com o objetivo de promover a vigilância à saúde da criança e de incorporar a resolução do Mercosul de "Informação Básica Comum para a Caderneta da Criança". O cartão foi então transformado na Caderneta de Saúde da Criança, para ser adotada por todas as crianças brasileiras nascidas a partir de 2005.

Em 2006, o MS, por meio da Área Técnica de Saúde da Criança e Aleitamento Materno, propôs a utilização das novas curvas de crescimento resultantes 
do Estudo Multicêntrico, da Organização Mundial de Saúde (WORLD HEALTH ORGANIZATION, 2006), para a avaliação de crianças brasileiras. Essas curvas foram incorporadas à Caderneta de Saúde da Criança e seu estudo será detaIhado adiante.

É importante destacar que até o lançamento da nova versão da caderneta os instrumentos anteriores eram diferentes para meninos (verde/azul) e para meninas (laranja/rosa). Assim, os gráficos mencionados acima são diferentes em cada cartão/caderneta. A versão atual da caderneta é única para ambos os sexos, porém os gráficos continuam específicos para meninos e meninas, e são diferenciados pelas cores das folhas: respectivamente azul e rosa.

Você conhece os gráficos que fazem parte da nova Caderneta de Saúde da Criança?

Neste Capítulo, vamos ter oportunidade de analisar esses gráficos. Antes, porém, consideramos oportuno aprofundar nossas reflexões sobre os estudos realizados pelo NCHS e pela OMS, já referenciados, a respeito das curvas de peso para idade.

\section{VAMOS CONHECER MELHOR AS CURVAS DE CRESCIMENTO DESENVOLVIDAS} PELO NCHS E PELA OMS?

0 órgão de pesquisa norte-americano NCHS reuniu dados antropométricos de diversas pesquisas sobre saúde e nutrição, realizadas nos Estados Unidos até a década de 1970. Esses valores passaram a ser utilizados como parâmetro para a avaliação do crescimento físico e do estado nutricional, e são popularmente conhecidos como a população de referência do NCHS.

Hoje, diversos países adotam a mesma população-referência, o que torna possível estabelecer comparações internacionais dos estudos realizados.

- Como esse estudo foi construído?

Foram utilizadas as variáveis peso, altura, idade e sexo e, a partir delas, construíram-se os seguintes índices: peso para idade, peso para altura e altura para idade. A distribuição das medidas está representada em percentis (de 1 a 100), em desvio-padrão e em escore z. O MS padronizou o uso do critério de percentis para realizar o diagnóstico nutricional de crianças na faixa etária de zero a cinco anos. 


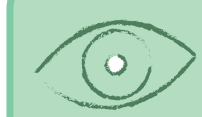

Um vídeo com a descrição da metodologia do estudo e todo o material sobre o Estudo Multicêntrico, incluindo as representações gráficas das curvas, pode ser visto na página eletrônica da OMS.
- Mas, o que é percentil?

0 percentil ( $p$ ) é como se fosse uma fila, onde foram colocadas 100 crianças, da menor para a maior, em peso ou em altura.

Figura 2 - Representação da distribuição percentilar de peso (p3, p50 e p97)

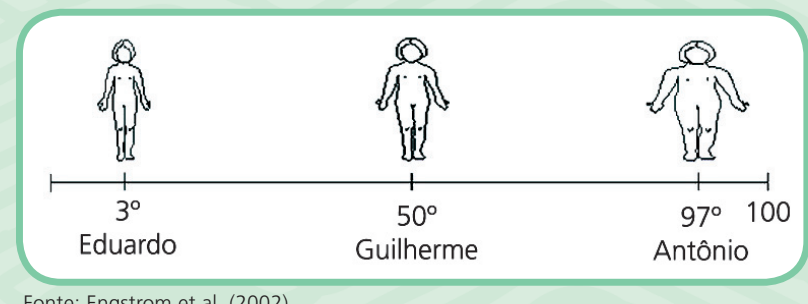

Fonte: Engstrom et al. (2002).

A primeira criança corresponde ao $\mathrm{p} 1$; a terceira criança ao $\mathrm{p3}$; a décima criança ao p10; a criança número 50 (que está na metade da fila) corresponde ao p50; e a criança de número 97, ao p97; até chegar ao p100. Considera-se que o p50 é a mediana.

Por conseguinte, a população-referência do NCHS é adotada internacionalmente, uma vez que estabelece parâmetros de normalidade de dados antropométricos para crianças, os quais possibilitam comparações entre os estudos.

Em 1996, o Programa de Nutrição da OMS iniciou um estudo internacional para a construção de novos referenciais de crescimento infantil que contemplasse a recomendação do aleitamento materno exclusivo durante os seis primeiros meses de vida. Seis países, de contexto cultural e étnico bastante diferentes, foram selecionados de modo a representarem as seis principais regiões geográficas do mundo. Participaram os seguintes países: Brasil (Pelotas), Ghana (Accra), Índia (Nova Delhi), Noruega (Oslo), Oman (Muscat) e Estados Unidos (Davis). 0 estudo envolveu aproximadamente 8.500 crianças desses países.

É importante ressaltar que o estudo contemplou crianças saudáveis, amamentadas por suas mães não-fumantes, bem nutridas e com desenvolvimento considerado adequado. 0 trabalho resultou na publicação de novas curvas de crescimento para crianças menores de cinco anos. 0 novo conjunto de gráficos inclui indicadores de crescimento como peso para idade, altura para idade e peso para altura, e pela primeira vez estabelece o IMC para crianças de até cinco anos de idade.

Em 2006, o MS propôs a utilização dessas curvas para a avaliação do crescimento de crianças brasileiras, incorporando-as na Caderneta de Saúde da Criança. 
Você deve estar se perguntando: como é possível comparar nossas crianças com as de outros países? E como comparar crianças indígenas com crianças não-indígenas?

Como sabemos, as medidas variam na população, mesmo nos indivíduos normais. No entanto, as diferenças genéticas nos potenciais de crescimento, ainda que existentes e manifestas já durante a infância, exercem neste período uma influência menos significativa sobre o crescimento infantil que os fatores de ordem ambiental. Isto é, as condições de saúde e nutrição a que as crianças são submetidas - suas condições de vida.

Portanto, até cerca de 10 anos de idade (período anterior à puberdade), o que mais influencia o crescimento infantil são os fatores externos. Durante essa fase, os fatores genéticos têm pouca influência sobre o ritmo de crescimento infantil.

Por isso, as curvas de crescimento construídas em países desenvolvidos seriam adequadas para avaliar o crescimento de crianças pertencentes a populações de origens distintas (WORLD HEALTH ORGANIZATION, 1995).

\section{Gráficos da Caderneta de Saúde da Criança}

\section{Gráfico perímetro cefálico}

Iniciaremos nosso estudo com o gráfico do perímetro cefálico, segundo o sexo e idade da criança.

Utiliza-se o PC no acompanhamento clínico rotineiro de bebês. É um bom indicador de crescimento em crianças sadias e permite identificar a ocorrência de patologias como hidrocefalia, microcefalia, desnutrição, entre outras. O acompanhamento do perímetro craniano deve ser feito, prioritariamente, nas crianças de zero a 24 meses, período de maior crescimento pós-natal da cabeça e do cérebro. Após os dois primeiros anos de vida, o perímetro da cabeça cresce tão lentamente que sua medida não reflete as alterações no estado nutricional (BARROS et al., 2005).

Desde 2005, o gráfico do perímetro cefálico para a idade, distinto por sexo, consta na Caderneta de Saúde da Criança. Esse gráfico foi construído com a mesma lógica de distribuição em percentis. O perímetro adequado é expresso na forma de uma faixa de normalidade que se situa entre os percentis 10 e 90 (NATIONAL CENTER FOR HEALTH STATISTICS, 1977). O quadro com os valores do PC já foi apresentado no Capítulo anterior.

O perímetro cefálico e os procedimentos para sua avaliação foram discutidos no Capítulo 2 deste livro. 
A seguir, a representação gráfica do PC para crianças de zero a dois anos. Embora haja uma pequena diferença entre os sexos (maior no sexo masculino), a diferença não excede $1 \mathrm{~cm}$ para a média em qualquer idade.

Gráfico 1 - Perímetro cefálico de zero a dois anos - Meninas

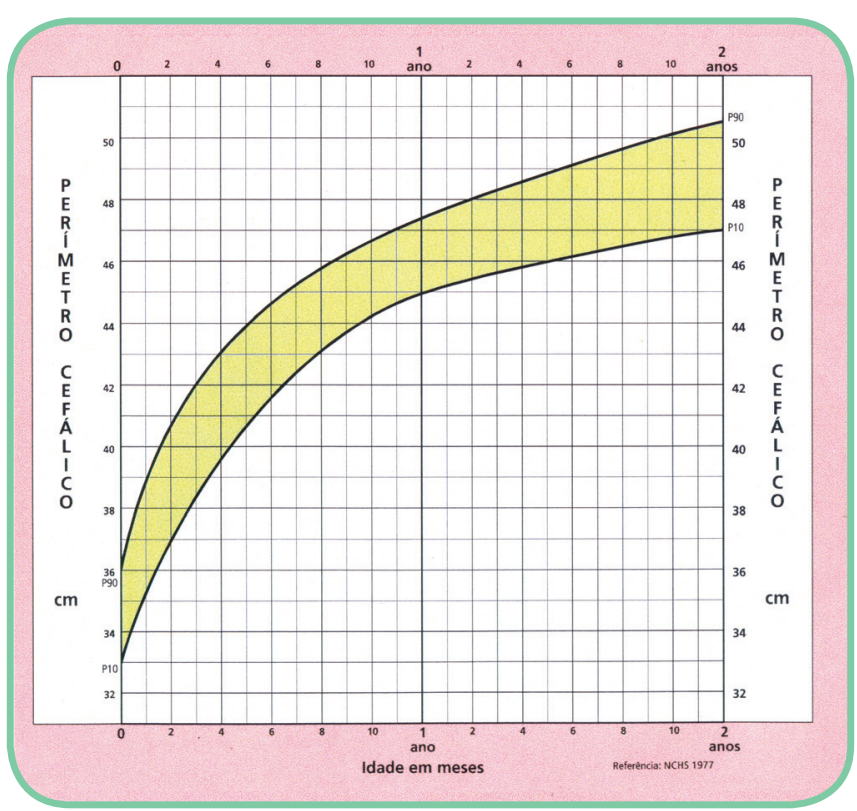

Fonte: Brasil (2007b)
Gráfico 2 - Perímetro cefálico de zero a dois anos - Meninos

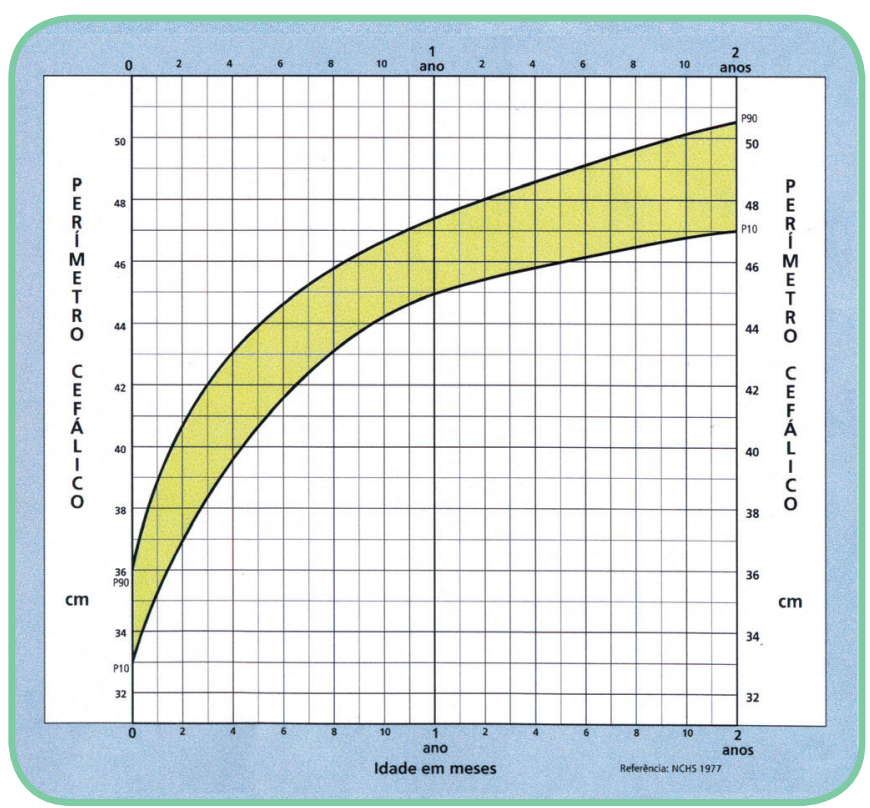

Fonte: Brasil (2007b).
A tabela com a distribuição em percentis dos valores de perímetro cefálico por idade está disponível no Capítulo 2 deste livro, no item medidas complementares.
O antigo Cartão da Criança não apresenta esse gráfico. Mesmo assim, a avaliação nutricional por meio do perímetro cefálico da criança poderá ser realizada normalmente, tendo por base as tabelas contidas no Capítulo anterior, ou por meio da impressão dos gráficos disponíveis no endereço eletrônico do MS. Os dados deverão ser repassados à mãe ou ao responsável, e anotados na ficha ou prontuário da criança.

No caso de o perímetro cefálico para a idade apresentar valores fora da faixa considerada de normalidade, a criança deve ser encaminhada para um especialista ou equipe multiprofissional, para afastar diagnóstico de microcefalia ou de macrocefalia.

\section{Gráfico peso para idade}

O gráfico peso para idade faz parte de todas as versões do Cartão da Criança e, agora, da Caderneta de Saúde da Criança. O mais importante é que, independentemente da versão do instrumento que exista na sua 
realidade, a forma de monitorar o estado nutricional das crianças é a mesma, ou seja, por meio de um gráfico e marcando pontos na interseção dos eixos da idade e do peso, formando assim a curva de ganho de peso da criança.

Vamos agora nos deter mais especificamente no gráfico peso para idade. As curvas que o formam compõem o "caminho da saúde". Se você olhar com atenção, elas realmente formam um "caminho" e cada uma tem um significado. É por meio dessas curvas que iremos monitorar o crescimento da criança até seu décimo ano de vida. Como você pode observar, o gráfico tem esse nome porque utiliza a relação Peso para Idade (P/I) como índice para monitorar o crescimento. Esse é o índice recomendado pela OMS (WORLD HEALTH ORGANIZATION, 1995) e pelo MS (BRASIL, 2002) para o acompanhamento do crescimento em crianças até os cinco anos. Por isso foi escolhido pela vigilância nutricional nos serviços básicos de saúde. A proposta atual é ampliar o uso desse índice para crianças de até 10 anos de idade.

A definição do uso do índice P/I para esse grupo etário tem como base o fato de que o peso é muito sensível às alterações nutricionais e de saúde, sendo mais adequado para o acompanhamento da criança. A variação do peso em relação à idade da criança é muito mais rápida do que a da altura, e reflete, quase que imediatamente, quaisquer alterações em seu estado de saúde, mesmo em processos agudos (BRASIL, 2005b). Ele tem por objetivo expressar a massa corporal (peso) relacionada à idade cronológica da criança.

Embora apresente algumas desvantagens, estas podem ser contornadas com o uso de indicadores complementares e avaliação clínica individual.

Quadro 4 - Vantagens e desvantagens do índice P/I

\begin{tabular}{|c|c|}
\hline Vantagens & Desvantagens \\
\hline $\begin{array}{l}\text { Peso e idade - dados coletados rotineiramente } \\
\text { e com simplicidade. }\end{array}$ & Não identifica se o déficit nutricional é atual ou de longo prazo. \\
\hline $\begin{array}{l}\text { Peso - medida de extrema sensibilidade } \\
\text { às alterações de saúde e nutrição; pode } \\
\text { ser avaliado em intervalos curtos; permite } \\
\text { diagnóstico precoce. }\end{array}$ & Não avalia o crescimento linear, pois a altura não é um dado utilizado. \\
\hline $\begin{array}{l}\text { Útil para triagem de casos de desnutrição. Essa } \\
\text { triagem é chamada de screening. }\end{array}$ & $\begin{array}{l}\text { Não avalia corretamente crianças desnutridas, que apresentam edema (kwashiorkor), pois o } \\
\text { peso pode estar mascarado pela retenção de líquidos, podendo ser considerado adequado } \\
\text { para a idade. }\end{array}$ \\
\hline Permite avaliação & \\
\hline
\end{tabular}


Em algumas Cadernetas de Saúde da Criança, você poderá encontrar, na área vermelha do gráfico, uma linha no percentil 0,1 (aproximadamente -3 escore z). Crianças abaixo dessa linha apresentam peso muito baixo para a idade; são consideradas de alto risco e necessitam de tratamento imediato.

Os Gráficos 3, 4 e 5 estão disponíveis ao final deste Capítulo - Anexos A, $B, C$, respectivamente -, para você consultá-los sempre que necessário.

\section{Conhecendo o gráfico peso para idade}

O gráfico peso para idade destina-se ao acompanhamento de crianças de até 10 anos de idade e está dividido pela idade em meses/anos.

Na Caderneta de Saúde da Criança, recentemente lançada, existem três gráficos peso para idade: Peso para idade para crianças de zero a dois anos (Gráfico 3 a seguir); Peso para idade para crianças de dois a cinco anos (Gráfico 4 a seguir); e Estatura e peso para idade para crianças de cinco a 10 anos (Gráfico 5 a seguir).

O gráfico P/I da Caderneta de Saúde da Criança possui um eixo vertical, que corresponde ao peso em quilogramas, e um eixo horizontal, expresso pela idade em meses/anos. Conta também com "quatro áreas de crescimento", limitadas por linhas estabelecidas a partir dos percentis de referência: a área branca/laranja representa os valores superiores ao percentil 97 (que corresponde, aproximadamente, $\mathrm{a}+2$ escores $\mathrm{z}$ ); a área verde estabelece os valores entre o percentil 97 e o percentil 10, considerada a faixa de peso adequada para a idade; a área amarela representa os valores entre o percentil 10 e o percentil 3 (que corresponde, aproximadamente, a -2 escore $\mathrm{z}$ ), considerado situação de risco ou alerta nutricional; a área vermelha representa os valores inferiores ao percentil 3 , indicando o peso baixo para a idade.

Gráfico 3 - Peso para idade de zero a dois anos

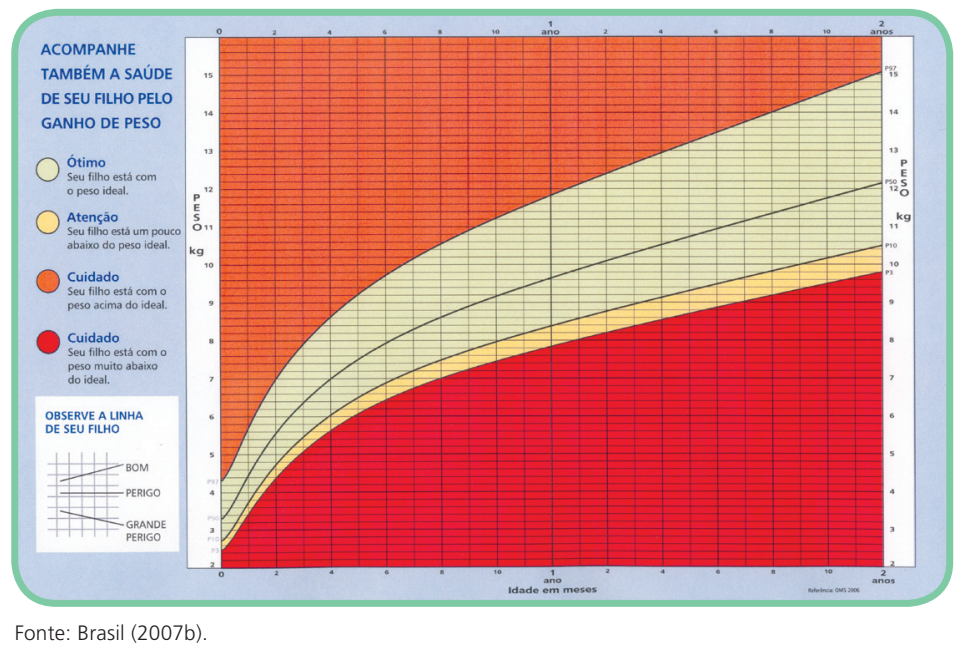


Gráfico 4 - Peso para idade de dois a cinco anos

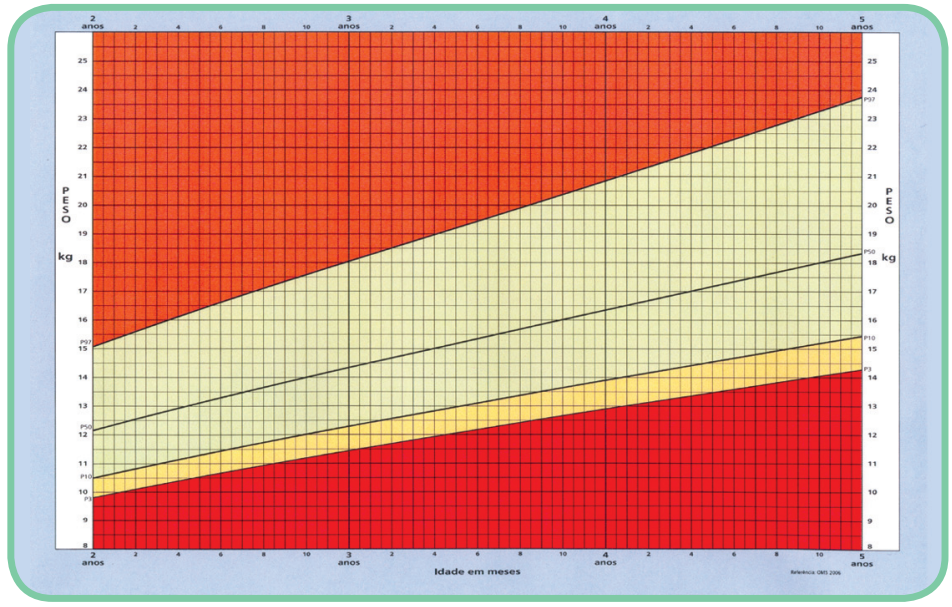

Fonte: Brasil (2007b)

Gráfico 5 - Estatura e peso para idade de cinco a 10 anos

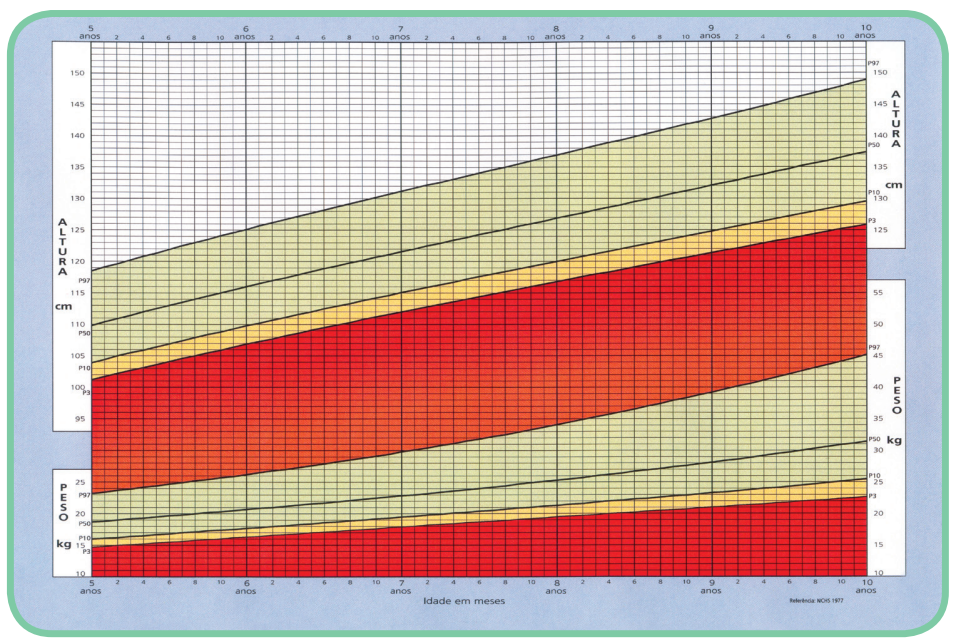

Fonte: Brasil (2007b).

Agora que você já conheceu os gráficos P/I e sabe que se destinam ao acompanhamento de crianças de até 10 anos de idade, lembramos que eles utilizam percentis de uma população-referência, tema discutido anteriormente neste Capítulo.

\section{Para refletir}

Pense no seu cotidiano:

Como é realizado o diagnóstico nutricional das crianças em sua unidade de saúde?

O Cartão da Criança e/ou a Caderneta de Saúde da Criança têm sido utilizados como instrumentos para avaliação do estado nutricional? 
Todos os procedimentos para a medição do peso foram abordados no Capítulo 2, "Antropometria".
Situações em que a informação da data de nascimento da criança não exista devem ser consideradas à parte. Para esses casos, é possível realizar o diagnóstico nutricional por meio do índice peso para altura. Esse índice representa a proporcionalidade corporal; portanto, não é indicado para análises epidemiológicas. O índice peso para altura será discutido mais adiante.

\section{Utilizando o gráfico peso para idade}

Vamos observar o exemplo de Mário, que chegou à unidade de saúde e foi pesado pelo agente indígena. Agora, o agente quer registrar esses dados na Caderneta de Saúde da Criança. O que ele deverá fazer?

A primeira etapa para realizar o diagnóstico individual é obter a medida do peso da criança. Para que o diagnóstico nutricional seja feito com qualidade, são necessários alguns cuidados em relação à coleta dos dados, já mencionados no Capítulo anterior e destacados a seguir:

- o profissional que realiza esse procedimento deve estar sempre bem treinado;

- a balança deve estar sempre regulada e em plena condição de funcionamento;

- a criança que será pesada deve estar sempre com o mínimo de roupa, sem fralda, sem sapatos, de preferência nua;

- o registro do valor obtido deverá ser feito, imediatamente após a pesagem, no prontuário ou ficha da criança, para em seguida ser marcado na caderneta.

Em seguida, precisamos calcular a idade da criança. Essa etapa exige atenção e muito cuidado! Muitas vezes há necessidade de fazer aproximações, pois, como já foi dito e você observou no gráfico, as idades são representadas em meses completos, de acordo com a seguinte regra:

\section{- Até 15 dias}

Aproxima-se a idade para baixo, isto é, para o mês já completado. Exemplo 1: cinco meses e 11 dias $=$ cinco meses .

Exemplo 2: três anos, dois meses e 15 dias = três anos e dois meses.

\section{- 16 dias ou mais}

Aproxima-se a idade para cima, isto é, para o mês a ser completado.

Exemplo 1: três meses e 18 dias $=$ quatro meses.

Exemplo 2: dois anos e 20 dias = dois anos e um mês.

De posse do peso e da idade, obtidos da forma anteriormente recomendada, é feita a marcação no gráfico de crescimento. Observe o exemplo de Mário. 
Mário nasceu dia 30/07/2005, e no dia da consulta, 15/10/2007, pesou 11.500g.

Então, sua idade é: dois anos, dois meses e 15 dias. Conforme a regra de aproximação, a idade que iremos considerar é dois anos e dois meses.

Gráfico 6 - Marcação do peso no gráfico peso para idade - de dois a cinco anos

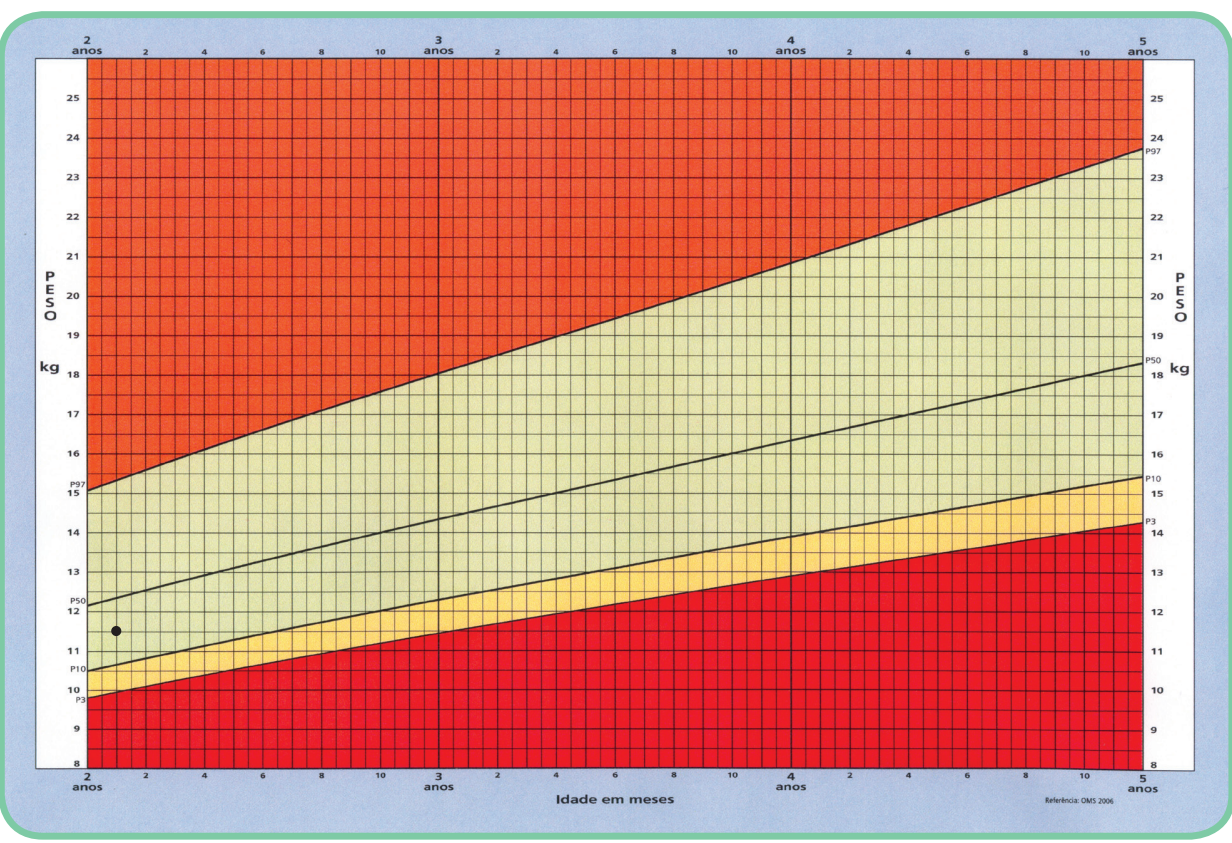

Fonte: Brasil (2007b).

Lembramos que o primeiro peso a ser marcado no gráfico de crescimento deve ser o do nascimento da criança. Seguindo orientação anterior, o ponto de interseção deverá também ser marcado. Dessa forma, será possível avaliar o "caminho da criança" desde seu nascimento. Esses dados (data de nascimento e peso ao nascer) são obtidos por meio do Registro de Nascimento ou da Declaração de Nascidos Vivos e devem constar da página da Caderneta de Saúde da Criança que contém os dados do nascimento. Caso a criança ainda não tenha sido registrada, ou na falta dos documentos, pode-se usar a informação dada pela mãe. Em alguns casos, missões religiosas presentes nas terras indígenas ou nos seus arredores mantêm registros precisos dos nascimentos. Deve-se optar sempre pela fonte mais segura, pois a memória pode falhar.

Vamos, agora, treinar o cálculo da idade e a marcação no gráfico P/I. Você encontrará a seguir os dados necessários para realizar a atividade.
A Declaração de Nascidos Vivos é um documento de preenchimento obrigatório pelas unidades de saúde, nos casos de partos ocorridos em hospitais e outros estabelecimentos de saúde, e pelos cartórios de registro civil, nos casos de partos ocorridos em domicílio ou outros locais. Esse documento é composto por três vias com destinos distintos.

A $1^{\text {a }}$ via permanece na maternidade, como fonte de informação para o Sistema de Informação de Nascidos Vivos (Sinasc); a $2^{\text {a }}$ via deve ser entregue à família para que seja providenciado o registro civil; e a $3^{\text {a }}$ via pode ser enviada diretamente pela maternidade à unidade de saúde que fará o acompanhamento da mãe, ou entregue em mãos para que a mãe a leve à unidade de saúde. 
O símbolo $\mid$ - representa o intervalo entre os valores descritos, incluindo o valor inferior e excluindo o superior. A convenção para apresentação dos intervalos será discutida no Capítulo 6, "Divulgação dos resultados".

\section{PARA PRATICAR - CÁLCULO DE IDADE}

A partir das informações a seguir, calcule a idade de Marcos.

\begin{tabular}{|l|c|c|c|c|}
\hline Nome & $\begin{array}{l}\text { Data de } \\
\text { Nascimento }\end{array}$ & $\begin{array}{l}\text { Data da } \\
\text { Consulta }\end{array}$ & Idade & Peso $(\mathrm{kg})$ \\
\hline Marcos & $17 / 06 / 2007$ & $08 / 12 / 2007$ & & 8,5 \\
\hline
\end{tabular}

Faça a marcação no gráfico de crescimento do Anexo A1 - Marcação do peso de Marcos no gráfico peso para idade -0 a 2 anos.

Agora você já sabe calcular a idade e registrar o peso no gráfico de crescimento da Caderneta de Saúde da Criança. Será que isso basta para o diagnóstico nutricional?

Em parte, sim. Porém, apenas uma marcação não é suficiente para selar o diagnóstico nutricional de uma criança. Essa única marcação fornecerá um diagnóstico pontual, por meio de pontos de corte predeterminados e adotados pelo MS, com base no estabelecido pela OMS. Veja a seguir.

Quadro 5 - Classificação do índice P/l segundo percentil

\begin{tabular}{|l|l|}
\hline Diagnóstico & Classificação do P/I segundo percentil \\
\hline Baixo peso & $<\mathrm{p3}$ [menor que o percentil 3 (exclusive)] \\
\hline Risco nutricional & p3 $1-$ p10 [entre o percentil 3 (inclusive) e o 10] \\
\hline Adequado & p10 I- p97 [entre o percentil 10 (inclusive) e o 97] \\
\hline Sobrepeso & $\geq$ p97 [igual ou maior que percentil 97] \\
\hline
\end{tabular}

Com o resultado de apenas uma marcação você já pode e deve intervir na situação encontrada, mas a intervenção adotada não deve ser definitiva. O esperado é que outras marcações sejam feitas nos gráficos de crescimento constantes da caderneta. Os pontos deverão ser unidos por uma reta, para que você possa avaliar como vem se desenvolvendo o "caminho" ou canal de crescimento da criança.

Caso a criança não compareça à unidade de saúde ou não tenha seu peso registrado na caderneta, o procedimento deverá ser o seguinte:

- se o intervalo entre as marcações for de dois meses, você deverá unir os pontos com uma linha tracejada; 
- se o intervalo entre as marcações for de três meses ou mais, você não deverá unir os pontos, deixando o espaço entre as pesagens em aberto.

\section{PARA PRATICAR - PESO PARA IDADE}

Luiz, durante seu primeiro ano de vida, apresentou os seguintes pesos:

\begin{tabular}{|l|c|}
\hline $\begin{array}{l}\text { Data da } \\
\text { pesagem }\end{array}$ & $\begin{array}{l}\text { Peso em } \\
\text { gramas }\end{array}$ \\
\hline Ao nascer & 2.800 \\
\hline 15 dias & 2.960 \\
\hline 1 mês & 3.400 \\
\hline 2 meses & 4.200 \\
\hline 4 meses & 5.500 \\
\hline 6 meses & 7.000 \\
\hline 9 meses & 9.500 \\
\hline 12 meses & 10.500 \\
\hline
\end{tabular}

1. Consulte o Anexo A - Gráfico de peso para idade - 0 a 2 anos e, depois, faça a marcação do peso de Luiz em cada mês no gráfico do Anexo A2 - Marcação do peso do Luiz no gráfico peso para idade - 0 a 2 anos.

2. 0 que você observou ao marcar o gráfico? Descreva o comportamento da curva peso para idade de Luiz.

Agora, observe mais uma vez o gráfico que você marcou e veja se há mais algum detalhe importante. Certamente você identificou que em alguns meses não há marcação. Faltam o $3^{\circ}, \mathrm{o}^{\circ}, \mathrm{o} 7^{\circ}, \mathrm{o} 8^{\circ}, \mathrm{o} 10^{\circ}$ e o $11^{\circ}$ meses, para que se tenha um acompanhamento mais detalhado.

É importante investigar por que nesses meses o peso não foi registrado. Se verificarmos o calendário mínimo de consultas estabelecido pelo MS, com a nova caderneta, constataremos que, no caso do Luiz, isso foi cumprido.

Segundo o MS (Brasil, 2005a), durante o primeiro ano de vida é recomendado que a criança não classificada como de alto risco compareça ao serviço de saúde no $1^{\circ}, 2^{\circ}, 4^{\circ}, 6^{\circ}, 9^{\circ}, 12^{\circ}, 18^{\circ}$ e $24^{\circ}$ meses. Se nesse período o calendário mínimo for cumprido, isso não significa uma "falta" da criança ao acompanhamento do crescimento. 
De acordo com a agenda de compromissos para a saúde integral da criança e redução da mortalidade infantil, existe uma primeira visita da criança (recém-nascida) à unidade básica de saúde que diz respeito à Primeira Semana Saúde Integral acolhimento da mulher e da criança na unidade.
Observe ainda que o calendário mínimo coincide com o calendário de vacinas obrigatórias no primeiro ano de vida.

Quadro 6 - Calendário mínimo de consultas segundo o MS

\begin{tabular}{|l|l|}
\hline Idade em anos & Número de consultas \\
\hline $1^{\circ}$ ano (seis consultas) & $1^{\circ}, 2^{\circ}, 4^{\circ}, 6^{\circ}, 9^{\circ}$ e $12^{\circ}$ meses \\
\hline $2^{\circ}$ ano (duas consultas) & $18^{\circ}$ e $24^{\circ}$ meses \\
\hline $3^{\circ}, 4^{\circ}$ e $5^{\circ}$ anos (uma consulta) & $\begin{array}{l}\text { A partir dos dois anos de idade, as consultas de rotina } \\
\text { podem ser anuais, próximas ao mês de aniversário. }\end{array}$ \\
\hline
\end{tabular}

Fonte: Brasil (2005a).

Toda e qualquer situação que possa promover alteração no peso da criança deve ser registrada no mês exato em que ocorreu, na parte do cartão ou da caderneta destinada a essa finalidade. O registro de alguma dessas ocorrências é importante para a avaliação do "caminho", ou seja, do traçado da curva da criança, bem como para a escolha da intervenção a ser adotada. A análise do traçado é tão ou mais importante do que a marcação dos pontos no gráfico de crescimento; se registrados e não analisados, de nada servem.

De acordo com os pontos marcados, teremos três tipos de traçado, cada um deles com um significado.
Gráfico 7 - Traçado da curva do menino

\section{OBSERVE A LINHA DE SEU FILHO}

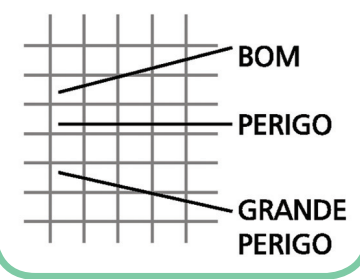

Fonte: Brasil (2007b)
Gráfico 8 - Traçado da curva da menina
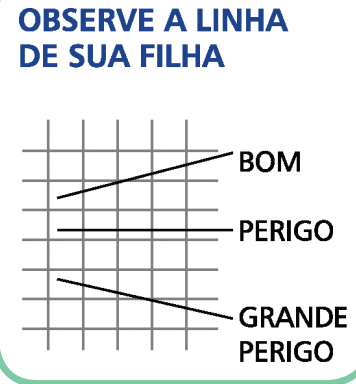

Fonte: Brasil (2007b)
- Traçado ascendente - significa que a evolução do estado nutricional da criança é satisfatória.

- Traçado horizontal - isto é um alerta, sinal de perigo. Sinaliza que a criança não está ganhando peso.

- Traçado descendente - revela grande perigo. Indica perda de peso, o que não é desejado para a criança durante esse período. 
Para uma análise mais detalhada do estado nutricional, podemos associar cada tipo de traçado às categorias de classificação do EN. Estas permitem uma interpretação ainda mais apurada da situação atual da criança. Veja o Quadro 7.

Quadro 7 - Traçados da curva segundo categorias de classificação do índice peso para idade

\begin{tabular}{|l|l|l|l|}
\hline Percentil & Traçado & Condição nutricional & $\begin{array}{l}\text { Diagnóstico } \\
\text { nutricional }\end{array}$ \\
\hline$\geq 97$ & $\begin{array}{l}\text { Ascendente } \\
\text { Horizontal } \\
\text { Descendente }\end{array}$ & $\begin{array}{l}\text { Risco de obesidade } \\
\text { Alerta } \\
\text { Alerta }\end{array}$ & Sobrepeso \\
\hline p10 I-p97 & $\begin{array}{l}\text { Ascendente } \\
\text { Horizontal } \\
\text { Descendente }\end{array}$ & $\begin{array}{l}\text { Satisfatório } \\
\text { Alerta } \\
\text { Insatisfatório }\end{array}$ & Adequado \\
\hline p3 1-p10 & $\begin{array}{l}\text { Ascendente } \\
\text { Horizontal } \\
\text { Descendente }\end{array}$ & $\begin{array}{l}\text { Alerta } \\
\text { Insatisfatório } \\
\text { Insatisfatório }\end{array}$ & Risco nutricional \\
\hline$<p 3$ & $\begin{array}{l}\text { Ascendente } \\
\text { Horizontal } \\
\text { Descendente }\end{array}$ & $\begin{array}{l}\text { Alerta } \\
\text { Insatisfatório } \\
\text { Insatisfatório }\end{array}$ & Peso baixo \\
\hline$<\mathrm{p} 0,1^{*}$ & $\begin{array}{l}\text { Ascendente } \\
\text { Horizontal } \\
\text { Descendente }\end{array}$ & $\begin{array}{l}\text { Desnutrição } \\
\text { Desnutrição } \\
\text { Desnutrição }\end{array}$ & Peso muito baixo \\
\hline
\end{tabular}

Lembre-se do significado do símbolo|-: intervalo que inclui o valor inferior e exclui o valor superior.

PARA PRATICAR - DIAGNÓSTICO NUTRICIONAL EM CRIANÇA MENOR DE CINCO ANOS: GANHO DE PESO

Para rever e aplicar os conhecimentos recém-adquiridos, realize as atividades propostas, a partir das informações apresentadas a seguir.

Tânia nasceu no dia 10/12/2006, com 3.000g.

\begin{tabular}{|c|c|c|c|c|c|}
\hline \multirow{2}{*}{$\begin{array}{l}\text { Data da } \\
\text { consulta } \\
\text { do traçado } \\
\text { Exemplo: } \\
\text { 23/12/2006 }\end{array}$} & \multirow{2}{*}{$\begin{array}{l}\text { Idade } \\
13 d\end{array}$} & \multirow{2}{*}{$\begin{array}{l}\begin{array}{l}\text { Peso na } \\
\text { consulta }\end{array} \\
\quad 3.100 \mathrm{~g}\end{array}$} & \multicolumn{2}{|c|}{ Diagnóstico nutricional } & \multirow{2}{*}{$\begin{array}{l}\text { Avaliação } \\
\text { do traçado }\end{array}$} \\
\hline & & & p10 l-p97 & Adequado & \\
\hline $10 / 01 / 2007$ & & $3.500 \mathrm{~g}$ & & & \\
\hline $10 / 02 / 2007$ & & $4.000 \mathrm{~g}$ & & & \\
\hline $10 / 04 / 2007$ & & $4.900 \mathrm{~g}$ & & & \\
\hline $10 / 06 / 2007$ & & $5.050 \mathrm{~g}$ & & & \\
\hline $10 / 09 / 2007$ & & $6.300 \mathrm{~g}$ & & & \\
\hline $10 / 12 / 2007$ & & $8.250 \mathrm{~g}$ & & & \\
\hline
\end{tabular}


As versões anteriores do Cartão/ Caderneta da Criança não contemplam o acompanhamento da altura para idade. Porém, nada impede que esse índice seja usado para realizar a avaliação nutricional. O profissional poderá usar as tabelas imprimindo os gráficos Altura para Idade disponíveis no endereço eletrônico do MS. As informações deverão ser repassadas à mãe e/ou ao responsável pela criança e anotadas em sua ficha ou prontuário.
1. Avalie o peso de Tânia ao nascer.

2. Calcule a idade da criança.

3. Faça o diagnóstico nutricional de Tânia, em cada consulta, verificando possíveis intercorrências.

4. Analise o traçado da curva.

5. Comente o calendário de consultas realizado pela criança.

Faça o diagnóstico nutricional da Tânia e a marcação no gráfico do Anexo A3 Marcação do peso da Tânia no gráfico peso para idade - de 0 a 2 anos.

\section{Gráfico altura para idade}

Na Caderneta de Saúde da Criança (BRASIL, 2007b) existe a curva de altura para idade (A/I), que se destina também à avaliação nutricional das crianças de zero a 10 anos. Ela foi construída com a mesma lógica de distribuição em percentis de altura segundo a idade da criança.

Vamos, agora, nos deter mais especificamente no gráfico A/I.

O gráfico utiliza o índice A/I com o objetivo de avaliar o crescimento linear, isto é, como se comporta a velocidade de crescimento. Na criança, a altura sofre interferência direta dos problemas nutricionais. Quando há um déficit nutricional e, principalmente, se este ocorrer por um longo período, a altura poderá ser afetada. Normalmente, quando a criança apresenta um déficit de altura, seu problema nutricional é de maior gravidade. Diferentemente do peso, que oscila facilmente na presença de algum problema de saúde e nutrição, a altura só será comprometida caso a duração desse problema seja muito longa.

Não devemos esquecer que a genética é um fator a ser considerado para avaliar o comprometimento da altura. O padrão da família pode ser de pessoas de baixa estatura, o que nos leva a crer que a criança recebeu essa herança familiar. As questões hormonais, embora raras, também devem ser consideradas, a exemplo de uma deficiência dos hormônios de crescimento. Nesse caso, só uma avaliação bioquímica poderá esclarecer se o déficit de altura é derivado de tal fator. 
O índice altura para idade é recomendado como complementar à implantação da vigilância nutricional nos serviços básicos de saúde e passa a fazer parte da avaliação do crescimento de crianças menores de 10 anos, de acordo com a nova Caderneta de Saúde da Criança (BRASIL, 2007b). O ganho de altura é um bom parâmetro para avaliação do crescimento da criança, por ser cumulativo, progressivo e não sofrer regressões. No entanto, é importante ressaltar que a medição da altura não é fácil de ser realizada: requer habilidade, paciência e muita precisão, principalmente em crianças pequenas. Por isso, a dificuldade de implantação/ implementação na rotina dos serviços.

Da mesma forma que as curvas do gráfico P/I, as curvas do gráfico A/I compõem o "caminho da saúde". É por meio dessas curvas que iremos monitorar o crescimento linear de crianças até seu décimo ano de vida. O Quadro 8 apresenta as vantagens e desvantagens do uso do índice $\mathrm{A} / \mathrm{I}$.

Quadro 8 - Vantagens e desvantagens do índice A/l

\begin{tabular}{|l|l|}
\hline Vantagens & Desvantagens \\
\hline $\begin{array}{l}\text { Possibilita acompanhar a dimensão linear do } \\
\text { corpo. }\end{array}$ & Dificuldade na medição da altura. \\
\hline $\begin{array}{l}\text { A altura é uma medida cumulativa, progressiva } \\
\text { e não sofre regressões. }\end{array}$ & $\begin{array}{l}\text { É pouco sensível a pequenas alterações. } \\
\text { Apesar de medir cumulativamente } \\
\text { o crescimento, o ganho de altura é } \\
\text { relativamente lento, o que faz com que os } \\
\text { problemas agudos de saúde e nutrição de } \\
\text { crianças menores de cinco anos demorem a } \\
\text { ser refletidos. }\end{array}$ \\
\hline $\begin{array}{l}\text { Possibilita diagnosticar carência de longa data } \\
\text { (déficit de A/l). }\end{array}$ & \begin{tabular}{c} 
Às vezes a idade é desconhecida. \\
\hline Permite avaliação de coletividades.
\end{tabular} \\
\hline
\end{tabular}

O déficit nutricional persistente na infância compromete inicialmente o peso da criança; a seguir, diminui a velocidade de crescimento e, por fim, compromete a altura. Os déficits de altura requerem um prazo mais longo de carência nutricional para ocorrerem, sendo esse índice menos sensível para pequenas oscilações nutricionais quando comparado ao P/I.

\section{Conhecendo o gráfico altura para idade}

Na Caderneta de Saúde da Criança existem três gráficos altura para idade, de acordo com o sexo: comprimento para idade para crianças de 
Escore z ajuda a entender onde um determinado valor individual se encontra em relação aos demais em uma distribuição. O escore padronizado indica, em unidades de Desvio-Padrão (DP), o sentido e o grau com que um dado escore bruto (valor observado) se afasta da média da distribuição à qual pertence. O escore z é calculado por meio da seguinte fórmula:

$z=\frac{\text { escore bruto (valor) }- \text { média }}{\text { desvio-padrão }}$

Os Gráficos 9, 10 e 11 estão disponíveis ao final deste Capítulo - Anexos D, E, F, respectivamente -, para você consultá-los sempre que necessário. zero a dois anos; estatura para idade para crianças de dois a cinco anos; e estatura e peso para idade para crianças de cinco a 10 anos.

O gráfico A/I possui um eixo vertical, que corresponde à altura em centímetros, e um eixo horizontal, expresso pela idade em meses/anos. Conta, também, com "quatro áreas de crescimento" limitadas por linhas estabelecidas a partir dos percentis de referência. A área branca/laranja representa os valores superiores ao percentil 97 (que corresponde, aproximadamente, a +2 escores $z$ ); a área verde estabelece os valores entre o percentil 97 e o percentil 10, considerada a faixa de altura adequada para a idade; a área amarela representa os valores entre o percentil 10 e o percentil 3 (que corresponde, aproximadamente, a -2 escore z), situação considerada de risco ou alerta nutricional; a área vermelha representa os valores inferiores ao percentil 3, indicando a baixa altura para a idade.

Gráfico 9 - Comprimento para idade de zero a dois anos

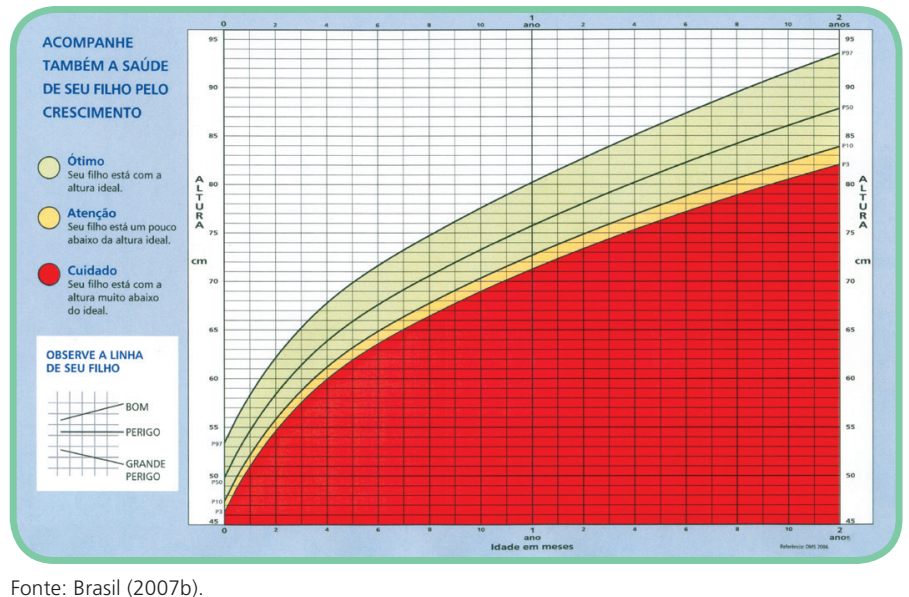

Fonte: Brasil (2007b).

Gráfico 10 - Estatura para idade de dois a cinco anos

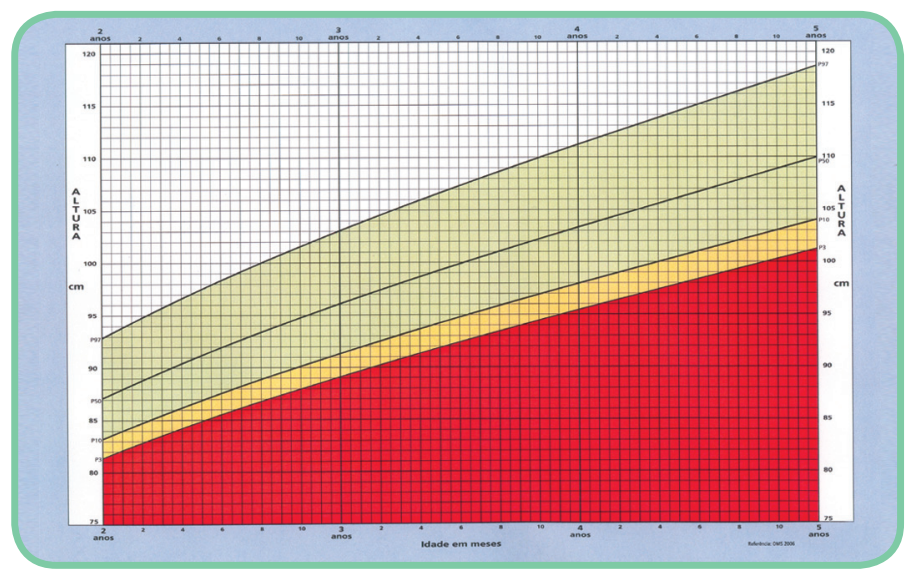

Fonte: Brasil (2007b). 
Gráfico 11 - Estatura e peso para idade de cinco a 10 anos

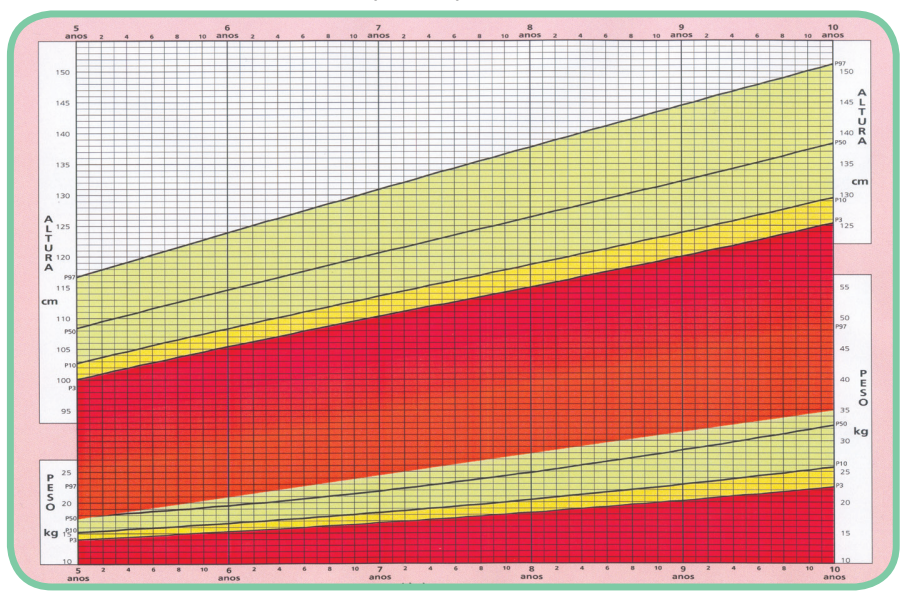

Fonte: Brasil (2007b).

Da mesma forma que os gráficos discutidos anteriormente, os de altura para idade também utilizam percentis de uma população de referência. Para os gráficos de zero a dois anos e de dois a cinco anos, a populaçãoreferência é a do Estudo Multicêntrico da OMS; já para os gráficos de cinco a 10 anos, a população-referência é do NCHS.

\section{Para refletir}

É possível realizar a medição da altura das crianças em sua unidade de saúde?

Como é realizado o diagnóstico nutricional do canal de crescimento das crianças?

\section{Utilizando o gráfico altura para idade}

Vamos retomar o exemplo de Mário, apresentado no item “Utilizando o gráfico peso para idade". Após o registro do peso na ficha e da marcação no gráfico peso para idade, o agente indígena de saúde fez a medição da estatura da criança. Tendo o valor da altura em mãos, como ele deverá prosseguir?

Algumas etapas já foram executadas e discutidas, mas vale relembrar que um diagnóstico nutricional de boa qualidade necessita de cuidados em relação à coleta dos dados, merecendo destaque os seguintes:

- o profissional que realiza esse procedimento deve estar sempre bem treinado;

- o equipamento preferencial para aferição da altura é o antropômetro vertical, que deve estar funcionando plenamente;
Todos os procedimentos para a medição da altura foram abordados no Capítulo 2, "Antropometria", deste livro. 
- a criança deve ser medida com o mínimo de roupa, de preferência nua e sem acessórios na cabeça;

- o valor obtido na medição deverá ser registrado imediatamente no prontuário ou na ficha da criança, para, em seguida, ser marcado na caderneta.

Como já iniciamos a avaliação nutricional de Mário pelo índice P/I, a sua idade já é conhecida. Você se lembra? Mário nasceu dia 30/07/2005 e no dia da consulta, 15/10/2007, estava com dois anos, dois meses e 15 dias. O agente indígena de saúde, após pesar Mário, realizou a medição da altura, encontrando o valor de $88,0 \mathrm{~cm}$. Conforme a regra de aproximação, consideramos Mário com dois anos e dois meses.

De posse dos dados sobre estatura e idade, obtidos da forma anteriormente recomendada, marcamos na caderneta.

Gráfico 12 - Marcação da estatura de Mário no gráfico estatura para idade - de dois a cinco anos

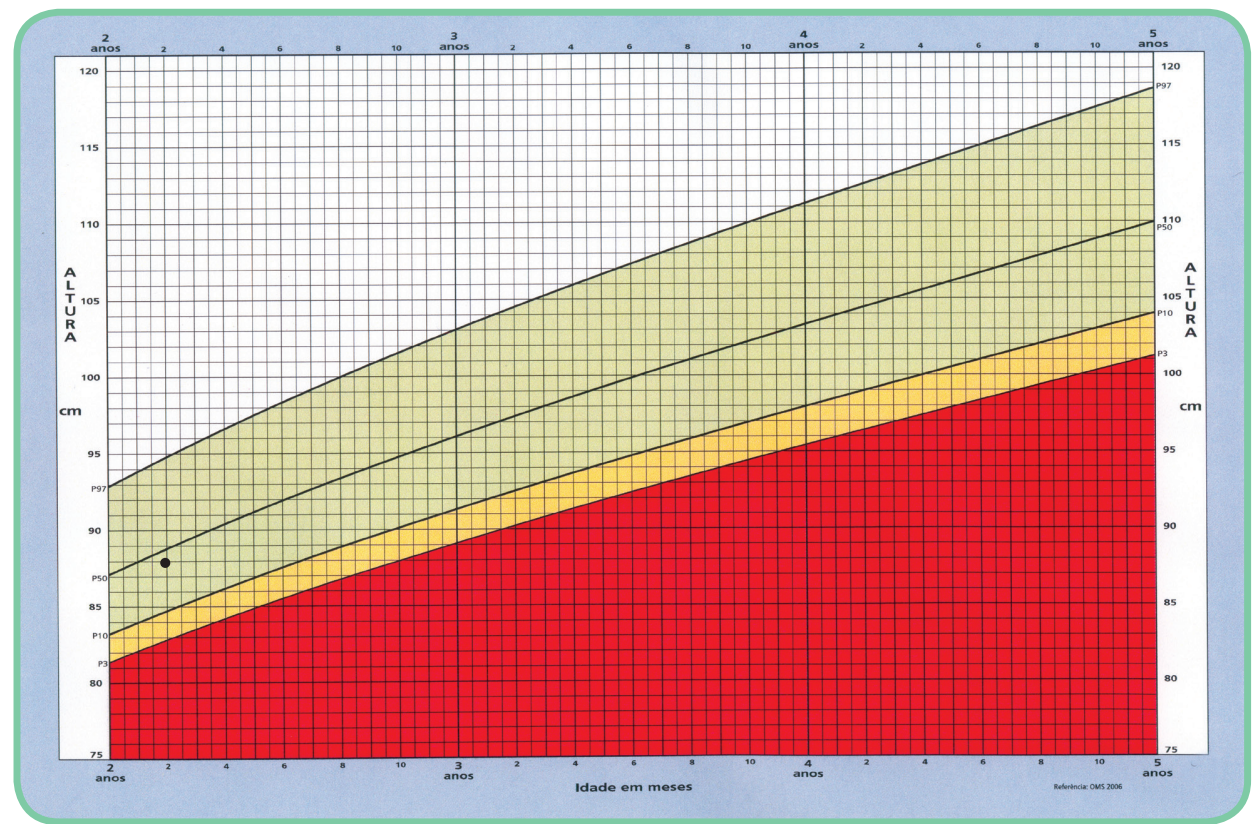

Fonte: Brasil (2007b).

Assim como no gráfico peso para idade, uma única marcação não é suficiente para selar o diagnóstico nutricional de uma criança. Essa marcação fornecerá somente um diagnóstico pontual, por meio de pontos de corte predeterminados e adotados pelo MS, com base no estabelecido pela OMS. Veja o Quadro 9. 
Quadro 9 - Classificação do índice A/l segundo percentil

\begin{tabular}{|l|l|}
\hline Diagnóstico & Classificação do A/l segundo percentil \\
\hline Baixa altura & $<\mathrm{p3}$ (exclusive) \\
\hline Vigilância para baixa altura & $\mathrm{p3} \mathrm{I-p10} \mathrm{[entre} \mathrm{o} \mathrm{percentil} \mathrm{3} \mathrm{(inclusive)} \mathrm{e} \mathrm{o} \mathrm{10]}$ \\
\hline Adequado & $\begin{array}{l}\mathrm{p} 10 \text { I- p97 [entre o percentil 10 (inclusive) e } \\
\text { o 97] }\end{array}$ \\
\hline Altura elevada & $\geq \mathrm{p97}$ [igual e maior que percentil 97] \\
\hline
\end{tabular}

Com o resultado de apenas uma marcação você já pode e deve intervir na situação encontrada, mas a intervenção adotada não deve ser definitiva. O esperado é que outras marcações sejam feitas no gráfico. Os pontos deverão ser unidos por uma reta, para que você possa avaliar como a criança está se desenvolvendo e como está o canal de crescimento dela.

\section{PARA PRATICAR - ALTURA PARA IDADE}

Voltando ao caso do Luiz, apresentado na atividade "Para praticar - peso para idade", marque no gráfico comprimento para idade, no Anexo D1 - Marcação do comprimento de Luiz no gráfico comprimento para idade - 0 a 2 anos, os seguintes valores:

\begin{tabular}{|l|c|}
\hline Data da medição & Altura em centímetros \\
\hline Ao nascer & 49,0 \\
\hline 15 dias & 50,0 \\
\hline 1 mês & 54,0 \\
\hline 2 meses & 57,5 \\
\hline 4 meses & 62,5 \\
\hline 6 meses & 67,2 \\
\hline 9 meses & 73,0 \\
\hline
\end{tabular}

1. 0 que você observou ao marcar o gráfico?

2. Descreva o comportamento da curva do crescimento linear do gráfico comprimento para idade de Luiz. 
Múltiplas marcações de pontos no gráfico A/I formam um "caminho", ou melhor, um traçado, e, como dito anteriormente, a análise do traçado é tão ou mais importante do que a marcação em si, pois se os valores de altura foram registrados e não analisados, de nada servem. A avaliação do traçado da altura segue a mesma regra para a avaliação do traçado do gráfico P/I. Podemos associar cada tipo de traçado às categorias de classificação do EN. Estas permitem uma interpretação ainda mais apurada da situação atual da criança. Veja o Quadro 10.

Quadro 10 - Traçados da curva segundo categorias de classificação do índice A/l

\begin{tabular}{|l|l|l|l|}
\hline Percentil & Traçado & Condição nutricional & Diagnóstico nutricional \\
\hline 97 & $\begin{array}{l}\text { Ascendente } \\
\text { Horizontal }\end{array}$ & $\begin{array}{l}\text { Alerta } \\
\text { Insatisfatório }\end{array}$ & Altura elevada \\
\hline p10 I-p97 & $\begin{array}{l}\text { Ascendente } \\
\text { Horizontal }\end{array}$ & $\begin{array}{l}\text { Satisfatório } \\
\text { Alerta/Insatisfatório }\end{array}$ & Adequado \\
\hline p3 I-p10 & $\begin{array}{l}\text { Ascendente } \\
\text { Horizontal }\end{array}$ & $\begin{array}{l}\text { Alerta } \\
\text { Insatisfatório }\end{array}$ & $\begin{array}{l}\text { Vigilância para baixa } \\
\text { altura }\end{array}$ \\
\hline$<$ p3 & $\begin{array}{l}\text { Ascendente } \\
\text { Horizontal }\end{array}$ & $\begin{array}{l}\text { Alerta } \\
\text { Insatisfatório }\end{array}$ & Baixa altura \\
\hline
\end{tabular}

PARA PRATICAR - DIAGNÓSTICO NUTRICIONAL EM CRIANÇA MENOR DE CINCO ANOS: CRESCIMENTO LINEAR

Voltando ao caso de Tânia, apresentado na atividade "Para praticar - diagnóstico nutricional em criança menor de cinco anos: ganho de peso", analisaremos agora o seu crescimento linear em cada consulta, a partir das informações a seguir.

Lembre-se de que Tânia nasceu no dia 10/12/2006, com $3.000 \mathrm{~g}$ e $49 \mathrm{~cm}$.

\begin{tabular}{|l|c|c|l|l|l|}
\hline $\begin{array}{l}\text { Data da } \\
\text { consulta do } \\
\text { traçado }\end{array}$ & Idade & $\begin{array}{l}\text { Altura na } \\
\text { consulta }\end{array}$ & \multicolumn{2}{|l|}{ Diagnóstico nutricional } & $\begin{array}{l}\text { Avaliação do } \\
\text { traçado }\end{array}$ \\
\hline $\begin{array}{l}\text { Exemplo: } \\
23 / 12 / 2006\end{array}$ & $13 \mathrm{~d}$ & $50,5 \mathrm{~cm}$ & P50-97 & Adequado & Ascendente \\
\hline $10 / 01 / 2007$ & & $52,0 \mathrm{~cm}$ & & & \\
\hline $10 / 02 / 2007$ & & $54,3 \mathrm{~cm}$ & & & \\
\hline $10 / 04 / 2007$ & & $58,0 \mathrm{~cm}$ & & & \\
\hline $10 / 06 / 2007$ & & $62,0 \mathrm{~cm}$ & & & \\
\hline $10 / 09 / 2007$ & & $65,5 \mathrm{~cm}$ & & & \\
\hline $10 / 12 / 2007$ & & $69,0 \mathrm{~cm}$ & & & \\
\hline
\end{tabular}


Faça o diagnóstico nutricional de Tânia, em cada consulta, verificando possíveis intercorrências. Utilizando o Anexo D - Gráfico de comprimento para idade - 0 a 2 anos, faça a marcação no gráfico do Anexo D2 - Marcação do comprimento de Tânia no gráfico de comprimento para idade - 0 a 2 anos e analise 0 traçado da curva.

Vamos rever os passos para realizar o diagnóstico nutricional da criança?

São eles:

1. Calcular a idade da criança em meses, fazendo as aproximações necessárias.

2. Pesar a criança, observando as técnicas e os equipamentos adequados.

3. Registrar os dados nas fichas ou nos prontuários do serviço.

4. Medir a criança, observando as técnicas e os procedimentos adequados.

5. Registrar os dados nas fichas ou nos prontuários do serviço.

6. Marcar os gráficos na Caderneta de Saúde da Criança.

7. Avaliar o estado nutricional da criança pela faixa de percentil (diagnóstico nutricional).

8. Analisar a inclinação das curvas de crescimento para confirmar o diagnóstico nutricional. Esse passo é realizado nas consultas subseqüentes, ou seja, desde que haja mais de um ponto marcado na caderneta.

9. Promover atenção diferenciada e prioritária às crianças abaixo do p3; entre p3 e p10; acima de p97 e àquelas com traçado desfavorável ("atitude de vigilância").

10. Realizar intervenção imediata.

11. Planejar/utilizar outras estratégias que possam contribuir para a promoção da saúde com base nas diretrizes da Política Nacional de Alimentação e Nutrição (PNAN).

\section{Para refletir}

Ao consolidar os passos do diagnóstico nutricional de crianças, que aspectos eram ignorados na sua prática?
Lembre-se de que nos locais onde ainda são utilizados o Cartão da Criança, ou a versão anterior da Caderneta de Saúde da Criança, você poderá realizar a avaliação do canal de crescimento por meio da impressão dos gráficos de altura para idade disponíveis na página eletrônica do MS. Não se esqueça de que os dados deverão ser repassados à mãe ou ao responsável e anotados na ficha ou no prontuário da criança.

As diretrizes da PNAN são discutidas no Capítulo 5, Parte II, do volume 1 do livro Vigilância Alimentar e Nutricional para a Saúde Indígena, de de Denise Cavalcante Barros, Denise Oliveira e Silva e Silvia Ângela Gugelmin (2007). Também há menção das políticas e intervenções nutricionais no Capítulo 9, Parte III, do mesmo livro. 
Valorizar o diagnóstico nutricional é ter atitude de vigilância!

Os serviços devem estar organizados de forma a acolher as crianças desnutridas. Recomenda-se, ainda, vigilância especial nos casos de traçados insatisfatórios de todas as crianças, sobretudo daquelas em risco nutricional. O objetivo da ação é a intervenção precoce e, conseqüentemente, uma reversão mais rápida e eficaz.
Vamos relembrar o que temos para fazer no diagnóstico nutricional de crianças?

Para realizá-lo, temos:

- Caderneta de Saúde da Criança - instrumento para o monitoramento do estado nutricional de crianças de até 10 anos de idade. Nela são registrados dados fundamentais para a avaliação nutricional, tais como data de nascimento, peso ao nascer, idade, altura e intercorrências.

- Índice P/I - utilizado para o diagnóstico nutricional, é o mais adequado para crianças de zero a cinco anos, pois o peso é mais sensível para detectar os agravos mais comuns.

- Índice A/I - utilizado para o diagnóstico nutricional, é o mais adequado para crianças de cinco a 10 anos; serve como índice complementar ao P/I para um diagnóstico nutricional mais completo de crianças menores de cinco anos.

- Curvas de referências - curva de crescimento baseada na população-referência do Estudo NCHS (NATIONAL CENTER FOR HEALTH STATISTICS, 1977) e do Estudo Multicêntrico da OMS (WORLD HEALTH ORGANIZATION, 2006).

- Classificação do EN - uso do critério de percentis padronizado pela OMS.

- Pontos de corte - p3; p10 e p97.

- Indicadores - parâmetros construídos com base nos intervalos entre os percentis:

- $\geq$ p97 - sobrepeso/alta altura;

- p97 a p10 - adequado;

- p10 a p3 - risco nutricional/vigilância para baixa altura;

- <p3 - baixo peso/baixa altura.

- Traçados - deverão ser analisados em cada consulta, e a sua interpretação variará de acordo com o EN da criança, em ascendente, horizontal ou descendente.

Concluindo: fazer o diagnóstico nutricional em crianças menores de cinco anos implica observar o comportamento do ganho de peso e de altura em relação à idade. Não podemos nos esquecer de quatro pontos fundamentais:

- os dados obtidos devem ser de extrema confiabilidade;

- o acompanhamento deve ser periódico;

- a intervenção, ao menor sinal de risco, deve ser imediata e coerente;

- o diagnóstico antropométrico deve ser acompanhado do diagnóstico clínico, sempre que possível. 


\section{Outros índices antropométricos utilizados para realizar o diagnóstico nutricional em crianças de até cinco anos de idade}

Além dos índices peso para idade e altura para idade, é possível utilizar, de forma complementar, outros índices antropométricos para avaliação do estado nutricional da criança. A escolha de um índice dependerá do objetivo do diagnóstico e da possibilidade operacional do serviço. Todos têm vantagens e desvantagens, e apresentam significados diferentes, pois expressam processos biológicos diversos.

Para crianças menores de cinco anos tem sido usado o índice peso para altura e, mais recentemente, vem sendo sugerida a utilização do Índice de Massa Corporal (IMC) nesse grupo etário.

\section{Peso para altura}

O índice peso para altura (P/A) não é usado rotineiramente nos serviços de saúde. Sua utilização ocorre conforme o interesse do serviço ou em pesquisas mais abrangentes. Como citado anteriormente, em casos específicos e pontuais de falta absoluta da informação da data de nascimento, ou seja, da idade da criança, esse índice pode ser utilizado. Ele se mostra útil principalmente em duas situações especiais: no caso do monitoramento de crianças com peso baixo e muito baixo, quando utilizado o índice P/I; e nos casos de crianças que apresentam traçados insatisfatórios no gráfico de crescimento da Caderneta de Saúde da Criança, pois a avaliação pode ser mais refinada.

O índice P/A expressa a relação da massa corporal com a altura atual e ajuda a detectar deficiências recentes de peso. Por meio dele, podemos identificar se há harmonia entre as duas variáveis. Esse índice deve ser utilizado sempre em complementação a outro, jamais sozinho, pois pode levar a uma interpretação falsa da situação real. Ele avalia os déficits ou o excesso de peso (sobrepeso) em relação à altura. Crianças com P/A abaixo do percentil 3, sobretudo aquelas menores de dois anos de idade, merecem atenção especial.

Seus pontos de corte são os percentis 97 (sobrepeso) e 3 (baixo peso). Essa classificação pode ser realizada nas unidades de saúde como medida complementar para a vigilância nutricional. Para isso, precisamos consultar as tabelas do NCHS que estão disponíveis na página eletrônica do MS, na opção Sisvan - tabela NCHS completa.
É oportuno destacar que a prevalência de déficit de peso para altura, em nosso meio, é baixa em geral, cerca de $5 \%$ - e tem pouca expressão epidemiológica. Entretanto, é importante verificar também a magnitude da prevalência do déficit de altura para idade. Pode ser que a relação P/A seja satisfatória devido à baixa altura para idade. Assim sendo, o que ocorre é uma adequação do peso para uma altura que é deficiente. Portanto, a ausência de déficit de P/A isoladamente não deve ser interpretada, de imediato, como ausência de déficit nutricional (BRASIL, 2002). 
A valorização do estado nutricional do indivíduo e o uso dessa informação como instrumento para repensar a prática e qualificar a assistência é amplamente discutida no Capítulo 6, Parte II do livro Vigilância Alimentar e Nutricional para a Saúde Indígena, volume 1, de Denise Cavalcante Barros, Denise Oliveira e Silva e Silvia Ângela Gugelmin (2007).
Tal como os índices peso para idade e altura para idade, o índice peso para altura também apresenta vantagens e desvantagens. Podemos citar como vantagens: não é necessário conhecer a idade da criança e permite avaliar déficit ou excesso de peso em relação à altura. Como desvantagens, temos: dificuldade na medição da altura, pouca sensibilidade a pequenas alterações no peso e pouca expressão epidemiológica.

\section{Índice de massa corporal}

Como veremos mais adiante, o IMC é o índice adotado para as demais fases do curso de vida (adolescentes, adultos, gestantes e idosos) e é indicado como complementar no diagnóstico nutricional de crianças, em especial para aquelas com risco para sobrepeso e obesidade. Ainda não é de uso rotineiro nos serviços de saúde, sendo adotado em situações especiais, conforme o interesse do serviço ou em pesquisas mais abrangentes.

Esse índice é constituído pelas variáveis peso e altura [IMC = peso $(\mathrm{kg}) /$ $\operatorname{altura}^{2}(\mathrm{~m})$ ], variando conforme a idade e o sexo.

Para o grupo das crianças de até cinco anos, a OMS disponibiliza as curvas de IMC como uma nova referência de crescimento infantil. Os gráficos são apresentados com os pontos de corte em percentil $(3,15,50,85,97)$, mas também estão disponíveis em escores z. Esses gráficos estão na página eletrônica da OMS (WORLD HEALTH ORGANIZATION, 2006).

Reafirmamos que é de extrema importância a captação e a intervenção precoce e eficaz na desnutrição energético-protéica em crianças, especialmente nas menores de dois anos. Isso é possível com o diagnóstico nutricional incorporado à rotina dos atendimentos nos serviços de saúde. Com o intuito de propor ações diferenciadas, deve-se estar atento a fatores de risco, como: baixo peso ao nascer; cuidado infantil inadequado; introdução precoce de alimentos na dieta; doenças prevalentes na infância.

As ações básicas de saúde devem caminhar lado a lado com a vigilância nutricional. Essa conjugação é fundamental para a atitude de vigilância, da qual falamos no Capítulo 1 deste livro. Com isso, será possível melhorar a eficiência de ações de prevenção e o combate aos problemas nutricionais. Dados clínicos e laboratoriais também são importantes e devem, sempre que possível, ser utilizados para complementar o diagnóstico nutricional das crianças menores de cinco anos. 


\section{Crianças maiores de cinco anos}

Nessa fase do curso de vida, diferentemente da primeira infância, temos um período de menor incidência de doenças e, conseqüentemente, menor demanda aos serviços de atenção básica à saúde. Essa faixa etária apresenta características próprias para diagnóstico nutricional e estratégias de intervenção. Em relação ao diagnóstico nutricional, em 2006 o MS padronizou os instrumentos necessários para serem utilizados na rede de saúde. Assim, a Caderneta de Saúde da Criança agora apresenta o gráfico de crescimento feito para maiores de cinco anos. No entanto, o diagnóstico e o monitoramento nutricionais em crianças maiores de cinco anos ainda são pouco realizados na rotina dos serviços de saúde.

Uma forma importante de obtenção de informações e de empreendimento de ações na área da alimentação e nutrição é a utilização do espaço das escolas, onde está concentrado um contingente expressivo das crianças nessa faixa etária. Há um movimento na área da saúde coletiva para valorizar espaços fora dos serviços de saúde, que possam estimular a opção por um estilo de vida saudável e de promoção de saúde e nutrição. As Escolas Promotoras de Saúde são exemplos desses espaços saudáveis, estratégia fundamental para direcionar ações eficazes aos escolares (BUSS, 1998).

Para subsidiar essas ações, o diagnóstico nutricional do escolar é uma ferramenta útil. Ele pode ser realizado nas próprias escolas, nas unidades de saúde e em estudos epidemiológicos, associando-se aos Programas de Saúde da Criança e de Saúde Escolar. Temos, como exemplo de estudos, os Censos de Estatura em Escolares, que podem ser realizados regularmente em todas as escolas (públicas e/ou privadas) de uma determinada localidade/município, no início do ano letivo, nos alunos da $1^{a}$ série do ensino fundamental. Estudos representativos das demais séries do ensino fundamental também são oportunos, quando, além do retardo de crescimento, incluem a avaliação de outros distúrbios nutricionais, como o baixo peso, a obesidade e a anemia. Esses, de fato, são problemas prevalentes nos escolares brasileiros, tanto indígenas como não-indígenas.

A obesidade, como já discutimos, é uma alteração nutricional em ascensão entre os povos indígenas do país, com sérias repercussões na saúde na vida adulta. Há interesse crescente em detectar-se precocemente a obesidade em crianças e incentivar hábitos e estilo de vida que propiciem saúde, alimentação e nutrição adequadas. 
Os problemas nutricionais (sobrepeso, obesidade, anemia) entre os povos indígenas é tema do Capítulo 8,

"Perfil nutricional dos povos indígenas do Brasil", Parte III do livro Vigilância Alimentar e Nutricional para a Saúde Indígena, volume 1, de Denise Cavalcante Barros, Denise Oliveira e Silva e Silvia Ângela Gugelmin (2007).

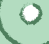

Saiba mais sobre anemia ferropriva e o Programa Nacional de Suplementação de Ferro, consultando a página eletrônica do MS.

A Caderneta de Saúde da Criança mais recente utiliza a distribuição dos valores de peso e estatura por percentis. No entanto, nas unidades de saúde que não dispõem desse instrumento, é possível utilizar as tabelas em DP. Para tanto, basta acessar a página eletrônica do MS e imprimir as tabelas do NCHS e/ou os gráficos que compõem a Caderneta de Saúde da Criança. O mais importante é que esses instrumentos estejam disponíveis para os profissionais da saúde da unidade.
Além disso, a anemia é um problema que atinge níveis alarmantes, geralmente atingindo crianças e mulheres em idade reprodutiva. Na infância, compromete o crescimento, o aprendizado e a saúde.

Diante de tal diversidade de alterações nutricionais, é necessária a seleção cuidadosa dos indicadores que melhor expressem os problemas a serem diagnosticados.

Podemos, então, perguntar quais são os indicadores recomendados pelo MS para a avaliação do estado nutricional de crianças de cinco a dez anos?

Descreveremos, a seguir, os dois indicadores que são preconizados, de acordo com a nova Caderneta de Saúde, para a avaliação nutricional nessa fase do curso de vida: Peso para Idade (P/I) e Estatura para Idade (E/I).

Para esses indicadores, a população-referência utilizada é aquela recomendada pela OMS, baseada no estudo do NCHS. Existem duas formas de classificação: por percentis ou por desvio-padrão/escore z. Na caderneta, existe o gráfico de estatura e peso para idade, no qual estão representados conjuntamente os valores de estatura e peso. Assim como para crianças menores de cinco anos, esses gráficos são distintos para meninos e meninas. A classificação do EN utiliza o critério de percentis padronizado pela OMS, e os pontos de corte são os mesmos adotados para crianças menores de cinco anos, ou seja, p3; p10 e p97.

\section{Peso para idade}

Utilizado como indicador direto para avaliar o estado nutricional de crianças. Conforme já visto no item sobre crianças menores de cinco anos, esse índice é utilizado para monitorar o ganho de peso individual e coletivo. As informações necessárias para a sua construção são:

- variáveis: peso e idade;

- índice: peso para idade;

- referência: NCHS;

- classificação: percentil (p);

- pontos de corte: p3; p10 e p97.

É importante lembrar que, com o resultado de apenas uma marcação, você já pode e deve intervir na situação encontrada, mas a intervenção adotada não deve ser definitiva. O esperado é que outras marcações sejam feitas na caderneta. 
Os pontos deverão ser unidos por uma reta, para que você possa avaliar como tem se desenvolvido o "caminho" ou canal de crescimento da criança.

\section{Estatura para idade}

Utilizado como indicador do crescimento linear de crianças. Comporta-se da mesma forma que o índice P/I, detalhado anteriormente na seção relativa a crianças menores de cinco anos. Para sua construção utilizam-se:

- variáveis: estatura e idade;

- índice: estatura para idade;

- referência: NCHS;

- classificação: percentil (p); desvio-padrão;

- pontos de corte: p3; p10 e p97.

Lembre-se de que apenas uma marcação não é suficiente para selar o diagnóstico nutricional de uma criança. Essa única marcação proporcionará um diagnóstico pontual. É importante construir o canal de crescimento.

Mas como procederemos para realizar o diagnóstico nutricional dessas crianças?

Aferindo o peso e a estatura da criança com as técnicas adequadas; marcando os valores no gráfico de estatura e peso para idade, de acordo com o sexo. A interpretação deve considerar os dois aspectos a seguir.

\section{- Diagnóstico nutricional}

Deve ser feita a classificação nutricional, segundo percentil, conforme o Quadro 11.

Quadro 11 - Classificação nutricional segundo percentil

\begin{tabular}{|l|l|l|}
\hline Classificação do percentil & $\begin{array}{l}\text { Diagnóstico } \\
\text { segundo P/I }\end{array}$ & Diagnóstico segundo E/I \\
\hline <p3 (exclusive) & Peso baixo & Baixa estatura* $^{*}$ \\
\hline $\begin{array}{l}\text { p3 I- p10 [entre o percentil 3 (inclusive) } \\
\text { e o 10] }\end{array}$ & Risco nutricional & Vigilância para baixa estatura \\
\hline $\begin{array}{l}\text { p10 I- p97 [entre o percentil 10 } \\
\text { (inclusive) e o 97] }\end{array}$ & Adequado & Adequado \\
\hline$\geq$ p97 [igual ou maior que percentil 97] & Sobrepeso & Estatura elevada \\
\hline
\end{tabular}

* A criança que está em um canal de crescimento inferior à adequação (A/l $<\mathrm{p} 3$ ou $-2 \mathrm{DP})$ tem diagnóstico inicial de baixa estatura. Essa criança pode ser considerada normal, ou seja, ela pode estar entre os cerca de $3 \%$ esperados, conforme encontrado na população-referência. A criança pode ser geneticamente mais baixa, principalmente se seu acompanhamento longitudinal evidenciar traçado ascendente.
O gráfico disponível na Caderneta de Saúde da Criança apresenta a distribuição dos valores de estatura para idade em percentis, considerando os pontos de corte já descritos para os menores de cinco anos. Caso o serviço de saúde ainda utilize as tabelas e os gráficos com a distribuição em desviopadrão, lembramos que o ponto de corte de-2DP para os indicadores antropométricos corresponde, aproximadamente, ao percentil 3, e +2DP, ao percentil 97. 
Exemplo:

Numa avaliação dos alunos de uma escola, em 25/07/2007, verificamos que:

- Luciana, nascida em 20/05/2000, pesava 25,5kg e media $109 \mathrm{~cm}$;

- Geraldo, nascido em 22/12/1998, pesava 40,5kg e media $134 \mathrm{~cm}$.

Segundo o índice estatura para idade, consultando os gráficos ou as tabelas específicas do NCHS, temos:

- Luciana: sete anos e dois meses, P/I - p10 I- p97 (o peso está entre o p10 e o p97), sendo classificada como peso adequado para a idade e A/I $-<$ p3 (está abaixo de p3), sendo classificada como baixa estatura para a idade.

- Geraldo: oito anos e sete meses, P/I - $\geq$ p97 (o peso está acima do percentil 97), sendo classificado como sobrepeso e A/I p10 I- p97 (a altura está entre o p10 e o p97), sendo classificado como adequado para a estatura.

Gráfico 13 - Marcação do peso e estatura de Geraldo no gráfico estatura e peso para idade - de cinco a 10 anos

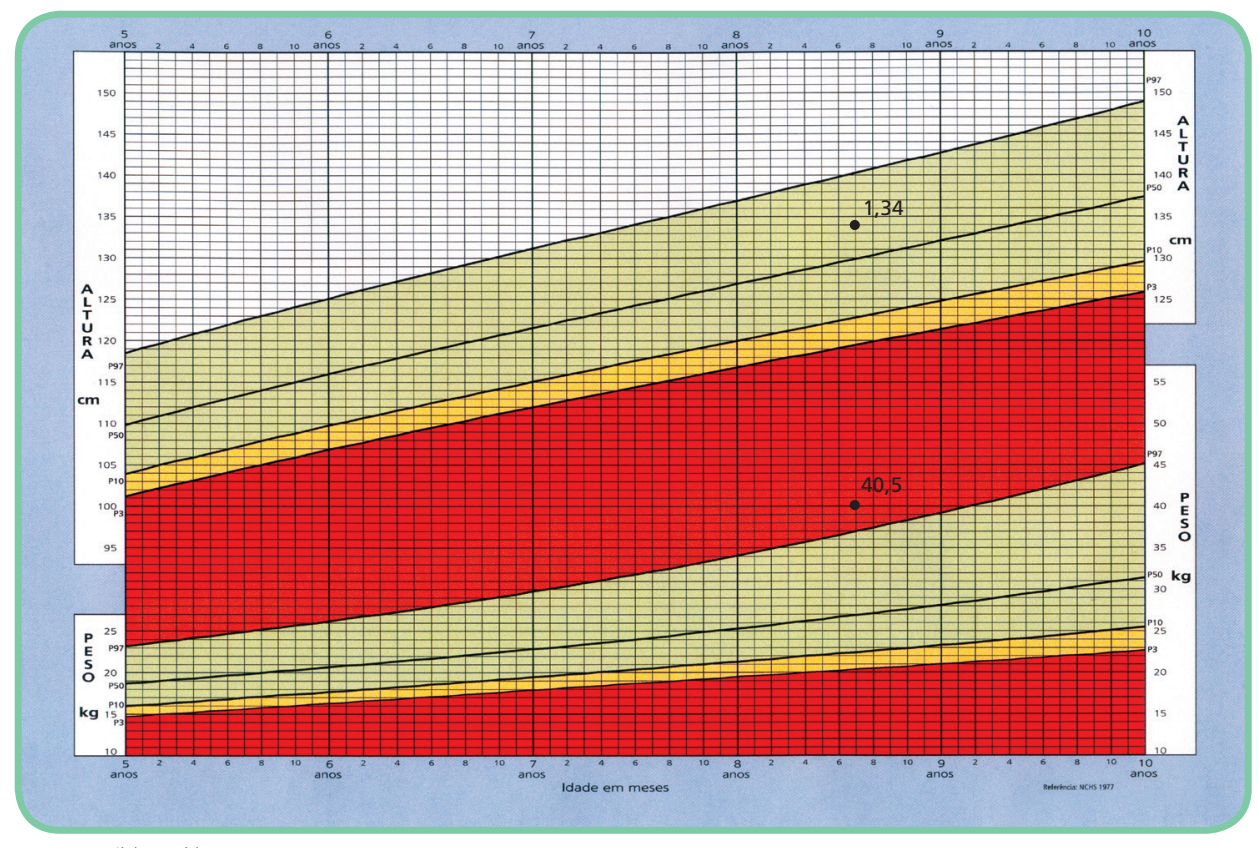

Fonte: Brasil (2007b).

\section{- Avaliação do canal do crescimento}

Refere-se à inclinação do traçado nos gráficos P/I e E/I, construídos pelo menos com duas medidas sucessivas de peso e estatura, em determinado intervalo de tempo. 
Assim, em nível individual, devemos acompanhar o canal de crescimento da criança tanto em relação ao peso para idade (ganho de peso) quanto em relação à estatura para idade (crescimento linear), à semelhança do que fazemos com os menores de cinco anos e os adolescentes, pois as crianças maiores de cinco anos também estão em fase de crescimento.

A avaliação do crescimento das crianças maiores de cinco anos pode ser realizada conforme os Quadros 11 e 12.
Se, na avaliação das crianças maiores de cinco anos, percebemos sinais de puberdade, devemos considerar a avaliação do estado nutricional recomendada para adolescentes.

Quadro 12 - Avaliação do canal de crescimento em relação a P/l

\begin{tabular}{|l|l|l|l|}
\hline Percentil & Traçado & Condição nutricional & Diagnóstico nutricional \\
\hline$\geq 97$ & $\begin{array}{l}\text { Ascendente } \\
\text { Horizontal } \\
\text { Descendente }\end{array}$ & $\begin{array}{l}\text { Risco de obesidade } \\
\text { Alerta } \\
\text { Alerta }\end{array}$ & Sobrepeso \\
\hline p10 $1-p 97$ & $\begin{array}{l}\text { Ascendente } \\
\text { Horizontal } \\
\text { Descendente }\end{array}$ & $\begin{array}{l}\text { Satisfatório } \\
\text { Alerta } \\
\text { Insatisfatório }\end{array}$ & Adequado \\
\hline p3 I-p10 & $\begin{array}{l}\text { Ascendente } \\
\text { Horizontal } \\
\text { Descendente }\end{array}$ & $\begin{array}{l}\text { Insatisfatório } \\
\text { Insatisfatório }\end{array}$ & Risco nutricional \\
\hline$<p 3$ & $\begin{array}{l}\text { Alerta } \\
\text { Insatisfatório } \\
\text { Insatisfatório }\end{array}$ & Peso baixo \\
\hline$<p 0,1$ & $\begin{array}{l}\text { Ascendente } \\
\text { Horizontal } \\
\text { Descendente }\end{array}$ & $\begin{array}{l}\text { Desnutrição } \\
\text { Desnutrição } \\
\text { Desnutrição }\end{array}$ & Peso muito baixo \\
\hline
\end{tabular}

Quadro 13 - Avaliação do canal de crescimento em relação a E/l

\begin{tabular}{|l|l|l|l|}
\hline Percentil & Traçado & Condição nutricional & Diagnóstico nutricional \\
\hline$\geq 97$ & $\begin{array}{l}\text { Ascendente } \\
\text { Horizontal }\end{array}$ & $\begin{array}{l}\text { Alerta } \\
\text { Alerta }\end{array}$ & Estatura elevada \\
\hline p10 I-p97 & $\begin{array}{l}\text { Satisfatório } \\
\text { Alerta }\end{array}$ & Adequado \\
\hline p3 I-p10 & $\begin{array}{l}\text { Ascendente } \\
\text { Horizontal }\end{array}$ & $\begin{array}{l}\text { Alerta } \\
\text { Insatisfatório }\end{array}$ & Vigilância para baixa estatura \\
\hline$<$ p3 & $\begin{array}{l}\text { Ascendente } \\
\text { Horizontal }\end{array}$ & Insatisfatório & Baixa estatura \\
\hline
\end{tabular}

Vale a pena repetir a informação: uma criança que está em um canal de crescimento inferior à adequação $(\mathrm{E} / \mathrm{I}<\mathrm{p} 3$ ou $-2 \mathrm{DP})$ tem diagnóstico inicial de baixa estatura. No entanto, apenas o acompanhamento individual do caso é que poderá elucidar o diagnóstico e o prognóstico finais, pois 
sua constituição física pode ser considerada adequada, principalmente se seu acompanhamento longitudinal evidenciar traçado ascendente. Ela pode ser simplesmente uma criança baixa, o que é esperado em 3\% da população-referência.

Vamos relembrar com o que contamos para fazer o diagnóstico nutricional de crianças maiores de cinco anos?

Para realizá-lo, temos:

- Caderneta de Saúde da Criança - instrumento para o monitoramento do estado nutricional de crianças de até 10 anos.

- Índice P/I - utilizado para o diagnóstico nutricional, pois o peso é mais sensível para detectar os agravos mais comuns.

- Índice E/I - utilizado para o diagnóstico nutricional - o mais adequado para crianças de cinco a 10 anos - e como índice complementar ao $\mathrm{P} / \mathrm{I}$, para um diagnóstico nutricional mais completo de crianças menores de cinco anos.

- Curvas de referências - curva de crescimento baseada na população-referência do Estudo NCHS (NATIONAL CENTER FOR HEALTH STATISTICS, 1977).

- Classificação do EN - uso do critério de percentis padronizado pela OMS.

- Pontos de corte - p3, p10 e p97.

- Indicadores - parâmetros construídos com base nos intervalos entre os percentis:

- $\geq$ p97 - sobrepeso/alta estatura;

- p97 a p10 - adequado;

- p10 a p3 - risco nutricional/vigilância para baixa estatura;

- < p3 - baixo peso/baixa estatura.

- Traçados - deverão ser analisados em cada consulta e sua interpretação variará de acordo com o EN da criança em ascendente, horizontal ou descendente.

\section{Outros indicadores}

- Índice peso para estatura;

- Índice de massa corporal;

- Dobras cutâneas; 
$\checkmark$ Perímetros;

- Índice de dentes cariados, perdidos e obturados (CPO).

Dados clínicos e laboratoriais também são importantes e devem, sempre que possível, ser utilizados para complementar o diagnóstico nutricional das crianças menores de 10 anos, especialmente em relação à anemia ferropriva.

\section{Peso para estatura}

Como já mencionado, esse índice avalia a proporcionalidade corporal, ou seja, a distribuição do peso em relação à estatura da criança. A deficiência de peso para estatura pode aumentar muito rapidamente. Em situações consideradas favoráveis, a recuperação, por sua vez, também pode ocorrer de modo acelerado. As informações necessárias para avaliação são:

- variáveis: peso e estatura;

- índice: P/E;

- referência: NCHS;

- classificação: DP;

- pontos de corte: $-2 \mathrm{DP} ;+2 \mathrm{DP}$.

Esse índice pode ser uma opção em locais onde a data de nascimento da criança e a idade sejam desconhecidas. Entretanto, é importante lembrar que ele reflete a proporcionalidade corporal, sendo perfeitamente possível encontrar uma criança com $\mathrm{P} / \mathrm{E}$ adequado, mas com déficit de P/I ou E/I. Por isso, na avaliação nutricional de crianças é importante combinar a utilização de mais de um índice antropométrico.

\section{Índice de massa corporal}

Como apontamos anteriormente, esse é um índice que ainda está em fase de discussão para uso em serviços de saúde, na realização do diagnóstico nutricional individual de crianças. Mas ele já é utilizado em pesquisas de base populacional, principalmente para diagnosticar sobrepeso e obesidade.

Até o momento, o Brasil não estabeleceu que critérios utilizar para avaliação do EN, segundo o índice IMC, em crianças e adolescentes. Portanto, para fins de comparação, sugerimos que sejam usados os parâmetros
A utilização de medidas antropométricas para avaliação da composição corporal, como perímetros braquial, da cintura e torácico, foi discutida no Capítulo "Antropometria", da Parte I deste livro.

Assim como para o índice E/l, a classificação do índice P/E pode ser feita em percentis ( $p)$, considerandose os mesmos pontos de corte descritos para os menores de cinco anos, disponíveis no endereço eletrônico do MS. Lembramos que o ponto de corte de-2DP para os indicadores antropométricos corresponde, aproximadamente, ao percentil 3, e o ponto de corte +2DP, ao percentil 97. 
recomendados pela OMS (WORLD HEALTH ORGANIZATION, 1995). Esse índice será apresentado e discutido com maior profundidade no item seguinte, relativo aos adolescentes.

PARA PRATICAR - DIAGNÓSTICO NUTRICIONAL DE CRIANÇAS MAIORES DE CINCO ANOS

1. Que indicadores antropométricos do estado nutricional podem ser utilizados nas crianças entre cinco e 10 anos de idade?

2. Durante um censo escolar, realizado em 28/11/2007, foram medidos o peso e a estatura das seguintes crianças:

\begin{tabular}{|l|l|l|l|l|l|l|}
\hline Nome & Data de & Idade & \multirow{2}{*}{$\begin{array}{l}\text { Peso } \\
\text { nascimento }\end{array}$} & & Estatura & \multicolumn{2}{l|}{ Diagnóstico nutricional } \\
& & & $(\mathrm{kg})$ & P/I & E/I \\
\hline Ana Paula & $20 / 03 / 2001$ & & 24,8 & 110,5 & & \\
\hline Célia & $05 / 01 / 2000$ & & 33,3 & 126,5 & & \\
\hline Cíntia & $31 / 08 / 2001$ & & 20,5 & 126,0 & & \\
\hline Daniel & $15 / 01 / 1999$ & & 20,0 & 123,5 & & \\
\hline Fernando & $06 / 12 / 2000$ & & 30,2 & 130,0 & & \\
\hline Otávio & $07 / 04 / 1998$ & & 31,5 & 140,5 & & \\
\hline Patrícia & $20 / 05 / 1999$ & & 30,0 & 129,5 & & \\
\hline Renato & $22 / 06 / 1998$ & & 31,3 & 145,0 & & \\
\hline Rodrigo & $25 / 10 / 2001$ & & 15,8 & 106,0 & & \\
\hline Sheila & $15 / 07 / 2000$ & & 20,2 & 114,5 & & \\
\hline
\end{tabular}

3. Com base nas informações apresentadas, faça o diagnóstico nutricional de cada uma das crianças.

Após executar esta atividade reveja, passo a passo, como realizar o diagnóstico do escolar.

\section{Adolescentes}

A adolescência é uma fase da vida em que ocorrem intensas mudanças. Os adolescentes estão crescendo e sofrendo transformações em suas dimensões corporais e em seu comportamento, adquirindo identidade própria e maturidade biológica, psicológica e social. 
Os termos puberdade e adolescência são usados, muitas vezes, como sinônimos, o que não é adequado. Puberdade se refere exclusivamente aos eventos biológicos dessa fase. Já adolescência tem um significado mais amplo, pois, além de englobar as modificações corporais típicas da puberdade, inclui também as modificações psicossociais. As modificações biológicas típicas da puberdade são a maturação sexual e o grande crescimento físico - o estirão da puberdade.

Excetuando o primeiro ano de vida, a adolescência é a fase na qual o indivíduo mais cresce. Existe uma grande variabilidade na idade do início do desenvolvimento puberal, podendo ocorrer entre oito e 14 anos, sendo que a idade mais freqüente de início é entre 10 e 12 anos (BRASIL, 2000b).

\section{Para refletir}

No contexto em que você trabalha, quais são os aspectos que definem um adolescente? Em que esses aspectos diferem daqueles considerados pela sociedade não-indígena e/ou pela biomedicina?

Segundo a OMS (WORLD HEALTH ORGANIZATION, 1995), a adolescência é definida como o período entre os 10 e os 19 anos e 11 meses de idade. Os adolescentes são um segmento expressivo em nosso país, correspondendo a cerca de $25 \%$ da população brasileira não-indígena. Segundo dados do Censo Populacional de 2000 (INSTITUTO BRASILEIRO DE GEOGRAFIA E ESTATÍSTICA, 2005), entre os indivíduos auto-declarados indígenas, residentes em municípios onde há terras indígenas, esse percentual é de 24,2\%. A configuração etária da população indígena brasileira é extremamente jovem, sendo que 43,2\% encontram-se abaixo de 15 anos de idade.

Nessa fase da vida, o apetite aumenta muito devido ao estirão do crescimento e às mudanças do corpo, que ocasionam aumento das necessidades nutricionais, no aporte total tanto de calorias/energia quanto de micronutrientes, como cálcio e ferro. Nesse período, ocorrem $20 \%$ do ganho total em estatura e $50 \%$ em massa óssea da fase adulta. E como as necessidades nutricionais estão particularmente aumentadas, os adolescentes são especialmente suscetíveis a desordens nutricionais, motivados pelo consumo inadequado de alimentos.

Estudos têm evidenciado o aumento do sobrepeso e da obesidade entre adolescentes não-indígenas (WANG; MONTEIRO; POPKIN, 2002; 
MAGALHÃES; MENDONÇA, 2003). A obesidade está, hoje, presente em diversas etnias indígenas, associando-se a uma série de disfunções, como a hipertensão arterial e a diabetes mellitus não-insulino-dependente. Se por um lado o problema assume uma magnitude significativa entre os adultos, por outro, os dados disponíveis apontam para o seu surgimento ainda na adolescência, com o aumento progressivo das médias de massa corporal (LEITE et al., 2007).

A desnutrição, com menor expressão do que a obesidade, ainda é um problema nutricional importante que precisa ser monitorado. A prevalência de desnutrição, apesar de decrescente, ainda é expressiva no Brasil, em particular nas classes socioeconômicas menos favorecidas e na zona rural (MONTEIRO, 2000; WANG; MONTEIRO; POPKIN, 2002).

Os adolescentes devem ser, por essa razão, o público de interesse de estratégias de prevenção da obesidade, o que inclui o acompanhamento do estado nutricional. Apresenta-se, dessa forma, a possibilidade de se realizar o diagnóstico precoce da desnutrição e da obesidade, de modo a intervir e minimizar seus efeitos deletérios sobre os perfis de saúde das populações afetadas.

Outra alteração importante durante a adolescência é a anemia por carência de ferro, que freqüentemente alcança níveis mais elevados no sexo feminino. Ela está associada à dieta pobre em ferro, à ocorrência de doenças infecciosas e parasitárias, às perdas menstruais e, ainda, à ocorrência da gravidez e lactação. Vale lembrar que as populações indígenas apresentam, de modo geral, elevadas taxas de fecundidade, o que significa que são comuns as gestações ainda durante a adolescência. Somam-se, assim, as necessidades nutricionais de um período caracterizado pelo rápido crescimento físico às novas demandas que se apresentam com a gravidez e a lactação.

Os adolescentes precisam de boas condições nutricionais para alcançar seu potencial genético de crescimento. Isso quer dizer que, embora as condições ambientais como a alimentação e a atividade física sejam importantes para o crescimento, cada indivíduo herda dos pais genes que determinam a estatura final alcançada. O crescimento acelerado é marca da adolescência e associa-se a um conjunto de modificações biológicas características da adolescência, a puberdade. Em um determinado momento da vida da criança, devido à 
ação de hormônios, os eventos da puberdade são desencadeados (TANNER, 1989):

- aceleração e posterior desaceleração do crescimento (estirão da puberdade);

- desenvolvimento das gônadas (testículos e ovários);

- surgimento de caracteres sexuais secundários (pêlos, mamas);

- mudanças na composição corporal (quantidade e distribuição de gordura, crescimento esquelético e ganho de massa muscular);

- desenvolvimento dos sistemas respiratório e circulatório.

Repare que o crescimento físico está diretamente relacionado ao amadurecimento sexual. O início da puberdade pode ser caracterizado pelo aumento dos testículos, nos meninos (em torno dos 11 aos 14 anos); desenvolvimento do broto mamário, no sexo feminino (em torno dos nove aos 13 anos). Ao término da puberdade, com o fim do crescimento esquelético, do amadurecimento das gônadas, o(a) adolescente terá atingido a maturidade sexual, estando apto(a) à reprodução. A idade de início e a duração dos eventos descritos variam entre os jovens sadios, particularmente influenciados por fatores genéticos. É certo que algumas condições ambientais que levam os jovens a apresentarem desnutrição prolongada ou doenças crônicas podem ser limitantes do crescimento e retardar a maturação.

As avaliações do crescimento e do estado nutricional baseadas unicamente em eventos cronológicos (tempo externo = idade do jovem) são inadequadas, especialmente se aplicadas individualmente, havendo necessidade de interpretação dos resultados associada à avaliação de maturação sexual (tempo interno = idade biológica).

Por que associar avaliação do crescimento e do estado nutricional à avaliação da maturação sexual?

Porque a velocidade de crescimento tem estreita relação com a maturação sexual, como pode ser visualizado nas Figuras 3 e 4, que fazem essa comparação. 
Figura 3 - Diferenciais de velocidade de crescimento na adolescência, segundo o sexo

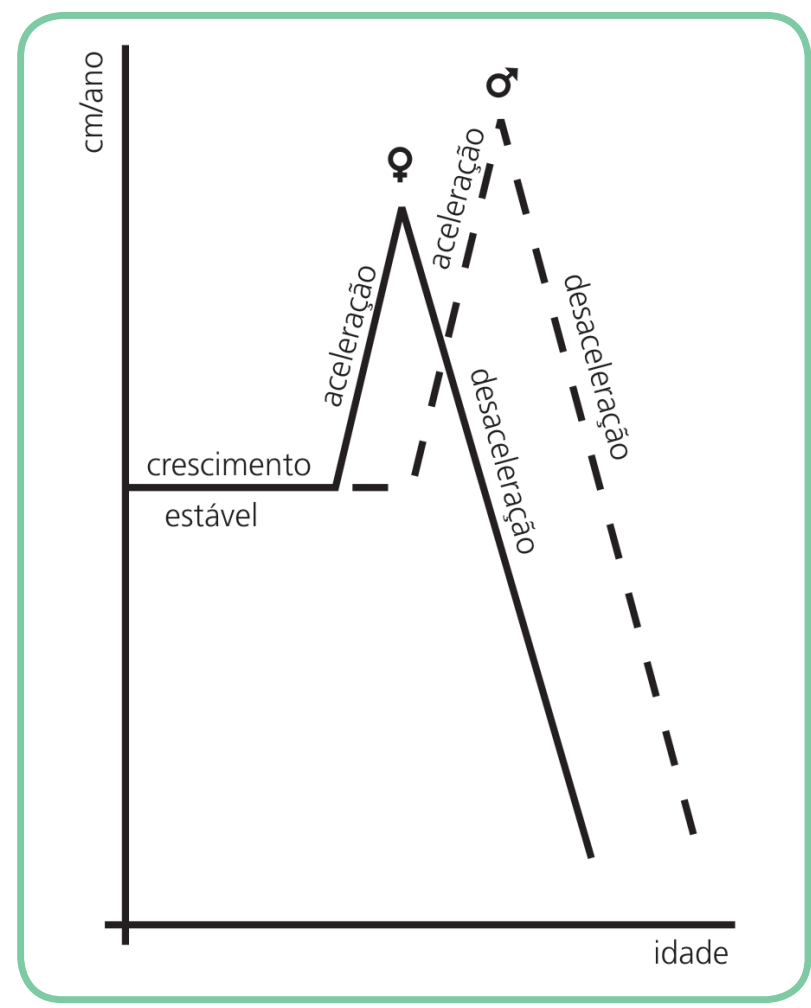

Fonte: Tanner (1989)

Figura 4 - Relações entre velocidade do crescimento e estágios de maturação sexual segundo critérios de Tanner para genitália (G) e mamas (M)
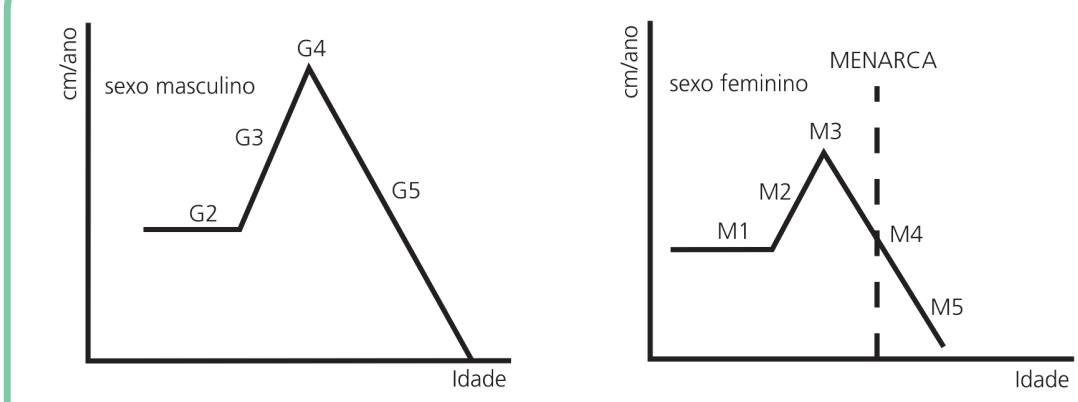

Fonte: Tanner (1989)

A avaliação de maturação sexual segue os critérios de Tanner (1989), preconizados pelo MS (BRASIL, 1993), com os estágios um a cinco para genitália/pêlos e mamas/pêlos, em meninos e meninas, respectivamente. Consideram-se Gl e Ml os estágios pré-púberes, sendo que os estágios 
dos pêlos pubianos podem ser diferentes dos da genitália e da mama. A associação entre os estágios de Tanner (1989) e a velocidade do crescimento é evidente: a aceleração coincide com o início da maturação ( $G 3$ e M2); o pico do crescimento coincide com G4, nos meninos, e com M3 - período que antecede a menarca - nas meninas.

\section{Avaliação do estágio de maturação sexual}

A maturação sexual está relacionada com o desenvolvimento muscular e com o aumento da estatura, do peso em ambos os sexos, e dos depósitos de gordura em meninas. Alguns autores observaram uma relação entre maturação sexual precoce e obesidade em meninas (FONSECA; SICHIERI; VEIGA, 1998). Portanto, a avaliação do estágio de maturação sexual é um aspecto importante na avaliação do crescimento e desenvolvimento físico dos adolescentes, e deve ser sempre realizada durante o seu acompanhamento.

Ela é realizada por meio do exame clínico direto, avaliando-se com um orquidômetro o tamanho dos testículos, as características da genitália e pêlos pubianos (meninos) e mamas e pêlos (meninas).

Nos casos em que não é possível realizar o exame clínico direto, ou o profissional não é capacitado para isso, deve ser utilizada a auto-avaliação do estágio de maturação, apresentando as pranchas ao jovem durante a consulta para que ele próprio se classifique no estágio de Tanner (1989) (Anexo G - Prancha de Tanner - desenvolvimento puberal masculino e feminino).

\section{Índices antropométricos preconizados para adolescentes}

Para o diagnóstico nutricional de adolescentes, os indicadores antropométricos recomendados são o índice de massa corporal e o índice estatura para idade, que precisa ser complementado por outros indicadores, pois avalia apenas os déficits de crescimento (BRASIL, 2008). $\mathrm{O}$ índice peso para idade é considerado inadequado para diagnóstico de déficits ou excesso de peso na adolescência, pois ignora a contribuição da estatura na proporcionalidade corporal, isto é, adolescentes da mesma idade podem apresentar estaturas diferentes e o peso deve ser proporcional à estatura atingida. Por essa razão, e por apresentar boa correlação com a composição corporal, o índice peso para estatura é o
Não está estabelecida uma referência antropométrica que incorpore os estágios de maturação sexual. No momento, o estágio maturacional serve para interpretar o significado do indicador antropométrico para o estado nutricional, ou seja, devese utilizar a idade biológica, não ficando restrito à idade cronológica.

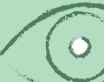

As alterações de puberdade podem ser vistas com mais detalhes nas publicações do MS disponibilizadas na página eletrônica, opção saúde de adolescentes e jovens. 
Lembre-se: a unidade de medida do IMC é $\mathrm{kg} / \mathrm{m}^{2}$. Na matemática a notação utilizada é $\mathrm{kg} \cdot \mathrm{m}^{-2}$, tendo o mesmo significado de $\mathrm{kg} / \mathrm{m}^{2}$. mais indicado para essa faixa etária. No entanto, não existem valores de referência internacionais para esses índices, no caso dos adolescentes.

O índice de massa corporal é recomendado internacionalmente para diagnósticos individuais e coletivos dos distúrbios nutricionais na adolescência (MUST; DALLAL; DIETZ, 1991; WORLD HEALTH ORGANIZATION, 1995; COLE et al.; DE ONIS et al., 2007), sendo o mais indicado no diagnóstico nutricional desse grupo etário. No Brasil, a tendência atual é a adoção do IMC não só em pesquisas, mas também na rotina dos serviços de saúde. A descrição desses indicadores e suas peculiaridades são apresentadas a seguir.

\section{Índice de massa corporal}

No jovem, que ainda está crescendo fisicamente, não podemos usar os mesmos pontos de corte já estabelecidos para diagnóstico do estado nutricional de adultos. Em adolescentes deve-se considerar a avaliação do IMC em relação a uma distribuição em uma população sadia, conforme o sexo e a idade.

O diagnóstico nutricional de adolescentes deve seguir algumas etapas. O primeiro passo é aferir o peso e a estatura do adolescente, usando as técnicas adequadas; depois, realizar o cálculo do IMC [peso $(\mathrm{kg})$ /estatura $^{2}(\mathrm{~m})$ ] e avaliar o valor encontrado, comparando-o com os valores na tabela de IMC para idade e sexo (Anexo Hl - Percentis e escore z selecionados de IMC (kg.m-2) segundo idade e sexo masculino de adolescentes (10 a 19 anos) e Anexo H2 - Percentis e escore z selecionados de IMC (kg.m-2) segundo idade e sexo feminino de adolescentes (10 a 19 anos).

A interpretação deve considerar, além do diagnóstico nutricional pelo IMC para idade e sexo, a avaliação do estágio de maturação sexual.

No caso de adolescentes, diferentemente das crianças, consideramos um problema a inexistência de pontos de corte e curvas nacionais, tendo em vista a diversidade e a influência de fatores genéticos na puberdade. Como alternativa, segundo uma visão crítica, a OMS (WORLD HEALTH ORGANIZATION, 2007) e o MS (BRASIL, 2008), sugerem o uso dos seguintes pontos de corte apresentados no Quadro 14. 
Quadro 14 - Pontos de corte de IMC para idade estabelecidos para adolescentes

\begin{tabular}{|l|l|l|}
\hline \multicolumn{2}{|l|}{ IMC para idade } & Diagnóstico nutricional \\
\hline$<$ Percentil 0,1 & $<$ Escore $z-3$ & IMC muito baixo para idade \\
\hline $\begin{array}{l}\geq \text { Percentil } 0,1 \mathrm{e} \\
<\text { Percentil } 3\end{array}$ & $\begin{array}{l}\geq \text { Escore } z-3 \text { e } \\
<\text { Escore } z-2\end{array}$ & IMC baixo para idade \\
\hline $\begin{array}{l}\geq \text { Percentil } 3 \mathrm{e} \\
<\text { Percentil } 97\end{array}$ & $\begin{array}{l}\geq \text { Escore } z-2 \\
<\text { Escore } z+2\end{array}$ & IMC adequado \\
\hline$\geq$ Percentil 97 & $\geq$ Escore $z+2$ & IMC elevado para a idade \\
\hline
\end{tabular}

Fonte: Brasil (2008).

\section{CLASSIFICAÇÃO DO ESTADO NUTRICIONAL DE ADOLESCENTES}

Como já mencionado, a recomendação da OMS (WORLD HEALTH ORGANIZATION, 2007) para classificação do EN dos adolescentes, com base no cálculo do IMC, utiliza os pontos de corte propostos por Must, Dallal e Dietz (1991). Essa classificação define como baixo peso, sobrepeso e obesidade crianças e adolescentes com IMC p5, p85 e p95, respectivamente. Esse tem sido um dos índices mais utilizados para a avaliação de crianças e adolescentes em saúde pública.

Uma segunda classificação do EN de adolescentes está fundamentada nas curvas para IMC para idade do Center Disease Control and Prevention (CDC), que envolveu uma população americana e traz limitações quando utilizada internacionalmente, pois não considera as influências ambientais no crescimento físico e maturacional do adolescente. Também subestima o diagnóstico de sobrepeso e obesidade em outras populações (KUCZMARSKI et al., 2002).

Cole et al. (2000) elaboraram uma nova proposta, na tentativa de atender as diferenças entre as diversidades nas diferentes populações. Eles propuseram um conjunto de curvas que foram desenvolvidas com base em estudos transversais com indivíduos de seis países (Brasil, Estados Unidos, Grã-Bretanha, China, Holanda e (ingapura). Essas curvas foram estimadas de forma que os pontos das curvas ajustadas dos percentis 85 e 95 de IMC, aos 18 anos, fossem obrigatoriamente os pontos de corte para sobrepeso e obesidade utilizados para adultos (25 e $30 \mathrm{~kg} \cdot \mathrm{m}^{-2}$, respectivamente). As curvas contemplam a distribuição por percentis de acordo com faixa etária e sexo, com pontos de corte menos arbitrários que os propostos pela CDC (KUCZMARSKI et al., 2002), permitindo a sua maior aceitação (SOARES, 2003).

Em 2007, pesquisadores (DE ONIS et al., 2007) - sob o aval da OMS - realizaram uma nova análise dos dados de peso e estatura publicados pelo NCHS em 1977, gerando novos valores para os índices antropométricos, como o IMC, para crianças maiores de cinco anos e adolescentes (com menos de 20 anos). 
Ressaltamos que até o momento não existe unanimidade em relação aos critérios utilizados para avaliação do EN, segundo o índice IMC em crianças e adolescentes. No entanto, a recomendação de organismos internacionais e do MS no Brasil é adotar a referência publicada em 2007 pela OMS (WORLD HEALTH ORGANIZATION, 2007) para a avaliação nutricional de adolescentes, ou seja, a adoção das curvas NCHS (NATIONAL CENTER FOR HEALTH STATISTICS, 1977) reanalisadas. Essa referência pode ser considerada uma curva internacional para a classificação dos índices antropométricos na adolescência: IMC por idade e estatura por idade.

Em anexo (Anexos H1, H2 e I), constam os valores desses índices para a avaliação do estado nutricional de adolescentes, em cada faixa de idade e por sexo, expressos tanto em percentis como em escores $z$.

\section{Estatura para idade}

- Variáveis: estatura e idade

- Índice: E/I

- Referência: NCHS

- Classificação: percentis (p)

- Pontos de corte: p3, p10, p97

É importante observar que a classificação pode ser feita em desvio-padrão, considerando os pontos de corte de $-2 \mathrm{DP}$ e $+2 \mathrm{DP}$. Pode ser uma opção em serviços de saúde, desde que estejam disponíveis tabelas e gráficos com tais medidas, sendo especialmente indicada em levantamentos de dados, estudos ou censos. Lembramos que, para os indicadores antropométricos, o ponto de corte de -2DP corresponde, aproximadamente, ao percentil 3, e o $+2 \mathrm{DP}$, ao percentil 97.

A primeira etapa para a realização do diagnóstico é aferir a estatura do adolescente usando as técnicas adequadas e avaliar o valor encontrado, comparando com a tabela de estatura para idade segundo sexo correspondente. Veja o Anexo I - Percentis e escore z selecionados de estatura $(\mathrm{cm})$ para idade (em anos) para adolescentes (10 aos 19 anos), segundo sexo (WORLD HEALTH ORGANIZATION, 2007).

A OMS (WORLD HEALTH ORGANIZATION, 2007) sugere a seguinte classificação nutricional para adolescentes com base no índice E/I: 
Quadro 15 - Pontos de corte de estatura para idade estabelecidos para adolescentes

\begin{tabular}{|l|l|l|}
\hline \multicolumn{2}{|l|}{ Valores críticos IMC } & Diagnóstico nutricional \\
\hline$<$ Percentil 0,1 & $<$ Escore $z-3$ & $\begin{array}{l}\text { Estatura muito baixa para a idade } \\
\text { (nanismo grave) }\end{array}$ \\
\hline $\begin{array}{l}\geq \text { Percentil } 0,1 \mathrm{e} \\
<\text { Percentil 3 }\end{array}$ & $\begin{array}{l}\geq \text { Escore } z-3 \text { e } \\
<\text { Escore } z-2\end{array}$ & $\begin{array}{l}\text { Estatura baixa para a idade (nanismo } \\
\text { moderado) }\end{array}$ \\
\hline$\geq$ Percentil 3 & $\geq$ Escore $z-2$ & Estatura adequada para a idade \\
\hline
\end{tabular}

Fonte: Brasil (2008).

\section{Outros indicadores}

O uso de outros indicadores pode ser útil para melhor avaliação da gordura corporal (obesidade), tais como os perímetros braquial e de cintura, e as dobras cutâneas. No Capítulo anterior, foram apresentados os perímetros de maior utilidade na atenção básica. As dobras cutâneas são medidas menos utilizadas devido à dificuldade de operacionalização no cotidiano do serviço, e pelo alto custo e manutenção dos equipamentos.

Dados clínicos e laboratoriais também são importantes e devem, sempre que possível, ser utilizados para complementar o diagnóstico nutricional do adolescente, principalmente no que se refere à anemia, que acomete um grande número de adolescentes indígenas do sexo feminino.

\section{Para refletir}

Os profissionais de saúde que atuam em sua unidade estão capacitados para realizar o diagnóstico nutricional de adolescentes?

Como tem sido realizado o diagnóstico nutricional dos adolescentes

em sua comunidade?

Quais são as especificidades que você encontra em sua realidade?

\section{PARA PRATICAR - DIAGNÓSTICO NUTRICIONAL DE ADOLESCENTES}

A partir da discussão realizada, propomos as atividades a seguir, para você fazer o diagnóstico nutricional de adolescentes.

1. No exame físico realizado em uma consulta com Zeca, de 13 anos e dois meses, foram coletadas as seguintes informações:

- Estatura: $1,38 \mathrm{~m}$

- Peso: $28 \mathrm{~kg}$ 
Foi observado também que Zeca não havia iniciado sua maturação sexual.

Com base no descrito, responda:

a) Qual o diagnóstico da situação do crescimento do adolescente?

b) Qual o estado nutricional de Zeca? Justifique o indicador utilizado.

c) Qual teria sido o critério para avaliar a maturação sexual? Qual o estágio de maturação sexual de Zeca?

d) Qual seria sua orientação quanto às perspectivas? Que medidas de intervenção poderiam ser realizadas nesse caso?

2. Rita tem 16 anos, pesa $70 \mathrm{~kg}$, tem estatura de $1,56 \mathrm{~m}$. A menarca foi aos 12 anos. Considerando esses dados, responda:

a) Qual o diagnóstico nutricional de Rita?

b) Qual a perspectiva quanto ao seu crescimento?

Agora, vamos rever passo a passo como realizar o diagnóstico do adolescente?

Os passos são os seguintes:

1. Avaliar o adolescente, considerando sua idade em anos e o sexo.

2. Aferir a estatura e o peso do adolescente, utilizando técnicas adequadas, e registrar os dados na ficha/prontuário do adolescente.

3. Proceder à avaliação do IMC para idade e da estatura para idade, em percentis ou escores z, para cada sexo. Avaliações subseqüentes permitirão a observação temporal do processo de crescimento.

4. Complementar o diagnóstico nutricional com avaliação de outros indicadores: dobras cutâneas, perímetro (braquial ou de cintura), conforme opção do serviço.

5. Avaliar o estágio de maturação sexual (Prancha de Tanner), registrá-lo na ficha do adolescente, possibilitando interpretar os achados antropométricos encontrados e as etapas dos eventos puberais.

6. Ter atitude de vigilância, especialmente para casos de baixa estatura, baixo peso e sobrepeso. Realizar intervenção adequada a cada distúrbio nutricional. 


\section{Gestantes}

Toda mulher, durante a gestação, deve receber atenção especial, pois esse período é marcado por intensas transformações que têm importantes repercussões em sua saúde e na da criança. No período gestacional, é fundamental que a mulher faça o pré-natal, que deve ser iniciado tão logo a gravidez seja confirmada, permitindo melhor acompanhamento da gestação e intervenção precoce nos possíveis problemas que porventura ocorram.

Vários fatores estão associados ao resultado obstétrico, tais como: idade materna, intervalo entre as gestações e partos, paridade, infecções maternas e trabalho físico durante a gestação, doenças associadas (diabetes tipo 2, síndrome hipertensiva da gravidez), carências nutricionais (anemia, carência de vitamina A), condições socioeconômicas, tabagismo, uso de bebidas alcoólicas e entorpecentes, e o estado nutricional materno, que deve ser acompanhado durante a assistência pré-natal.

O desconhecimento sobre aspectos da saúde das mulheres indígenas durante a gestação, parto, puerpério e em sua vida reprodutiva - representa uma lacuna importante para os serviços de saúde. Além de apresentarem a vulnerabilidade biológica inerente ao período, as mulheres indígenas têm características diferenciadas sob o ponto de vista social e reprodutivo: início da vida sexual ativa na puberdade, intervalos intergenésicos curtos e elevadas taxas de fecundidade. Por isso, constituem um grupo prioritário para a assistência pré-natal.

Com base em estudos de caso específicos, tentamos delinear a realidade dessas mulheres. O que mais chama atenção é o elevado nível de fecundidade entre as índias, via de regra superior a cinco ou seis filhos (AZEVEDO, 2000; SOUZA; SANTOS, 2001). É importante destacar que os dados do Censo Demográfico de 2000 (INSTITUTO BRASILEIRO DE GEOGRAFIA E ESTATÍSTICA, 2005) também apontaram para uma Taxa de Fecundidade Total (TFT) próxima a seis filhos, nas mulheres auto-declaradas indígenas e residentes em áreas rurais. No caso do Brasil este valor era de 2,32 em 1996, variando de 2,05, na região Sudeste, a 3,01, no Norte (COIMBRA JUNIOR; GARNELO, 2004).

Segundo dados da Funasa (FUNDAÇÃO NACIONAL DE SAÚDE, 2006), o número de nascidos vivos em 2003 foi de 12.399 e, em 2004, o valor chegou a 12.724 crianças. No entanto, não existe registro oficial disponível sobre atendimentos realizados no pré-natal. Oliveira, Escobar e Coimbra
Nível de fecundidade é a relação entre o número de crianças nascidas vivas e o número de mulheres em idade reprodutiva - de 15 a 49 anos.

Taxa de Fecundidade Total referese ao número médio de filhos que uma mulher teria ao longo de sua vida reprodutiva. 
Júnior (2005) constataram, com base em registros de prontuários na Casa de Saúde do Índio, que as recomendações estabelecidas pelo MS para a assistência pré-natal não vêm sendo realizadas de forma satisfatória entre mulheres Suruí. Os autores identificaram que o ingresso no pré-natal acontece por volta da $25^{\mathrm{a}}$ semana gestacional. O início tardio do pré-natal interfere no número total de consultas, que fica em torno de quatro.

Neste Capítulo iremos apresentar o que o Ministério da Saúde preconiza para o acompanhamento da mulher nesse período, explicitando a importância do monitoramento do ganho de peso e os métodos para sua realização.

\section{Para refletir}

O que você observa em sua realidade quanto ao acompanhamento da gestante durante o pré-natal?

Você sabe como tem sido desenvolvido o pré-natal nas aldeias de seu pólo-base/distrito?

Qual tem sido a periodicidade das consultas?

Quais são as dificuldades e as facilidades que os profissionais de saúde encontram no dia-a-dia?

\section{Cartão da Gestante: instrumento de acompanhamento}

O Cartão da Gestante é o instrumento preconizado pelo MS com a finalidade de acompanhar a mulher durante a gestação. Nesse período, o monitoramento da saúde e da nutrição favorece bons resultados para a mãe e para a criança, desde o seu desenvolvimento como feto até o primeiro ano de vida.

O Manual técnico de atenção ao pré-natal e ao puerpério, publicado pelo MS, contém as orientações necessárias para o preenchimento do cartão da gestante. Sua finalidade é servir como referência para a organização da rede assistencial, a capacitação profissional e a normatização das práticas de saúde durante a gestação e o puerpério (BRASIL, 2006a).

Mas por que é tão importante o acompanhamento do estado nutricional da gestante? 
Figura 5 - Cartão da Gestante
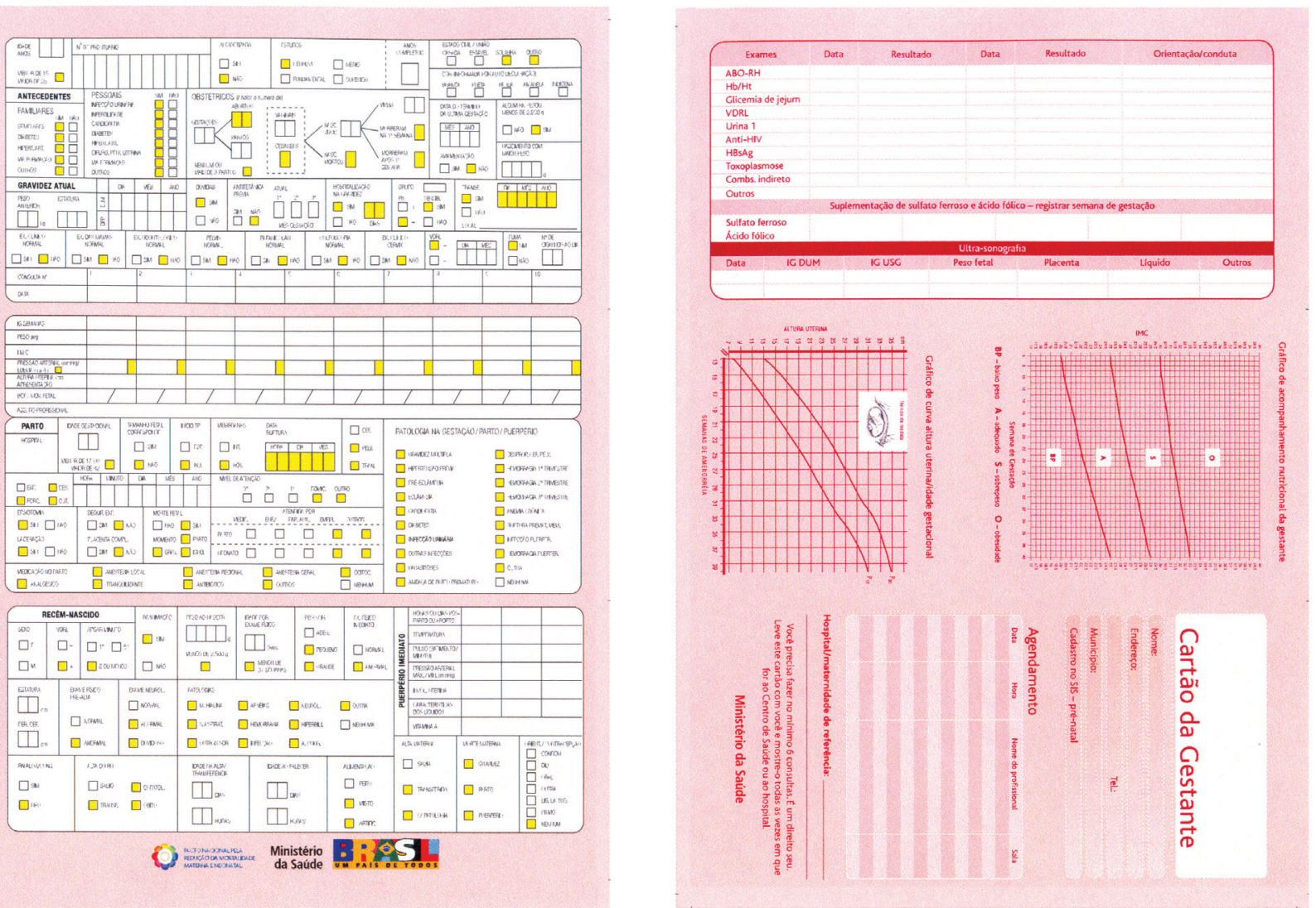

Fonte: Brasil (2006a)

A gravidez é um período de intenso gasto energético (cerca de $80.000 \mathrm{kcal}$ durante toda a gestação), devido às muitas transformações que ocorrem no organismo materno, como: aumento do volume sangüíneo e das mamas; formação de reserva energética para a amamentação; crescimento do útero; bem como desenvolvimento da placenta, do líquido amniótico e do feto.

Nesse sentido, as necessidades nutricionais estão aumentadas tanto em relação aos macronutrientes (carboidratos, proteínas e gorduras) como aos micronutrientes (vitaminas e minerais). A alimentação da mulher deve ser balanceada e orientada. Esse não é o momento de a gestante perder peso, tampouco de "comer por dois". O ganho de peso inadequado - seja déficit, seja excesso - poderá ser prejudicial tanto para a saúde da mulher quanto para a do bebê (SAUNDERS; BESSA, 2002).
Como podemos observar no Cartão da Gestante, a avaliação e o acompanhamento do ganho de peso devem estar incorporados à rotina do pré-natal. 
Mulheres que iniciam a gravidez abaixo ou acima de seu peso normal em relação à estatura exigem atenção especial. Nesses casos, o cuidado pré-natal deverá ser redobrado, visando à promoção da saúde, e possibilitando melhores resultados para a mãe e o bebê.
O MS (BRASIL, 2006a) recomenda que o ganho de peso na gestação varie entre 7 e $18 \mathrm{~kg}$, estando essa faixa relacionada a melhores resultados obstétricos, por menores incidências de intercorrências. Essa recomendação deve ser individual e baseada no estado nutricional da mulher no período pré-gestacional. Na avaliação do ganho de peso, devemos ficar atentos ao consumo alimentar, em qualidade e quantidade adequadas, e também às particularidades de cada mulher.

Um ganho de peso inferior ao recomendado tem relação direta com o peso da criança ao nascimento. Geralmente mulheres com ganho de peso insuficiente têm filhos com baixo peso $(<2,5 \mathrm{~kg})$. Elas também estão mais propícias à ocorrência de infecções, a carências nutricionais, entre outros aspectos.

O ganho excessivo de peso também pode ser prejudicial para mãe e filho, principalmente se a mulher inicia sua gravidez apresentando sobrepeso. Essa situação tem uma correlação importante com macrossomia fetal, hipertensão, diabetes, indicação de parto cirúrgico e obesidade pós-parto.

Quando constatamos um ganho excessivo de peso, é preciso identificar se esse fato está relacionado ao aumento de massa corporal, à retenção de líquidos (edema) ou à gestação múltipla. Em cada situação, a interpretação clínica será diferente, bem como a conduta a ser adotada. O aparecimento de edema, de certa forma esperado durante a gestação, deve ser clinicamente avaliado, podendo estar associado a patologias próprias da gravidez.

Outros acompanhamentos são necessários nessa fase da vida, como a verificação rotineira da pressão arterial, dos níveis de glicose, de hemoglobina e hematócrito, bem como a verificação dos níveis de proteínas e albumina na urina. Alterações nesses valores podem estar relacionadas a distúrbios hipertensivos específicos da gestação, diabetes gestacional, anemia e pré-eclâmpsia ou eclâmpsia. Outros fatores também devem ser considerados, como a idade materna, o intervalo entre as gestações e os partos, o número de gestações (paridade) e suas intercorrências, o tipo de trabalho da mulher, a preexistência de patologias, hábitos de vida (fumo, álcool, drogas) e uso de medicamentos (BRASIL, 2006a).

Fatores de risco importantes também devem ser considerados na análise do diagnóstico nutricional da gestante, tais como, tipo da dieta consumida, sedentarismo, história familiar de doenças, hábito de fumar, uso de 
bebidas alcoólicas entre outros. Essas situações podem influenciar negativamente na determinação do estado nutricional e de saúde do indivíduo, sendo causa ou agravante da patologia que estiver associada.

\section{Indicadores para o diagnóstico nutricional da gestante}

Até o final da década de 1990, o MS indicava, para a avaliação nutricional das gestantes, a curva de adequação do peso em relação à estatura, segundo a idade gestacional, construída por Rosso (1985), e que foi incorporada ao Cartão da Gestante. O MS identificou uma série de limitações nesse instrumento de avaliação e passou a adotar o indicador ganho de peso em relação à idade gestacional, recomendado pelo Centro Latino-Americano de Perinatologia e Desenvolvimento Humano (Clap) (FESCINA, 1983). No processo de implementação dessa nova proposta, verificou-se grande dificuldade de aplicação do método pelos profissionais de saúde, o que resultou na falta de adesão ao método e ao uso do Cartão da Gestante em vários estados do país. Em 2005 o MS adotou o método proposto por Atalah, Castillo e Castro (1997), combinado com a proposta do IOM (INSTITUTE OF MEDICINE, 1990).

Agora que já temos informações importantes sobre cuidados pré-natais e o método adotado pelo MS para realizar o diagnóstico nutricional da gestante, vamos ver como utilizá-lo na rotina de acompanhamento pré-natal.

\section{Primeira consulta}

Nesse primeiro momento a avaliação deverá ser realizada em duas etapas:

- Diagnóstico nutricional das gestantes por meio da classificação do IMC por semana gestacional. O seu estado nutricional pode ser classificado em baixo peso, peso adequado, sobrepeso e obesidade, segundo a semana gestacional. Veja, mais adiante, a Tabela 2 - Avaliação do estado nutricional da gestante acima de 19 anos segundo IMC por semana gestacional (ATALAH; CASTILLO; CASTRO, 1997; BRASIL, 2006a).

- Estimativa do ganho de peso segundo estado nutricional até o final da gestação (INSTITUTE OF MEDICINE, 1990; BRASIL, 2006a; WORLD HEALTH ORGANIZATION, 1995). Esse método permite estimar o ganho de peso total no primeiro trimestre de gestação; o ganho de peso semanal médio no segundo e terceiro trimestres; e o ganho de peso total na gestação, de acordo com o diagnóstico do seu estado nutricional pré-gestacional ou inicial. Veja o Quadro 16 - Ganho de peso recomendado (em $\mathrm{kg}$ ) na gestação segundo estado nutricional inicial, apresentado mais adiante.
A classificação do estado nutricional da gestante por IMC é diferente da recomendada para a população adulta de um modo geral. Os pontos de corte que determinam o diagnóstico variam de acordo com a semana gestacional. 
Reveja as técnicas corretas de pesagem e medição apresentadas no Capítulo anterior, "Antropometria", na Parte I deste livro.

\section{Diagnóstico nutricional baseado no IMC por semana gestacional}

Permite a avaliação nutricional da gestante a qualquer momento do período da gravidez, não necessitando informação do peso pré-gestacional. Para a construção desse indicador, precisamos calcular o índice de massa corporal e a idade gestacional.

a) Índice de Massa Corporal (IMC)

É calculado por meio da seguinte fórmula:

$$
\mathrm{IMC}=\frac{\text { Peso atual }(\mathrm{kg})}{\text { Estatura }^{2}(\mathrm{~m})}
$$

Nessa fórmula consideramos:

- Peso - é o peso atual da gestante em quilogramas. Deve ser aferido em todas as consultas de pré-natal.

- Estatura - é medida, em metros, por ocasião da primeira consulta de pré-natal.

Existem outras formas de conhecer o IMC, sem que seja necessário usar essa fórmula. Isso é feito usando-se um Nomograma ou um Disco. Esses instrumentos fornecem a classificação do estado nutricional e são os mesmos utilizados para o diagnóstico nutricional de adultos. A composição de cada um e a forma de utilização estão descritas a seguir (Figuras 6 e 7):

Figura 6 - Nomograma para cálculo do IMC

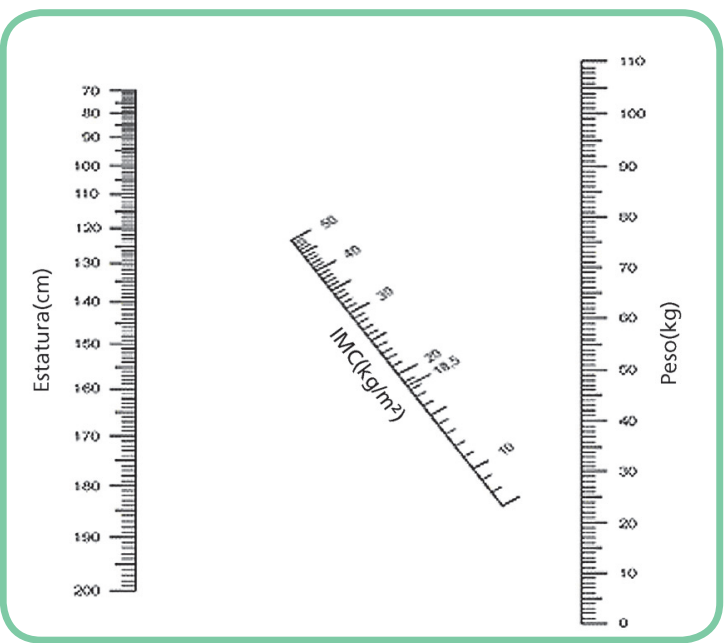

Fonte: Engstrom et al. (2002). 
O Nomograma apresenta as variáveis peso, estatura e valor do IMC, dispostos em três colunas:

- Primeira coluna (esquerda): valores de estatura em centímetros (cm)

- Segunda coluna (intermediária): refere-se aos valores de IMC $\left(\mathrm{kg} . \mathrm{m}^{2}{ }^{2}\right)$

- Terceira coluna (direita): refere-se ao peso da gestante em quilogramas $(\mathrm{kg})$

A partir do peso e da estatura da gestante, você deve localizar esses valores nas colunas correspondentes. Com a ajuda de uma régua, você deve unir com uma linha imaginária esses dois valores e identificar em qual ponto a reta intermediária será cortada por essa linha. Este será o valor do IMC.

Figura 7 - Disco para cálculo do IMC

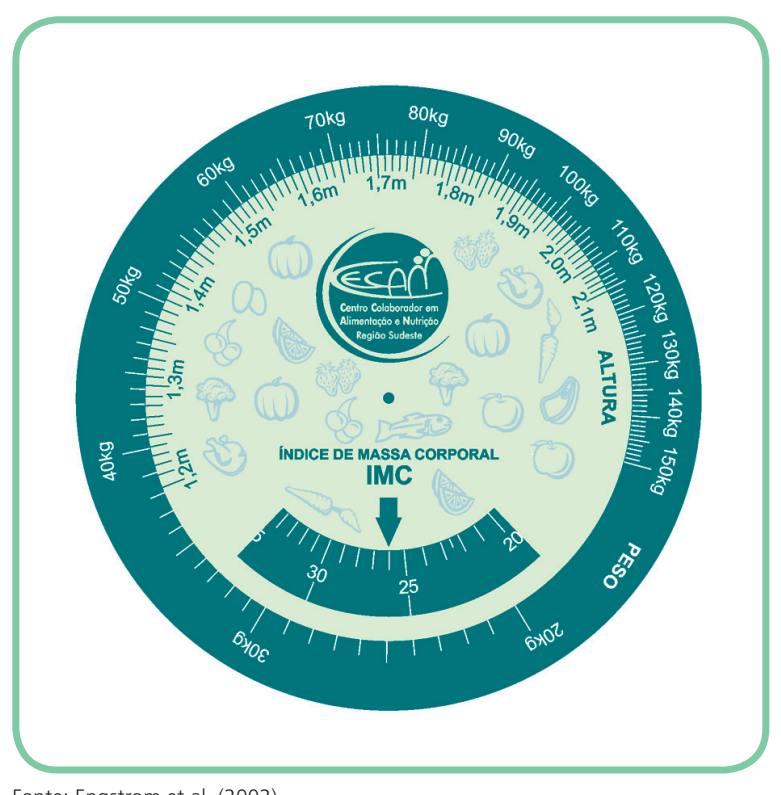

Fonte: Engstrom et al. (2002)

O disco é formado por dois planos circulares sobrepostos. O primeiro (maior) registra o peso em quilogramas; o segundo (menor), a estatura em metros e o valor do IMC com sua classificação. Você deve localizar os valores de peso e estatura da gestante em cada esfera e uni-los. Nesse momento aparecerão abaixo da seta, na janela do IMC, o valor do IMC.

\section{b) Idade gestacional}

É o tempo de gravidez de uma mulher, isto é, o número de semanas que a mulher está grávida. Para obter a IG de forma correta, precisamos primeiro saber a Data da Última Menstruação (DUM). 
O MS conta com um manual técnico para atenção qualificada e humanizada ao pré-natal e puerpério, disponível na sua página eletrônica, que orienta os passos para o cálculo e a interpretação da altura uterina e sua relação com a IG.
Embora o período menstrual dure em torno de quatro a cinco dias (na maioria das mulheres), para calcular a IG, o que nos interessa é o primeiro dia da última menstruação. O cálculo da IG é feito geralmente em semanas gestacionais, isto é, o número de semanas de gravidez. Para isso, precisamos saber o número de semanas existentes entre a data atual e a da DUM. O profissional de saúde pode utilizar alguns instrumentos que facilitam o cálculo, como o calendário, o disco obstétrico e a régua obstétrica.

Pode ocorrer de a mulher não saber informar, com certeza, o primeiro dia da última menstruação. Caso isso aconteça, a DUM poderá ser estimada de acordo com o período em que ocorreu a menstruação, usando-se a seguinte regra (BRASIL, 2006a):

- se ocorreu no início do mês, o dia a ser considerado será o 5;

- se foi no meio do mês, o dia a ser considerado será 15;

- se foi no final do mês, o dia a ser considerado será 25.

Pode acontecer, ainda, de a mulher não saber informar, com certeza, a data e o período da última menstruação. O que fazer nesse caso?

A idade gestacional e a data provável do parto serão, inicialmente, determinadas por aproximação, basicamente pela medida da altura do fundo do útero e pelo toque vaginal. Também é importante a informação sobre a data de início dos movimentos fetais, que habitualmente ocorre entre 16 e 20 semanas (BRASIL, 2006a).

Nas primeiras oito semanas de gestação, o útero está dentro da pelve. Assim, no toque vaginal, um diâmetro em torno de $6 \mathrm{~cm}$ representa aproximadamente quatro semanas; e um diâmetro de $10 \mathrm{~cm}$ representa em torno de oito semanas de gestação.

A Tabela 1 apresenta as estimativas da idade gestacional a partir da medida da altura uterina.

Tabela 1 - Idade gestacional a partir da medida da altura uterina

\begin{tabular}{c|c|c} 
Altura uterina $(\mathrm{cm})$ & Idade gestacional (semanas) & Variação (semanas) \\
\hline 8 a 9,9 & 13 & $\pm 2,5$ \\
\hline 10 a 11,9 & 14 & $\pm 2,5$ \\
\hline 12 a 12,9 & 15 & $\pm 3,0$ \\
\hline 13 a 13,9 & 16 & $\pm 3,0$ \\
\hline
\end{tabular}


Tabela 1 - Idade gestacional a partir da medida da altura uterina (cont.)

\begin{tabular}{|c|c|c|}
\hline Altura uterina $(\mathrm{cm})$ & Idade gestacional (semanas) & Variação (semanas) \\
\hline 14 a 14,9 & 17 & $\pm 3,0$ \\
\hline 15 a 15,9 & 18 & $\pm 4,0$ \\
\hline 16 a 16,9 & 19 & $\pm 4,0$ \\
\hline 17 a 17,9 & 20 & $\pm 4,0$ \\
\hline 18 a 18,9 & 21 & $\pm 4,0$ \\
\hline 19 a 19,9 & 22 & $\pm 4,0$ \\
\hline 20 a 20,9 & 23 & $\pm 4,0$ \\
\hline 21 a 21,9 & 24 & $\pm 4,0$ \\
\hline 22 а 22,9 & 25 & $\pm 4,0$ \\
\hline 23 a 23,9 & 26 & $\pm 4,0$ \\
\hline 24 a 24,9 & 27 & $\pm 4,0$ \\
\hline 25 a 25,9 & 28 & $\pm 4,0$ \\
\hline 26 a 26,9 & 29 & $\pm 4,0$ \\
\hline 27 a 27,4 & 30 & $\pm 4,5$ \\
\hline 27,5 a 27,9 & 31 & $\pm 4,5$ \\
\hline 28 a 28,9 & 32 & $\pm 4,5$ \\
\hline 29 a 29,9 & 33 & $\pm 4,5$ \\
\hline 30 a 30,9 & 34 & $\pm 4,5$ \\
\hline 31 a 31,9 & 35 & $\pm 4,5$ \\
\hline 32 a 32,9 & 36 & $\pm 4,5$ \\
\hline 33 а 33,9 & 37 & $\pm 4,5$ \\
\hline 34 a 34,9 & 38 & $\pm 4,5$ \\
\hline
\end{tabular}

Outro detalhe importante é que todos os instrumentos (gráficos, tabelas) utilizados para o diagnóstico da gestante trabalham em semanas gestacionais, que são cheias, isto é, não apresentam variação de dias. Quando as semanas não forem completas, será preciso fazer aproximações. Não há uma regra definida, mas vamos apresentar uma sugestão que servirá para padronizar as aproximações. Como a semana tem sete dias, faremos o seguinte:

- se a semana incompleta for de até três dias, iremos arredondar para baixo. Por exemplo: 12 semanas e dois dias = 12 semanas;

- se a semana incompleta for de quatro dias ou mais, iremos arredondar para cima. Por exemplo: 20 semanas e cinco dias $=21$ semanas.

De posse da DUM e com o instrumento escolhido em mãos, temos a IG. No entanto, se não houver qualquer possibilidade de obter a DUM, somente um exame físico ou a ultra-sonografia serão capazes de esclarecer a IG. Para fins práticos, a idade gestacional vem muitas vezes expressa 
em trimestres, agregando as semanas gestacionais. Consideramos que a duração média da gravidez é de 40 semanas, assim subdivididas:

$\checkmark \quad 1^{\circ}$ trimestre: IG < 14 semanas;

- $2^{\circ}$ trimestre: IG $14 \mid-28$ semanas;

- $3^{\circ}$ trimestre: IG $\geq 28$ semanas.

Agora que já aprendemos a calcular o IMC e a IG, vamos realizar o diagnóstico nutricional da gestante?

O diagnóstico nutricional é feito por meio de consulta à Tabela 2, na qual encontramos os valores de IMC distribuídos por semana gestacional.

Tabela 2 - Avaliação do estado nutricional da gestante acima de 19 anos segundo IMC por semana gestacional

\begin{tabular}{|c|c|c|c|c|c|c|}
\hline \multirow{3}{*}{$\begin{array}{l}\text { IG } \\
6\end{array}$} & \multirow{3}{*}{$\begin{array}{c}\text { Baixo peso } \\
\text { IMC } \leq \\
19,9\end{array}$} & \multicolumn{2}{|c|}{ Adequado } & \multicolumn{2}{|c|}{ Sobrepeso } & \multirow{3}{*}{$\begin{array}{c}\text { Obesidade } \\
\qquad \text { IMC } \geq \\
30,1\end{array}$} \\
\hline & & \multicolumn{2}{|c|}{ IMC entre } & \multicolumn{2}{|c|}{ IMC entre } & \\
\hline & & 20,0 & 24,9 & 25,0 & 30,0 & \\
\hline 8 & 20,1 & 20,2 & 25,0 & 25,1 & 30,1 & 30,2 \\
\hline 10 & 20,2 & 20,3 & 25,2 & 25,3 & 30,2 & 30,3 \\
\hline 11 & 20,3 & 20,4 & 25,3 & 25,4 & 30,3 & 30,4 \\
\hline 12 & 20,4 & 20,5 & 25,4 & 25,5 & 30,3 & 30,4 \\
\hline 13 & 20,6 & 20,7 & 25,6 & 25,7 & 30,4 & 30,5 \\
\hline 14 & 20,7 & 20,8 & 25,7 & 25,8 & 30,5 & 30,6 \\
\hline 15 & 20,8 & 20,9 & 25,8 & 25,9 & 30,6 & 30,7 \\
\hline 16 & 21,0 & 21,1 & 25,9 & 26,0 & 30,7 & 30,8 \\
\hline 17 & 21,1 & 21,2 & 26,0 & 26,1 & 30,8 & 30,9 \\
\hline 18 & 21,2 & 21,3 & 26,1 & 26,2 & 30,9 & 31,0 \\
\hline 19 & 21,4 & 21,5 & 26,2 & 26,3 & 30,9 & 31,0 \\
\hline 20 & 21,5 & 21,6 & 26,3 & 26,4 & 31,0 & 31,1 \\
\hline 21 & 21,7 & 21,8 & 26,4 & 26,5 & 31,1 & 31,2 \\
\hline 22 & 21,8 & 21,9 & 26,6 & 26,7 & 31,2 & 31,3 \\
\hline 23 & 22,0 & 22,1 & 26,8 & 26,9 & 31,3 & 31,4 \\
\hline 24 & 22,2 & 22,3 & 26,9 & 27,0 & 31,5 & 31,6 \\
\hline 25 & 22,4 & 22,5 & 27,0 & 27,1 & 31,6 & 31,7 \\
\hline 26 & 22,6 & 22,7 & 27,2 & 27,3 & 31,7 & 31,8 \\
\hline 27 & 22,7 & 22,8 & 27,3 & 27,4 & 31,8 & 31,9 \\
\hline 28 & 22,9 & 23,0 & 27,5 & 27,6 & 31,9 & 32,0 \\
\hline 29 & 23,1 & 23,2 & 27,6 & 27,7 & 32,0 & 32,1 \\
\hline 30 & 23,3 & 23,4 & 27,8 & 27,9 & 32,1 & 32,2 \\
\hline 31 & 23,4 & 23,5 & 27,9 & 28,0 & 32,2 & 32,3 \\
\hline 32 & 23,6 & 23,7 & 28,0 & 28,1 & 32,3 & 32,4 \\
\hline
\end{tabular}


Tabela 2 - Avaliação do estado nutricional da gestante acima de 19 anos segundo IMC por semana gestacional (cont.)

\begin{tabular}{c|c|c|c|c|c|c}
\hline \multirow{2}{*}{ IG } & Baixo peso & \multicolumn{2}{|c|}{ Adequado } & \multicolumn{2}{c|}{ Sobrepeso } & Obesidade \\
\hline \multirow{2}{*}{33} & IMC $\leq$ & \multicolumn{2}{|c|}{ IMC entre } & \multicolumn{2}{c}{ IMC entre } & IMC $\geq$ \\
\hline 34 & 23,8 & 23,9 & 28,1 & 28,2 & 32,4 & 32,5 \\
\hline 35 & 23,9 & 24,0 & 28,3 & 28,4 & 32,5 & 32,6 \\
\hline 36 & 24,1 & 24,2 & 28,4 & 28,5 & 32,6 & 32,7 \\
\hline 37 & 24,4 & 24,3 & 28,5 & 28,6 & 32,7 & 32,8 \\
\hline 38 & 24,5 & 24,6 & 28,8 & 28,9 & 32,9 & 33,0 \\
\hline 39 & 24,7 & 24,8 & 28,9 & 29,0 & 33,0 & 33,1 \\
\hline 40 & 24,9 & 25,0 & 29,1 & 29,2 & 33,1 & 33,2 \\
\hline 41 & 25,0 & 25,1 & 29,2 & 29,3 & 33,2 & 33,3 \\
\hline 42 & 25,0 & 25,1 & 29,2 & 29,3 & 33,2 & 33,3 \\
\hline
\end{tabular}

Fonte: Atalah; Castillo; Castro (1997).

Para fazer o diagnóstico nutricional, é preciso inicialmente localizar, na primeira coluna, a semana gestacional calculada. A seguir, identificar nas demais colunas em que faixa está situado o valor do IMC da gestante, considerando:

- Baixo peso (BP) - quando o valor do IMC observado for igual ou menor que os valores apresentados na coluna correspondente ao baixo peso (segunda coluna);

- Adequado (A) - quando o valor do IMC observado estiver entre os valores apresentados na coluna correspondente ao peso adequado (terceira coluna);

- Sobrepeso (S) - quando o valor do IMC observado estiver entre os valores apresentados na coluna correspondente ao sobrepeso (quarta coluna);

- Obesidade $(\mathrm{O})$ - quando o valor do IMC observado for igual ou maior que os valores apresentados na coluna correspondente à obesidade (quinta coluna).

Vejamos o exemplo:

No dia 26/05/2007, em uma visita domiciliar, a auxiliar de enfermagem Solange, conversando com Isabel, 26 anos, mãe de quatro crianças, descobriu que esta estava grávida. Quando Solange perguntou a data de sua última menstruação, ela relatou que desde fevereiro não sangrava. Solange perguntou novamente se a menstruação tinha vindo no início, no meio ou no final de janeiro, e Isabel respondeu que havia sido no 
meio do mês. Solange pediu a Isabel para ir ao posto iniciar o pré-natal e explicou a importância desse tipo de acompanhamento para a mulher e para o bebê. No dia 27/05, Isabel compareceu à sua primeira consulta de pré-natal. Como a vigilância nutricional de adultos estava implantada há quase um ano naquela aldeia, Solange conseguiu resgatar o registro do peso de Isabel antes de ela engravidar (em dezembro de 2006, Isabel estava com $60 \mathrm{~kg}$ ). Ao ser pesada e medida, verificou-se que seu peso atual era $65 \mathrm{~kg}$ e sua estatura, $1,67 \mathrm{~m}$.

Qual era o estado nutricional de Isabel na primeira consulta?

Cálculo da IG: de 15/01/2007 até 27/05/2007 são 19 semanas completas.

Cálculo do IMC:

$$
\frac{\text { Peso }(\mathrm{kg})}{\text { Estatura }^{2}(\mathrm{~m})}=\frac{65 \mathrm{~kg}}{(1,67 \mathrm{~m})^{2}}=\frac{65 \mathrm{~kg}}{2,789 \mathrm{~m}^{2}}=23,38 \mathrm{~kg} \cdot \mathrm{m}^{-2}
$$

Segundo o cálculo apresentado, na $19^{a}$ semana gestacional, o valor do IMC de 23,4 kg.m-2 corresponde ao estado nutricional adequado (entre 21,5 e $26,2 \mathrm{~kg} \cdot \mathrm{m}^{-2}$ ). Observe que utilizando esta metodologia, o valor do peso pré-gestacional não é considerado.

Após avaliar o estado nutricional da gestante pela metodologia de Atalah, Castillo e Castro (1997) - IMC por semana gestacional -, passamos à fase de acompanhamento do estado nutricional pelo ganho de peso.

\section{Estimativa do ganho de peso segundo o estado nutricional}

Em geral o ganho de peso é determinado pela diferença entre o peso atual da gestante e o peso antes ou no início da gestação. Temos, portanto, a seguinte fórmula:

- Ganho de peso = PA - PPG

Considerando:

PA - Peso atual

PPG - Peso pré-gestacional 
O ideal é que o ganho de peso seja acompanhado desde o início da gestação, com base no conhecimento do peso pré-gestacional referido. Caso não seja possível, inicie a estimativa com os dados da primeira consulta do pré-natal.

Usando o exemplo anterior, vamos agora verificar o ganho de peso de Isabel até o momento da primeira consulta?

Relembrando:

$$
\begin{aligned}
& I G=19 \text { semanas; IMC }=23,4 \text { (adequado); PPG =60kg; PA =65kg } \\
& \text { Ganho de peso }=65 \mathrm{~kg}(P A)-60 \mathrm{~kg}(P P G)=5 \mathrm{~kg}
\end{aligned}
$$

Isabel teve ganho de peso de $5 \mathrm{~kg}$ até a $19^{\mathrm{a}}$ semana gestacional. Agora que sabemos calcular o ganho de peso, vamos aprender a estimar e acompanhar o ganho de peso da gestante durante toda a gestação.

A partir do diagnóstico do estado nutricional realizado na primeira consulta, o ganho de peso de cada gestante deverá ser estimado, havendo uma faixa recomendada, segundo o estado nutricional (INSTITUTE OF MEDICINE, 1990).

Para fazer esse acompanhamento, sugerimos utilizar as informações do Quadro 16, que indica o ganho de peso recomendado segundo o estado nutricional da gestante no início do pré-natal.
Não nos basta saber quanto peso uma gestante deverá ganhar até o final da gravidez. É preciso monitorar esse ganho acompanhando sua evolução em todas as consultas, pois um ganho súbito - ou uma perda repentina - de peso pode indicar situações de risco para a mulher e o bebê.

Quadro 16 - Ganho de peso recomendado (em kg) na gestação segundo estado nutricional inicial

\begin{tabular}{|l|c|c|c|c|}
\hline $\begin{array}{l}\text { Estado Nutricional } \\
\text { Inicial }(\mathrm{IMC})\end{array}$ & $\begin{array}{l}\text { Classificação IMC } \\
\text { pré-gestacional }\end{array}$ & $\begin{array}{l}\text { Ganho de peso total } \\
(\mathrm{kg}) \text { no } \mathbf{1}^{\circ} \text { trimestre }\end{array}$ & $\begin{array}{l}\text { Ganho de peso semanal médio } \\
(\mathrm{kg}) \text { no 2 }{ }^{\circ} \text { e 3 }{ }^{\circ} \text { trimestres }\end{array}$ & $\begin{array}{l}\text { Ganho de peso total } \\
(\mathrm{kg})\end{array}$ \\
\hline Baixo peso & $<18,5$ & 2,3 & 0,5 & $12,5-18,0$ \\
\hline Adequado & $18,51-25,0$ & 1,6 & 0,4 & $11,5-16,0$ \\
\hline Sobrepeso & $25,01-30,0$ & 0,9 & 0,3 & $7,0-11,5$ \\
\hline Obesidade & $\geq 30,0$ & - & 0,3 & 7,0 \\
\hline
\end{tabular}

Fonte: Institute of Medicine (1990); World Health Organization (1995); Brasil (2006a).

\section{Observe:}

- na $1^{a}$ coluna está o diagnóstico do estado nutricional inicial, segundo o IMC pré-gestacional;

- a $2^{a}$ coluna apresenta os pontos de corte utilizados para classificar

o estado nutricional pré-gestacional; 


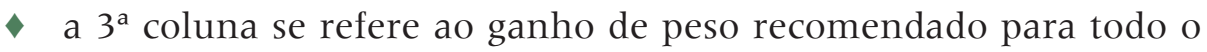
$1^{\circ}$ trimestre de gravidez, segundo o estado nutricional;

- a $4^{\mathrm{a}}$ coluna se refere ao ganho de peso semanal médio recomendado para o $2^{\circ}$ e $3^{\circ}$ trimestres de gravidez, segundo o estado nutricional;

- a $5^{a}$ coluna apresenta o ganho de peso total recomendado, também segundo o estado nutricional.

Em função do estado nutricional pré-gestacional ou no início do pré-natal, há uma faixa de ganho de peso recomendado. Por exemplo: uma gestante com sobrepeso deverá ganhar entre sete e $11,5 \mathrm{~kg}$ durante toda a gestação - em média, $0,9 \mathrm{~kg}$ durante todo o primeiro trimestre (até a $14^{\mathrm{a}}$ semana) e $0,3 \mathrm{~kg}$ semanais nos $2^{\circ}$ e $3^{\circ}$ trimestres. Já uma gestante com obesidade deverá ganhar cerca de $7 \mathrm{~kg}$ durante toda a gestação, sendo que não deverá haver ganho de peso durante todo o primeiro trimestre (até a $14^{\mathrm{a}}$ semana) e nos $2^{\circ}$ e $3^{\circ}$ trimestres o ganho semanal deverá ser de $0,3 \mathrm{~kg}$.

Voltando ao nosso exemplo inicial, vamos estimar o ganho de peso de Isabel?

$I G=19$ semanas; IMC $=23,4$ (adequado); PPG $=60 \mathrm{~kg} ; \mathrm{PA}=65 \mathrm{~kg}$

Ganho de peso até a $19^{\mathrm{a}}$ semana $=5 \mathrm{~kg}$

Segundo as recomendações, Isabel deveria ter ganho:

$1,6 \mathrm{~kg}$ (até a $13^{\mathrm{a}}$ semana $)+0,4 \mathrm{~kg} \times 6$ (da $14^{\mathrm{a}}$ à $19^{\mathrm{a}}$ semana $)=1,6 \mathrm{~kg}+2,4 \mathrm{~kg}=4,0 \mathrm{~kg}$

Verificamos que ela ganhou $1,0 \mathrm{~kg}$ a mais do que o recomendado, mas continua com o estado nutricional adequado. Sendo assim, vamos estimar seu ganho até o final da gestação, orientando-a para os riscos de ultrapassar os valores previstos.

Ganho de peso projetado até o final da gestação (40 semanas) $=0,4 \mathrm{~kg} / \mathrm{semana}$ (ganho de peso recomendado para gestantes com estado nutricional adequado no $2^{\mathrm{a}}$ e $3^{\mathrm{a}}$ trimestres) $\times 21$ semanas (número de semanas que ainda faltam para o final da gestação) $=8,4 \mathrm{~kg}$.

Ganho de peso total $=5 \mathrm{~kg}$ (já ganho até a $20^{\mathrm{a}}$ semana $)+8,4 \mathrm{~kg}$ (a ganhar) $=$ $13,4 \mathrm{~kg}$. 
Esse ganho de peso total durante a gestação é considerado satisfatório, dentro da faixa recomendada para gestante com IMC adequado $(11,5$ a $16,0 \mathrm{~kg}$ ). A variabilidade de ganho de peso recomendado se justifica por ser o estado nutricional diagnosticado também por faixa. Sendo assim, uma gestante considerada baixo peso e que esteja mais distante da faixa de normalidade deverá ganhar mais peso do que outra, com o mesmo estado nutricional, mas com o IMC mais próximo à normalidade.

\section{Consultas subseqüentes}

Nas consultas, a avaliação do estado nutricional deve ser realizada conforme descrito anteriormente: fazer o diagnóstico nutricional pelo IMC, segundo semana gestacional, e, a seguir, avaliar o ganho de peso, verificando se esse ganho está adequado ao estado nutricional da gestante. Esses procedimentos permitem acompanhar a evolução do ganho de peso durante a gestação.

Um método mais prático para o acompanhamento do estado nutricional da gestante é pelo uso do gráfico de IMC por semana gestacional (Anexo JGráfico para avaliação nutricional de gestantes, segundo IMC por semana gestacional).

Gráfico 14 - Gráfico para avaliação nutricional de gestantes segundo IMC por semana gestacional

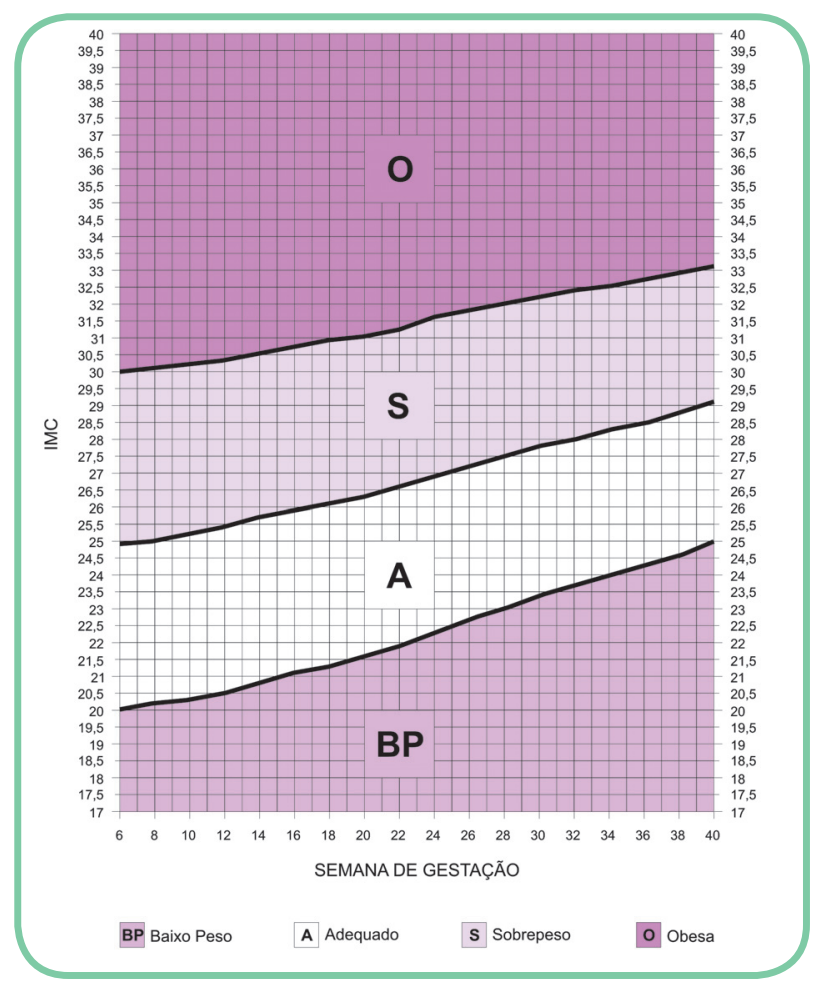

Fonte: Atalah; Castillo; Castro (1997)
Atenção prioritária deve ser dada às gestantes com baixo peso ou obesidade pré-gestacional, assim como às que tiverem ganhos inferiores ou superiores ao recomendado.

Nas situações em que a gestante obtém todo o ganho de peso recomendado para a sua gestação antes do término do período gestacional, deve-se adotar o ganho de peso mínimo preconizado.

Nos casos de ganho de peso insuficiente, o ganho deve ser aumentado até o máximo de $0,5 \mathrm{~kg}$ por semana (INSTITUTE OF MEDICINE, 1990).

Para ter uma visão mais clara e completa do Gráfico para avaliação nutricional de gestantes segundo IMC por semana gestacional, consulte o Anexo J. Mais adiante, você irá trabalhar com ele. 
Observe no gráfico de acompanhamento nutricional da gestante:

- o eixo horizontal, que corresponde às semanas gestacionais;

- o eixo vertical, que corresponde aos valores de IMC;

- as três curvas que delimitam as quatro faixas de estado nutricional (de baixo para cima), isto é:

- abaixo da curva inferior, estão as gestantes de Baixo Peso (BP),

- entre a curva inferior e a $2^{a}$ curva, estão as gestantes com peso Adequado (A),

- entre a $2^{\mathrm{a}}$ e a $3^{\mathrm{a}}$ curva, estão as gestantes com Sobrepeso (S),

- acima da $3^{a}$ curva, estão as gestantes com Obesidade $(\mathrm{O})$.

Para fazer o diagnóstico nutricional a cada consulta, deve-se:

- calcular a idade gestacional e o IMC da gestante;

- localizar no eixo horizontal a idade gestacional;

- localizar no eixo vertical o valor do IMC;

- marcar o ponto de interseção desses valores;

- classificar o estado nutricional conforme a localização desse ponto no gráfico;

- acompanhar a evolução do IMC segundo a idade gestacional, com atenção ao traçado da curva, considerando:

- traçado ascendente - estado nutricional adequado;

- traçado horizontal ou descendente - estado nutricional inadequado (gestante de risco).

A proposta apresentada é para gestantes acima de 19 anos de idade. Mas para gestantes adolescentes, a interpretação é a mesma?

No caso de gestantes adolescentes, a interpretação deve ser mais flexível, por elas ainda estarem em fase de crescimento e serem consideradas imaturas biologicamente. Por isso, elas devem ter sua estatura mensurada em todas as consultas.

Para adolescentes que engravidaram dois ou mais anos após a menarca, a interpretação deve ser a mesma de gestantes adultas; as que engravidaram menos de dois anos após a menarca deverão ser consideradas de "risco", sendo mais importante, nesses casos, acompanhar o traçado da curva (que deve ser ascendente). 
O diagnóstico e a intervenção nutricional dos casos de risco não podem estar dissociados do bom acompanhamento pré-natal, com atuação clínica e nutricional conjunta. Cabe organizar a atenção nos serviços de saúde de forma a:

- garantir agendamento de consultas para esses casos;

- prevenir e controlar doenças e intercorrências clínicas;

- promover ações básicas de saúde da mulher e hábitos de vida saudáveis;

- incluir as gestantes de baixo peso em programas de suplementação alimentar.

Concluindo: a vigilância do estado nutricional de gestantes é um procedimento simples e de baixo custo, capaz de melhorar o resultado obstétrico (condições da criança ao nascer e saúde materna). Tal vigilância se dá por meio do diagnóstico do estado nutricional da gestante o mais precocemente possível, do monitoramento do ganho de peso durante todo o período gestacional, da observação dos fatores de risco associados e de intervenções adequadas, diminuindo os riscos de morbimortalidade na mulher e no bebê.

Dados clínicos e laboratoriais também são importantes e devem, sempre que possível, ser utilizados para complementar o diagnóstico nutricional da gestante, principalmente no que se refere à anemia ferropriva, à deficiência de micronutrientes como ácido fólico, vitamina A, cálcio, à hipertensão arterial e ao diabetes mellitus.

\section{PARA PRATICAR - DIAGNÓSTICO NUTRICIONAL DE GESTANTE}

1. No dia 20/04/2007, três gestantes de primeira vez (primigestas) foram atendidas, no posto de saúde, pela auxiliar de enfermagem e pela enfermeira. Na ocasião, as profissionais de saúde coletaram os seguintes dados:

\begin{tabular}{|l|c|l|c|c|c|}
\hline Nome & Idade (anos) & DUM & PPG $(\mathrm{kg})$ & $\begin{array}{l}\text { Peso } \\
\text { consulta }\end{array}$ & Estatura $(\mathrm{m})$ \\
\hline Lúcia & 23 & $10 / 01 / 2007$ & 58,5 & 60,5 & 1,59 \\
\hline Teresa & 32 & Início janeiro & 72,5 & 74,3 & 1,65 \\
\hline Marta & 16 & desconhecida & desconhecido & 61,4 & 1,60 \\
\hline
\end{tabular}

Como Marta não sabia a data da última menstruação, a enfermeira fez o toque vaginal e depois mediu o fundo do útero; o valor encontrado foi de $17,6 \mathrm{~cm}$.

Considere os dados coletados e faça as atividades a seguir para cada uma das gestantes. 
a) Calcule a idade gestacional.

b) Calcule o IMC.

c) Faça a avaliação nutricional com base no Anexo J - Gráfico para avaliação nutricional de gestante segundo IMC por semana gestacional.

d) Programe o ganho de peso até o final da gravidez.

2. Lúcia, Teresa e Marta tiveram suas consultas remarcadas para dar continuidade ao atendimento pré-natal. Foi observada a seguinte evolução no ganho de peso dessas gestantes:

\begin{tabular}{|l|c|c|}
\hline Nome & $\begin{array}{l}\text { Consulta: 31/05/2007 } \\
\text { Peso }(\mathrm{kg})\end{array}$ & $\begin{array}{l}\text { Consulta: } 11 / 07 / 2007 \\
\text { Peso }(\mathrm{kg})\end{array}$ \\
\hline Lúcia & 64,5 & 67,2 \\
\hline Teresa & 76,5 & 79,6 \\
\hline Marta & 63,0 & Não compareceu \\
\hline
\end{tabular}

A partir desses dados:

a) Faça a avaliação do ganho de peso de cada gestante. Utilizando os Anexos J1, J2 e J3, faça a marcação nos gráficos.

b) Comente os resultados.

Agora vamos rever, passo a passo, como realizar o diagnóstico individual de gestantes?

Os passos são os seguintes:

1. Na primeira consulta de pré-natal (se possível ainda no primeiro trimestre), pesar e medir a gestante com a técnica adequada.

2. Calcular o IMC.

3. Calcular a idade gestacional, fazendo as aproximações necessárias.

4. Consultar a Tabela 2 - Avaliação do estado nutricional da gestante acima de 19 anos segundo IMC por semana gestacional - para fazer a classificação do estado nutricional.

5. Estimar o ganho de peso recomendado até o final da gestação, conforme o Quadro 16 - Ganho de peso recomendado (em kg) na gestação segundo estado nutricional inicial (INSTITUTE OF MEDICINE, 1990; WORLD HEALTH ORGANIZATION, 1995; BRASIL, 2006a). 
6. Nas consultas subseqüentes, avaliar o estado nutricional, recalculando a idade gestacional e o IMC (aferir apenas o peso, sendo necessário repetir a medição da estatura só para as adolescentes).

7. A cada consulta, marcar no Anexo J - Gráfico para avaliação nutricional de gestante segundo IMC por semana gestacional - o ponto de interseção entre a idade gestacional vigente e o IMC, fazendo a classificação nutricional.

8. Unir o ponto marcado a cada consulta ao ponto anterior, traçando a curva da gestante.

9. Fazer as orientações, adequando o valor do ganho de peso estimado para os demais meses de gestação.

10. Identificar as gestantes de risco, fazer o registro na ficha/prontuário e intervir precocemente.

11. Promover ações de saúde e orientação alimentar que favoreçam o ganho de peso adequado.

\section{Adultos}

Os últimos estudos nacionais constataram uma queda significativa na desnutrição em crianças e um aumento dos casos de obesidade, principalmente entre os adultos (20 a 60 anos), em todas as classes econômicas (MONTEIRO, 2000; INSTITUTO BRASILEIRO DE GEOGRAFIA E ESTATÍSTICA, 2006). Esses estudos, como já mencionado em capítulos anteriores, não contemplaram as populações indígenas do país como segmento de análise.

Nas populações indígenas, embora não possamos falar em uma redução consistente das prevalências de desnutrição, é possível constatar que a obesidade vem sendo registrada em números crescentes. Muito embora não constitua um problema generalizado no conjunto dos povos indígenas do país, trata-se de um agravo de grande relevância. Associadas à obesidade, estão outras doenças, tais como hipertensão, diabetes, cardiopatias, conhecidas como doenças crônicas não-transmissíveis, que necessitam de acompanhamento periódico e podem ser fatais. Sabemos que o incremento dessas patologias tem relação direta com o estilo de vida ocidental. Este se traduz, simplificadamente, em mudanças importantes na dieta e nos níveis de atividade física. Essas transformações
O perfil nutricional da população brasileira, as mudanças ocorridas nos últimos anos e seus determinantes, e a descrição dos inquéritos nacionais já realizados no Brasil são discutidos nos Capítulos 4, 7 e 8 do livro Vigilância Alimentar e Nutricional para a Saúde Indígena, volume 1, de Denise Cavalcante Barros, Denise Oliveira e Silva e Silvia Ângela Gugelmin (2007). 
acontecem em direção ao aumento do consumo de alimentos ricos em gorduras e açúcares, e a uma diminuição significativa dos níveis de atividade física.

Mas não é só a obesidade que preocupa; a desnutrição, representada pelo baixo peso e pela anemia, pode alcançar também níveis expressivos. Ela pode estar associada a doenças como tuberculose e malária, responsáveis por altas taxas de mortalidade entre adultos. Essas doenças constituem hoje as principais endemias a atingir os povos indígenas do país (SANTOS; COIMBRA JÚNIOR, 2003). Ambas são causas expressivas de morbidade e mortalidade, e resultam em um impacto significativamente negativo sobre o estado nutricional de indivíduos e populações.

Para o diagnóstico nutricional dos adultos, utilizaremos a recomendação da OMS (WORLD HEALTH ORGANIZATION, 1995, 1997), ou seja, o IMC. Para isso, precisamos conhecer as variáveis peso e estatura do indivíduo.

Para refletir

O que você tem observado quanto ao estado nutricional dos adultos em sua realidade?

Quais são as principais doenças que acometem esse grupo?

O que tem sido realizado para melhorar essa situação?

\section{Diagnóstico nutricional em adultos}

O IMC, também chamado de índice de Quetelet, avalia o estado nutricional de um indivíduo, relacionando o seu peso corporal com a sua altura; o resultado é expresso em quilogramas por metro quadrado:

$$
\mathrm{IMC}=\frac{\text { peso }(\mathrm{kg})}{\text { altura }(\mathrm{m})^{2}}
$$

Por exemplo, Caetano, 37 anos, foi ao posto de saúde, pois estava com uma forte dor nas costas. Uma vez que a equipe de saúde implantou recentemente a vigilância nutricional de adultos, o auxiliar de enfermagem realizou a pesagem e aferiu a altura de Caetano, anotou em sua ficha e providenciou um medicamento para dor. O peso aferido foi $68 \mathrm{~kg}$ e a altura, $1,58 \mathrm{~cm}$. Usando a fórmula, teríamos: 


$$
\mathrm{IMC}=\frac{68 \mathrm{~kg}}{(1,58 \mathrm{~m})^{2}}=\frac{68}{2,50}=27,2 \mathrm{~kg} \cdot \mathrm{m}^{-2}
$$

Para determinar o estado nutricional, precisamos conhecer os valores de uma população normal. No caso do IMC, não dispomos de uma distribuição de valores de IMC para uma população-referência. A OMS (WORLD HEALTH ORGANIZATION, 1997), após estudos em populações sadias, estabeleceu parâmetros, chamados ponto de corte, que são utilizados como limites para classificação do estado nutricional da população adulta.

Sendo assim, consideramos:

Quadro 17 - Pontos de corte do IMC para diagnóstico nutricional de adultos

\begin{tabular}{|l|c|}
\hline \multicolumn{1}{|c|}{ Diagnóstico } & Valores de IMC \\
\hline Baixo peso & $<18,5$ \\
\hline Adequado & $18,5 I-25,0$ \\
\hline Sobrepeso & $\geq 25,0$ \\
\hline Pré-obesidade & $25,0 I-30,0$ \\
\hline Obesidade grau I & $30,0 I-35,0$ \\
\hline Obesidade grau II & $35,0 I-40,0$ \\
\hline Obesidade grau III & $\geq 40,0$ \\
\hline
\end{tabular}

Fonte: World Health Organization (1997).

A OMS considera como sobrepeso toda e qualquer variação com IMC > 25,0. Na categoria sobrepeso estão incluídas tanto a pré-obesidade quanto a obesidade.

Todo indivíduo que estiver com IMC igual ou maior que 25,0 será considerado como sobrepeso. Todo indivíduo que estiver com IMC igual ou maior que 30,0 será considerado como obeso.

Portanto, no exemplo citado, Caetano estaria com sobrepeso, pois seu IMC foi igual a $27,2 \mathrm{~kg} \cdot \mathrm{m}^{-2}$. No entanto, como estamos trabalhando o diagnóstico individual, precisamos estar atentos a algumas questões, como as mencionadas a seguir.

Alguns fatores de risco devem ser considerados na análise do diagnóstico nutricional, tais como: hábito de fumar, tipo da dieta consumida, sedentarismo, história familiar, entre outros. Esses fatores podem afetar negativamente o estado nutricional e de saúde do indivíduo, sendo causas ou
Essa fórmula não permite estabelecer com precisão a proporção de massa gorda e massa magra distribuídas no corpo do indivíduo. Para isso você poderá usar outro índice, como a relação cintura/quadril, já estudada no Capítulo 2, "Antropometria", na Parte I deste livro. 
Atividade física é definida como qualquer movimento corporal, produzido pelos músculos esqueléticos, que resulte em gasto energético maior que os níveis de repouso. Ela pode ser uma atividade do cotidiano - varrer a casa, lavar roupa, andar para o trabalho, cortar lenha, fazer farinha de mandioca, realizar corridas, excursões ao roçado para coletar alimentos, entre outras. agravantes da patologia a que estiverem associados. Por outro lado, não é incomum que, em indivíduos muito ativos fisicamente, os valores de IMC sejam mais elevados pelo aumento da massa muscular, e não por um acúmulo de gordura corporal. Esse tipo de perfil será mais facilmente encontrado entre populações que realizam regularmente atividades de subsistência como caça, pesca, coleta e mesmo a agricultura, que, em geral, exigem muito do físico.

No caso de Caetano, que acabamos de avaliar, é importante procurarmos conhecer outros dados sobre sua vida, para que possamos interpretar melhor seu estado nutricional. Há pelo menos duas possibilidades: Caetano pode ter sobrepeso por aumento da quantidade de gordura corporal - o que é preocupante, porque aumenta a sua chance de desenvolver outras doenças, como a hipertensão arterial e diabetes - ou então porque possui uma atividade física intensa, musculatura mais desenvolvida e, portanto, maior peso corporal. Nesse caso, não aumenta sua chance de ter outras doenças. Na verdade, seus níveis de atividade física o protegem do desenvolvimento de diabetes e doenças cardiovasculares, por exemplo. Reiteramos, assim, que o diagnóstico nutricional deve ser cuidadosamente analisado à luz de dados relativos às condições de vida dos indivíduos avaliados.

Como vimos, o cálculo do IMC é um método extremamente prático e rápido. Além disso, ele possui também outras vantagens:

- o peso e a altura são dados simples de serem obtidos e fazem parte da rotina de atendimentos;

- dispensa comparação com curvas de referência;

- os pontos de corte são aceitos internacionalmente;

- a correlação com a massa corporal e os indicadores de composição corporal é alta;

- há possibilidade de comparações com grupos e indivíduos;

- permite predizer riscos de morbimortalidade.

\section{Riscos de morbimortalidade}

Certas medidas e índices antropométricos, como o perímetro da cintura e o IMC, permitem predizer o risco de morbimortalidade.

O que significa predizer riscos de morbimortalidade? 
Significa que podemos identificar, pela classificação do estado nutricional, o grau de risco do indivíduo para desenvolver doenças ou para morrer. O aumento do risco de co-morbidades está diretamente ligado ao aumento do perímetro da cintura, da razão cintura-quadril e do IMC (FERREIRA; SICHIERI, 2007). Sendo assim, é essencial a classificação dos riscos de co-morbidades e, especialmente, a subdivisão do IMC por categorias de obesidade (graus I, II, III) para o planejamento das ações de intervenção a serem desenvolvidas. Observe o Quadro 18.

Quadro 18 - Risco de co-morbidade segundo classificação de IMC

\begin{tabular}{|c|c|c|c|}
\hline \multicolumn{2}{|c|}{ Classificação } & IMC $\left(\mathrm{kg} \cdot \mathrm{m}^{-2}\right)$ & $\begin{array}{l}\text { Risco de } \\
\text { co-morbidades }\end{array}$ \\
\hline \multicolumn{2}{|l|}{ Baixo peso } & $<18,5$ & Baixo \\
\hline \multicolumn{2}{|c|}{ Normal (Adequado) } & $18,5 \mid-25,0$ & Médio \\
\hline \multirow[t]{4}{*}{ Sobrepeso } & Pré-obesidade & $25,01-30,0$ & Aumentado \\
\hline & Obesidade classe I & $30,01-35,0$ & Moderado \\
\hline & Obesidade classe II & $35,01-40,0$ & Grave \\
\hline & Obesidade classe III (obesidade mórbida) & $\geq 40,0$ & Muito grave \\
\hline
\end{tabular}

Fonte: World Health Organization (1997).

Com essas informações, devemos estabelecer rotinas diferenciadas de atendimento, priorizando atividades/ações a serem desenvolvidas nos serviços de saúde, segundo o estado nutricional do indivíduo.

O baixo peso também pode ser subdividido em classes, principalmente nos casos de maior risco, ou em regiões onde a desnutrição em adultos seja considerada problema de saúde pública. Para uma avaliação mais precisa, a OMS (WORLD HEALTH ORGANIZATION, 1995) recomenda:

Quadro 19 - Pontos de corte do IMC para classificação do baixo peso

\begin{tabular}{|l|c|}
\hline Diagnóstico baixo peso & Valores de IMC \\
\hline Classe I & $18,4-17,0$ \\
\hline Classe II & $16,9-16,0$ \\
\hline Classe III & $<16,0$ \\
\hline
\end{tabular}

Fonte: World Health Organization (1995).

Como já visto, o IMC pode também ser determinado por instrumentos especiais, tais como o Nomograma e o Disco do IMC, práticos e de fácil utilização, fornecendo de imediato o valor do IMC, sem necessitar da realização de cálculos.
Os pontos de corte utilizados como marcadores de risco para o perímetro da cintura e a razão cintura-quadril foram discutidos no Capítulo 2,

"Antropometria", deste livro.
Para relembrar como calcular o IMC pelo Nomograma ou pelo Disco, volte ao item "Gestantes", neste Capítulo. 
Para realizar o diagnóstico nutricional de adultos precisamos:

- Variáveis: peso e estatura

Indicador: IMC

- Referência: não utilizada

- Pontos de corte: 18,5 / 25,0 / 30,0 kg.m²

- Classificação: kg.m²

- Baixo peso: IMC $<18,5 \mathrm{~kg} \cdot \mathrm{m}^{-2}$

- Normal: IMC 18,5 - 24,9 kg.m-2

- Sobrepeso/ pré-obesidade: IMC 25,0/25,0 -29,9 kg.m²

Obesidade: IMC $\geq 30,0 \mathrm{~kg} \cdot \mathrm{m}^{-2}$

Concluindo: fazer um diagnóstico nutricional em adultos implica observar o comportamento do seu ganho de peso em relação à sua altura. Do mesmo modo que em qualquer diagnóstico, reafirmamos que aqui não podemos esquecer três pontos fundamentais:

- os dados obtidos devem ser de extrema confiabilidade;

- o acompanhamento deve ser periódico;

- a intervenção em situações de risco deve ser imediata e coerente.

Dados clínicos e laboratoriais também são importantes e devem, sempre que possível, ser utilizados para complementar o diagnóstico nutricional do adulto.

\section{PARA PRATICAR - DIAGNÓSTICO NUTRICIONAL DE ADULTOS}

Agora que fizemos o diagnóstico nutricional de adultos, vamos realizar algumas atividades para consolidar os conhecimentos.

1. Com base nos dados apresentados a seguir, calcule o IMC e faça o diagnóstico nutricional.

\begin{tabular}{|l|c|c|l|l|}
\hline Nome & Peso $(\mathrm{kg})$ & Altura $(\mathrm{m})$ & IMC & Diagnóstico Nutricional \\
\hline Álvaro & 120,0 & 1,70 & & \\
\hline Andréia & 57,0 & 1,83 & & \\
\hline Antônio & 70,0 & 1,65 & & \\
\hline Cláudia & 46,0 & 1,54 & & \\
\hline Cristiano & 55,5 & 1,49 & & \\
\hline Denise & 76,0 & 1,45 & & \\
\hline
\end{tabular}




\begin{tabular}{|l|c|c|l|l|}
\hline Nome & Peso $(\mathrm{kg})$ & Altura $(\mathrm{m})$ & IMC & Diagnóstico Nutricional \\
\hline José & 120,0 & 1,97 & & \\
\hline Maria & 84,3 & 1,76 & & \\
\hline Pedro & 45,7 & 1,63 & & \\
\hline Sandro & 62,4 & 1,59 & & \\
\hline
\end{tabular}

2. Descreva como tem sido feito o diagnóstico nutricional de adultos em sua realidade.

3. Defina o indicador antropométrico que melhor retrata os possíveis riscos de doenças crônicas não-transmissíveis e explique a relação existente entre o indicador e os riscos.

4. 0 que você tem observado na rotina de seu serviço sobre o IMC como marcador de risco para doenças crônicas não-transmissíveis?

Agora, vamos rever, passo a passo, como realizar o diagnóstico nutricional do adulto?

Os passos são os seguintes:

1. Pesar, a cada consulta; medir a altura na primeira consulta e anualmente.

2. Calcular o IMC usando o Nomograma ou a fórmula.

Classificar o IMC segundo os pontos de corte OMS (veja o Quadro 18 Risco de co-morbidade segundo classificação de IMC).

3. Registrar os dados em fichas ou prontuários próprios do serviço.

4. Manter vigilância especial aos extremos, graus II e III, tanto para obesidade - avaliando os fatores de risco cardiovasculares - quanto para o baixo peso.

5. Promover ações de saúde e educação adequadas a cada caso: promover hábitos de vida saudáveis, controlar doenças associadas, realizar investigação especializada para casos de maior complexidade, encaminhar para tratamento ou realização de exames bioquímicos. 


\section{Idosos}

No Brasil, dados demográficos têm demonstrado que a partir dos anos 1970 a população de pessoas mais velhas vem aumentando lentamente, isto é, a população brasileira aos poucos está envelhecendo. Isso tem ocorrido por várias razões, dentre as quais podemos destacar a diminuição das taxas de mortalidade infantil e de fecundidade, e o aumento da expectativa de vida, características compatíveis com as dos países desenvolvidos.

Entre os povos indígenas, a despeito da escassez de estudos demográficos, existe uma tendência semelhante, de envelhecimento da população. A análise dos dados relativos aos indivíduos auto-declarados indígenas nos censos demográficos de 1991 e 2000 aponta para um aumento consistente da população idosa (com 65 anos ou mais), embora o grau de aumento varie significativamente de uma região para outra. De modo geral, o envelhecimento tem ocorrido principalmente nas populações urbanas, estando associado aos mesmos determinantes observados entre não-indígenas - a redução da fecundidade e da mortalidade infantil. Isso significa que nas populações rurais - correspondendo de modo geral às populações aldeadas - o grau de envelhecimento foi menor. Também não parece ter havido uma redução da fecundidade nessas populações, além do que há poucos dados para justificar a afirmação de que reduziu-se a mortalidade infantil (INSTITUTO BRASILEIRO DE GEOGRAFIA E ESTATÍSTICA, 2005).

De todo modo, é importante considerar que doenças pouco expressivas no passado estão se tornando cada vez mais prevalentes, em especial as crônicas não-transmissíveis (hipertensão, diabetes, câncer etc.). Essas doenças podem ser responsáveis por limitações em seus portadores, prejudicando atividades importantes da vida cotidiana, como o trabalho, o lazer e até mesmo aquelas mais simples como caminhar, vestir-se e alimentar-se. Além disso, o caráter crônico dessas doenças confere ao seu acompanhamento e tratamento maior complexidade, por exigir cuidados permanentes tanto por parte dos indivíduos como por parte dos serviços de saúde.

Uma pessoa que apresenta uma doença crônica não-transmissível normalmente tem alguma outra patologia a ela associada, podendo uma ser a causa ou a conseqüência da outra. É muito comum encontrar a obesidade associada à hipertensão e/ou à diabetes; o baixo peso à tuberculose, entre outras relações. 
A incidência de doenças crônicas é alta nos indivíduos idosos e o risco de desenvolvê-las ou de torná-las mais graves, levando a incapacidades, deve ser identificado precocemente. Isso é possível a partir da avaliação adequada do estado nutricional, que deve considerar as especificidades de cada indivíduo idoso, uma vez que estes são parte de um grupo bastante heterogêneo.

A determinação do diagnóstico nutricional e a identificação dos fatores que contribuem para tal diagnóstico no indivíduo idoso são, portanto, processos fundamentais, mas complexos. A complexidade se deve à ocorrência de diversas alterações, tanto fisiológicas quanto patológicas, além de modificações de aspectos econômicos e de estilo de vida, entre outros, com o avançar da idade.

Assim como para as demais fases do curso de vida, a antropometria é o método mais utilizado para fazer o diagnóstico nutricional da população idosa, mesmo em situações de incapacidade física ou de locomoção. Essa parcela da população é extremamente vulnerável e possui características próprias que precisam ser levadas em consideração na avaliação nutricional.

\section{Peso corporal}

À medida que a idade avança (principalmente após os 70 anos), a tendência natural, fisiológica, é que o peso diminua, variando entre os sexos. E o que explica essa situação? Os dois fatores que mais contribuem para essa redução são: diminuição do conteúdo da água corporal e da massa muscular, sendo esta última mais expressiva entre os homens.

Quando não é possível a aferição dessa medida, por falta de equipamentos ou por dificuldade de o idoso manter-se de pé, o peso corporal pode ser estimado com o uso de equações. No entanto, deve-se considerar que a estimação do peso apresenta elevada margem de erro, além de necessitar de várias medidas corporais, como perímetros da panturilha e do braço, comprimento da perna e dobra cutânea subescapular.

O peso é uma medida que deve ser avaliada com freqüência, pois, para idosos, perdas ponderais graves, recentes e involuntárias, associam-se com aumento da taxa de morbidade e mortalidade. A variação de peso é determinada pela seguinte fórmula:

$$
\text { Perda de peso }(\%)=\frac{(\text { Peso habitual }- \text { Peso atual }) \times 100}{\text { Peso habitual }}
$$

O setor de saúde deve estar atento e preparado para atender toda e qualquer demanda derivada da realidade atual, e acompanhar com cuidado a saúde e a nutrição dos idosos.

A avaliação nutricional em situações específicas, como pessoas acamadas ou que não andam, é analisada no Capítulo 2, "Antropometria", deste livro. 
Qualquer porcentagem de perda ponderal é considerada clinicamente importante nesse grupo etário.

Perdas muito rápidas: possibilidade de presença de patologias adjacentes e associação com aumento da mortalidade.
A perda habitual de $5 \%$ do peso corporal em um mês, para idosos, é considerada clinicamente significativa, e causas nutricionais e não nutricionais devem ser investigadas. O Quadro 20 apresenta a relação de perda de peso e o tempo como demonstrativo da gravidade.

Quadro 20 - Perda de peso por período tempo

\begin{tabular}{|l|c|c|}
\hline Tempo & Perda significativa de peso & Perda grave de peso \\
\hline 1 semana & 1 a $2 \%$ & $>2 \%$ \\
\hline 1 mês & $5 \%$ & $>5 \%$ \\
\hline 3 meses & $7,5 \%$ & $>7,5 \%$ \\
\hline$\geq 6$ meses & $10 \%$ & $>10 \%$ \\
\hline
\end{tabular}

Fonte: Blackburn e Bistrain (1977).

\section{Estatura}

Observa-se redução na estatura com o aumento da idade. Esse processo inicia-se, em geral, por volta dos 40 anos, acentuando-se com o avançar da idade. Isso se deve à compressão vertebral, à redução dos discos intervertebrais, à perda do tônus muscular e às alterações na postura e/ou achatamento do arco plantar. Desse modo, é recomendada a avaliação periódica da estatura em maiores de 60 anos, visando minimizar o erro relacionado a essas variações.

Figura 8 - Representação de alterações estruturais e posturais na estatura, conforme o processo de envelhecimento

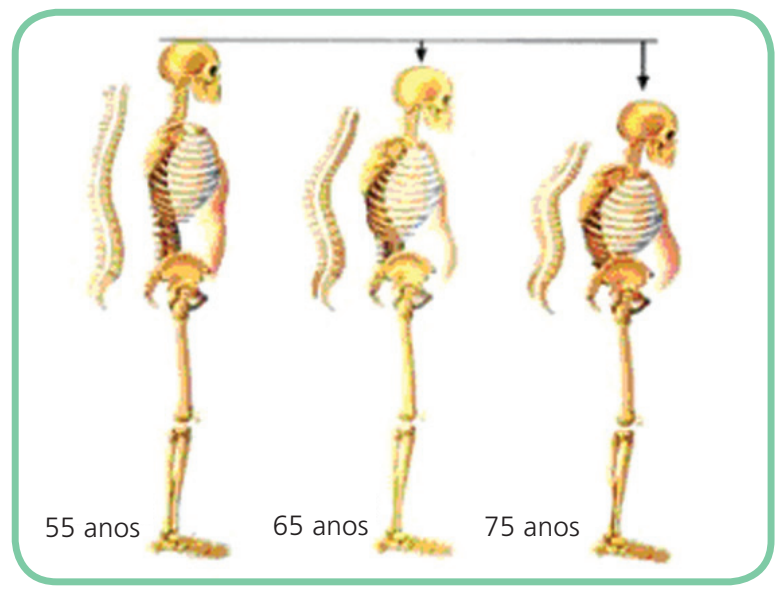

Fonte: Engstrom et al (2002).

A estatura também pode ser estimada a partir do comprimento da perna e sua associação a outras medidas (CHUMLEA et al., 1988). Essa medida é considerada mais vantajosa do que a envergadura do braço, uma vez que nessa última medida pode haver dificuldade na aferição em função da rigidez nas articulações, freqüentemente observada nesse grupo 
etário. Além disso, o comprimento da perna muda pouco com a idade e apresenta alta correlação com a estatura, possibilitando uma boa estimativa do peso corporal.

Então, como devemos fazer o diagnóstico nutricional dos idosos?

O índice mais utilizado para avaliação nutricional de idosos é o IMC, e sua aplicação acontece da mesma forma como nos adultos, diferindo apenas nos pontos de corte (veja o Quadro 21). Essa diferença se deve às alterações fisiológicas observadas nesta faixa etária.

Na determinação do IMC, devemos levar em consideração a tendência de diminuição do peso e da estatura com o avanço da idade. Isto é, o IMC diminui com o avanço da idade, mais especificamente após os 70 a 75 anos, em ambos os sexos. Cada caso deve ser analisado individualmente, pois a história de cada indivíduo traz informações distintas e que podem esclarecer o diagnóstico.

Quadro 21 - Pontos de corte para o IMC para diagnóstico nutricional de idosos

\begin{tabular}{|c|l|}
\hline Valores de IMC & Diagnóstico nutricional \\
\hline$<22,0$ & Baixo peso \\
\hline $22,01-27,0$ & Adequado ou eutrófico \\
\hline$\geq 27,0$ & Sobrepeso \\
\hline
\end{tabular}

Fonte: Adaptado de Lipschitz (1994).

Apesar de não haver consenso sobre os pontos de corte a serem adotados para o diagnóstico nutricional de idosos, o Ministério da Saúde (BRASIL, 2008) adotou os critérios sugeridos por Lipschitz (1994).

\section{Dobras e perímetros}

A estimativa de massa muscular também deve ser utilizada para avaliar o estado nutricional dos idosos. A medida mais indicada é o perímetro da panturrilha, pois é nessa região que se reflete com mais sensibilidade qualquer alteração muscular.

Quanto ao tecido adiposo, devido à redução do tecido muscular e da água corporal no envelhecimento, ocorre uma perda da elasticidade e da compressibilidade dos tecidos, dificultando a medição das dobras cutâneas. Além disso, há uma redistribuição da gordura corporal, com maior acúmulo na região intra-abdominal, diminuindo ainda mais a correlação das dobras cutâneas com o tecido adiposo visceral. 
As técnicas e os procedimentos para a tomada de medidas antropométricas complementares foram descritas no

Capítulo 2, "Antropometria".

\section{Outras medidas}

A avaliação antropométrica na população idosa não constitui uma tarefa simples, devido às mudanças na estrutura óssea, características da própria idade, bem como possíveis restrições físicas. Por isso, o uso de outras medidas, tais como a altura do joelho, comprimento da perna e envergadura, é útil para resolver essas limitações e realizar a avaliação desse grupo etário.

Dados clínicos e laboratoriais também são importantes e devem, sempre que possível, ser utilizados para complementar o diagnóstico nutricional do idoso.

\section{PARA PRATICAR - DIAGNÓSTICO NUTRICIONAL DE IDOSOS}

Agora, que tal sistematizar os conhecimentos acerca do diagnóstico nutricional de idosos, refletindo sobre as indagações propostas a seguir?

1. 0 que você tem observado em sua realidade a respeito do estado nutricional da população idosa?

2. O contexto epidemiológico e social dos idosos descrito neste Capítulo faz parte de seu cotidiano? Faça seu relato.

3. Quais são as facilidades e os obstáculos encontrados em sua rotina para a realização do diagnóstico nutricional de idosos?

\section{Referências}

ANJOS, L. A. et al. Distribuição dos valores do índice de massa corporal da população brasileira até 25 anos. Revista Panamericana de Salud Pública/Pan American Journal of Public Health, v. 3, n. 3, p. 164-173, 1998.

ATALAH, E.; CASTILLO, C.; CASTRO, R. Propuesta de un nuevo estándar de evaluación nutricional en embarazadas. Revista Médica de Chile, v. 125, n. 12, p. 1429-1436, 1997.

AZEVEDO, E. Censos demográficos e os "'índios": dificuldades para reconhecer e contar. In: RICARDO, C. A. (Org.). Povos indígenas no Brasil, 1996-2000. São Paulo: ISA, 2000. p. 79-83.

BARROS, D.C. (Org.). Sisvan: instrumento para o combate aos distúrbios nutricionais na atenção à saúde: a antropometria. Rio de Janeiro: SDE/ENSP/Fiocruz, 2005. 
(Org.); SILVA, D. O. e (Org.); GUGELMIN, S. Â. (Org.). Vigilância alimentar e nutricional para a saúde indígena, 1. Rio de Janeiro: Fiocruz/ENSP/Educação a Distância, 2007.

BLACKBURN, G. L.; BISTRAIN, B. R. Nutritional and metabolic assessment of the hospitalized patient. Journal of Parenteral and Enteral Nutrition, v. 1, n. 1, p. 11-22, 1977.

BRASIL. Ministério da Saúde. Atendimento pré-natal: manual técnico. Brasília, 2000a.

Normas de atenção à saúde integral do adolescente, v. I. Brasília, 1993.

Secretaria de Assistência a Saúde. Gestação de alto risco. Brasília, 1995.

e manuais técnicos).

Glossário temático: alimentação e nutrição. Brasilia, 2007a. (Série A Normas

Saúde integral de adolescentes e jovens: orientações para a organização de serviços de saúde. Brasília, 2005a.

. Coordenação Geral de Políticas de Alimentação e Nutrição. Vigilância alimentar e nutricional - Sisvan: orientações básicas para a coleta, o processamento, a análise de dados e a informação em serviços de saúde. Brasília, 2004a. (Série A Normas e manuais técnicos)

Vigilância alimentar e nutricional - Sisvan: orientações para a coleta e análise de dados antropométricos em serviços de saúde. Brasília, 2008. Norma técnica - Sisvan. Material preliminar. Disponível em: <dtr2004.saude.gov.br/nutrição/documentos/sisvan_norma_ tecnica_preliminar_criancas.pdf> Acesso em: 28 fev. 2008.

Departamento de Ações Programáticas Estratégicas. Agenda de compromissos para a saúde integral da criança e redução da mortalidade infantil. Brasília, 2004b.

. Caderneta de saúde da criança. Brasília, 2007b.

Manual para utilização da caderneta de saúde da criança. Brasília, 2005b.

Secretaria de Políticas de Saúde. Departamento de Atenção Básica. Manual técnico de atenção ao pré-natal e puerpério. Brasília, 2006a.

Saúde da criança: acompanhamento do crescimento e desenvolvimento infantil. Brasília, 2002. (Série Cadernos de Atenção Básica, n.11).

Secretaria de Assistência à Saúde. A saúde de adolescentes e jovens: uma metodologia de auto-aprendizagem para equipes de atenção básica de saúde, módulo I. Brasília, 2000b.

BUSS, P. M. Promoção da saúde e a saúde pública: contribuição para o debate entre as escolas de Saúde Públicas da América Latina. Rio de Janeiro: ENSP/Fiocruz, 1998. 
CHUMLEA, W. C. et al. Prediction of body weight for nonambulatory elderly from anthropometry. Journal of the American Dietetic Association, v. 88, n. 5, p. 564-568, 1988.

COIMBRA JÚNIOR, C. E. A.; GARNELO, L. Questões de saúde reprodutiva da mulher indígena no Brasil. In: MONTEIRO, S. (Org.); SANSONE, L. (Org.). Etnicidade na América Latina: um debate sobre raça, saúde e direitos reprodutivos. Rio de Janeiro: Ed. Fiocruz, 2004. p. 153-173.

COLE, T. J. et al. Establishing a standard definition for child overweight and obesity worldwide: international survey. British Medical Journal, v. 320, p. 1-6, 2000.

; FREEMAN, J. V.; PREECE, M. A. Body mass index reference curves for the UK, 1990. Archives of Disease in Childhood, v. 73, p. 25-29, 1995.

DE ONIS, M. et al. Development of a WHO growth reference for school-aged children and adolescents. Bulletin of the World Health Organization, v. 85, p. 660-667, 2007.

ENGSTROM, E. M. (Org.) Sisvan: instrumento para o combate aos distúrbios nutricionais em serviços de saúde: o diagnóstico nutricional. Rio de Janeiro: CECAN/ENSP/Fiocruz, 2002.

FERREIRA, M. G.; SICHIERI, R. Antropometria como método de avaliação do estado de nutrição e saúde do adulto. In: KAC, G.; SICHIERI, R.; GIGANTE, D. P. Epidemiologia nutricional. Rio de Janeiro: Fiocruz; São Paulo: Atheneu, 2007. p. 93-104.

FESCINA, R. H. Aumento de peso durante el embarazo: metodo para su calculo cuando se desconece el peso habitual. Boletim de la Oficina Sanitaria Pan-Americana, Washington, DC, v. 95, n. 2, p. $156-162,1983$.

FONSECA, V. M.; SICHIERI, R.; VEIGA, G. V. Fatores associados à obesidade em adolescentes. Revista de Saúde Pública, São Paulo, v. 32, n. 6, p. 541-549, 1998.

FUNDAÇÃO NACIONAL DE SAÚDE. Boletim Informativo, Brasília, n. 1, 2006.

GARNELO, L.; MACEDO, G.; BRANDÃO, L.C. Os povos indígenas e a construção das políticas de saúde no Brasil. Brasília: Organização Pan-Americana da Saúde, 2003.

GUTIERREZ, Y.; KING, J. C. Nutrition during teenage pregnancy. Pediatrics Annals, Boston, v. 22, n. 2, p. 99-108, 1992.

INSTITUTE OF MEDICINE (Estados Unidos). Committee on Nutritional Status During Pregnancy and Lactation. Nutrition during pregnancy. Washington, DC: National Academy Press, 1990.

INSTITUTO BRASILEIRO DE GEOGRAFIA E ESTATÍSTICA. Pesquisa de orçamentos familiares 2002/2003: antropometria e análise do estado nutricional de crianças e adolescentes no Brasil. Rio de Janeiro, 2006.

Tendências demográficas: uma análise dos indígenas com base nos resultados da amostra dos Censos Demográficos 1991 e 2000. Rio de Janeiro, 2005. 144 p. (Relatórios metodológicos, v. 16). 
JELLIFFE, D. B. Evoluación del estado de nutrición de la comunidad. Genebra: WHO, 1968.

KUCZMARSKI, R. J. et al. 2000 CDC growth charts for the United States: methods and development. Hyattsville: National Center for Health Statistics, 2002. (Vital and health statistics, v. 11. Data from the National Health Survey, n. 246).

LEITE, M.S. et al. Alimentação e nutrição dos povos indígenas no Brasil. In: KAC, G.; SICHIERI, R.; GIGANTE, D. P. Epidemiologia nutricional. Rio de Janeiro: Fiocruz; São Paulo: Atheneu, 2007. p. 503-517.

LIPSCHITZ, D. A. Screening for nutritional status in the elderly. Primary Care, Philadelphia, v. 21, n. 1, p. 55-67, 1994

MAGALHÃES, V. C.; MENDONÇA, G. A. S. Prevalência e fatores associados a sobrepeso e obesidade em adolescentes de 15 a 19 anos das regiões Nordeste e Sudeste do Brasil, 1996 a 1997. Cadernos de Saúde Pública, Rio de Janeiro, v. 19, p. S129-S139, 2003. Suplemento 1.

MONTEIRO, C. A. Velhos e novos males da saúde no Brasil: a evolução do país e de suas doenças. 2 ed. São Paulo: Hucitec; Nupens; USP, 2000.

MUST, A.; DALLAL, G. E.; DIETZ, W. H. Reference data for obesity: 85th and 95th percentiles of body mass index (wt/ht2) and triceps skinfold thickness. American Journal of Clinical Nutrition, v. 53, p. 839-846, 1991.

NATIONAL CENTER FOR HEALTH STATISTICS. NCHS growth curves for children, birth-18 years. Hyattsville: US Department of Health, Education and Welfare, Public Health Service, 1977. (Vital and health statistics series 11, n 165. Departament of Health, Education and Welfare publication n. (PHS) 78-1650).

OLIVEIRA, M. V. G.; ESCOBAR, A. L.; COIMBRA JÚNIOR, C. E. A. Avaliação do pré-natal em mulheres indígenas Suruí, Rondônia. Pesquisa \& Criação, Porto Velho, n. 4, p. 380-384, 2005.

ROSSO, P. A new chart to monitor weight gain during pregnancy. American Journal of Clinical Nutrition, n. 41, p. 644-652, 1985.

SANTOS, R. V.; COIMBRA JÚNIOR, C. E. A. Cenários e tendências da saúde e da epidemiologia dos povos indígenas no Brasil. In: COIMBRA JÚNIOR, C. E. A. (Org.); SANTOS, R. V. (Org.); ESCOBAR, A L. (Org.). Epidemiologia e saúde dos povos indígenas no Brasil. Rio de Janeiro: Ed. Fiocruz; Abrasco, 2003. p. 13-47.

SAUNDERS, C.; BESSA, T.C.A.A. A assitência nutricional pré-natal. In: ACCIOLY, E.; SAUNDERS, C.; LACERDA, E. Nutrição em obstetrícia e pediatria. Rio de Janeiro: Cultura Médica, 2002. p. 119-144.

SOARES, N. T. Um novo referencial antropométrico de crescimento: significados e implicações. Revista de Nutrição, Campinas, v. 16, n. 1, p. 93-104, 2003.

SOUZA, L. G.; SANTOS, R. V. Perfil demográfico da população indígena Xavante de SangradouroVolta Grande, Mato Grosso (1993-1997), Brasil. Cadernos de Saúde Pública, Rio de Janeiro, v. 17 n. 2, p. 355-365, 2001. 
TANNER, J. M. Foetus intro Man: physical growth from conception to maturity. 2nd. ed. London: Castlenuad Publications, 1989.

VASCONCELOS, F. A. G. Avaliação nutricional de coletividades. 4. ed. Florianópolis: Ed. da UFSC, 2007.

WANG, Y.; MONTEIRO, C.; POPKIN, B. M.. Trends of obesity and underweight in older children and adolescents in the United States, Brazil, China, and Russia. American Journal of Clinical Nutrition, n. 75, p. 971-977, 2002.

WORLD HEALTH ORGANIZATION. WHO reference 2007: growth reference data for 5-19 years. Geneve, 2007. Disponível em: < http://www.who.int/growthref/en>. Acesso em: 04 jan 2008.

Obesity: preventing and managing the global epidemic. Geneva, 1997.

Physical status: the use and interpretation of anthropometric indicators of nutritional status. Geneva, 1995. (WHO technical report series, 854).

WHO child growth standards: methods and development. Geneva, 2006. 336 p. Disponível em: <http://www.who.int/childgrowth/standards/en/>. Acesso em: 04 jun. 2007. 


\section{Anexos}

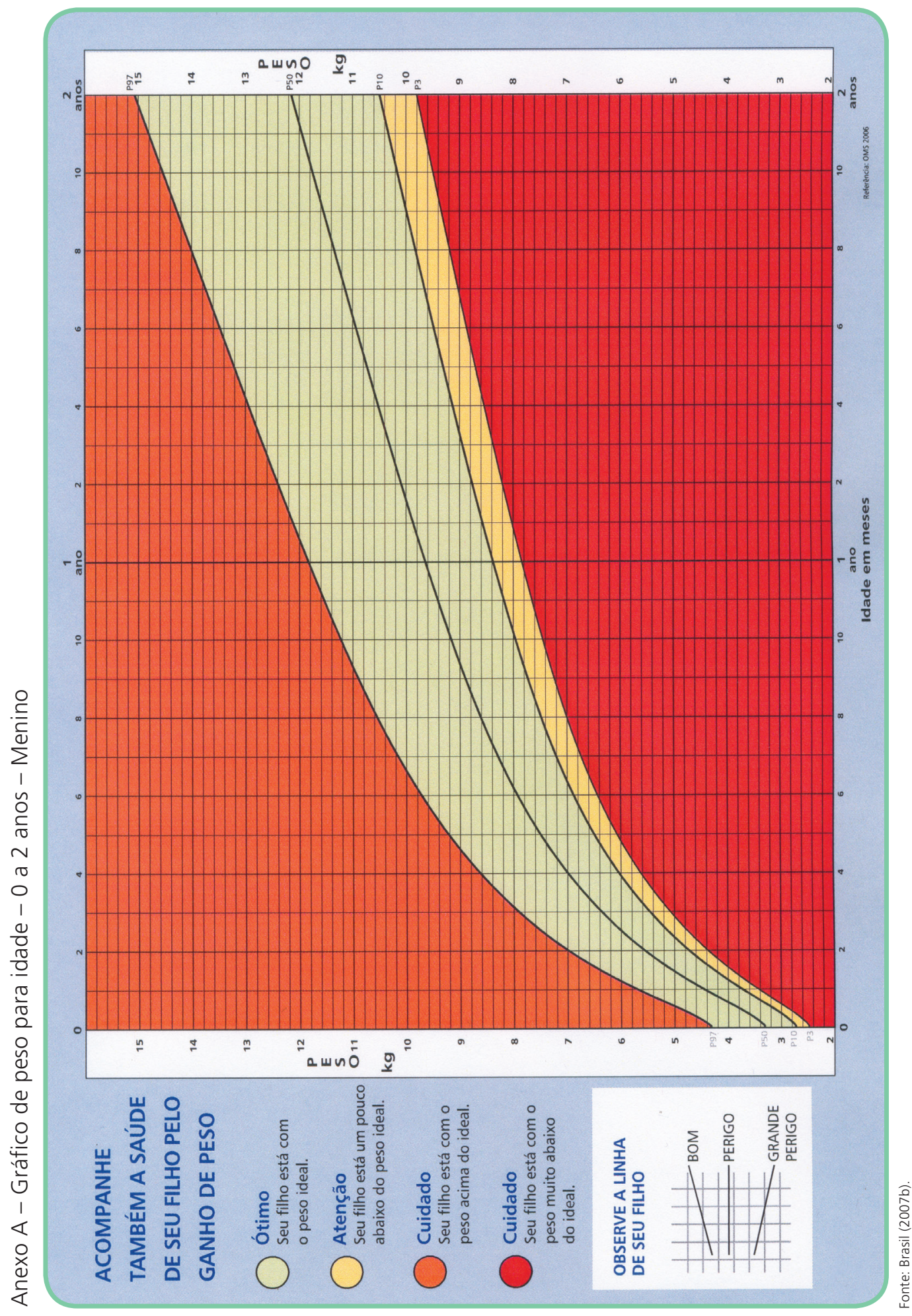




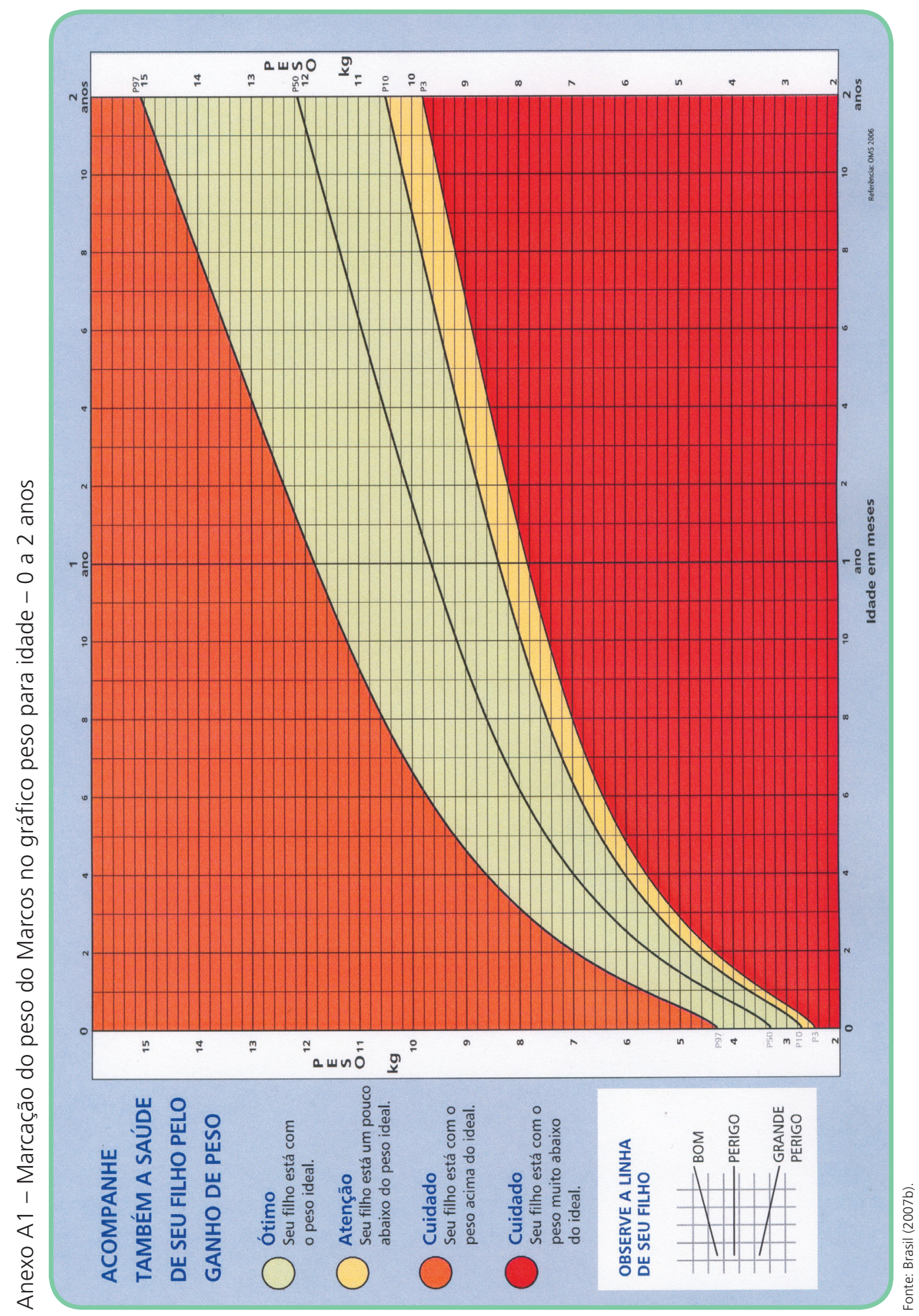




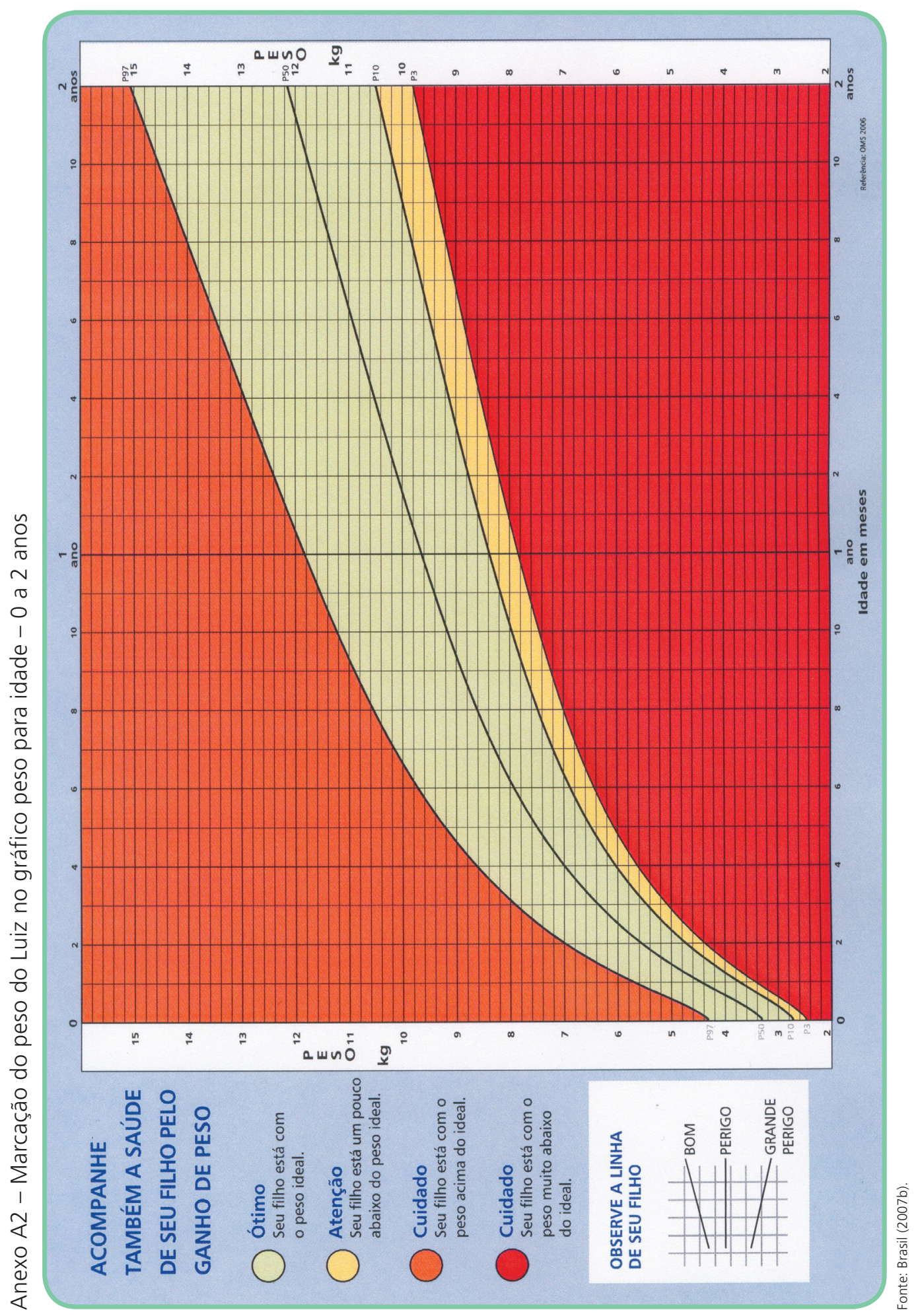




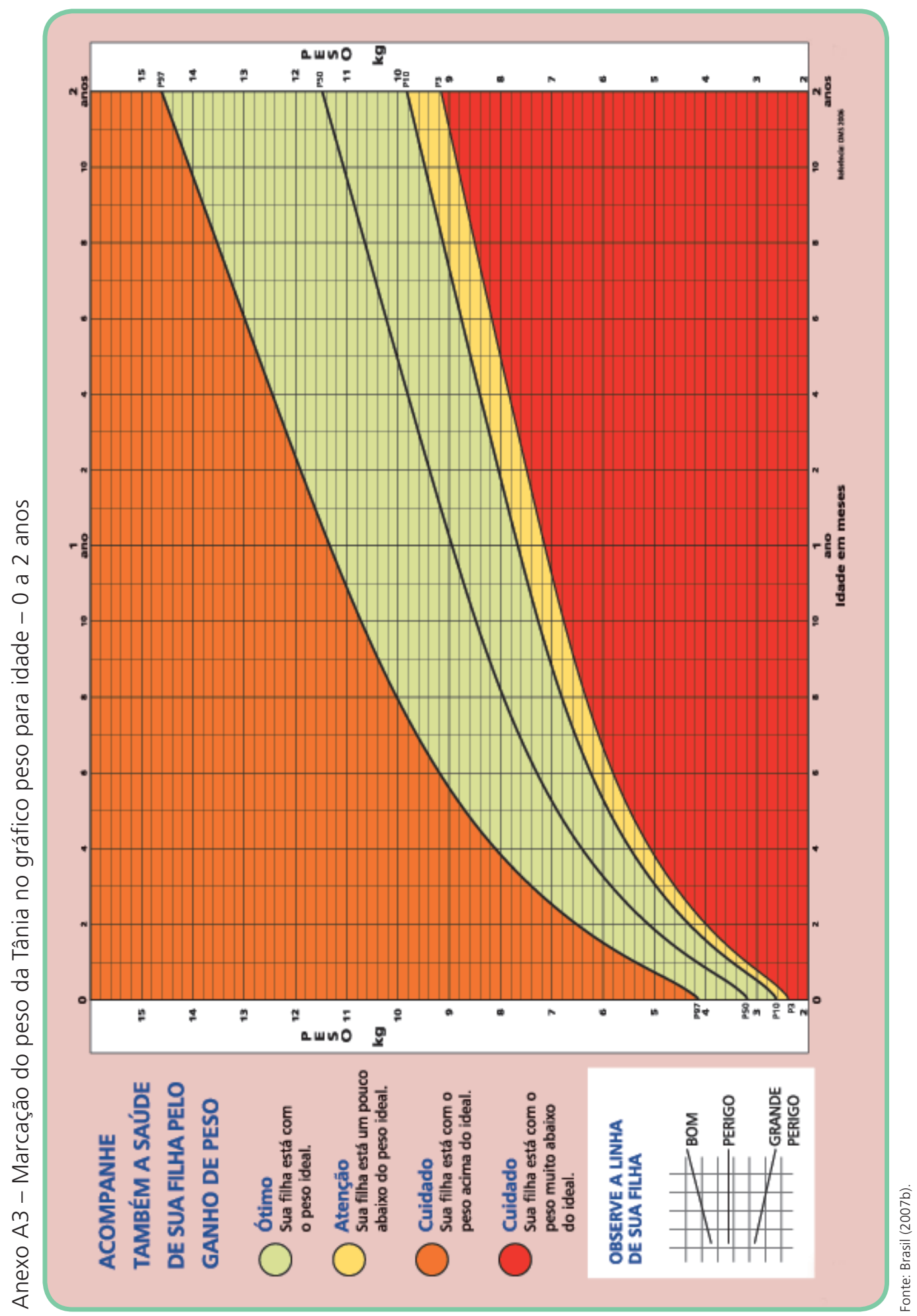




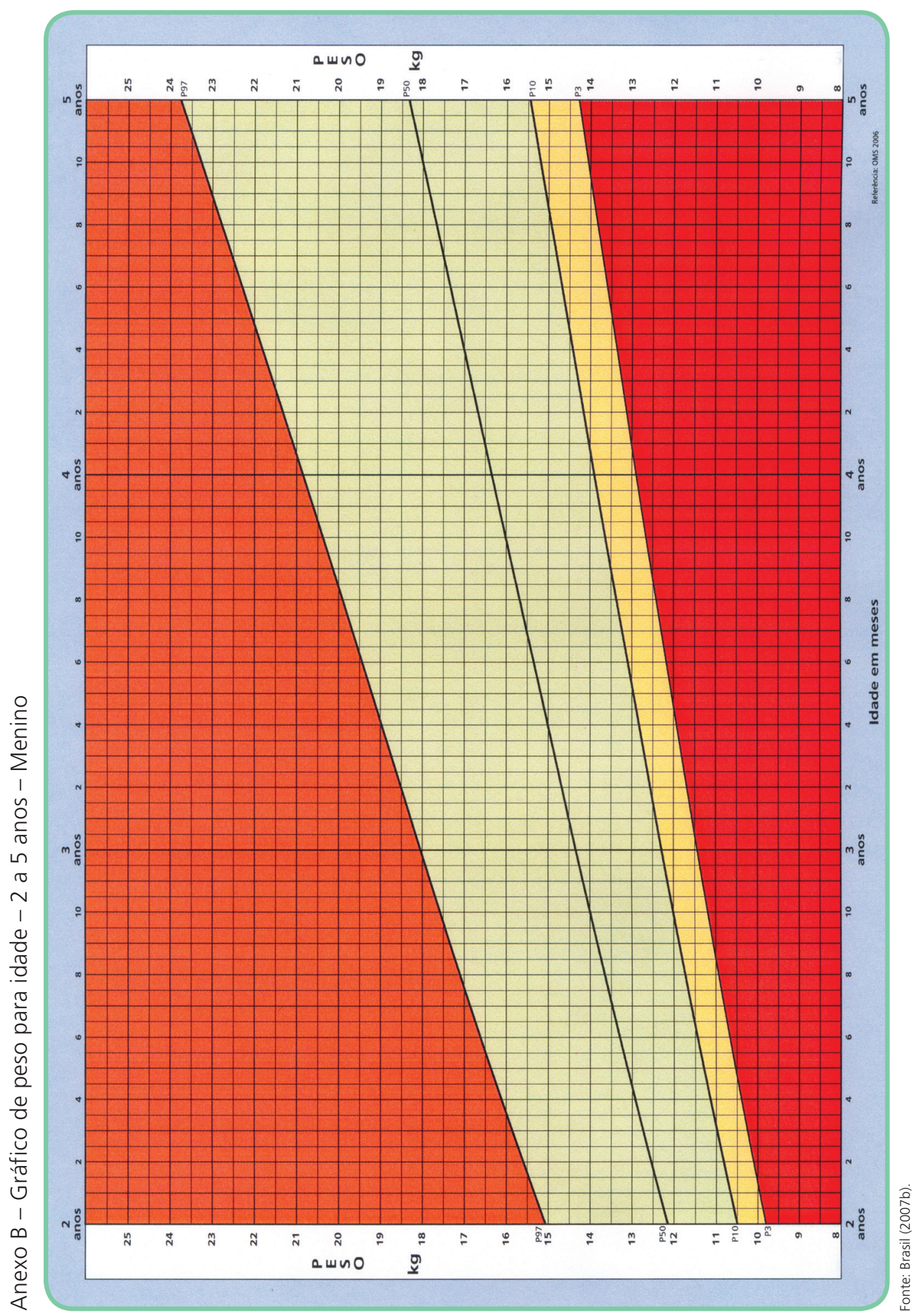




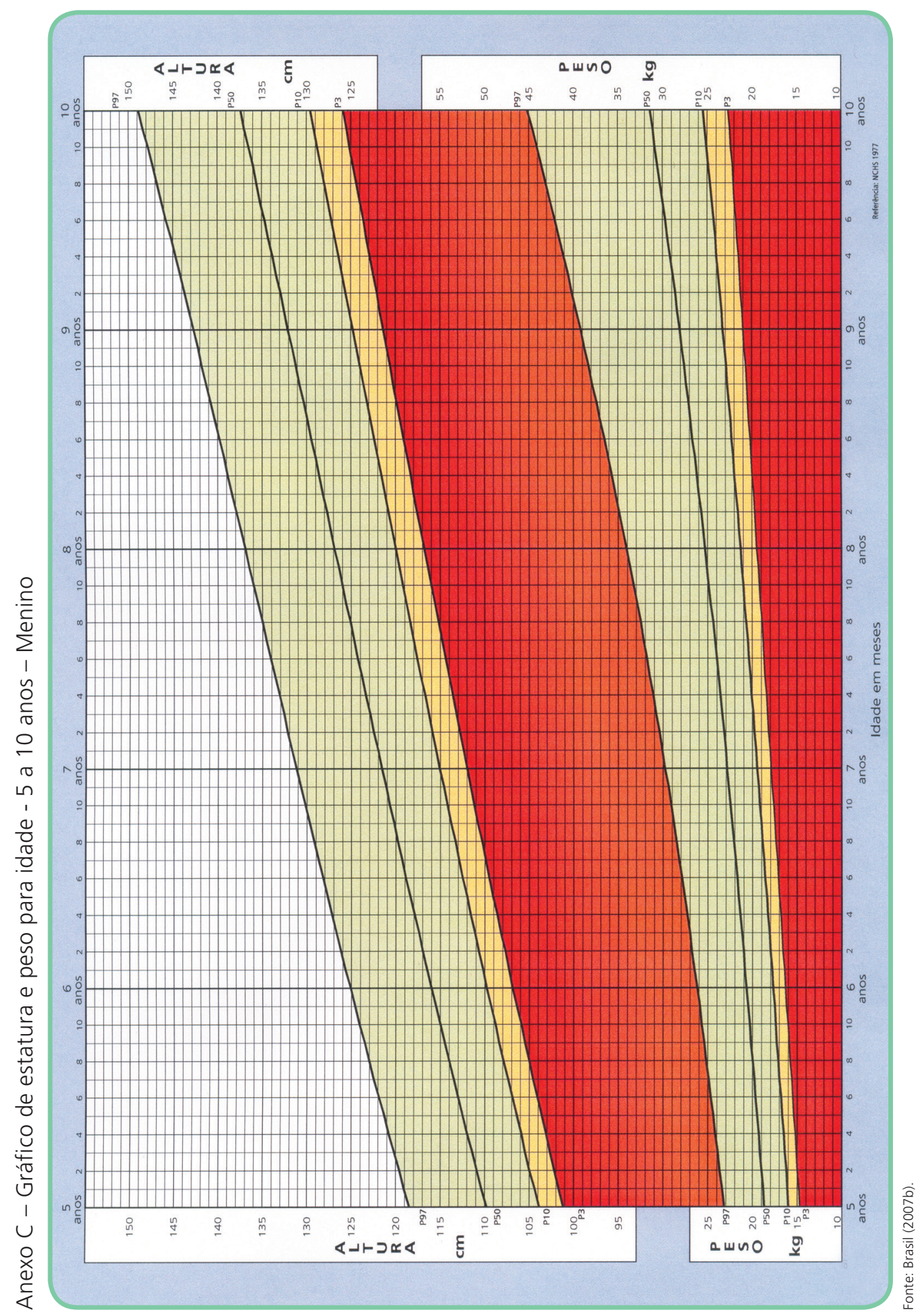




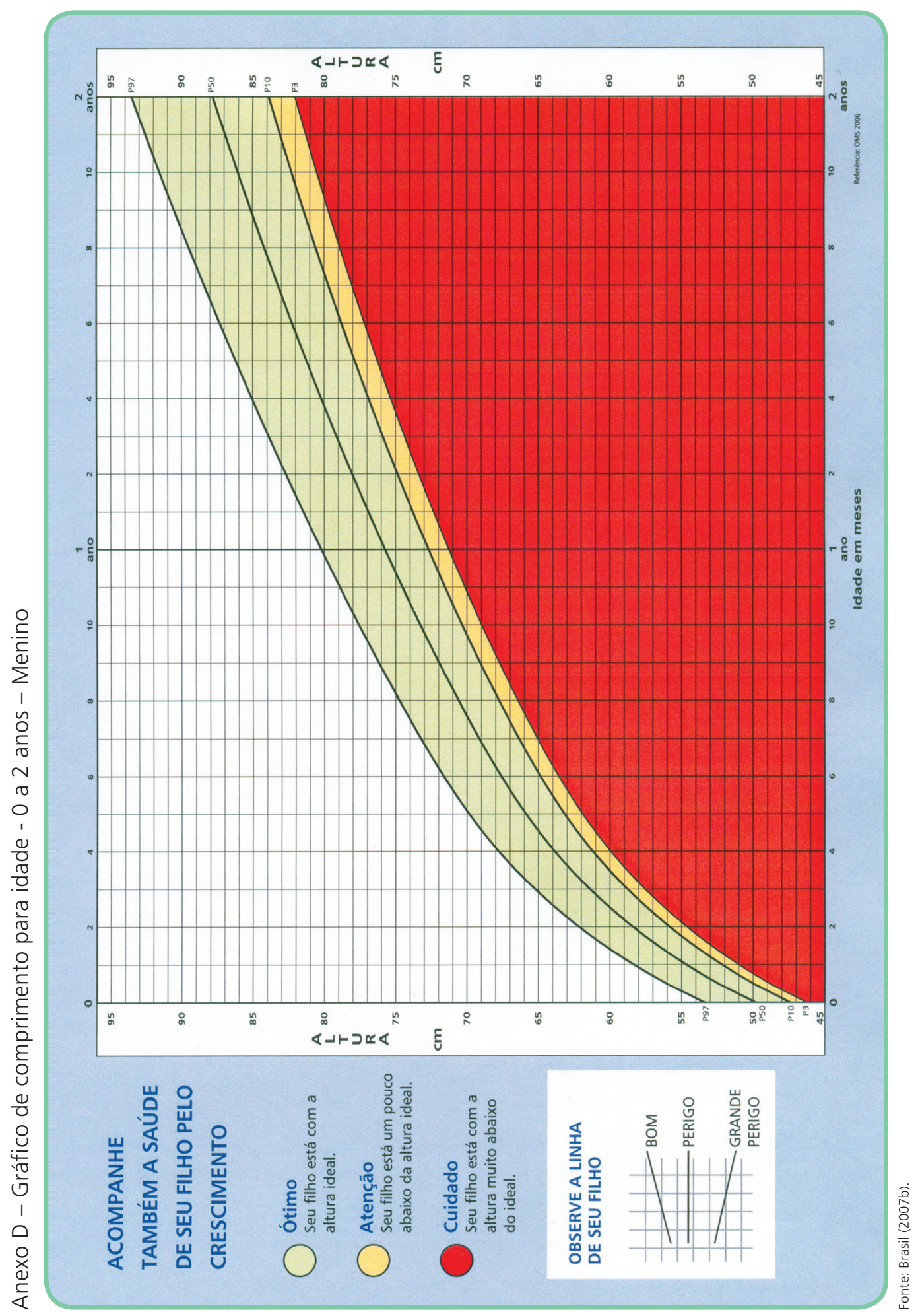




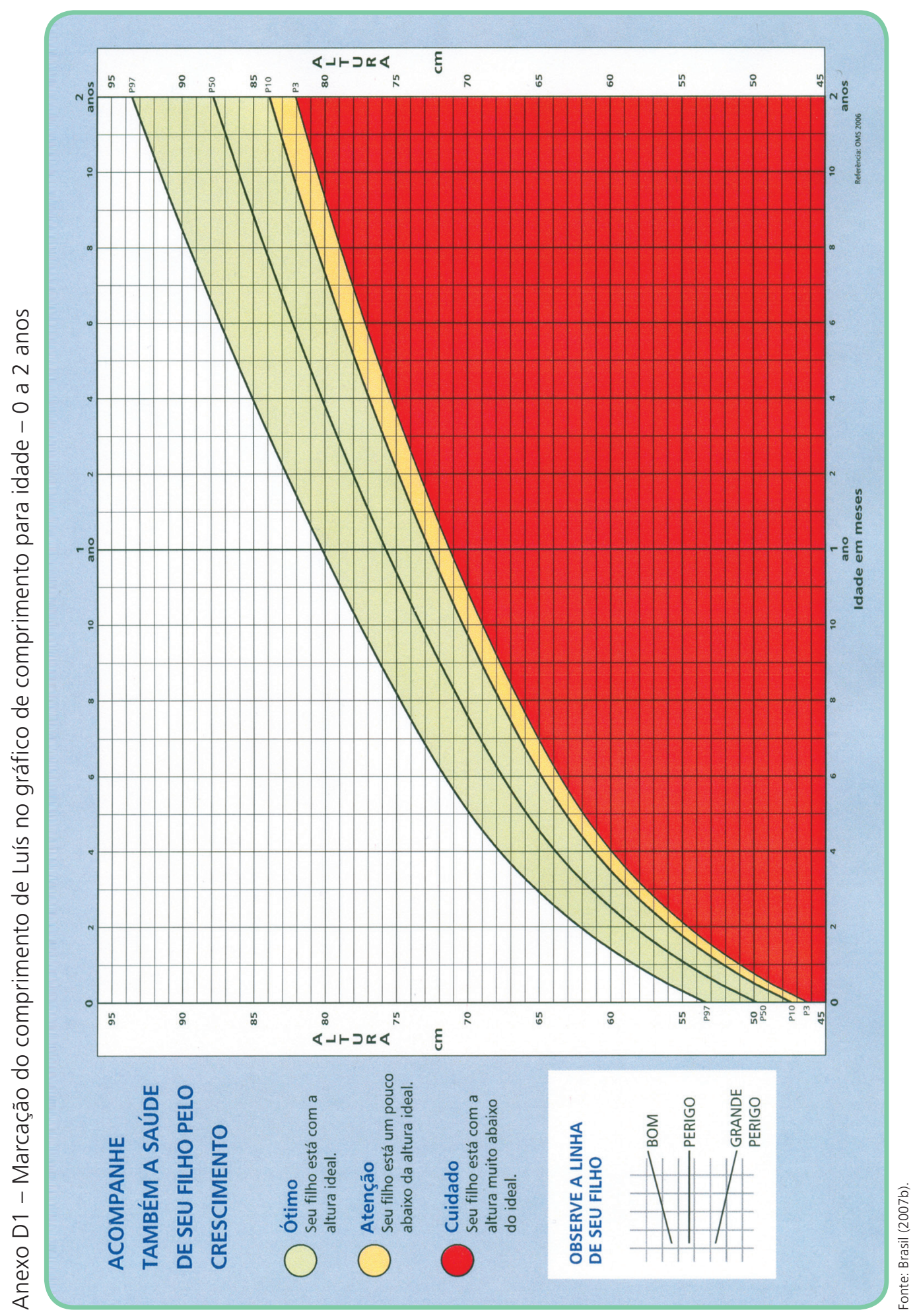




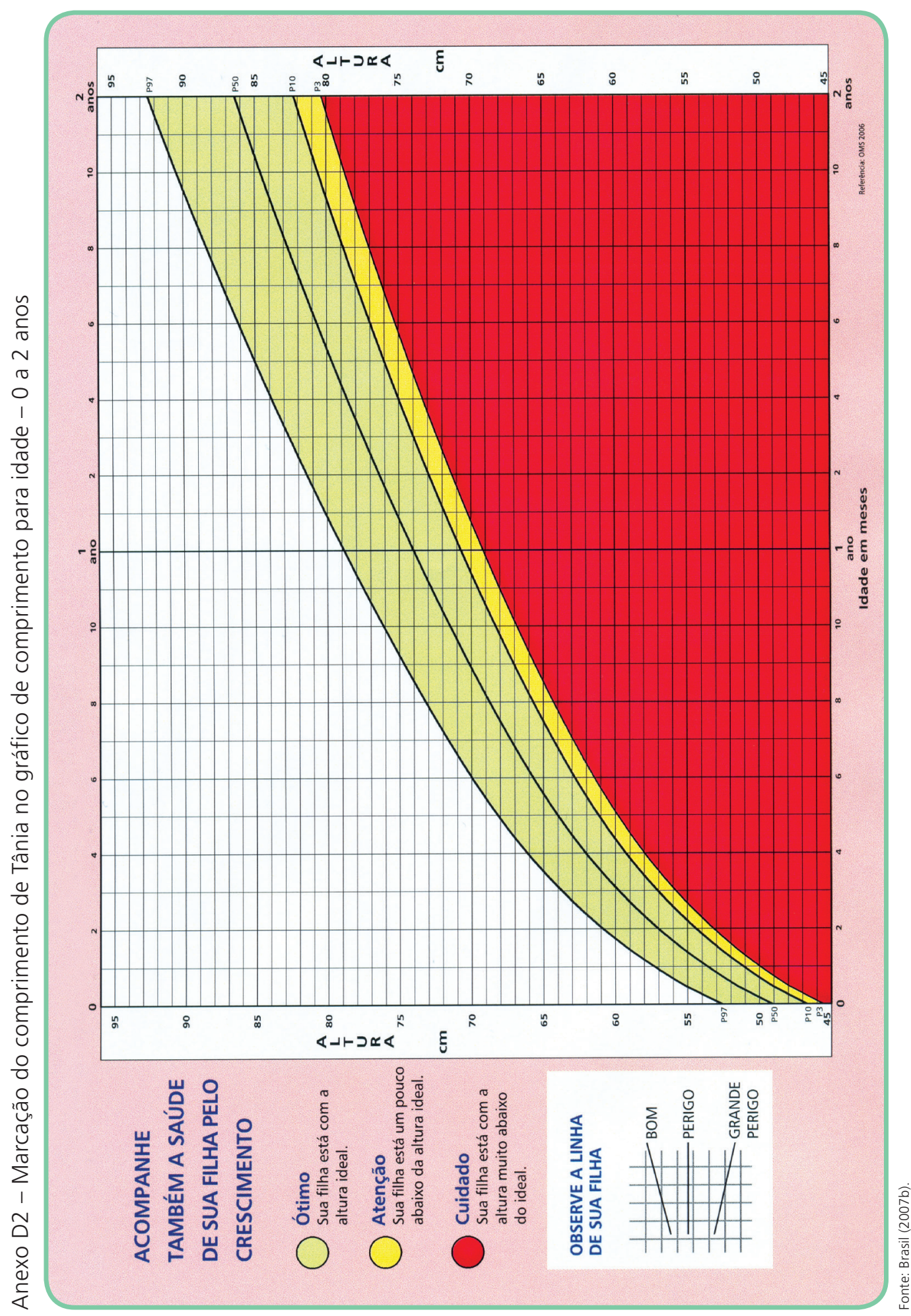




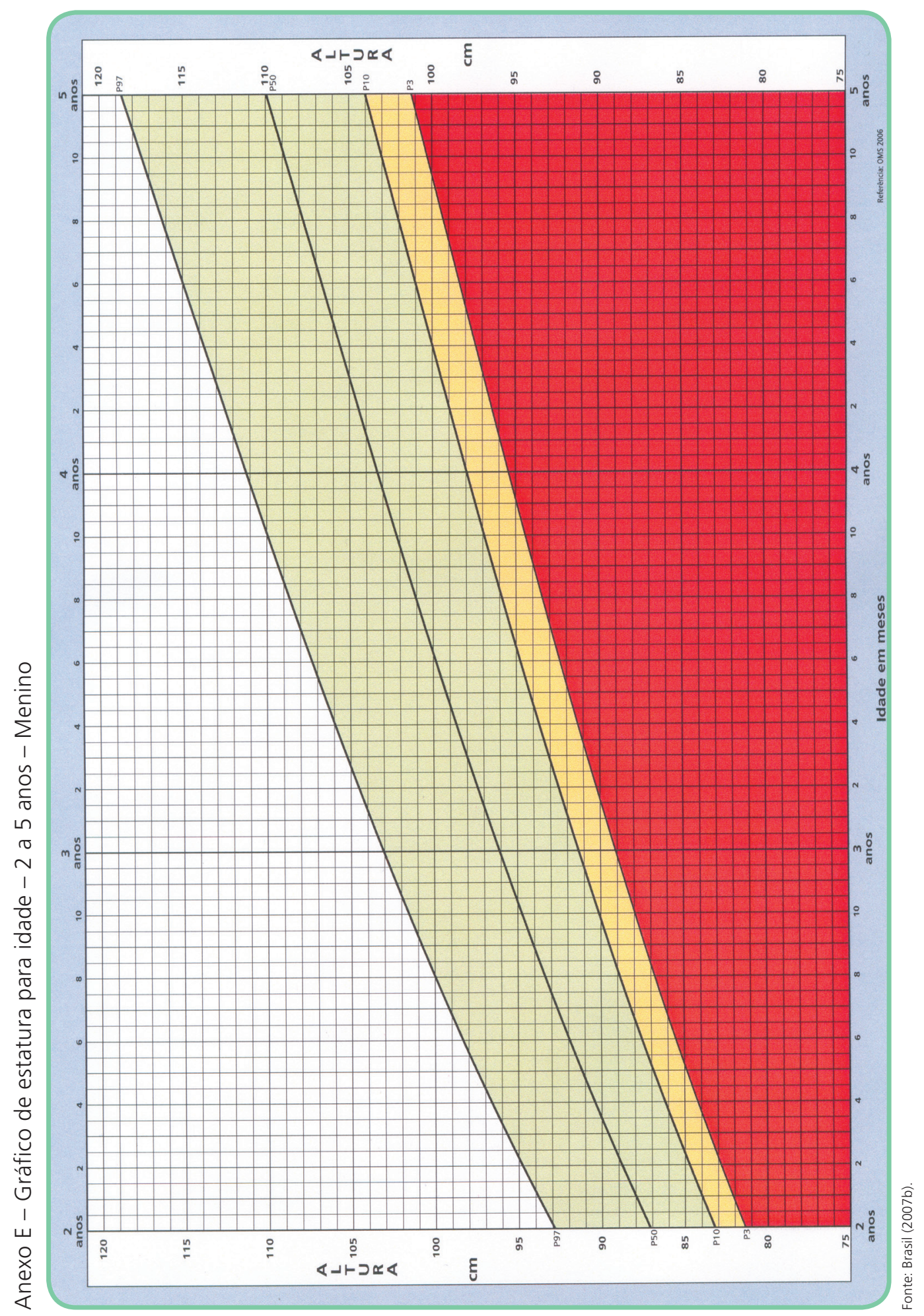




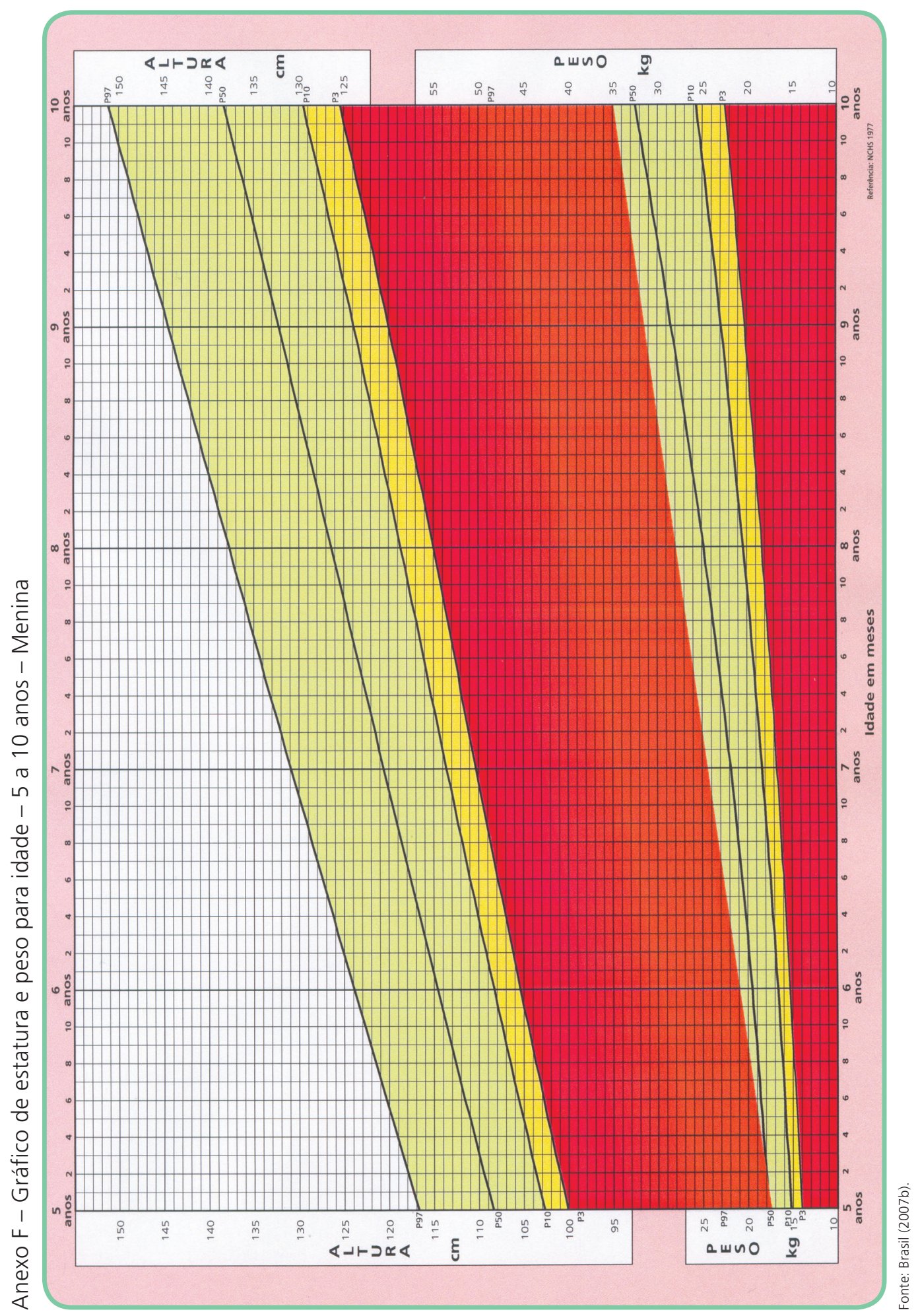




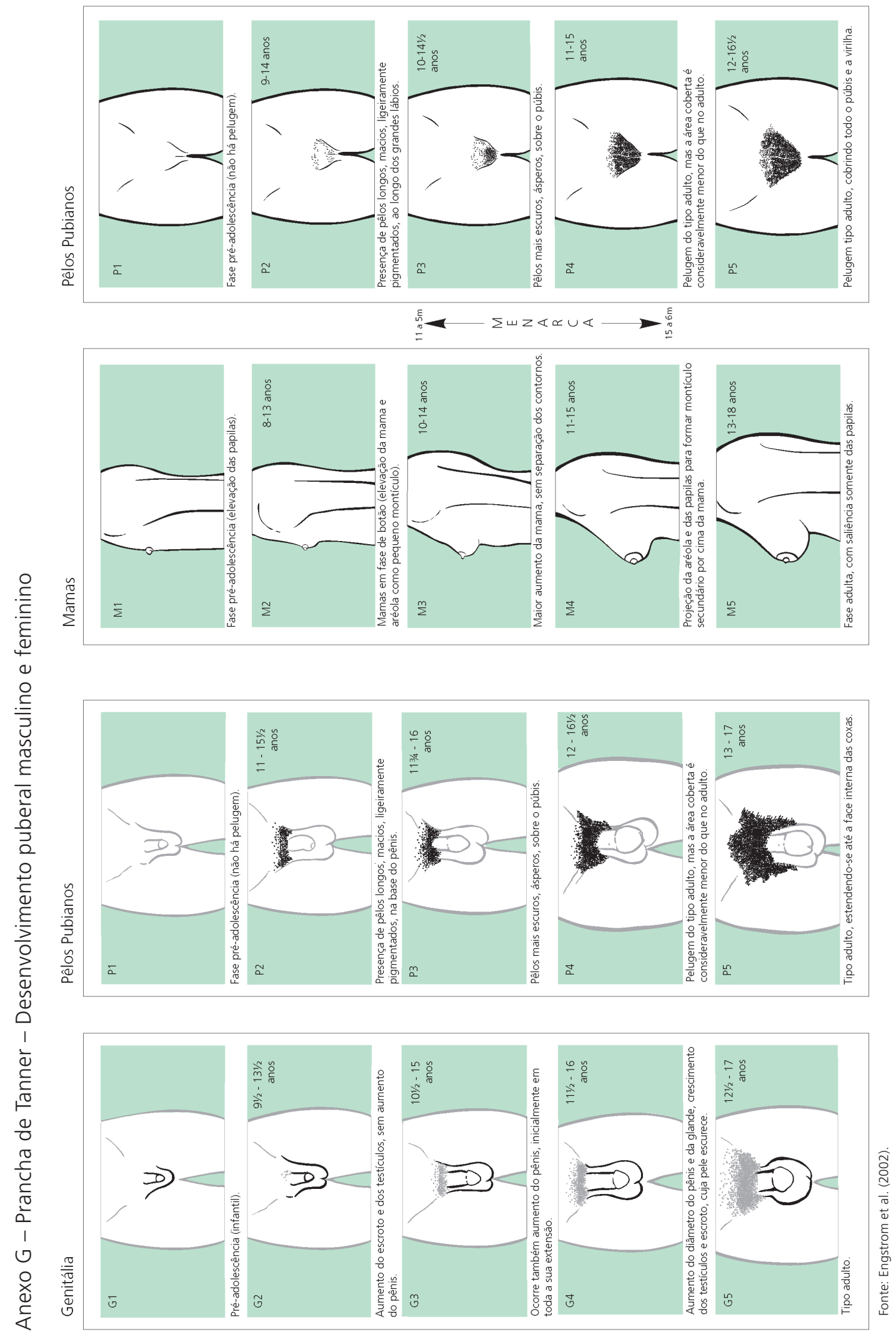


Anexo $\mathrm{H} 1$ - Percentis e escore z selecionados de IMC $\left(\mathrm{kg} \cdot \mathrm{m}^{-2}\right)$ segundo idade e sexo masculino de adolescentes (10 a 19 anos)

\begin{tabular}{|c|c|c|c|c|c|c|c|c|c|c|c|c|}
\hline \multirow[t]{2}{*}{ Idade } & \multicolumn{5}{|c|}{ Percentil } & \multicolumn{7}{|c|}{ Escore z } \\
\hline & 3 & 15 & 50 & 85 & 97 & -3 & -2 & -1 & 0 & 1 & 2 & 3 \\
\hline 10 anos & 13,9 & 14,9 & 16,4 & 18,6 & 21,0 & 12,8 & 13,7 & 14,9 & 16,4 & 18,5 & 21,4 & 26,1 \\
\hline 10 anos e 1 mês & 13,9 & 14,9 & 16,5 & 18,6 & 21,1 & 12,8 & 13,8 & 15,0 & 16,5 & 18,5 & 21,5 & 26,2 \\
\hline 10 anos e 2 meses & 13,9 & 14,9 & 16,5 & 18,7 & 21,1 & 12,8 & 13,8 & 15,0 & 16,5 & 18,6 & 21,6 & 26,4 \\
\hline 10 anos e 3 meses & 13,9 & 15,0 & 16,6 & 18,7 & 21,2 & 12,8 & 13,8 & 15,0 & 16,5 & 18,6 & 21,7 & 26,6 \\
\hline 10 anos e 4 meses & 14,0 & 15,0 & 16,6 & 18,8 & 21,3 & 12,9 & 13,8 & 15,0 & 16,6 & 18,7 & 21,7 & 26,7 \\
\hline 10 anos e 5 meses & 14,0 & 15,0 & 16,6 & 18,8 & 21,4 & 12,9 & 13,9 & 15,1 & 16,6 & 18,8 & 21,8 & 26,9 \\
\hline 10 anos e 6 meses & 14,0 & 15,1 & 16,7 & 18,9 & 21,5 & 12,9 & 13,9 & 15,1 & 16,7 & 18,8 & 21,9 & 27,0 \\
\hline 10 anos e 7 meses & 14,0 & 15,1 & 16,7 & 19,0 & 21,6 & 12,9 & 13,9 & 15,1 & 16,7 & 18,9 & 22,0 & 27,2 \\
\hline 10 anos e 8 meses & 14,1 & 15,1 & 16,8 & 19,0 & 21,6 & 13,0 & 13,9 & 15,2 & 16,8 & 18,9 & 22,1 & 27,4 \\
\hline 10 anos e 9 meses & 14,1 & 15,2 & 16,8 & 19,1 & 21,7 & 13,0 & 14,0 & 15,2 & 16,8 & 19,0 & 22,2 & 27,5 \\
\hline 10 anos e 10 meses & 14,1 & 15,2 & 16,9 & 19,1 & 21,8 & 13,0 & 14,0 & 15,2 & 16,9 & 19,0 & 22,3 & 27,7 \\
\hline 10 anos e 11 meses & 14,2 & 15,2 & 16,9 & 19,2 & 21,9 & 13,0 & 14,0 & 15,3 & 16,9 & 19,1 & 22,4 & 27,9 \\
\hline 11 anos & 14,2 & 15,3 & 16,9 & 19,3 & 22,0 & 13,1 & 14,1 & 15,3 & 16,9 & 19,2 & 22,5 & 28,0 \\
\hline 11 anos e 1 mês & 14,2 & 15,3 & 17,0 & 19,3 & 22,1 & 13,1 & 14,1 & 15,3 & 17,0 & 19,2 & 22,5 & 28,2 \\
\hline 11 anos e 2 meses & 14,3 & 15,3 & 17,0 & 19,4 & 22,2 & 13,1 & 14,1 & 15,4 & 17,0 & 19,3 & 22,6 & 28,4 \\
\hline 11 anos e 3 meses & 14,3 & 15,4 & 17,1 & 19,4 & 22,2 & 13,1 & 14,1 & 15,4 & 17,1 & 19,3 & 22,7 & 28,5 \\
\hline 11 anos e 4 meses & 14,3 & 15,4 & 17,1 & 19,5 & 22,3 & 13,2 & 14,2 & 15,5 & 17,1 & 19,4 & 22,8 & 28,7 \\
\hline 11 anos e 5 meses & 14,4 & 15,4 & 17,2 & 19,6 & 22,4 & 13,2 & 14,2 & 15,5 & 17,2 & 19,5 & 22,9 & 28,8 \\
\hline 11 anos e 6 meses & 14,4 & 15,5 & 17,2 & 19,6 & 22,5 & 13,2 & 14,2 & 15,5 & 17,2 & 19,5 & 23,0 & 29,0 \\
\hline 11 anos e 7 meses & 14,4 & 15,5 & 17,3 & 19,7 & 22,6 & 13,2 & 14,3 & 15,6 & 17,3 & 19,6 & 23,1 & 29,2 \\
\hline 11 anos e 8 meses & 14,5 & 15,6 & 17,3 & 19,8 & 22,7 & 13,3 & 14,3 & 15,6 & 17,3 & 19,7 & 23,2 & 29,3 \\
\hline 11 anos e 9 meses & 14,5 & 15,6 & 17,4 & 19,8 & 22,8 & 13,3 & 14,3 & 15,7 & 17,4 & 19,7 & 23,3 & 29,5 \\
\hline 11 anos e 10 meses & 14,5 & 15,6 & 17,4 & 19,9 & 22,9 & 13,3 & 14,4 & 15,7 & 17,4 & 19,8 & 23,4 & 29,6 \\
\hline 11 anos e 11 meses & 14,6 & 15,7 & 17,5 & 20,0 & 23,0 & 13,4 & 14,4 & 15,7 & 17,5 & 19,9 & 23,5 & 29,8 \\
\hline 12 anos & 14,6 & 15,7 & 17,5 & 20,1 & 23,1 & 13,4 & 14,5 & 15,8 & 17,5 & 19,9 & 23,6 & 30,0 \\
\hline 12 anos e 1 mês & 14,6 & 15,8 & 17,6 & 20,1 & 23,1 & 13,4 & 14,5 & 15,8 & 17,6 & 20,0 & 23,7 & 30,1 \\
\hline 12 anos e 2 meses & 14,7 & 15,8 & 17,6 & 20,2 & 23,2 & 13,5 & 14,5 & 15,9 & 17,6 & 20,1 & 23,8 & 30,3 \\
\hline 12 anos e 3 meses & 14,7 & 15,9 & 17,7 & 20,3 & 23,3 & 13,5 & 14,6 & 15,9 & 17,7 & 20,2 & 23,9 & 30,4 \\
\hline 12 anos e 4 meses & 14,8 & 15,9 & 17,8 & 20,3 & 23,4 & 13,5 & 14,6 & 16,0 & 17,8 & 20,2 & 24,0 & 30,6 \\
\hline 12 anos e 5 meses & 14,8 & 16,0 & 17,8 & 20,4 & 23,5 & 13,6 & 14,6 & 16,0 & 17,8 & 20,3 & 24,1 & 30,7 \\
\hline 12 anos e 6 meses & 14,8 & 16,0 & 17,9 & 20,5 & 23,6 & 13,6 & 14,7 & 16,1 & 17,9 & 20,4 & 24,2 & 30,9 \\
\hline 12 anos e 7 meses & 14,9 & 16,1 & 17,9 & 20,6 & 23,7 & 13,6 & 14,7 & 16,1 & 17,9 & 20,4 & 24,3 & 31,0 \\
\hline 12 anos e 8 meses & 14,9 & 16,1 & 18,0 & 20,6 & 23,8 & 13,7 & 14,8 & 16,2 & 18,0 & 20,5 & 24,4 & 31,1 \\
\hline 12 anos e 9 meses & 15,0 & 16,2 & 18,0 & 20,7 & 23,9 & 13,7 & 14,8 & 16,2 & 18,0 & 20,6 & 24,5 & 31,3 \\
\hline 12 anos e 10 meses & 15,0 & 16,2 & 18,1 & 20,8 & 24,0 & 13,7 & 14,8 & 16,3 & 18,1 & 20,7 & 24,6 & 31,4 \\
\hline 12 anos e 11 meses & 15,0 & 16,3 & 18,2 & 20,9 & 24,1 & 13,8 & 14,9 & 16,3 & 18,2 & 20,8 & 24,7 & 31,6 \\
\hline 13 anos & 15,1 & 16,3 & 18,2 & 20,9 & 24,2 & 13,8 & 14,9 & 16,4 & 18,2 & 20,8 & 24,8 & 31,7 \\
\hline 13 anos e 1 mês & 15,1 & 16,4 & 18,3 & 21,0 & 24,3 & 13,8 & 15,0 & 16,4 & 18,3 & 20,9 & 24,9 & 31,8 \\
\hline 13 anos e 2 meses & 15,2 & 16,4 & 18,4 & 21,1 & 24,4 & 13,9 & 15,0 & 16,5 & 18,4 & 21,0 & 25,0 & 31,9 \\
\hline
\end{tabular}


Anexo $\mathrm{H} 1$ - Percentis e escore z selecionados de IMC $\left(\mathrm{kg} \cdot \mathrm{m}^{-2}\right)$ segundo idade e sexo masculino de adolescentes (10 a 19 anos) (cont.)

\begin{tabular}{|c|c|c|c|c|c|c|c|c|c|c|c|c|}
\hline \multirow[t]{2}{*}{ Idade } & \multicolumn{5}{|c|}{ Percentil } & \multicolumn{7}{|c|}{ Escore z } \\
\hline & 3 & 15 & 50 & 85 & 97 & -3 & -2 & -1 & 0 & 1 & 2 & 3 \\
\hline 13 anos e 3 meses & 15,2 & 16,5 & 18,4 & 21,2 & 24,5 & 13,9 & 15,1 & 16,5 & 18,4 & 21,1 & 25,1 & 32,1 \\
\hline 13 anos e 4 meses & 15,3 & 16,5 & 18,5 & 21,3 & 24,6 & 14,0 & 15,1 & 16,6 & 18,5 & 21,1 & 25,2 & 32,2 \\
\hline 13 anos e 5 meses & 15,3 & 16,6 & 18,6 & 21,3 & 24,7 & 14,0 & 15,2 & 16,6 & 18,6 & 21,2 & 25,2 & 32,3 \\
\hline 13 anos e 6 meses & 15,4 & 16,6 & 18,6 & 21,4 & 24,8 & 14,0 & 15,2 & 16,7 & 18,6 & 21,3 & 25,3 & 32,4 \\
\hline 13 anos e 7 meses & 15,4 & 16,7 & 18,7 & 21,5 & 24,9 & 14,1 & 15,2 & 16,7 & 18,7 & 21,4 & 25,4 & 32,6 \\
\hline 13 anos e 8 meses & 15,5 & 16,7 & 18,7 & 21,6 & 24,9 & 14,1 & 15,3 & 16,8 & 18,7 & 21,5 & 25,5 & 32,7 \\
\hline 13 anos e 9 meses & 15,5 & 16,8 & 18,8 & 21,7 & 25,0 & 14,1 & 15,3 & 16,8 & 18,8 & 21,5 & 25,6 & 32,8 \\
\hline 13 anos e 10 meses & 15,5 & 16,8 & 18,9 & 21,7 & 25,1 & 14,2 & 15,4 & 16,9 & 18,9 & 21,6 & 25,7 & 32,9 \\
\hline 13 anos e 11 meses & 15,6 & 16,9 & 18,9 & 21,8 & 25,2 & 14,2 & 15,4 & 17,0 & 18,9 & 21,7 & 25,8 & 33,0 \\
\hline 14 anos & 15,6 & 16,9 & 19,0 & 21,9 & 25,3 & 14,3 & 15,5 & 17,0 & 19,0 & 21,8 & 25,9 & 33,1 \\
\hline 14 anos e 1 mês & 15,7 & 17,0 & 19,1 & 22,0 & 25,4 & 14,3 & 15,5 & 17,1 & 19,1 & 21,8 & 26,0 & 33,2 \\
\hline 14 anos e 2 meses & 15,7 & 17,0 & 19,1 & 22,0 & 25,5 & 14,3 & 15,6 & 17,1 & 19,1 & 21,9 & 26,1 & 33,3 \\
\hline 14 anos e 3 meses & 15,8 & 17,1 & 19,2 & 22,1 & 25,6 & 14,4 & 15,6 & 17,2 & 19,2 & 22,0 & 26,2 & 33,4 \\
\hline 14 anos e 4 meses & 15,8 & 17,2 & 19,3 & 22,2 & 25,7 & 14,4 & 15,7 & 17,2 & 19,3 & 22,1 & 26,3 & 33,5 \\
\hline 14 anos e 5 meses & 15,9 & 17,2 & 19,3 & 22,3 & 25,8 & 14,5 & 15,7 & 17,3 & 19,3 & 22,2 & 26,4 & 33,5 \\
\hline 14 anos e 6 meses & 15,9 & 17,3 & 19,4 & 22,4 & 25,8 & 14,5 & 15,7 & 17,3 & 19,4 & 22,2 & 26,5 & 33,6 \\
\hline 14 anos e 7 meses & 16,0 & 17,3 & 19,5 & 22,4 & 25,9 & 14,5 & 15,8 & 17,4 & 19,5 & 22,3 & 26,5 & 33,7 \\
\hline 14 anos e 8 meses & 16,0 & 17,4 & 19,5 & 22,5 & 26,0 & 14,6 & 15,8 & 17,4 & 19,5 & 22,4 & 26,6 & 33,8 \\
\hline 14 anos e 9 meses & 16,1 & 17,4 & 19,6 & 22,6 & 26,1 & 14,6 & 15,9 & 17,5 & 19,6 & 22,5 & 26,7 & 33,9 \\
\hline 14 anos e 10 meses & 16,1 & 17,5 & 19,6 & 22,7 & 26,2 & 14,6 & 15,9 & 17,5 & 19,6 & 22,5 & 26,8 & 33,9 \\
\hline 14 anos e 11 meses & 16,1 & 17,5 & 19,7 & 22,7 & 26,3 & 14,7 & 16,0 & 17,6 & 19,7 & 22,6 & 26,9 & 34,0 \\
\hline 15 anos & 16,2 & 17,6 & 19,8 & 22,8 & 26,4 & 14,7 & 16,0 & 17,6 & 19,8 & 22,7 & 27,0 & 34,1 \\
\hline 15 anos e 1 mês & 16,2 & 17,6 & 19,8 & 22,9 & 26,4 & 14,7 & 16,1 & 17,7 & 19,8 & 22,8 & 27,1 & 34,1 \\
\hline 15 anos e 2 meses & 16,3 & 17,7 & 19,9 & 23,0 & 26,5 & 14,8 & 16,1 & 17,8 & 19,9 & 22,8 & 27,1 & 34,2 \\
\hline 15 anos e 3 meses & 16,3 & 17,7 & 20,0 & 23,0 & 26,6 & 14,8 & 16,1 & 17,8 & 20,0 & 22,9 & 27,2 & 34,3 \\
\hline 15 anos e 4 meses & 16,4 & 17,8 & 20,0 & 23,1 & 26,7 & 14,8 & 16,2 & 17,9 & 20,0 & 23,0 & 27,3 & 34,3 \\
\hline 15 anos e 5 meses & 16,4 & 17,8 & 20,1 & 23,2 & 26,7 & 14,9 & 16,2 & 17,9 & 20,1 & 23,0 & 27,4 & 34,4 \\
\hline 15 anos e 6 meses & 16,4 & 17,9 & 20,1 & 23,2 & 26,8 & 14,9 & 16,3 & 18,0 & 20,1 & 23,1 & 27,4 & 34,5 \\
\hline 15 anos e 7 meses & 16,5 & 17,9 & 20,2 & 23,3 & 26,9 & 15,0 & 16,3 & 18,0 & 20,2 & 23,2 & 27,5 & 34,5 \\
\hline 15 anos e 8 meses & 16,5 & 18,0 & 20,3 & 23,4 & 27,0 & 15,0 & 16,3 & 18,1 & 20,3 & 23,3 & 27,6 & 34,6 \\
\hline 15 anos e 9 meses & 16,6 & 18,0 & 20,3 & 23,5 & 27,0 & 15,0 & 16,4 & 18,1 & 20,3 & 23,3 & 27,7 & 34,6 \\
\hline 15 anos e 10 meses & 16,6 & 18,1 & 20,4 & 23,5 & 27,1 & 15,0 & 16,4 & 18,2 & 20,4 & 23,4 & 27,7 & 34,7 \\
\hline 15 anos e 11 meses & 16,7 & 18,1 & 20,4 & 23,6 & 27,2 & 15,1 & 16,5 & 18,2 & 20,4 & 23,5 & 27,8 & 34,7 \\
\hline 16 anos & 16,7 & 18,2 & 20,5 & 23,7 & 27,3 & 15,1 & 16,5 & 18,2 & 20,5 & 23,5 & 27,9 & 34,8 \\
\hline 16 anos e 1 mês & 16,7 & 18,2 & 20,6 & 23,7 & 27,3 & 15,1 & 16,5 & 18,3 & 20,6 & 23,6 & 27,9 & 34,8 \\
\hline 16 anos e 2 meses & 16,8 & 18,3 & 20,6 & 23,8 & 27,4 & 15,2 & 16,6 & 18,3 & 20,6 & 23,7 & 28,0 & 34,8 \\
\hline
\end{tabular}


Anexo $\mathrm{H} 1$ - Percentis e escore z selecionados de IMC $\left(\mathrm{kg} \cdot \mathrm{m}^{-2}\right)$ segundo idade e sexo masculino de adolescentes (10 a 19 anos) (cont.)

\begin{tabular}{|c|c|c|c|c|c|c|c|c|c|c|c|c|}
\hline \multirow[t]{2}{*}{ Idade } & \multicolumn{5}{|c|}{ Percentil } & \multicolumn{7}{|c|}{ Escore z } \\
\hline & 3 & 15 & 50 & 85 & 97 & -3 & -2 & -1 & 0 & 1 & 2 & 3 \\
\hline 16 anos e 3 meses & 16,8 & 18,3 & 20,7 & 23,9 & 27,5 & 15,2 & 16,6 & 18,4 & 20,7 & 23,7 & 28,1 & 34,9 \\
\hline 16 anos e 4 meses & 16,8 & 18,4 & 20,7 & 23,9 & 27,5 & 15,2 & 16,7 & 18,4 & 20,7 & 23,8 & 28,1 & 34,9 \\
\hline 16 anos e 5 meses & 16,9 & 18,4 & 20,8 & 24,0 & 27,6 & 15,3 & 16,7 & 18,5 & 20,8 & 23,8 & 28,2 & 35,0 \\
\hline 16 anos e 6 meses & 16,9 & 18,5 & 20,8 & 24,0 & 27,7 & 15,3 & 16,7 & 18,5 & 20,8 & 23,9 & 28,3 & 35,0 \\
\hline 16 anos e 7 meses & 17,0 & 18,5 & 20,9 & 24,1 & 27,7 & 15,3 & 16,8 & 18,6 & 20,9 & 24,0 & 28,3 & 35,0 \\
\hline 16 anos e 8 meses & 17,0 & 18,5 & 20,9 & 24,2 & 27,8 & 15,3 & 16,8 & 18,6 & 20,9 & 24,0 & 28,4 & 35,1 \\
\hline 16 anos e 9 meses & 17,0 & 18,6 & 21,0 & 24,2 & 27,8 & 15,4 & 16,8 & 18,7 & 21,0 & 24,1 & 28,5 & 35,1 \\
\hline 16 anos e 10 meses & 17,1 & 18,6 & 21,0 & 24,3 & 27,9 & 15,4 & 16,9 & 18,7 & 21,0 & 24,2 & 28,5 & 35,1 \\
\hline 16 anos e 11 meses & 17,1 & 18,7 & 21,1 & 24,3 & 28,0 & 15,4 & 16,9 & 18,7 & 21,1 & 24,2 & 28,6 & 35,2 \\
\hline 17 anos & 17,1 & 18,7 & 21,1 & 24,4 & 28,0 & 15,4 & 16,9 & 18,8 & 21,1 & 24,3 & 28,6 & 35,2 \\
\hline 17 anos e 1 mês & 17,2 & 18,7 & 21,2 & 24,5 & 28,1 & 15,5 & 17,0 & 18,8 & 21,2 & 24,3 & 28,7 & 35,2 \\
\hline 17 anos e 2 meses & 17,2 & 18,8 & 21,2 & 24,5 & 28,1 & 15,5 & 17,0 & 18,9 & 21,2 & 24,4 & 28,7 & 35,2 \\
\hline 17 anos e 3 meses & 17,2 & 18,8 & 21,3 & 24,6 & 28,2 & 15,5 & 17,0 & 18,9 & 21,3 & 24,4 & 28,8 & 35,3 \\
\hline 17 anos e 4 meses & 17,3 & 18,9 & 21,3 & 24,6 & 28,2 & 15,5 & 17,1 & 18,9 & 21,3 & 24,5 & 28,9 & 35,3 \\
\hline 17 anos e 5 meses & 17,3 & 18,9 & 21,4 & 24,7 & 28,3 & 15,6 & 17,1 & 19,0 & 21,4 & 24,5 & 28,9 & 35,3 \\
\hline 17 anos e 6 meses & 17,3 & 18,9 & 21,4 & 24,7 & 28,4 & 15,6 & 17,1 & 19,0 & 21,4 & 24,6 & 29,0 & 35,3 \\
\hline 17 anos e 7 meses & 17,4 & 19,0 & 21,5 & 24,8 & 28,4 & 15,6 & 17,1 & 19,1 & 21,5 & 24,7 & 29,0 & 35,4 \\
\hline 17 anos e 8 meses & 17,4 & 19,0 & 21,5 & 24,8 & 28,5 & 15,6 & 17,2 & 19,1 & 21,5 & 24,7 & 29,1 & 35,4 \\
\hline 17 anos e 9 meses & 17,4 & 19,1 & 21,6 & 24,9 & 28,5 & 15,6 & 17,2 & 19,1 & 21,6 & 24,8 & 29,1 & 35,4 \\
\hline 17 anos e 10 meses & 17,4 & 19,1 & 21,6 & 24,9 & 28,6 & 15,7 & 17,2 & 19,2 & 21,6 & 24,8 & 29,2 & 35,4 \\
\hline 17 anos e 11 meses & 17,5 & 19,1 & 21,7 & 25,0 & 28,6 & 15,7 & 17,3 & 19,2 & 21,7 & 24,9 & 29,2 & 35,4 \\
\hline 18 anos & 17,5 & 19,2 & 21,7 & 25,0 & 28,6 & 15,7 & 17,3 & 19,2 & 21,7 & 24,9 & 29,2 & 35,4 \\
\hline 18 anos e 1 mês & 17,5 & 19,2 & 21,8 & 25,1 & 28,7 & 15,7 & 17,3 & 19,3 & 21,8 & 25,0 & 29,3 & 35,4 \\
\hline 18 anos e 2 meses & 17,5 & 19,2 & 21,8 & 25,1 & 28,7 & 15,7 & 17,3 & 19,3 & 21,8 & 25,0 & 29,3 & 35,5 \\
\hline 18 anos e 3 meses & 17,6 & 19,3 & 21,8 & 25,2 & 28,8 & 15,7 & 17,4 & 19,3 & 21,8 & 25,1 & 29,4 & 35,5 \\
\hline 18 anos e 4 meses & 17,6 & 19,3 & 21,9 & 25,2 & 28,8 & 15,8 & 17,4 & 19,4 & 21,9 & 25,1 & 29,4 & 35,5 \\
\hline 18 anos e 5 meses & 17,6 & 19,3 & 21,9 & 25,3 & 28,9 & 15,8 & 17,4 & 19,4 & 21,9 & 25,1 & 29,5 & 35,5 \\
\hline 18 anos e 6 meses & 17,6 & 19,4 & 22,0 & 25,3 & 28,9 & 15,8 & 17,4 & 19,4 & 22,0 & 25,2 & 29,5 & 35,5 \\
\hline 18 anos e 7 meses & 17,7 & 19,4 & 22,0 & 25,4 & 29,0 & 15,8 & 17,5 & 19,5 & 22,0 & 25,2 & 29,5 & 35,5 \\
\hline 18 anos e 8 meses & 17,7 & 19,4 & 22,0 & 25,4 & 29,0 & 15,8 & 17,5 & 19,5 & 22,0 & 25,3 & 29,6 & 35,5 \\
\hline 18 anos e 9 meses & 17,7 & 19,5 & 22,1 & 25,5 & 29,0 & 15,8 & 17,5 & 19,5 & 22,1 & 25,3 & 29,6 & 35,5 \\
\hline 18 anos e 10 meses & 17,7 & 19,5 & 22,1 & 25,5 & 29,1 & 15,8 & 17,5 & 19,6 & 22,1 & 25,4 & 29,6 & 35,5 \\
\hline 18 anos e 11 meses & 17,8 & 19,5 & 22,2 & 25,5 & 29,1 & 15,8 & 17,5 & 19,6 & 22,2 & 25,4 & 29,7 & 35,5 \\
\hline 19 anos & 17,8 & 19,5 & 22,2 & 25,6 & 29,1 & 15,9 & 17,6 & 19,6 & 22,2 & 25,4 & 29,7 & 35,5 \\
\hline
\end{tabular}

Fonte: World Health Organization (2007). 
Anexo H2 - Percentis e escore z selecionados de IMC $\left(\mathrm{kg} \cdot \mathrm{m}^{-2}\right)$ segundo idade e sexo feminino de adolescentes (10 a 19 anos)

\begin{tabular}{|c|c|c|c|c|c|c|c|c|c|c|c|c|}
\hline \multirow[t]{2}{*}{ Idade } & \multicolumn{5}{|c|}{ Percentil } & \multicolumn{7}{|c|}{ Escore z } \\
\hline & 3 & 15 & 50 & 85 & 97 & -3 & -2 & -1 & 0 & 1 & 2 & 3 \\
\hline 10 anos & 13,6 & 14.8 & 16,6 & 19,1 & 22,1 & 12,4 & 13,5 & 14,8 & 16,6 & 19,0 & 22,6 & 28,4 \\
\hline 10 anos e 1 mês & 13,6 & 14.8 & 16,7 & 19,2 & 22,2 & 12,4 & 13,5 & 14,9 & 16,7 & 19,1 & 22,7 & 28,5 \\
\hline 10 anos e 2 meses & 13,7 & 14,9 & 16,7 & 19,3 & 22,2 & 12,4 & 13,5 & 14,9 & 16,7 & 19,2 & 22,8 & 28,7 \\
\hline 10 anos e 3 meses & 13,7 & 14,9 & 16,8 & 19,3 & 22,3 & 12,5 & 13,6 & 15,0 & 16,8 & 19,2 & 22,8 & 28,8 \\
\hline 10 anos e 4 meses & 13,7 & 14,9 & 16,8 & 19,4 & 22,4 & 12,5 & 13,6 & 15,0 & 16,8 & 19,3 & 22,9 & 29,0 \\
\hline 10 anos e 5 meses & 13,8 & 15,0 & 16,9 & 19,5 & 22,5 & 12,5 & 13,6 & 15,0 & 16,9 & 19,4 & 23,0 & 29,1 \\
\hline 10 anos e 6 meses & 13,8 & 15,0 & 16,9 & 19,5 & 22,6 & 12,5 & 13,7 & 15,1 & 16,9 & 19,4 & 23,1 & 29,3 \\
\hline 10 anos e 7 meses & 13,9 & 15,1 & 17,0 & 19,6 & 22,7 & 12,6 & 13,7 & 15,1 & 17,0 & 19,5 & 23,2 & 29,4 \\
\hline 10 anos e 8 meses & 13,9 & 15,1 & 17,0 & 19,7 & 22,8 & 12,6 & 13,7 & 15,2 & 17,0 & 19,6 & 23,3 & 29,6 \\
\hline 10 anos e 9 meses & 13,9 & 15,1 & 17,1 & 19,8 & 22,9 & 12,6 & 13,8 & 15,2 & 17,1 & 19,6 & 23,4 & 29,7 \\
\hline 10 anos e 10 meses & 14,0 & 15,2 & 17,1 & 19,8 & 23,0 & 12,7 & 13,8 & 15,3 & 17,1 & 19,7 & 23,5 & 29,9 \\
\hline 10 anos e 11 meses & 14,0 & 15,2 & 17,2 & 19,9 & 23,1 & 12,7 & 13,8 & 15,3 & 17,2 & 19,8 & 23,6 & 30,0 \\
\hline 11 anos & 14,0 & 15,3 & 17,2 & 20,0 & 23,2 & 12,7 & 13,9 & 15,3 & 17,2 & 19,9 & 23,7 & 30,2 \\
\hline 11 anos e 1 mês & 14,1 & 15,3 & 17,3 & 20,0 & 23,3 & 12,8 & 13,9 & 15,4 & 17,3 & 19,9 & 23,8 & 30,3 \\
\hline 11 anos e 2 meses & 14,1 & 15,4 & 17,4 & 20,1 & 23,4 & 12,8 & 14,0 & 15,4 & 17,4 & 20,0 & 23,9 & 30,5 \\
\hline 11 anos e 3 meses & 14,2 & 15,4 & 17,4 & 20,2 & 23,5 & 12,8 & 14,0 & 15,5 & 17,4 & 20,1 & 24,0 & 30,6 \\
\hline 11 anos e 4 meses & 14,2 & 15,5 & 17,5 & 20,3 & 23,6 & 12,9 & 14,0 & 15,5 & 17,5 & 20,2 & 24,1 & 30,8 \\
\hline 11 anos e 5 meses & 14,2 & 15,5 & 17,5 & 20,4 & 23,7 & 12,9 & 14,1 & 15,6 & 17,5 & 20,2 & 24,2 & 30,9 \\
\hline 11 anos e 6 meses & 14,3 & 15,6 & 17,6 & 20,4 & 23,8 & 12,9 & 14,1 & 15,6 & 17,6 & 20,3 & 24,3 & 31,1 \\
\hline 11 anos e 7 meses & 14,3 & 15,6 & 17,7 & 20,5 & 23,9 & 13,0 & 14,2 & 15,7 & 17,7 & 20,4 & 24,4 & 31,2 \\
\hline 11 anos e 8 meses & 14,4 & 15,7 & 17,7 & 20,6 & 24,0 & 13,0 & 14,2 & 15,7 & 17,7 & 20,5 & 24,5 & 31,4 \\
\hline 11 anos e 9 meses & 14,4 & 15,7 & 17,8 & 20,7 & 24,1 & 13,0 & 14,3 & 15,8 & 17,8 & 20,6 & 24,7 & 31,5 \\
\hline 11 anos e 10 meses & 14,5 & 15,8 & 17,9 & 20,8 & 24,2 & 13,1 & 14,3 & 15,8 & 17,9 & 20,6 & 24,8 & 31,6 \\
\hline 11 anos e 11 meses & 14,5 & 15,8 & 17,9 & 20,8 & 24,3 & 13,1 & 14,3 & 15,9 & 17,9 & 20,7 & 24,9 & 31,8 \\
\hline 12 anos & 14,6 & 15,9 & 18,0 & 20,9 & 24,4 & 13,2 & 14,4 & 16,0 & 18,0 & 20,8 & 25,0 & 31,9 \\
\hline 12 anos e 1 mês & 14,6 & 15,9 & 18,1 & 21,0 & 24,5 & 13,2 & 14,4 & 16,0 & 18,1 & 20,9 & 25,1 & 32,0 \\
\hline 12 anos e 2 meses & 14,7 & 16,0 & 18,1 & 21,1 & 24,6 & 13,2 & 14,5 & 16,1 & 18,1 & 21,0 & 25,2 & 32,2 \\
\hline 12 anos e 3 meses & 14,7 & 16,1 & 18,2 & 21,2 & 24,7 & 13,3 & 14,5 & 16,1 & 18,2 & 21,1 & 25,3 & 32,3 \\
\hline 12 anos e 4 meses & 14,7 & 16,1 & 18,3 & 21,3 & 24,8 & 13,3 & 14,6 & 16,2 & 18,3 & 21,1 & 25,4 & 32,4 \\
\hline 12 anos e 5 meses & 14,8 & 16,2 & 18,3 & 21,3 & 24,9 & 13,3 & 14,6 & 16,2 & 18,3 & 21,2 & 25,5 & 32,6 \\
\hline 12 anos e 6 meses & 14,8 & 16,2 & 18,4 & 21,4 & 25,0 & 13,4 & 14,7 & 16,3 & 18,4 & 21,3 & 25,6 & 32,7 \\
\hline 12 anos e 7 meses & 14,9 & 16,3 & 18,5 & 21,5 & 25,1 & 13,4 & 14,7 & 16,3 & 18,5 & 21,4 & 25,7 & 32,8 \\
\hline 12 anos e 8 meses & 14,9 & 16,3 & 18,5 & 21,6 & 25,2 & 13,5 & 14,8 & 16,4 & 18,5 & 21,5 & 25,8 & 33,0 \\
\hline 12 anos e 9 meses & 15,0 & 16,4 & 18,6 & 21,7 & 25,3 & 13,5 & 14,8 & 16,4 & 18,6 & 21,6 & 25,9 & 33,1 \\
\hline 12 anos e 10 meses & 15,0 & 16,4 & 18,7 & 21,8 & 25,4 & 13,5 & 14,8 & 16,5 & 18,7 & 21,6 & 26,0 & 33,2 \\
\hline 12 anos e 11 meses & 15,1 & 16,5 & 18,7 & 21,8 & 25,5 & 13,6 & 14,9 & 16,6 & 18,7 & 21,7 & 26,1 & 33,3 \\
\hline 13 anos & 15,1 & 16,5 & 18,8 & 21,9 & 25,6 & 13,6 & 14,9 & 16,6 & 18,8 & 21,8 & 26,2 & 33,4 \\
\hline 13 anos e 1 mês & 15,2 & 16,6 & 18,9 & 22,0 & 25,7 & 13,6 & 15,0 & 16,7 & 18,9 & 21,9 & 26,3 & 33,6 \\
\hline 13 anos e 2 meses & 15,2 & 16,7 & 18,9 & 22,1 & 25,8 & 13,7 & 15,0 & 16,7 & 18,9 & 22,0 & 26,4 & 33,7 \\
\hline
\end{tabular}


Anexo $\mathrm{H} 2$ - Percentis e escore $\mathrm{z}$ selecionados de IMC $\left(\mathrm{kg} \cdot \mathrm{m}^{-2}\right)$ segundo idade e sexo feminino de adolescentes (10 a 19 anos) (cont.)

\begin{tabular}{|c|c|c|c|c|c|c|c|c|c|c|c|c|}
\hline \multirow[t]{2}{*}{ Idade } & \multicolumn{5}{|c|}{ Percentil } & \multicolumn{7}{|c|}{ Escore z } \\
\hline & 3 & 15 & 50 & 85 & 97 & -3 & -2 & -1 & 0 & 1 & 2 & 3 \\
\hline 13 anos e 3 meses & 15,3 & 16,7 & 19,0 & 22,2 & 25,9 & 13,7 & 15,1 & 16,8 & 19,0 & 22,0 & 26,5 & 33,8 \\
\hline 13 anos e 4 meses & 15,3 & 16,8 & 19,1 & 22,3 & 26,0 & 13,7 & 15,1 & 16,8 & 19,0 & 22,0 & 26,5 & 33,8 \\
\hline 13 anos e 5 meses & 15,3 & 16,8 & 19,1 & 22,3 & 26,1 & 13,8 & 15,1 & 16,8 & 19,1 & 22,1 & 26,6 & 33,9 \\
\hline 13 anos e 6 meses & 15,4 & 16,9 & 19,2 & 22,4 & 26,1 & 13,8 & 15,2 & 16,9 & 19,1 & 22,2 & 26,7 & 34,0 \\
\hline 13 anos e 7 meses & 15,4 & 16,9 & 19,3 & 22,5 & 26,2 & 13,8 & 15,2 & 16,9 & 19,2 & 22,3 & 26,8 & 34,1 \\
\hline 13 anos e 8 meses & 15,5 & 17,0 & 19,3 & 22,6 & 26,3 & 13,9 & 15,3 & 17,0 & 19,3 & 22,4 & 27,0 & 34,3 \\
\hline 13 anos e 9 meses & 15,5 & 17,0 & 19,4 & 22,6 & 26,4 & 13,9 & 15,3 & 17,1 & 19,4 & 22,5 & 27,1 & 34,4 \\
\hline 13 anos e 10 meses & 15,6 & 17,1 & 19,4 & 22,7 & 26,5 & 14,0 & 15,4 & 17,1 & 19,4 & 22,6 & 27,1 & 34,5 \\
\hline 13 anos e 11 meses & 15,6 & 17,1 & 19,5 & 22,8 & 26,6 & 14,0 & 15,4 & 17,2 & 19,5 & 22,7 & 27,2 & 34,6 \\
\hline 14 anos & 15,6 & 17,2 & 19,6 & 22,9 & 26,7 & 14,0 & 15,4 & 17,2 & 19,6 & 22,7 & 27,3 & 34,7 \\
\hline 14 anos e 1 mês & 15,7 & 17,2 & 19,6 & 22,9 & 26,8 & 14,1 & 15,5 & 17,3 & 19,6 & 22,8 & 27,4 & 34,7 \\
\hline 14 anos e 2 meses & 15,7 & 17,3 & 19,7 & 23,0 & 26,8 & 14,1 & 15,5 & 17,3 & 19,7 & 22,9 & 27,5 & 34,8 \\
\hline 14 anos e 3 meses & 15,8 & 17,3 & 19,7 & 23,1 & 26,9 & 14,1 & 15,6 & 17,4 & 19,7 & 22,9 & 27,6 & 34,9 \\
\hline 14 anos e 4 meses & 15,8 & 17,4 & 19,8 & 23,2 & 27,0 & 14,1 & 15,6 & 17,4 & 19,8 & 23,0 & 27,7 & 35,0 \\
\hline 14 anos e 5 meses & 15,8 & 17,4 & 19,9 & 23,2 & 27,1 & 14,2 & 15,6 & 17,5 & 19,9 & 23,1 & 27,7 & 35,1 \\
\hline 14 anos e 6 meses & 15,9 & 17,4 & 19,9 & 23,3 & 27,1 & 14,2 & 15,7 & 17,5 & 19,9 & 23,1 & 27,8 & 35,1 \\
\hline 14 anos e 7 meses & 15,9 & 17,5 & 20,0 & 23,4 & 27,2 & 14,2 & 15,7 & 17,6 & 20,0 & 23,2 & 27,9 & 35,2 \\
\hline 14 anos e 8 meses & 15,9 & 17,5 & 20,0 & 23,4 & 27,3 & 14,3 & 15,7 & 17,6 & 20,0 & 23,3 & 28,0 & 35,3 \\
\hline 14 anos e 9 meses & 16,0 & 17,6 & 20,1 & 23,5 & 27,4 & 14,3 & 15,8 & 17,6 & 20,1 & 23,3 & 28,0 & 35,4 \\
\hline 14 anos e 10 meses & 16,0 & 17,6 & 20,1 & 23,5 & 27,4 & 14,3 & 15,8 & 17,7 & 20,1 & 23,4 & 28,1 & 35,4 \\
\hline 14 anos e 11 meses & 16,0 & 17,6 & 20,2 & 23,6 & 27,5 & 14,3 & 15,8 & 17,7 & 20,2 & 23,5 & 28,2 & 35,5 \\
\hline 15 anos & 16,1 & 17,7 & 20,2 & 23,7 & 27,6 & 14,4 & 15,9 & 17,8 & 20,2 & 23,5 & 28,2 & 35,5 \\
\hline 15 anos e 1 mês & 16,1 & 17,7 & 20,3 & 23,7 & 27,6 & 14,4 & 15,9 & 17,8 & 20,3 & 23,6 & 28,3 & 35,6 \\
\hline 15 anos e 2 meses & 16,1 & 17,8 & 20,3 & 23,8 & 27,7 & 14,4 & 15,9 & 17,8 & 20,3 & 23,6 & 28,4 & 35,7 \\
\hline 15 anos e 3 meses & 16,2 & 17,8 & 20,4 & 23,8 & 27,7 & 14,4 & 16,0 & 17,9 & 20,4 & 23,7 & 28,4 & 35,7 \\
\hline 15 anos e 4 meses & 16,2 & 17,8 & 20,4 & 23,9 & 27,8 & 14,5 & 16,0 & 17,9 & 20,4 & 23,7 & 28,5 & 35,8 \\
\hline 15 anos e 5 meses & 16,2 & 17,9 & 20,4 & 23,9 & 27,9 & 14,5 & 16,0 & 18,0 & 20,5 & 23,8 & 28,6 & 35,8 \\
\hline 15 anos e 6 meses & 16,2 & 17,9 & 20,5 & 24,0 & 27,9 & 14,5 & 16,0 & 18,0 & 20,5 & 23,8 & 28,6 & 35,8 \\
\hline 15 anos e 7 meses & 16,3 & 17,9 & 20,5 & 24,0 & 28,0 & 14,5 & 16,1 & 18,0 & 20,5 & 23,9 & 28,6 & 35,9 \\
\hline 15 anos e 8 meses & 16,3 & 18,0 & 20,6 & 24,1 & 28,0 & 14,5 & 16,1 & 18,0 & 20,6 & 23,9 & 28,7 & 35,9 \\
\hline 15 anos e 9 meses & 16,3 & 18,0 & 20,6 & 24,1 & 28,1 & 14,5 & 16,1 & 18,1 & 20,6 & 24,0 & 28,7 & 36,0 \\
\hline 15 anos e 10 meses & 16,3 & 18,0 & 20,6 & 24,2 & 28,1 & 14,6 & 16,1 & 18,1 & 20,6 & 24,0 & 28,8 & 36,0 \\
\hline 15 anos e 11 meses & 16,4 & 18,0 & 20,7 & 24,2 & 28,2 & 14,6 & 16,2 & 18,1 & 20,7 & 24,1 & 28,8 & 36,0 \\
\hline 16 anos & 16,4 & 18,1 & 20,7 & 24,2 & 28,2 & 14,6 & 16,2 & 18,2 & 20,7 & 24,1 & 28,9 & 36,1 \\
\hline 16 anos e 1 mês & 16,4 & 18,1 & 20,7 & 24,3 & 28,2 & 14,6 & 16,2 & 18,2 & 20,7 & 24,1 & 28,9 & 36,1 \\
\hline 16 anos e 2 meses & 16,4 & 18,1 & 20,8 & 24,3 & 28,3 & 14,6 & 16,2 & 18,2 & 20,8 & 24,2 & 29,0 & 36,1 \\
\hline
\end{tabular}


Anexo H2 - Percentis e escore z selecionados de IMC $\left(\mathrm{kg} \cdot \mathrm{m}^{-2}\right)$ segundo idade e sexo feminino de adolescentes (10 a 19 anos) (cont.)

\begin{tabular}{|c|c|c|c|c|c|c|c|c|c|c|c|c|}
\hline \multirow[t]{2}{*}{ Idade } & \multicolumn{5}{|c|}{ Percentil } & \multicolumn{7}{|c|}{ Escore z } \\
\hline & 3 & 15 & 50 & 85 & 97 & -3 & -2 & -1 & 0 & 1 & 2 & 3 \\
\hline 16 anos e 3 meses & 16,4 & 18,1 & 20,8 & 24,4 & 28,3 & 14,6 & 16,2 & 18,2 & 20,8 & 24,2 & 29,0 & 36,1 \\
\hline 16 anos e 4 meses & 16,5 & 18,2 & 20,8 & 24,4 & 28,4 & 14,6 & 16,2 & 18,2 & 20,8 & 24,2 & 29,0 & 36,2 \\
\hline 16 anos e 5 meses & 16,5 & 18,2 & 20,9 & 24,4 & 28,4 & 14,6 & 16,3 & 18,3 & 20,9 & 24,3 & 29,1 & 36,2 \\
\hline 16 anos e 6 meses & 16,5 & 18,2 & 20,9 & 24,5 & 28,4 & 14,7 & 16,3 & 18,3 & 20,9 & 24,3 & 29,1 & 36,2 \\
\hline 16 anos e 7 meses & 16,5 & 18,2 & 20,9 & 24,5 & 28,5 & 14,7 & 16,3 & 18,3 & 20,9 & 24,4 & 29,1 & 36,2 \\
\hline 16 anos e 8 meses & 16,5 & 18,3 & 20,9 & 24,5 & 28,5 & 14,7 & 16,3 & 18,3 & 20,9 & 24,4 & 29,2 & 36,2 \\
\hline 16 anos e 9 meses & 16,5 & 18,3 & 21,0 & 24,6 & 28,5 & 14,7 & 16,3 & 18,4 & 21,0 & 24,4 & 29,2 & 36,3 \\
\hline 16 anos e 10 meses & 16,6 & 18,3 & 21,0 & 24,6 & 28,6 & 14,7 & 16,3 & 18,4 & 21,0 & 24,4 & 29,2 & 36,3 \\
\hline 16 anos e 11 meses & 16,6 & 18,3 & 21,0 & 24,6 & 28,6 & 14,7 & 16,3 & 18,4 & 21,0 & 24,5 & 29,3 & 36,3 \\
\hline 17 anos & 16,6 & 18,3 & 21,0 & 24,7 & 28,6 & 14,7 & 16,4 & 18,4 & 21,0 & 24,5 & 29,3 & 36,3 \\
\hline 17 anos e 1 mês & 16,6 & 18,3 & 21,1 & 24,7 & 28,6 & 14,7 & 16,4 & 18,4 & 21,1 & 24,5 & 29,3 & 36,3 \\
\hline 17 anos e 2 meses & 16,6 & 18,4 & 21,1 & 24,7 & 28,7 & 14,7 & 16,4 & 18,4 & 21,1 & 24,6 & 29,3 & 36,3 \\
\hline 17 anos e 3 meses & 16,6 & 18,4 & 21,1 & 24,7 & 28,7 & 14,7 & 16,4 & 18,5 & 21,1 & 24,6 & 29,4 & 36,3 \\
\hline 17 anos e 4 meses & 16,6 & 18,4 & 21,1 & 24,8 & 28,7 & 14,7 & 16,4 & 18,5 & 21,1 & 24,6 & 29,4 & 36,3 \\
\hline 17 anos e 5 meses & 16,6 & 18,4 & 21,1 & 24,8 & 28,7 & 14,7 & 16,4 & 18,5 & 21,1 & 24,6 & 29,4 & 36,3 \\
\hline 17 anos e 6 meses & 16,6 & 18,4 & 21,2 & 24,8 & 28,8 & 14,7 & 16,4 & 18,5 & 21,2 & 24,6 & 29,4 & 36,3 \\
\hline 17 anos e 7 meses & 16,6 & 18,4 & 21,2 & 24,8 & 28,8 & 14,7 & 16,4 & 18,5 & 21,2 & 24,7 & 29,4 & 36,3 \\
\hline 17 anos e 8 meses & 16,7 & 18,4 & 21,2 & 24,8 & 28,8 & 14,7 & 16,4 & 18,5 & 21,2 & 24,7 & 29,5 & 36,3 \\
\hline 17 anos e 9 meses & 16,7 & 18,5 & 21,2 & 24,9 & 28,8 & 14,7 & 16,4 & 18,5 & 21,2 & 24,7 & 29,5 & 36,3 \\
\hline 17 anos e 10 meses & 16,7 & 18,5 & 21,2 & 24,9 & 28,8 & 14,7 & 16,4 & 18,5 & 21,2 & 24,7 & 29,5 & 36,3 \\
\hline 17 anos e 11 meses & 16,7 & 18,5 & 21,2 & 24,9 & 28,9 & 14,7 & 16,4 & 18,6 & 21,2 & 24,8 & 29,5 & 36,3 \\
\hline 18 anos & 16,7 & 18,5 & 21,3 & 24,9 & 28,9 & 14,7 & 16,4 & 18,6 & 21,3 & 24,8 & 29,5 & 36,3 \\
\hline 18 anos e 1 mês & 16,7 & 18,5 & 21,3 & 24,9 & 28,9 & 14,7 & 16,5 & 18,6 & 21,3 & 24,8 & 29,5 & 36,3 \\
\hline 18 anos e 2 meses & 16,7 & 18,5 & 21,3 & 25,0 & 28,9 & 14,7 & 16,5 & 18,6 & 21,3 & 24,8 & 29,6 & 36,3 \\
\hline 18 anos e 3 meses & 16,7 & 18,5 & 21,3 & 25,0 & 28,9 & 14,7 & 16,5 & 18,6 & 21,3 & 24,8 & 29,6 & 36,3 \\
\hline 18 anos e 4 meses & 16,7 & 18,5 & 21,3 & 25,0 & 28,9 & 14,7 & 16,5 & 18,6 & 21,3 & 24,8 & 29,6 & 36,3 \\
\hline 18 anos e 5 meses & 16,7 & 18,5 & 21,3 & 25,0 & 28,9 & 14,7 & 16,5 & 18,6 & 21,3 & 24,9 & 29,6 & 36,2 \\
\hline 18 anos e 6 meses & 16,7 & 18,5 & 21,3 & 25,0 & 29,0 & 14,7 & 16,5 & 18,6 & 21,3 & 24,9 & 29,6 & 36,2 \\
\hline 18 anos e 7 meses & 16,7 & 18,6 & 21,4 & 25,0 & 29,0 & 14,7 & 16,5 & 18,6 & 21,4 & 24,9 & 29,6 & 36,2 \\
\hline 18 anos e 8 meses & 16,7 & 18,6 & 21,4 & 25,1 & 29,0 & 14,7 & 16,5 & 18,6 & 21,4 & 24,9 & 29,6 & 36,2 \\
\hline 18 anos e 9 meses & 16,7 & 18,6 & 21,4 & 25,1 & 29,0 & 14,7 & 16,5 & 18,7 & 21,4 & 24,9 & 29,6 & 36,2 \\
\hline 18 anos e 10 meses & 16,7 & 18,6 & 21,4 & 25,1 & 29,0 & 14,7 & 16,5 & 18,7 & 21,4 & 24,9 & 29,6 & 36,2 \\
\hline 18 anos e 11 meses & 16,7 & 18,6 & 21,4 & 25,1 & 29,0 & 14,7 & 16,5 & 18,7 & 21,4 & 25,0 & 29,7 & 36,2 \\
\hline 19 anos & 16,7 & 18,6 & 21,4 & 25,1 & 29,0 & 14,7 & 16,5 & 18,7 & 21,4 & 25,0 & 29,7 & 36,2 \\
\hline
\end{tabular}

Fonte: World Health Organization (2007). 
Anexo I - Percentis e escore z selecionados de estatura $(\mathrm{cm})$ para idade (em anos) para adolescentes (10 aos 19 anos), segundo sexo

\begin{tabular}{|c|c|c|c|c|c|c|c|c|c|c|c|c|}
\hline \multirow[b]{2}{*}{ Idade (anos) } & \multicolumn{5}{|c|}{ Percentis } & \multicolumn{7}{|c|}{ Escore $z$} \\
\hline & 3 & 15 & 50 & 85 & 97 & -3 & -2 & -1 & 0 & 1 & 2 & 3 \\
\hline \multicolumn{13}{|c|}{ Masculino } \\
\hline 10 & 118,1 & 125,8 & 129,6 & 137,8 & 149,8 & 118,7 & 125,0 & 131,4 & 137,8 & 144,2 & 150,5 & 156,9 \\
\hline 11 & 122,3 & 130,5 & 134,5 & 143,1 & 155,8 & 122,9 & 129,7 & 136,4 & 143,1 & 149,8 & 156,6 & 163,3 \\
\hline 12 & 127,2 & 135,8 & 140,0 & 149,1 & 162,4 & 127,8 & 134,9 & 142,0 & 149,1 & 156,2 & 163,3 & 170,3 \\
\hline 13 & 133,1 & 142,1 & 146,5 & 156,0 & 170,0 & 133,8 & 141,2 & 148,6 & 156,0 & 163,5 & 170,9 & 178,3 \\
\hline 14 & 139,4 & 148,7 & 153,3 & 163,2 & 177,6 & 140,1 & 147,8 & 155,5 & 163,2 & 170,9 & 178,6 & 186,3 \\
\hline 15 & 144,8 & 154,3 & 159,0 & 169,0 & 183,6 & 145,5 & 153,4 & 161,2 & 169,0 & 176,8 & 184,6 & 192,4 \\
\hline 16 & 148,9 & 158,3 & 162,9 & 172,9 & 187,5 & 149,6 & 157,4 & 165,1 & 172,9 & 180,7 & 188,4 & 196,2 \\
\hline 17 & 151,5 & 160,8 & 165,4 & 175,2 & 189,5 & 152,2 & 159,9 & 167,5 & 175,2 & 182,8 & 190,4 & 198,1 \\
\hline 18 & 153,1 & 162,1 & 166,6 & 176,1 & 190,2 & 153,7 & 161,2 & 168,7 & 176,1 & 183,6 & 191,1 & 198,6 \\
\hline 19 & 154,0 & 162,8 & 167,2 & 176,5 & 190,3 & 154,6 & 161,9 & 169,2 & 176,5 & 183,8 & 191,1 & 198,4 \\
\hline \multicolumn{13}{|c|}{ Feminino } \\
\hline 10 & 118,9 & 126,6 & 130,4 & 138,6 & 150,7 & 119,4 & 125,8 & 132,2 & 138,6 & 145,0 & 151,4 & 157,8 \\
\hline 11 & 124,5 & 132,5 & 136,5 & 145,0 & 157,5 & 125,1 & 131,7 & 138,3 & 145,0 & 151,6 & 158,3 & 164,9 \\
\hline 12 & 130,1 & 138,4 & 142,5 & 151,2 & 164,1 & 130,7 & 137,6 & 144,4 & 151,2 & 158,1 & 164,9 & 171,8 \\
\hline 13 & 134,9 & 143,3 & 147,5 & 156,4 & 169,4 & 135,6 & 142,5 & 149,4 & 156,4 & 163,3 & 170,3 & 177,2 \\
\hline 14 & 138,3 & 146,7 & 150,9 & 159,8 & 172,8 & 139,0 & 145,9 & 152,8 & 159,8 & 166,7 & 173,7 & 180,6 \\
\hline 15 & 140,4 & 148,7 & 152,9 & 161,7 & 174,6 & 141,0 & 147,9 & 154,8 & 161,7 & 168,5 & 175,4 & 182,3 \\
\hline 16 & 141,5 & 149,8 & 153,8 & 162,5 & 175,3 & 142,2 & 148,9 & 155,7 & 162,5 & 169,3 & 176,1 & 182,9 \\
\hline 17 & 142,2 & 150,3 & 154,3 & 162,9 & 175,4 & 142,8 & 149,5 & 156,2 & 162,9 & 169,5 & 176,2 & 182,9 \\
\hline 18 & 142,6 & 150,6 & 154,6 & 163,1 & 175,5 & 143,2 & 149,8 & 156,5 & 163,1 & 169,7 & 176,3 & 182,9 \\
\hline 19 & 142,9 & 150,9 & 154,8 & 163,2 & 175,5 & 143,5 & 150,1 & 156,6 & 163,2 & 169,7 & 176,2 & 182,8 \\
\hline
\end{tabular}

Fonte: World Health Organization (2007). 
Anexo J - Gráfico para avaliação nutricional de gestante segundo IMC por semana gestacional

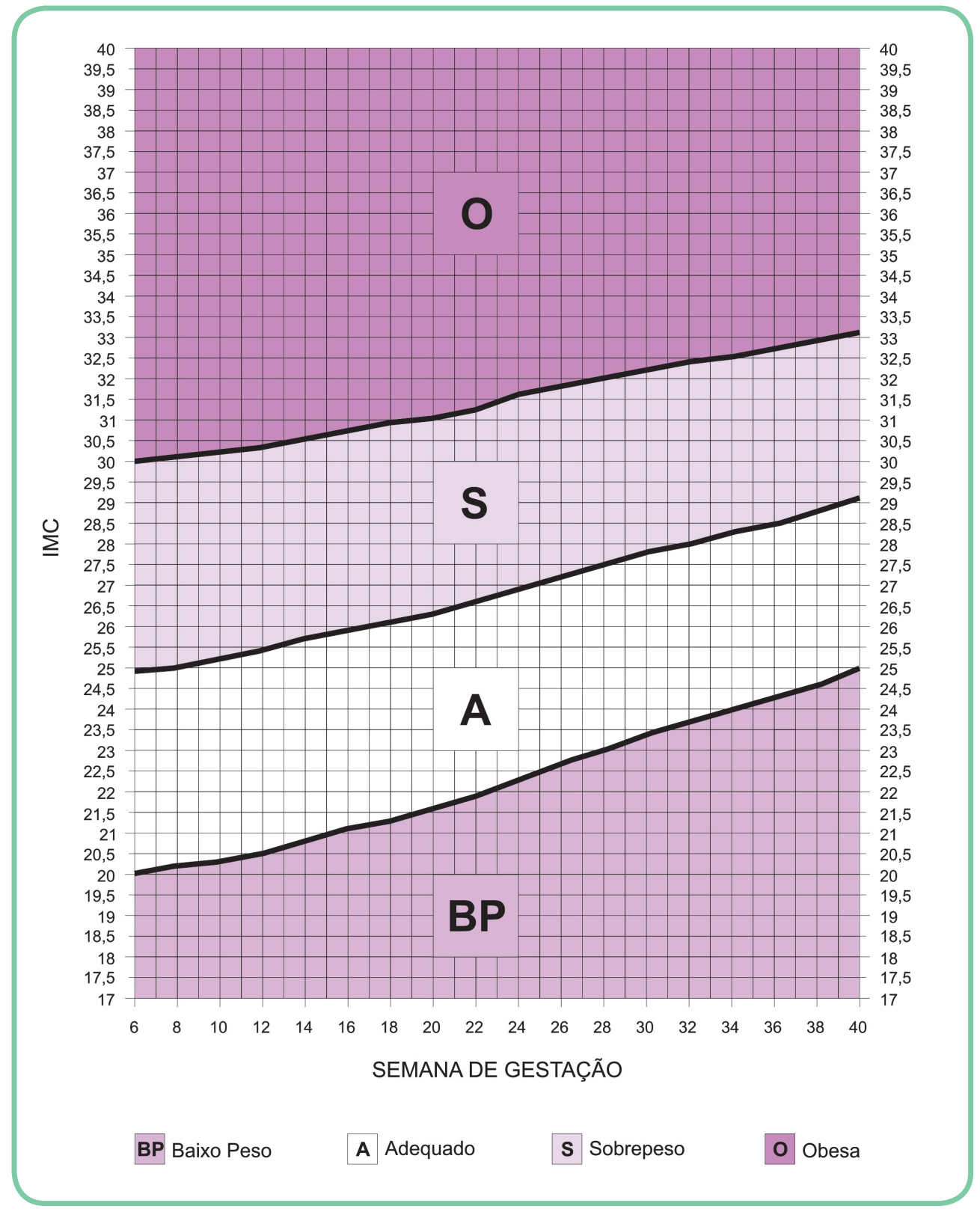

Fonte: Atalah; Castilho; Castro (1997) 
Anexo J1 - Gráfico para avaliação nutricional de gestante segundo IMC por semana gestacional, para marcação da gestante Lúcia

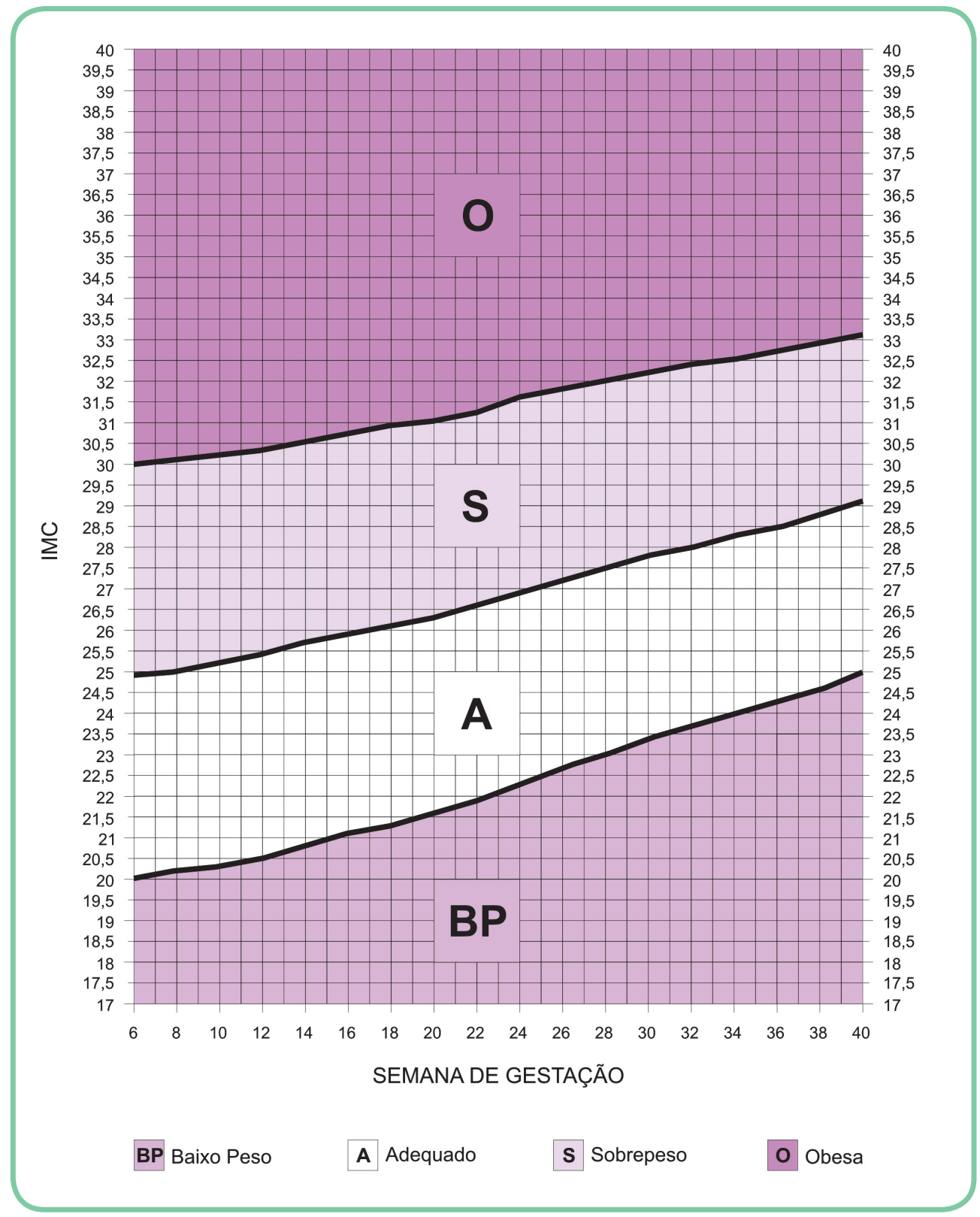

Fonte: Atalah; Castilho; Castro (1997). 
Anexo J2 - Gráfico para avaliação nutricional de gestante segundo IMC por semana gestacional, para marcação da gestante Teresa

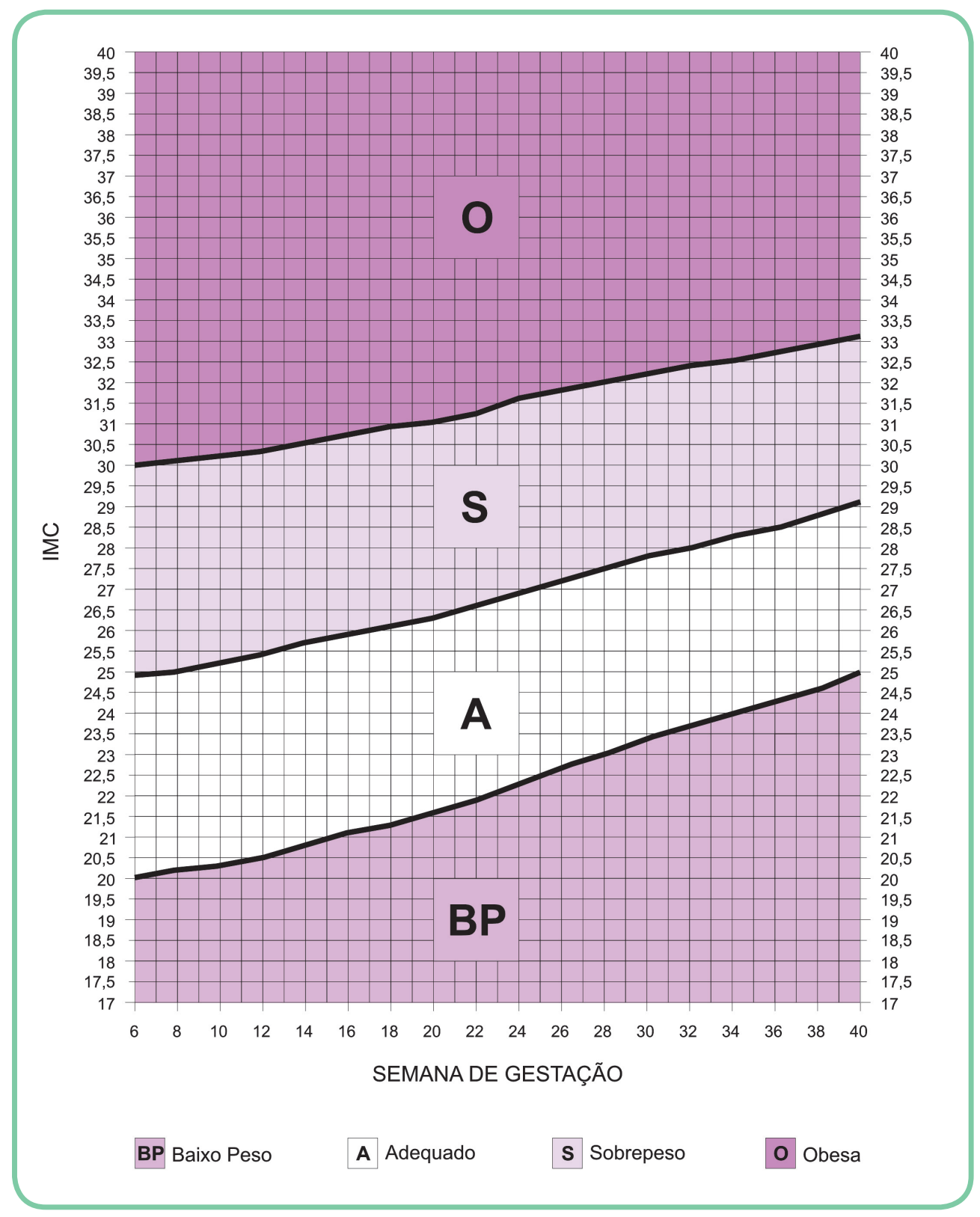

Fonte: Atalah; Castilho; Castro (1997) 
Anexo J3 - Gráfico para avaliação nutricional de gestante segundo IMC por semana gestacional, para marcação da gestante Marta

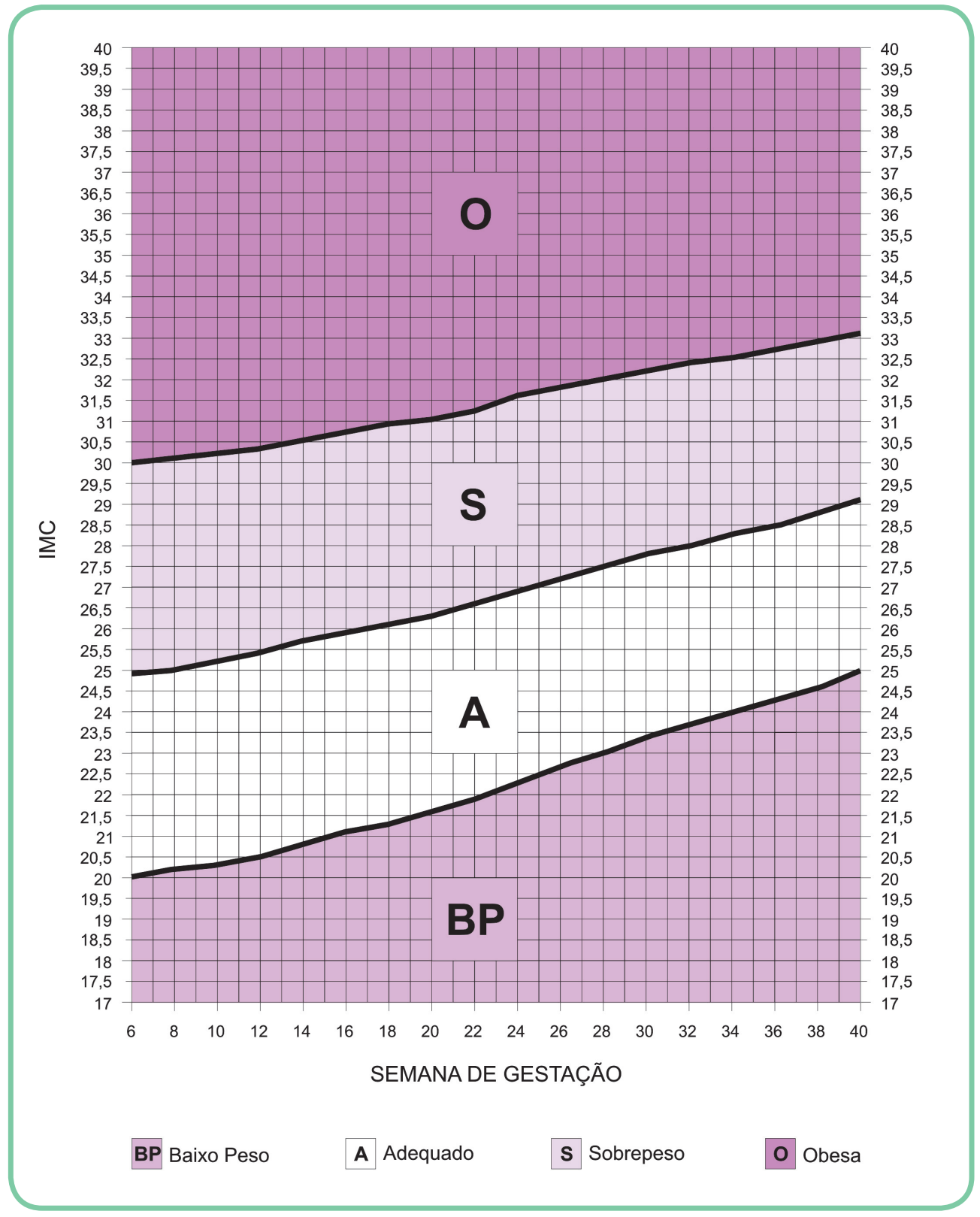

Fonte: Atalah; Castilho; Castro (1997). 


\section{Diagnóstico nutricional coletivo}




\section{Construção do fluxo de dados}

Denise Oliveira e Silva

Aline Diniz Rodrigues Caldas

Este Capítulo tem por objetivo discutir as bases do Sisvan, isto é, os aspectos a considerar no planejamento e organização de um sistema de informação. Nele são discutidas questões relacionadas ao diagnóstico coletivo, tais como, fluxo, fonte, coleta e tratamento dos dados para o diagnóstico nutricional de um indivíduo e, posteriormente, da coletividade.

Nosso intuito é oferecer fundamentos teóricos para que você possa realizar o diagnóstico nutricional coletivo, ou seja, conhecer a situação de saúde e nutrição de uma coletividade, gerando informações que possam contribuir para orientar as ações a serem propostas pelos técnicos e/ou gestores, permitindo, assim, a reorganização dos serviços e, conseqüentemente, a melhoria da qualidade da assistência prestada à saúde.

\section{Diagnóstico nutricional coletivo}

O conhecimento da situação de saúde e nutrição de uma coletividade - seja de pessoas atendidas nos serviços de saúde (clientela), seja da população de uma dada região geográfica (comunidade) - é denominado diagnóstico nutricional coletivo (SILVA; ENGSTROM; ZABOROWSKI, 2002).

O diagnóstico coletivo é sempre precedido por diagnósticos individuais, sendo resultante de agregações destes. Isso quer dizer que somente por meio de diagnósticos realizados em cada pessoa separadamente poderemos construir o diagnóstico de uma determinada população. Ao realizar 
As técnicas e procedimentos para a realização do diagnóstico nutricional individual em cada fase do curso de vida foram abordados no Capítulo 2, "Antropometria", deste livro.

Para a análise dos dados produzidos nos serviços de saúde são utilizados métodos epidemiológicos e estatísticos que serão aprofundados no próximo Capítulo, "Análise e interpretação dos dados".

O conceito, o histórico e a organização do Sisvan são discutidos no Capítulo 6, volume 1 do livro Vigilância Alimentar e Nutricional para a Saúde Indígena, de Denise Cavalcante Barros, Denise Oliveira e Silva e Silvia Ângela Gugelmin (2007).
Observe que em todas as etapas do diagnóstico nutricional, seja na tomada de medidas antropométricas, no diagnóstico nutricional e coletivo, reforçamos a importância de usar informações de boa qualidade e confiáveis. Para obtê-las, recomendamos adotar procedimentos e critérios padronizados na rotina de diagnósticos, de registro e fluxo de trabalho, em paralelo à formação permanente dos profissionais envolvidos no Sisvan. um diagnóstico coletivo é preciso ter clareza do que ele representa, considerando seus limites (perda da identidade individual) e potencialidades (possibilidade de representação coletiva).

O diagnóstico individual é feito rotineiramente nos serviços de saúde, sendo facilmente entendido pela maioria dos profissionais. Para realizá-lo, é preciso organizar uma série de procedimentos, com ferramentas de trabalho próprias. No caso do diagnóstico individual, é recomendado o uso da antropometria e de indicadores específicos para cada fase do curso de vida.

O diagnóstico coletivo, embora de grande importância para os serviços de saúde, é desconhecido por quase todos os profissionais. Só por meio dele é possível traçar um perfil ou um "retrato" de um grupo/coletividade. Para realizá-lo também precisamos organizar uma seqüência de procedimentos e, para isso, usamos alguns conceitos e métodos da epidemiologia e da estatística, os quais serão tratados mais adiante.

Devido à diversidade de problemas nutricionais e dos serviços de saúde existentes, faz-se necessária a realização de diagnósticos coletivos locais atualizados e com informações de boa qualidade. Eles servirão para orientar as ações a serem propostas pelos técnicos e/ou gestores, permitindo a reorganização dos serviços e, conseqüentemente, melhorando a qualidade da assistência prestada à saúde.

Esta é a missão do Sisvan: transformar os "vários casos" em informação para ação (SILVA; BARROS, 2007). Para isso acontecer é essencial que haja uma padronização das atividades, a fim de propiciar uma homogeneidade de procedimentos em todos os serviços. Assim, os dados coletados permitirão a construção de um sistema de informação confiável.

Para fazermos um diagnóstico coletivo, precisamos seguir uma série de etapas, que chamamos de fluxo de dados. Esse fluxo tem de ser padronizado, de modo a gerar informações confiáveis e relevantes, resultando em ações que possam promover a saúde, assim como prevenir e reverter agravos nutricionais detectados. 


\section{Fluxo de dados}

O primeiro passo para a construção do Sisvan é a definição do fluxo de dados, cujo objetivo é padronizar e tornar mais ágil o caminho percorrido pelos dados. Desse modo, poderemos acertar o relógio da informação-ação, gerando informações confiáveis para proporcionar a harmonia eficiente entre a epidemiologia e o planejamento de ações. “Acertar o relógio do diagnóstico nutricional no âmbito do Sisvan é buscar a confiabilidade das informações para ações de promoção, prevenção e recuperação nutricional. Para isso, é preciso organizar o sistema, construindo um fluxo para a geração de informações" (SILVA; ENGSTROM; ZABOROWSKI, 2002, p.82).

Para começar, vamos exemplificar um fluxo de dados básico de qualquer sistema de informação. Como você verá a seguir, esse esquema gráfico é muito simples.

Figura 1 - Desenho básico de fluxo de dados de um sistema de informação

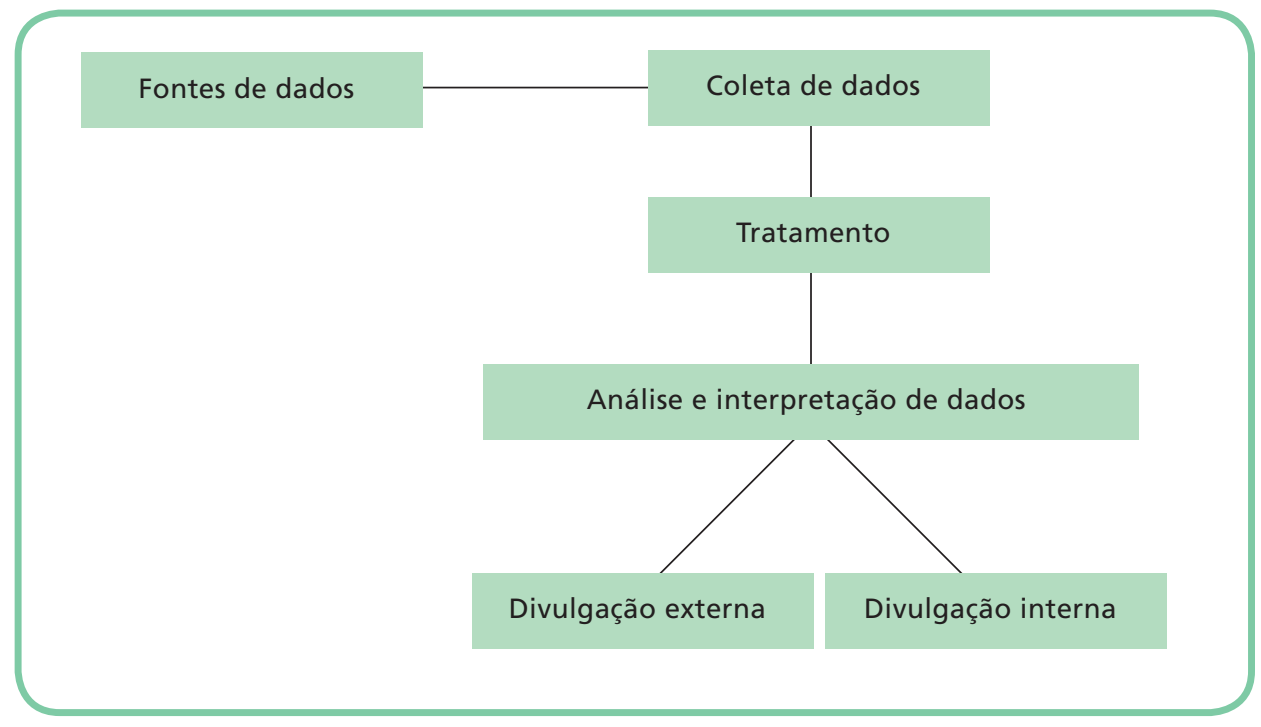

Fonte: Silva; Engstrom; Zaborowski (2002, p.83).

\section{Para refletir}

Vamos organizar o fluxo de dados de seu distrito sanitário ou pólo-base? Você já realizou essa ação? Em caso afirmativo, reflita sobre as etapas executadas no processo. Agora trace um paralelo entre sua experiência e o proposto até o momento. 
Um maior detalhamento sobre a organização do Sisvan no Brasil pode ser encontrado no Capítulo 6 , volume 1 do livro Vigilância Alimentar e Nutricional para a Saúde Indígena, de Denise Cavalcante Barros, Denise Oliveira e Silva e Silvia Ângela Gugelmin (2007).

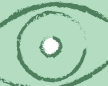

Conheça os sistemas de informação e vigilância em saúde do Brasil no endereço eletrônico do Datasus, na opção produtos e serviços, com destaque para o Sisvan-Nacional, que você pode consultar na página eletrônica do MS, na opção Sisvan. Leia atentamente os objetivos dos sistemas e registre seus comentários.
Antes de iniciarmos, é fundamental que você tenha lido a publicação Vigilância Alimentar e Nutricional para os Distritos Sanitários Especiais Indígenas: Norma Técnica da Funasa para o Sisvan Indígena (FUNDAÇÃO NACIONAL DE SAÚDE, 2005), disponível no endereço eletrônico da instituição, na parte referente às publicações da área de saúde indígena. Ela oferece os alicerces para que você possa construir o fluxograma ao final deste Capítulo. Vamos por etapas!

Como devemos identificar a fonte de dados?

O Sisvan no Brasil é um sistema que pode ser construído com dados primários coletados diretamente de procedimentos realizados em serviços de saúde e programas comunitários. Também pode ter como ponto de partida dados secundários baseados em fontes de sistemas de informação e vigilância em saúde, como o Sistema de Informação de Mortalidade (Sim), o Sistema de Informação de Nascidos Vivos (Sinasc), o Sistema de Informação de Agravos de Notificação (Sinan), o Sistema de Informação da Atenção Básica (Siab) e o Sistema de Informação Hospitalar do SUS (SIH-SUS).

Nas áreas indígenas - e atualmente nos DSEI - a Funasa estabeleceu um modelo diferenciado para a implantação do Sisvan, baseado em três fontes de informação:

- dados produzidos na rotina dos serviços (dados primários);

- inquéritos populacionais, como o Inquérito Nacional de Saúde e Nutrição dos Povos Indígenas, iniciativa da Funasa/Projeto Vigisus II, com a coordenação da Associação Brasileira de Pós-Graduação em Saúde Coletiva (Abrasco) e o apoio técnico do Ministério do Desenvolvimento Social e Combate à Fome (MDS);

- sistema de informação e vigilância em saúde próprio, o Sistema de Informação em Saúde Indígena (Siasi).

Por isso, cuidados devem ser tomados para permitir que haja interface entre os processos e procedimentos realizados para evitar a duplicidade de tarefas e informações.

Neste livro vamos destacar a fonte de dados primários baseada nos procedimentos de atenção básica à saúde da população indígena nos DSEI.

Você já pensou onde o seu fluxo de dados vai começar? Com esse ponto definido, estabelecemos o início do fluxo e, portanto, a fonte de dados 
que vamos utilizar. Pode ser, por exemplo, o local onde são realizados os primeiros procedimentos antropométricos.

Como você deve ter observado na leitura da Norma Técnica para o Sisvan Indígena, a proposta é que os dados sejam gerados pela equipe de profissionais do pólo-base. É importante que a definição dessa fonte seja compatível e adequada à realidade operacional e à logística das ações ou dos programas desenvolvidos. Nesse momento devem ser definidos quem, o que e como começa o fluxo de dados.

\section{PARA PRATICAR - DEFINIÇÃO DA FONTE DE DADOS}

Com base na proposta da Funasa a respeito do fluxo de dados, reflita sobre a sua realidade e justifique a fonte de dados escolhida para a construção do fluxograma em seu serviço. Sugerimos que essa escolha seja partilhada com os parceiros de trabalho.

Agora que estamos com a(s) fonte(s) de dados definida(s) podemos passar à próxima etapa da construção. Vamos ao caminho da coleta de dados!

Como deve ser feita a coleta de dados?

Releia a Norma Técnica para o Sisvan Indígena e resgate a descrição dos procedimentos de organização da coleta de dados. Observe que a proposta do documento deve ser considerada como recomendações gerais de padronização. Você deve atender a essas recomendações com base na sua realidade operacional, considerando a disponibilidade de recursos financeiros, de pessoal e equipamentos em sua(s) unidade (s).

Essa etapa pressupõe que vamos coletar dados produzidos pelo serviço. As perguntas que devemos responder são:

- Que dados serão coletados?

- Que instrumentos serão necessários para a coleta dos dados selecionados?

- Quando os dados serão coletados?

- Qual será o local da coleta?

- Quem serão os responsáveis pela coleta dos dados?

- Os responsáveis foram capacitados para a coleta e padronização dos dados? 
Embora a Norma Técnica para o Sisvan Indígena (FUNDAÇÃO NACIONAL DE SAÚDE, 2005) responda a essas perguntas, é necessário compatibilizar as recomendações com a realidade local e com a oportunidade de intervir nos casos de risco nutricional. É preciso ter cuidado, pois a informação de que dispomos nesse momento se refere a um ser humano e, portanto, deve ser priorizada. Não podemos transformar o número em nossa maior prioridade, e sim valorizar esse momento da coleta de dados como importante na identificação dos casos de risco nutricional.

A coleta de dados é a base de sustentação do Sisvan, por ser a porta de entrada do sistema. Essa fase é um momento único, uma oportunidade singular que deve ser aproveitada e valorizada tanto para a geração de informação quanto para intervenção nos casos de risco nutricional Procedimentos padronizados e organizados contribuirão na qualidade dos dados, na melhoria da assistência prestada à população, e também na consolidação de um sistema de informação confiável (SILVA; ENGSTROM; ZABOROWSKI, 2002).

Um procedimento muito adequado para organizar bem essa etapa é a construção de um quadro com os dados e instrumentos necessários para o diagnóstico nutricional, segundo a fase do curso de vida. Veja o exemplo apresentado no Quadro 1.

Quadro 1 - Dados e instrumentos necessários para o diagnóstico nutricional, segundo as fases do curso de vida

\begin{tabular}{|c|c|c|c|}
\hline \multirow[t]{2}{*}{ Curso de vida } & \multicolumn{2}{|l|}{ Dados para coletar } & \multirow{2}{*}{$\begin{array}{l}\text { Instrumentos para classificação do } \\
\text { estado nutricional }\end{array}$} \\
\hline & Identificação & Antropométricos & \\
\hline $\begin{array}{l}\text { Crianças } \\
\text { menores de } \\
5 \text { anos }\end{array}$ & $\begin{array}{l}\text { - Data de nascimento/data de consulta (cálculo de idade) } \\
\text { - Número de prontuário } \\
\text { - Tipo de consulta no mês: primeira vez ou subseqüente } \\
\text { - Estado nutricional } \\
\text { - Condição do diagnóstico nutricional } \\
\text { - Participação em programas de suplementação alimentar }\end{array}$ & - Peso na consulta & $\begin{array}{l}\text { - Caderneta de Saúde da Criança com o } \\
\text { gráfico peso/idade em percentis ou tabela } \\
\text { com peso/idade } \\
\text { - Equipamentos: balanças, bancada ou } \\
\text { mesa para troca de roupa de bebês }\end{array}$ \\
\hline $\begin{array}{l}\text { Escolares } \\
\text { e } \\
\text { adolescentes }\end{array}$ & $\begin{array}{l}\text { - Data de nascimento/data da consulta (cálculo de idade) } \\
\text { - Número de prontuário ou ficha escolar } \\
\text { - Tipo de consulta no mês: primeira vez ou subseqüente } \\
\text { - Estado nutricional } \\
\text { - Condição do diagnóstico nutricional }\end{array}$ & $\begin{array}{l}\text { - Peso na consulta } \\
\text { - Estatura na } \\
\text { consulta }\end{array}$ & $\begin{array}{l}\text { - Escolar: Caderneta de Saúde da Criança } \\
\text { com gráfico estatura e peso para idade em } \\
\text { percentis ou tabelas de estatura/idade e } \\
\text { peso/idade em desvio-padrão (NCHS) } \\
\text { - Adolescente: cálculo IMC por } \\
\text { nomograma ou calculadora } \\
\text { - Tabela em percentis de IMC } \\
\text { - Pranchas de Tanner } \\
\text { - Equipamentos: balança, antropômetro }\end{array}$ \\
\hline
\end{tabular}


Quadro 1 - Dados e instrumentos necessários para o diagnóstico nutricional, segundo as fases do curso de vida (cont.)

\begin{tabular}{|c|c|c|c|}
\hline \multirow[t]{2}{*}{ Curso de vida } & \multicolumn{2}{|l|}{ Dados para coletar } & \multirow{2}{*}{$\begin{array}{l}\text { Instrumentos para classificação do } \\
\text { estado nutricional }\end{array}$} \\
\hline & Identificação & Antropométricos & \\
\hline Gestantes & $\begin{array}{l}\text { - Número de prontuário } \\
\text { - Idade } \\
\text { - Semana gestacional } \\
\text { - Tipo de consulta no mês: primeira vez ou subseqüente } \\
\text { - Estado nutricional } \\
\text { - Condição do diagnóstico nutricional } \\
\text { - Participação em programas de suplementação } \\
\text { alimentar }\end{array}$ & $\begin{array}{l}\text { - Peso } \\
\text { pré-gestacional } \\
\text { - Peso na consulta } \\
\text { - Estatura na } \\
\text { 1'a consulta }\end{array}$ & $\begin{array}{l}\text { - Cálculo do IMC: disco, nomograma ou } \\
\text { calculadora } \\
\text { - Cálculo semana gestacional por fórmula, } \\
\text { tabela ou disco } \\
\text { - Tabela ou gráficos com valores IMC por } \\
\text { semana gestacional } \\
\text { - Tabela para cálculo ganho de peso } \\
\text { recomendado por peso pré-gestacional } \\
\text { - Equipamentos: balança, antropômetro }\end{array}$ \\
\hline $\begin{array}{l}\text { Adultos } \\
\text { e idosos }\end{array}$ & $\begin{array}{l}\text { - Número de prontuário } \\
\text { - Idade } \\
\text { - Tipo de consulta no mês: primeira vez ou subseqüente } \\
\text { - Estado nutricional } \\
\text { - Condição do diagnóstico nutricional }\end{array}$ & $\begin{array}{l}\text { - Peso na consulta } \\
\text { - Estatura na } \\
1^{\text {a }} \text { consulta/ano }\end{array}$ & $\begin{array}{l}\text { - Cálculo do IMC por nomograma da } \\
\text { OMS, disco ou calculadora } \\
\text { - Equipamentos: balança, antropômetro }\end{array}$ \\
\hline
\end{tabular}

Fonte: Adaptado de Silva; Engstrom; Zaborowski (2002, p. 93).

Os dados mencionados no Quadro 1 deverão ser registrados, diariamente, na rotina de visitas e nas consultas das equipes multidisciplinares de saúde, incluindo os Agentes Indígenas de Saúde (AIS), e também nas unidades de saúde que prestam atendimento aos usuários indígenas. O registro deve ser feito em folhas padronizadas, denominadas formulários, mapas, planilhas. A periodicidade diária é importante, pois a informação do estado nutricional do indivíduo deve vir sempre acompanhada por uma intervenção adequada. O registro da condição do diagnóstico nutricional deve esclarecer se é um primeiro diagnóstico, ou um diagnóstico de acompanhamento, que se refere a uma mudança na situação nutricional (melhora ou piora), ou manutenção do estado nutricional. Portanto, a equipe técnica responsável pela organização do Sisvan deve estabelecer uma rotina de coleta, oferecendo boas condições para a realização de todos os procedimentos (FUNDAÇÃO NACIONAL DE SAÚDE, 2005).

Quase sempre as condições de logística e equipamentos para a realização das medidas antropométricas nas aldeias, nos pólos e distritos sanitários são variadas e complexas. Em geral existem muitas dificuldades operacionais para a efetuação dessas medidas e, principalmente, do registro dos dados nos formulários. É importante que os responsáveis pelo Sisvan encontrem soluções adequadas à realidade local e que garantam a confiabilidade da coleta dos dados. Para isso, é preciso ter em mente que todos são responsáveis pela coleta. Embora exista um coordenador 
Os cuidados na realização dos procedimentos antropométricos foram apresentados no Capítulo 2 deste livro.
Para compreender melhor a dinâmica dos formulários, consulte os exemplos propostos pela Funasa (FUNDAÇÃO NACIONAL DE SAÚDE, 2005), apresentados no Anexo A Mapa diário de acompanhamento, e no Anexo B - Mapa mensal de acompanhamento. ou responsável perante a Funasa, todos os envolvidos precisam ter suas tarefas definidas e padronizadas. A supervisão de todas as ações realizadas nessa etapa, dada a rotatividade de pessoal, é fundamental para a qualidade do dado.

Na coleta de dados é importante estar atento à produção e ao registro do dado. É preciso lembrar que na produção dos dados podem surgir erros na aferição das medidas antropométricas e na classificação do estado nutricional. Geralmente esses erros se relacionam à falta de atenção na realização dos procedimentos, das técnicas de medição ou do registro de informações; a problemas no uso de instrumentos - como tabelas e gráficos - incorretos, equipamentos mal conservados; e à falta de supervisão e reciclagem de pessoal. Devemos evitar erros que possam comprometer a qualidade dos dados, pois dificilmente poderemos aproveitar dados mal coletados (SILVA; ENGSTROM; ZABOROWSKI, 2002).

\section{PARA PRATICAR - COLETA DE DADOS}

Observe, detalhadamente, como a coleta de dados referente ao estado nutricional está organizada em seu serviço. Veja se os requisitos necessários para que ela seja bem feita estão sendo seguidos, tanto na produção quanto no registro de dados. Ao final, comente essa fase e faça uma proposta de reorganização, apontando a(s) falha(s) porventura existente(s), para que a coleta seja realizada corretamente. Se você trabalha em um serviço em que a coleta ainda não é realizada, organize-a. Para sua orientação, considere as seguintes questões: população de interesse; dados a serem coletados; indicadores; periodicidade de coleta; local de coleta; responsáveis pela coleta; uniformização e padronização na aferição das medidas e na classificação do estado nutricional; supervisão.

Para finalizar essa etapa é importante pensar na utilização dos formulários. Segundo a Norma Técnica (FUNDAÇÃO NACIONAL DE SAÚDE, 2005) foram propostos dois formulários para o registro dos dados:

- Mapas diários de acompanhamento - separados por fases do curso de vida, neles constam dados básicos, tais como identificação do sujeito, faixa etária, sexo, estado nutricional, tipo de consulta. A coleta de dados de forma individualizada permite resgatar a informação no momento do tratamento e da análise dos dados, confirmando o registro, uma vez detectado algum erro. Os formulários devem ser preenchidos pela equipe multidisciplinar de saúde na rotina diária. 
- Mapas mensais de acompanhamento - também divididos por fases do curso de vida, já apresentam os dados consolidados. A Funasa construiu mapas mensais para consolidação e envio de dados nos diferentes níveis de atuação - da equipe para o pólo; dos pólos para o DSEI; e dos DSEI para o DESAI.

Até agora, a previsão é que esses formulários sejam preenchidos manualmente e de forma paralela ao Sistema de Informação da Atenção à Saúde Indígena (Siasi), pois ainda não existe um módulo informatizado para registro das informações nutricionais. Os procedimentos para o preenchimento podem ser alterados a qualquer momento, caso o Siasi incorpore o registro do estado nutricional e funcione de forma contínua e confiável.

\section{SISTEMA DE INFORMAÇÃO DA ATENÇÃO À SAÚDE INDÍGENA}

A Funasa utiliza o Sistema de Informação da Atenção à Saúde Indígena (Siasi) com o objetivo de acompanhar a situação de saúde dos índios e de agilizar a tomada de decisões sobre ações de combate, controle e prevenção de doenças. Esse sistema foi estruturado para funcionar em módulos e permitir um melhor acompanhamento de dados sobre demografia, morbidade, imunização, estado nutricional, saúde bucal, entre outros. No entanto, diversas limitações impossibilitam seu pleno funcionamento em nível nacional. Uma delas diz respeito ao acesso à informação, pois o sistema não disponibiliza as informações para o público, limitando a participação e o controle social no acompanhamento das ações de saúde. A normatização da entrada de dados, com filtros para evitar duplicidade de registro e erros de digitação; a ampliação de sua capacidade de análise; a atualização constante de seus registros; e a construção de uma interface com os diversos sistemas de informação existentes são problemas a serem superados, a fim de que funcione, de fato, como um instrumento para a vigilância em saúde (SOUSA; SCATENA; SANTOS, 2007). Apesar de todas as fragilidades do Siasi, a equipe técnica do Sisvan reconhece a importância de se ter um sistema de informação que possibilite, de forma contínua e efetiva, o acompanhamento e a avaliação das condições de saúde de uma população.

Com o módulo "Nutrição" do Siasi implantado em nível nacional, os procedimentos de coleta de dados deverão ser adaptados ao sistema informatizado pelos responsáveis do Sisvan, como uma prioridade. O intuito será organizar um processo de coleta de dados único para todo o Distrito Sanitário, evitando paralelismo e duplicidade de formulários 


\section{0}

O Epi Info é um programa de domínio público, desenvolvido pelo Centro de Controle e Prevenção de Doenças dos EUA, e de fácil acesso na página eletrônica do CDC (www. cdc.org). A OMS também disponibiliza, em sua página eletrônica (www.who.int), a ferramenta Anthro-2005, de domínio público, para consolidação e análise de dados antropométricos de crianças menores de cinco anos. para a coleta de dados. Essa estratégia fortalecerá o ideário de unificação de sistemas de informação e vigilância em saúde, onde os dados preconizados para o Sisvan devem estar contemplados no Siasi.

Finalizada a etapa da coleta, precisamos ter certeza de que os dados são confiáveis para a construção do perfil de estado nutricional de nossa população. Para isso precisamos realizar o tratamento dos dados.

Como deve ser realizada a etapa de tratamento dos dados?

O tratamento dos dados é a etapa

na qual realizamos a "arrumação" dos valores brutos coletados, ou seja, sistematizamos os dados sobre o estado nutricional da clientela assistida. Essa fase ratifica o papel das informações do Sisvan como instrumento de planejamento, acompanhamento e avaliação das ações desenvolvidas na atenção à saúde (SILVA; ENGSTROM; ZABOROWSKI, 2002, p.113).

Essa etapa compreende, basicamente, a verificação de consistência e a consolidação dos dados.

A verificação de consistência ou "limpeza" de dados é um conjunto de procedimentos que busca identificar todos os erros porventura cometidos no momento da produção e do registro dos dados. Como os erros comprometem a qualidade da informação - seja qual for a situação -, precisamos estar atentos no momento da coleta dos dados, evitando assim possíveis equívocos.

Para identificarmos os erros devemos fazer uma leitura minuciosa dos formulários, realizando um checklist, ou seja, verificando se todos os dados previstos foram coletados; se os dados foram coletados conforme a padronização do serviço; se existem outliers (valores aberrantes ou não esperados para aquele procedimento).

A forma de realizar esse procedimento é identificar os dados coletados linha por linha, coluna por coluna do formulário. Baseado nos procedimentos propostos pela Norma Técnica (FUNDAÇÃO NACIONAL DE SAÚDE, 2005), o formulário que deve ser avaliado é o consolidado mensal (mapa mensal de acompanhamento), uma vez que ele é o instrumento que será utilizado na etapa de digitação dos dados. Esse procedimento pode ser feito a partir de sistemas informatizados (por exemplo, planilhas do Excel for Windows, banco de dados do Epi Info), que agrupam todos os dados segundo uma 
ordem preestabelecida, e mostra valores extremos ou incorretos (por exemplo: de faixa etária, sexo, peso, estatura e estado nutricional). É importante que a limpeza dos dados seja realizada concomitantemente com a digitação, evitando o acúmulo de formulários (BARROS; VICTORA, 1994).

O que fazer quando encontramos erros?

Em geral, quando encontramos erros, temos que identificar se podem ser corrigidos ou se o dado incorreto precisa ser excluído. Nos casos de correção, temos que retornar ao Mapa Diário e verificar se no momento da transposição do dado houve algum equívoco no registro. Caso não seja possível identificar o erro, o responsável deve começar a pensar na possibilidade de exclusão desse dado. Isso pode determinar a perda parcial ou total da informação. Por exemplo: se houve uma perda na coleta ou no registro do peso ou da altura, o estado nutricional não pode ser classificado. O mesmo problema pode ser constatado no caso de ausência de informação de sexo e faixa etária. Todos esses problemas determinam a perda total da informação nutricional.

Vejamos o seguinte exemplo: em uma unidade de saúde do pólo-base Cajueiro, DSEI Rio Folhas, a enfermeira Lúcia, em seu atendimento do dia 05/08/2007, preencheu o formulário apresentado a seguir.

Quadro 2 - Unidade de saúde da aldeia Picuí, Pólo-base Cajueiro, DSEl Rio Folhas, 2007

\begin{tabular}{|c|c|c|c|c|c|c|}
\hline \multicolumn{7}{|c|}{$\begin{array}{l}\text { Estado nutricional de crianças menores de cinco anos de idade } \\
\text { Dia: } 05 / 08 / 2007 \\
\text { Profissional: Lúcia }\end{array}$} \\
\hline Identificação & $\begin{array}{l}1^{\text {a }} \text { vez ou } \\
\text { subseqüente }\end{array}$ & Nome & $\begin{array}{l}\text { Data } \\
\text { nascimento }\end{array}$ & Idade & Peso & EN \\
\hline 2703 & $1^{\mathrm{a}} \mathrm{vez}$ & Daniel & 05/05/07 & $3 m$ & 5.100 & $\geq p 97$ \\
\hline ----- & $1^{\text {a }}$ vez & Maria & 02/02/05 & 2 a $6 m$ & 9.350 & $<\mathrm{p} 3$ \\
\hline 2957 & $1^{\text {a }}$ vez & Lea & $10 / 06 / 07$ & $2 m$ & 3.700 & p10-p3 \\
\hline 2302 & $1^{\text {a }}$ vez & Luís & 09/02/07 & $6 m$ & 8.050 & p97-p10 \\
\hline 2881 & $1^{\text {a }}$ vez & Denise & 10/09/07 & $1 \mathrm{~m}$ & 4.800 & p97-p10 \\
\hline 1476 & $1^{\text {a }}$ vez & Antônio & 29/07/04 & $3 a$ & 10.200 & $<\mathrm{P} 3$ \\
\hline 2100 & Subseqüente & Ricardo & 08/07/06 & 1a $1 \mathrm{~m}$ & 26.500 & $\geq 97$ \\
\hline ---- & $1^{\text {a }}$ vez & Kátia & $15 / 11 / 05$ & $9 m$ & 7.400 & p97-p10 \\
\hline 2235 & $1^{\text {a }}$ vez & José & 07/03/06 & $1 \mathrm{a} 5 \mathrm{~m}$ & 12.600 & p97-p10 \\
\hline 1834 & $1^{\text {a }}$ vez & Sônia & $20 / 12 / 04$ & $2 a 8 m$ & 11.550 & p10-p3 \\
\hline 1030 & Subseqüente & Paulo & 09/07/03 & $4 a 1 m$ & ---- & ---- \\
\hline
\end{tabular}


Conferindo os dados, podemos identificar, nas linhas destacadas:

a) classificação errada do estado nutricional, segundo o gráfico do Cartão da Criança: criança com três meses de idade e com 5.100 g tem peso adequado para a idade, sendo seu estado nutricional normal (entre plo e p97); o EN pode ser modificado e o dado, reaproveitado;

b) a data de nascimento (10/09/2007) é posterior à data da consulta (05/08/2007). É necessário rever a idade correta da criança no prontuário para reaproveitar o dado;

c) na idade de um ano e um mês, o peso de $26.500 \mathrm{~g}$ é aberrante. Confirmar se o dado é o mesmo que consta no prontuário; caso esteja correto, provavelmente houve erro de aferição ou no registro do peso. Desprezar o dado;

d) cálculo da idade errado: pela data de nascimento, a idade é um ano e nove meses, e não nove meses, como assinalado. Reaproveitar o dado;

e) omissão do registro do peso. Caso o valor do peso não conste do prontuário, será considerado sem informação.

Observe, ainda, que houve omissão de dois registros de identificação - o de Maria e o de Kátia -, embora as demais informações estejam presentes. Os dados das duas crianças podem ser aproveitados, porém teríamos dificuldade de retornar ao prontuário confirmando dados, se fosse necessário. Em determinadas situações, as correções não poderão ser realizadas, visto que os dados não foram coletados no momento oportuno (item e). Nesse caso, perdeu-se a oportunidade de realizar o diagnóstico nutricional da criança.

A verificação da consistência deverá ser sistemática e com revisão dos cálculos de estado nutricional e idade, caso se constatem erros. A revisão deve ser realizada por um profissional experiente e capacitado, que possa detectar erros em um "olhar atento" (itens b, c e d).

A periodicidade deve ser estipulada pelo serviço de saúde, de acordo com as suas reais possibilidades. Não devem ser acumulados muitos formulários para revisão, para não prejudicar as outras etapas do fluxo de dados. De acordo com o volume de dados, a verificação poderá ser diária ou semanal.

Existem duas opções para corrigir os possíveis erros encontrados nessa fase. A primeira é revisar as informações que constam no próprio formulário e corrigi-las. A segunda é fazer uma consulta ao prontuário/ ficha do usuário, que permitirá: 
- o resgate de dados que não foram registrados (data de nascimento; tipo de consulta: $1^{a}$ vez ou subseqüente; peso na consulta);

- a correção de dados, visto que alguns erros podem ter sido cometidos na transferência dos dados do prontuário/ficha para o formulário.

Quando temos que excluir dados de um consolidado mensal do Sisvan, essa decisão vai interferir no quantitativo geral do sistema. Trata-se de uma perda de informação que deve ser consolidada à parte, para dimensionarmos a qualidade do registro e da coleta de dados.

As recomendações são: excluir os casos e criar uma categoria denominada "sem informação" para estabelecer o valor absoluto e percentual desse problema. Essa medida permitirá, a cada mês, observar se o registro e a coleta estão inadequados e acionar estratégias de capacitação de pessoal e outras medidas, para melhorar a qualidade dos dados.

Você pode se perguntar qual o percentual de perdas de dados que aceitaríamos como adequado ao Sisvan. A resposta é zero. Temos que desenvolver um sistema de coleta em que esse problema não exista. É claro que as áreas indígenas apresentam problemas em relação à definição de data de nascimento, semana gestacional, peso ao nascer e outros relacionados à cultura dos povos indígenas. Mas recomendamos que o percentual de perdas seja sempre um valor desprezível.

Como consolidar os dados?

Com os dados limpos, temos que cumprir uma última etapa antes de começar a análise dos dados, que é a consolidação geral. Esse procedimento pode ser considerado uma pré-análise, porque consiste em uma ordenação baseada nas categorias previstas nos formulários e orientadas por níveis de agregação de variáveis.

Por exemplo: quando consolidamos faixa etária de menores de cinco anos, recomenda-se que sejam efetuadas freqüências absolutas e percentuais em cinco faixas: zero a cinco meses e 29 dias; seis a 11 meses e 29 dias; 12 a 23 meses e 29 dias; 24 a 35 meses e 29 dias; 36 a 59 meses e 29 dias. No caso dos indicadores de classificação de estado nutricional de crianças menores de cinco anos: p97 a p10; p10 a p3; $\geq 97 ;<$ p3.

A primeira consolidação é realizada em cada serviço de saúde. Ela deve ser feita mensalmente, visando totalizar os dados coletados diariamente na rotina dos atendimentos. Com os dados ordenados e consolidados
Os procedimentos para análise dos dados serão discutidos no próximo Capítulo deste livro, "Análise e interpretação dos dados". 
conforme os critérios previamente estabelecidos pela Funasa, será possível calcular as freqüências totais e percentuais, ou seja, iniciar o processo de análise dos dados.

A fase de tratamento de dados deve ser realizada em todos os níveis de atenção (unidades de saúde; pólos-base, distritos sanitários, departamento de saúde indígena - nível nacional do Sisvan) com verificação de consistência, ordenação e consolidação, formando o perfil nutricional da clientela atendida. Podemos, portanto, organizar diversos formulários de consolidação, com períodos de tempo e localizações geográficas distintas, segundo os objetivos definidos.

Os resultados dessa fase iniciam uma etapa fundamental do Sisvan: a análise dos dados. Nela você utilizará ferramentas estatísticas e epidemiológicas que ajudarão a transformar os dados em informações úteis para o desenvolvimento do seu trabalho na atenção à saúde.

\section{PARA PRATICAR - ANÁLISE DE CONSISTÊNCIA DOS DADOS}

Verifique se os formulários de coleta de dados estão adequados à rotina diária de seu serviço. Para isso, converse com os demais profissionais de saúde que atuam na coleta de dados com o intuito de identificar sua praticabilidade. Tendo em mãos um mapa diário de acompanhamento de crianças menores de cinco anos faça uma análise de consistência dos dados, explicando as etapas cumpridas para a identificação dos possíveis erros de registro e de classificação do estado nutricional.

\section{Referências}

BARROS, F.; VICTORA, C. G. Processamento de dados. In: Epidemiologia da saúde infantil: um manual para diagnósticos comunitários. 2. ed. São Paulo: Hucitec; Unicef, 1994. p. 125-136.

FUNDAÇÃO NACIONAL DE SAÚDE. Departamento Saúde Indígena. Vigilância alimentar e nutricional para os distritos sanitários especiais indígenas: norma técnica. Brasília, 2005.

SILVA, D. O.; BARROS, D. C. O sistema de vigilância alimentar e nutricional. In: BARROS, D. C.; SILVA, D. O.; GUGELMIN, S. A. Vigilância alimentar e nutricional para a saúde indígena. Rio de Janeiro: Fiocruz, 2007. p. 155-167.

ENGSTROM, E. M.; ZABOROWSKI, E. L. Sisvan: instrumento para o combate aos distúrbios nutricionais de saúde: diagnóstico coletivo. Rio de Janeiro: Fiocruz/Centro Colaborador em Alimentação e Nutrição, 2002.

SOUSA, M. C.; SCATENA, J. H. G.; SANTOS, R. V. O sistema de informação da atenção à saúde indígena (SIASI): criação, estrutura e funcionamento. Cadernos de Saúde Pública, Rio de Janeiro, v. 23, n. 4, p. 853-861, abr. 2007. 


\section{Anexos}

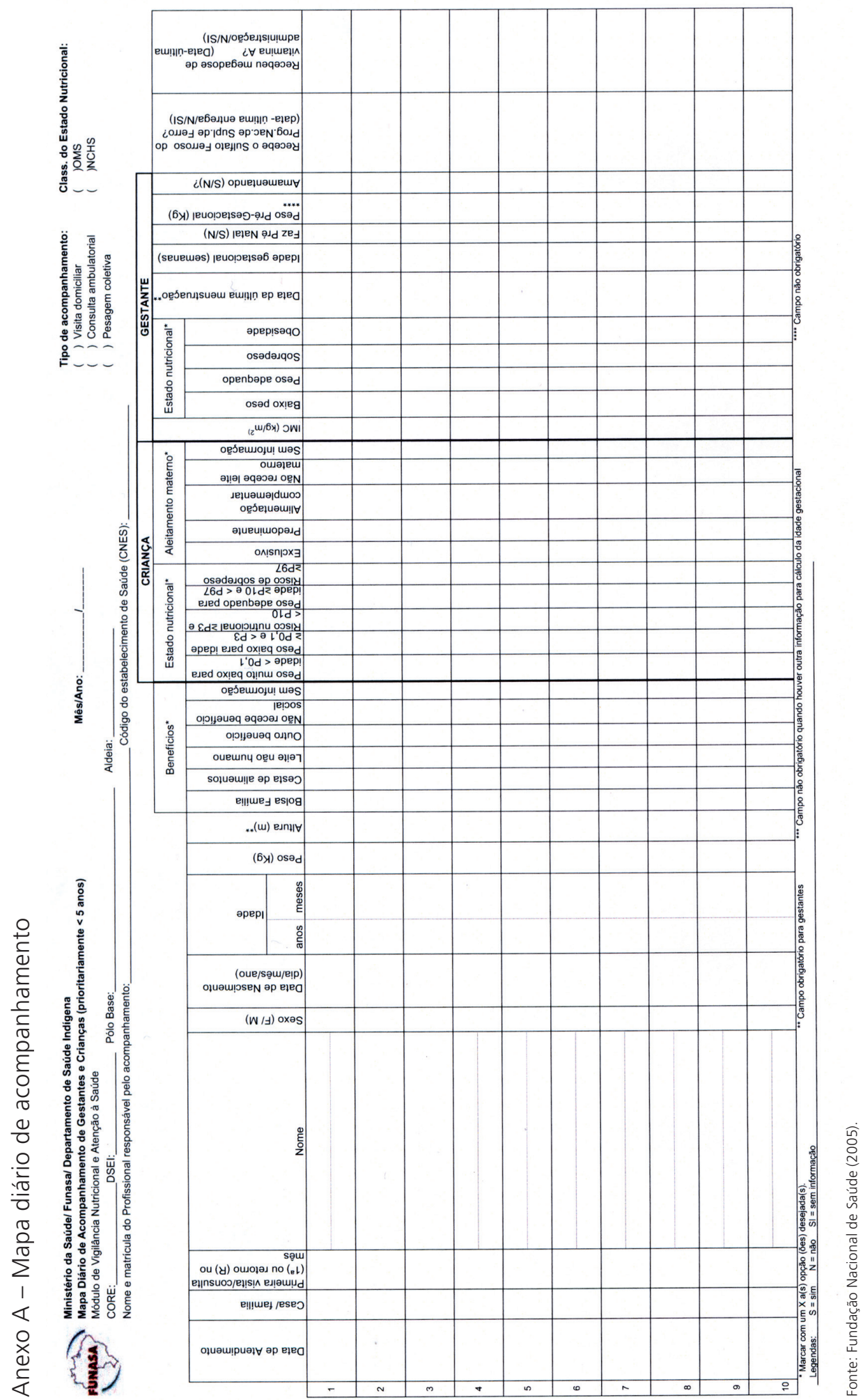


Anexo B - Mapa consolidado mensal

Ministério da Saúde/ Funasa/ Departamento de Saúde Indígena

Sistema de Vigilância Alimentar e Nutricional - SISVAN Indígena

Funasa Total do(a): ( )Aldeia ( ) Pólo-base （）DSEI

DSEl:

CORE:

Pólo-base:

Aldeia:

Mês/Ano: I

Consolidado Mensal de Acompanhamento de Crianças - Total do DSEI

\begin{tabular}{|c|c|c|c|c|c|c|c|c|c|c|c|c|}
\hline \multirow[t]{2}{*}{ Idade (meses) } & \multicolumn{2}{|c|}{$01-6 m$} & \multicolumn{2}{|c|}{$6-12 m$} & \multicolumn{2}{|c|}{$12-24 m$} & \multicolumn{2}{|c|}{$24-36 m$} & \multicolumn{2}{|c|}{36 - $-60 \mathrm{~m}$} & \multicolumn{2}{|c|}{$\begin{array}{c}\text { TOTAL por estado } \\
\text { nutricional }\end{array}$} \\
\hline & Qtd. & $\%$ & Qtd. & $\%$ & Qtd. & $\%$ & Qtd. & $\%$ & Qtd. & $\%$ & Qtd. & $\%$ \\
\hline \multicolumn{13}{|l|}{$\begin{array}{c}\text { Muito baixo peso } \\
\mathrm{p}<0,1\end{array}$} \\
\hline \multicolumn{13}{|l|}{$\begin{array}{l}\text { Baixo peso } \\
\text { p0,1 I- p3 }\end{array}$} \\
\hline \multicolumn{13}{|l|}{$\begin{array}{c}\text { Risco Nutricional } \\
\text { p3 I- p10 }\end{array}$} \\
\hline \multicolumn{13}{|l|}{$\begin{array}{l}\text { Adequado } \\
\text { p10 I- p97 }\end{array}$} \\
\hline \multicolumn{13}{|l|}{$\begin{array}{c}\text { Risco de sobrepeso } \\
\geq \mathrm{p} 97\end{array}$} \\
\hline TOTAL por faixa etária & & $100 \%$ & & $100 \%$ & & $100 \%$ & & $100 \%$ & & $100 \%$ & & $100 \%$ \\
\hline & $\begin{array}{l}\text { Total d } \\
\text { Total d } \\
\text { Cobert }\end{array}$ & $\begin{array}{l}\text { cria } \\
\text { a: }\end{array}$ & & $\begin{array}{l}\text { na } \\
\text { sd }\end{array}$ & & $\begin{array}{l}\text { el c } \\
\text { ente }\end{array}$ & & & & & & \\
\hline
\end{tabular}

Fonte: Fundação Nacional de Saúde (2005). 


\section{Análise e interpretação dos dados}

Silvana Granado Nogueira da Gama

Denise Oliveira e Silva

Chegamos ao momento da análise dos dados, em que poderemos conhecer a situação nutricional da população.

Nessa etapa vamos falar em linguagem numérica, baseada em conceitos epidemiológicos e estatísticos. Isso é essencial, pois com base nas informações geradas será possível planejar a intervenção na realidade encontrada - seja pela elaboração de políticas de saúde e nutrição, seja na organização da prestação de serviços nas diferentes áreas: promoção da saúde, prevenção, controle e recuperação de agravos nutricionais.

\section{Para que serve a análise dos dados?}

Essa é a etapa em que os dados são transformados em informações. Isso significa que, após o tratamento dos dados coletados, vamos manuseálos para serem aproveitados ao máximo, gerando informações relevantes para os serviços de saúde.

O primeiro produto da análise é a construção dos indicadores, que devem ser agrupados em categorias de informações, baseadas nos objetivos institucionais. Após sua construção, é preciso interpretar os resultados, compreendendo as potencialidades e limitações das informações geradas. Os resultados obtidos deverão permitir o entendimento da situação nutricional da população assistida, subsidiando intervenções adequadas.

Epidemiologia é tradicionalmente definida como o estudo da distribuição e determinação das doenças e outros agravos à saúde. Pode também ser classificada como epidemiologia descritiva e epidemiologia analítica, respectivamente (SZKLO; JAVIER NIETO, 2007).

Este Capítulo se aterá aos estudos descritivos, que distribuem as características da população segundo as pessoas, o tempo e o lugar de ocorrência.

Os indicadores de saúde costumam ser medidos negativamente, por meio da freqüência de eventos que expressam a "não saúde", tais como a morte (mortalidade) e a doença (morbidade). Assim, a medida de saúde é tomada a partir do quantitativo de pessoas que morrem ou adoecem por determinadas causas, em uma dada população, em um período determinado de tempo (PALMEIRA, 2000). 
Informações relevantes e pertinentes nos serviços de saúde sobre diagnóstico nutricional são aquelas que orientam para a reorganização das políticas e ações, visando o controle dos distúrbios nutricionais e a promoção da alimentação e nutrição saudáveis.
Vale lembrar que é preciso termos clareza do que pretendemos saber com as informações do Sisvan. Podemos destacar dois grandes objetivos das informações produzidas:

- monitorar a situação nutricional de grupos específicos, segundo características definidas;

- subsidiar políticas e ações para promoção da saúde e alimentação saudável, prevenção e controle de agravos nutricionais.

Com isso, as informações têm utilidade:

- desde o âmbito municipal até o federal, para a tomada de decisões dos gestores da área;

- no âmbito local, para melhorar a assistência.

Reafirmamos a necessidade de que todas as etapas de fluxo de dados do Sisvan sejam desenvolvidas de forma rotineira e contínua. A coleta e o tratamento de dados não podem ser considerados apenas como atividades burocráticas. É preciso que essas atividades sejam compreendidas como parte fundamental de um processo, um caminho natural a ser percorrido pelos dados com a finalidade de gerar informações por meio de sua análise.

Assim como na etapa de tratamento dos dados, a análise deve ser realizada nos diferentes níveis de atenção à saúde (aldeias, pólos-base, distritos sanitários), no país. As informações decorrentes dessa etapa deverão responder a dois grandes objetivos básicos do Sisvan, mencionados anteriormente.

\section{Como interpretar os dados?}

Ao analisar os dados, precisamos contextualizá-los, isto é, saber em que situação foram produzidos. Vejamos o exemplo a seguir.

Um pólo-base apresenta altas taxas de desnutrição em crianças entre 24 e 36 meses de idade. Observando a dinâmica do atendimento prestado à população infantil, verifica-se que as crianças dessa faixa etária são atendidas apenas pela demanda espontânea. Esse simples fato pode explicar a presença desse alto percentual de crianças com risco nutricional/desnutrição nos atendimentos, visto que elas, provavelmente, 
compareceram mais aos serviços de saúde devido à maior freqüência de doenças infecciosas agudas na infância entre crianças desnutridas.

Para refletir

Que ações você identifica como possíveis de realizar na situação que acabou de ler? Justifique.

Uma ação a ser desencadeada com o conhecimento dessa situação poderá ser o estabelecimento de uma atenção prioritária às crianças desnutridas / em risco nutricional, mediante a criação de uma agenda de consultas que permita seu acompanhamento regular.

Tendo ciência da importância do Sisvan, vamos retornar à sua análise.

Na consolidação dos dados referentes ao atendimento mensal de uma aldeia e/ou de um pólo-base, usando o mapa diário é possível conseguir uma primeira visão coletiva dos dados do Sisvan. Nele temos a descrição do estado nutricional da população atendida, segundo sua distribuição numérica total e percentual.

A etapa de análise desses dados nos permitirá entender o seu significado, gerando informações fidedignas e úteis. Por isso, é preciso ter clareza do que eles representam para evitar conclusões errôneas. Como exemplo, vejamos algumas situações que ajudam nas interpretações feitas a partir dos dados:

- ter clareza de que os dados oriundos da rotina de assistência representam apenas o universo delimitado à sua demanda, que pode ser influenciado por uma série de fatores, como a localização geográfica, a oferta de consultas, o oferecimento de suplementação alimentar, a qualidade da atenção prestada;

- uma aldeia, um pólo-base e um DSEI trabalham com uma população adstrita - é o caso dos profissionais da Estratégia Saúde da Família (ESF) - e têm boa captação da população, isto é, uma boa cobertura, podendo produzir informações mais representativas desse grupo específico;

- se há muitos casos sem informações, isto é, em que os dados necessários para formar os indicadores não foram coletados, a representatividade do serviço estará comprometida;

- a utilização do número de atendimentos como número de indivíduos atendidos dará origem a informações incorretas. Precisamos 
ter em mente que um mesmo indivíduo pode ser atendido mais de uma vez e, dessa forma, seus dados também contariam mais de uma vez no período de coleta. Não é errado considerar o número de atendimentos, apenas devemos atentar para que isso fique bem claro ao construirmos as informações que desejamos.

Após essas considerações, começaremos a analisar nossos dados.

\section{Ferramentas epidemiológicas e estatísticas para análise dos dados}

A análise dos dados pode ser dividida em duas fases: análise interna, realizada com a observação atenta aos dados consolidados; e análise externa, em que comparamos esses dados com os de outras fontes como, por exemplo, de outros estudos, serviços ou com a população-referência.

A análise interna permite olhar para os dados produzidos e entendê-los em suas potencialidades e limitações (SILVA, ENGSTROM, ZABOROWSKI, 2002). Nesse "olhar" interno somos capazes de compreender quais são as informações importantes sobre o perfil nutricional da população.

A epidemiologia e a estatística são as ciências que nos oferecem instrumentos úteis para subsidiar esse "olhar". Alguns desses instrumentos são muito complexos e não serão abordados neste livro. Mas outros são elementares e permitem medir:

- a freqüência dos eventos em população (incidência, prevalência, letalidade, percentual);

- a cobertura dos serviços;

- a distribuição da freqüência dos eventos (percentis, desvio-padrão etc.).

É necessário conhecer bem os conceitos de cada instrumento para fazer afirmações corretas. Não é possível confundir o uso dos termos incidência, prevalência, letalidade, percentual. Seus significados são completamente diferentes e caso façamos uso indevido do termo, certamente estaremos gerando informações incorretas. É preciso ter muito cuidado no seu uso.

Vamos conhecer um pouco esses conceitos? 
As medidas de freqüências, como a expressão indica, são usadas quando precisamos medir a freqüência de doenças, problemas de saúde e/ou de utilização de serviços de saúde (chamados de "casos"). Assim, usamos a incidência para medir a ocorrência de "casos" novos; e a prevalência para medir a totalidade de "casos" observados, sejam novos ou antigos (PEREIRA, 2000).

A letalidade é uma percentagem utilizada para avaliar a gravidade de uma doença. É calculada dividindo o número de óbitos ocorridos em relação ao total de doentes, multiplicado por 100 .

Ex: Percentual de óbitos por diarréia em menores de cinco anos, entre as crianças da mesma faixa etária que adoeceram por diarréia no mesmo local e período.

$$
\begin{aligned}
& \text { n. de óbitos por doença/agravo ocorridos } \\
& \text { Letalidade }=\frac{\text { em determinado local e período especificado }}{n \cdot \text { de casos de doença/agravo ocorridos }} \times 10^{2}
\end{aligned}
$$

\section{Para refletir}

Agora que já relembrou os conceitos, ilustre cada um deles com um exemplo de sua realidade e relate se o seu serviço aplica esses conceitos conforme descrito neste Capítulo.

As medidas estão sempre relacionadas a uma população sob risco de desenvolver um determinado agravo, em local e período especificados. Podem ser expressas tanto em números absolutos como em percentuais, taxas e/ou proporções. Na maioria das vezes, é mais indicado o uso de taxas ou proporções, pois elas facilitam a comparação entre vários grupos ou no mesmo grupo ao longo do tempo.

Calculamos a incidência e prevalência por meio de uma fórmula em que o numerador representa o número de "casos" e o denominador, a população total em risco (sempre referenciados a um determinado local e tempo). Como o resultado é sempre um valor inferior à unidade (decimal), multiplicamos o valor encontrado por um fator $\left(10^{\mathrm{n}}\right)$, a fim de obter um número inteiro. Esse fator pode ser 1.000, 10.000, 100.000. O importante é
Taxa é uma medida resultante da divisão do número total de casos incidentes em um período de tempo, pelo número de pessoas acompanhadas nesse tempo (pessoas-tempo). Ela é uma medida que representa o potencial de mudança instantânea no tempo (MERCHÁN-HAMANN; TAUIL; COSTA, 2000).

Proporções é uma medida em que os eventos do numerador estão contidos no denominador. Geralmente esses eventos representam um risco de ocorrência em relação ao denominador (MERCHÁN-HAMANN; TAUIL; COSTA, 2000).

Quando calculamos taxas e proporções, devemos evitar a multiplicação pelo fator 100 para não ser confundido com cálculo de percentual. 
compreender que quanto mais raro for o evento estudado, maior deverá ser o fator, para que o número final se torne inteiro.

Sempre que formos comparar duas taxas ou duas proporções, sejam elas de incidência ou de prevalência, devemos utilizar o mesmo fator para padronizar os resultados. Caso contrário, estaríamos comparando coisas diferentes, o que seria um grande equívoco.

Por exemplo: 20 casos de uma dada doença em 3.000 crianças de 8 anos, multiplicados por 1.000 , teria como resultado 6,67. Caso outro profissional resolvesse calcular a mesma taxa multiplicando por 10.000, o resultado seria 66,7, o que dificultaria a comparação, gerando um erro no momento da análise.

Na padronização, para evitar dúvidas, é indispensável informarmos por qual fator o resultado foi multiplicado.

Para o cálculo da incidência temos a seguinte fórmula:

$$
\text { Incidência }=\frac{\begin{array}{c}
\text { n. de "casos novos" ocorridos em determinado } \\
\text { local e período especificado }
\end{array}}{\text { população em risco do mesmo local e período }} \times 10^{n}
$$

A incidência é muito útil na medição de eventos únicos, como os óbitos ou doenças agudas. Ela mede a intensidade com que uma doença ou um evento acontece em uma população.

Por exemplo:

O município de Esperança registrou 154 casos de hepatite viral aguda em crianças menores de um ano de idade, em 2007. Considerando que a população menor de um ano era de 1.532 crianças, qual foi a incidência de hepatite nessa população, no ano de 2007?

$$
\text { Incidência }=\frac{\begin{array}{c}
\text { n. crianças menores de um ano com hepatite } \\
(\text { Esperança, 2007) }
\end{array}}{n \text {. total de crianças menores de um ano }} \times 10^{3}
$$




$$
\text { Incidência }=\frac{154}{1532} \times 1.000=0,10 \times 1.000=\begin{aligned}
& 100,52 \text { crianças com hepatite } \\
& \text { por mil crianças }<1 \text { ano, } \\
& \text { Esperança, } 2007
\end{aligned}
$$

Então, a incidência de hepatite viral aguda em menores de um ano, em Esperança, no ano 2007, foi de 100 casos/1.000 crianças menores de 1 ano.

\section{PARA PRATICAR - CÁLCULO DA INCIDÊNCIA}

Que tal praticar um pouco?

0 pólo-base Santana apresenta uma população de 1.571 índios. Em 2007 foram notificados 34 casos de tuberculose, distribuídos conforme a tabela a seguir.

Incidência de tuberculose segundo faixa etária no pólo-base Santana, 2007

\begin{tabular}{|c|c|c|l|}
\hline $\begin{array}{l}\text { Faixa etária } \\
\text { (anos) }\end{array}$ & População & Casos & Incidência \\
\hline$<1$ & 98 & 1 & \\
\hline $1-5$ & 136 & 5 & \\
\hline $51-15$ & 605 & 7 & \\
\hline $15-60$ & 613 & 17 & \\
\hline 60 e mais & 119 & 4 & \\
\hline Total & 1571 & 34 & \\
\hline
\end{tabular}

Calcule a incidência total de tuberculose no pólo-base e a incidência por faixa etária. Comente seus resultados.

Em eventos crônicos e/ou insidiosos, como os distúrbios nutricionais e a hipertensão, muitas vezes torna-se difícil definir o momento em que o caso surge; quando detectado, não sabemos se é um caso novo ou antigo. Para essas situações, devemos usar a prevalência, cuja fórmula é apresentada a seguir:

n. total de "casos" ocorridos em determinado

$$
\text { Prevalência }=\frac{\text { local e período especificado }}{\text { população em risco do mesmo local e período }} \times 10^{n}
$$


Um exemplo para o cálculo da prevalência: Marlene, agente indígena de saúde, fez um levantamento do estado nutricional das 153 crianças menores de cinco anos de idade, moradoras da aldeia Perequê, no mês de julho de 2007. Verificou que 11 estavam desnutridas $(\mathrm{P} / \mathrm{I}<\mathrm{p} 3)$. Qual a prevalência de desnutrição na aldeia Perequê, em julho de 2007?

$$
\begin{aligned}
& \text { n. de crianças }<5 \text { anos com } \mathrm{P} / \mathrm{l}<\mathrm{p} 3 \\
& \text { na aldeia Perequê (2007) } \times 10^{3} \\
& \text { n. total de crianças }<5 \text { anos na } \\
& \text { aldeia Perequê (2007) } \\
& \text { Prevalência }=\frac{11}{153} \times 1.000=0,072 \times 1.000=\begin{array}{l}
72,0 \text { crianças desnutridas } \\
\text { por mil crianças }<5 \text { anos } \\
\text { Perequê em julho } 2007
\end{array}
\end{aligned}
$$

Ou seja, a prevalência de desnutrição $(\mathrm{P} / \mathrm{I}<\mathrm{p} 3)$ em crianças menores de cinco anos da aldeia Perequê, em julho de 2007, foi de 72 casos/ 1.000 crianças $<5$ anos.

Observamos que a prevalência apresenta o número total de casos de uma doença, independentemente de o fato ser caso novo ou antigo. Por isso, fica evidente que ela é afetada pela incidência (número de casos novos) e também pela duração da doença e pela migração - seja pela entrada (imigração, nascimentos) de indivíduos nas aldeias/comunidades, seja pela saída (óbitos, cura, emigração).

A falta de entendimento dos significados de incidência e prevalência pode levar a conclusões errôneas e/ou precipitadas. Um exemplo é quando se discute sobre a necessidade de promover a distribuição de alimentos não só para os menores de 24 meses, mas também para as crianças entre 24 e 36 meses, devido ao elevado percentual de desnutrição encontrado entre elas. É preciso, antes de tudo, saber se a freqüência de desnutrição observada é referente a casos novos nessa faixa etária (incidência), ou a casos remanescentes dos primeiros 24 meses de idade, não detectados ou não recuperados pelos serviços de saúde (prevalência). Somente com esse esclarecimento é possível planejar adequadamente novas propostas de intervenção. 
Na interpretação da prevalência, cabe um alerta: um erro observado freqüentemente é a generalização, extrapolando, para outros grupos populacionais (por exemplo, para a população de um município ou de uma etnia), resultados referentes a apenas um serviço ou comunidade. Se assim fizermos, estaremos gerando informações com "viés", pois, na realidade, elas representam apenas uma parcela da população. Isso porque, em um serviço de saúde, tanto o número de "casos" detectados quanto a parcela da população observada são referentes apenas àqueles que utilizam o serviço. Nessa situação, só podemos calcular a prevalência naquele serviço.

Vejamos um exemplo: no posto de saúde do pólo-base Rio Seco foram atendidos, em outubro de 2007, 832 adultos e todos tiveram seu estado nutricional avaliado. Identificou-se que 267 estavam com sobrepeso (IMC > 25). Qual o percentual do sobrepeso na população atendida em outubro de 2007?

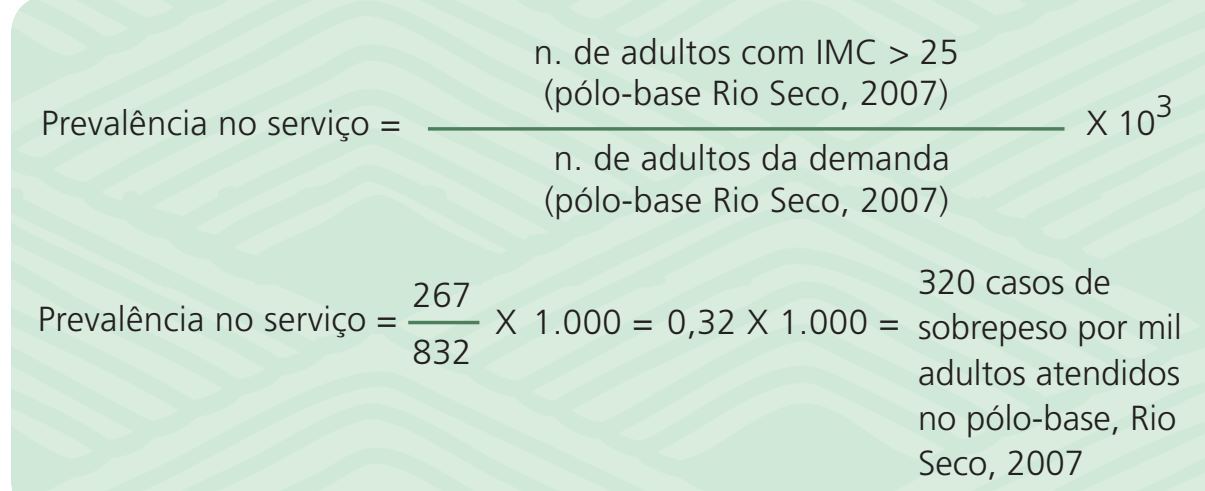

A prevalência de sobrepeso em adultos atendidos no pólo-base Rio Seco foi de 320/1.000 adultos, em outubro de 2007.

\section{PARA PRATICAR - CÁLCULO DA PREVALÊNCIA}

Você pode praticar o cálculo da prevalência no serviço, escolhendo os casos de desnutrição em menores de cinco anos de seu cotidiano e aplicando a fórmula indicada para esse caso. Busque os dados junto à sua equipe, pólo ou distrito.
Viés refere-se a dados e informações que se desviam sistematicamente dos valores verdadeiros; vício, tendenciosidade.

Quando os serviços de saúde estão informatizados, é possível calcular a prevalência do serviço pela identificação dos usuários. Para isso, cada usuário só poderá ter seus dados computados uma única vez no período de análise 
Outra questão, já assinalada, se refere ao fato de que, muitas vezes, os dados de serviços representam o número de atendimentos prestados, e não de pessoas atendidas. Nessa situação, não é possível gerar a medida de prevalência. Podemos, no entanto, conhecer o percentual de "casos" atendidos, por meio de uma simples regra de três, em que o número total de atendimentos corresponde a $100 \%$.

Agora, vejamos o exemplo: no posto de saúde da aldeia Jutiá foram efetuados 487 atendimentos em crianças menores de cinco anos de idade, durante os meses de janeiro a março de 2007. Entre esses atendimentos, 98 estavam registrados com diagnóstico de desnutrição. Qual a proporção de atendimentos de desnutrição em crianças menores de cinco anos realizados no posto, nesse período?

Proporção/percentual:

$\begin{array}{ll}487----100 & \frac{98 \times 100}{487}=20,1 \%\end{array}$

Portanto, o percentual de atendimentos de crianças menores de cinco anos de idade com desnutrição nessa comunidade, no período de janeiro a março de 2007, foi de 20,1\%.

Uma outra medida comumente utilizada nos serviços de saúde é a de cobertura. Ela estabelece a relação entre o número de pessoas ou domicílios atendidos por um programa ou serviço de saúde e o número total dos que deveriam ser atendidos. Geralmente, o resultado é expresso em percentuais. Essa medida é calculada do seguinte modo:

$$
\text { Cobertura }=\frac{n \cdot \text { de pessoas/domicílios atendidos }}{n \cdot \text { total de pessoas/domicílios-alvo da atenção }} \times 100
$$

Vejamos os exemplos (fictícios) a seguir:

1. A Comunidade Indígena Parketêjê tem uma população de menores de cinco anos de idade de 179 crianças, segundo estimativa da Funasa. Na última campanha de vacinação antipólio (agosto de 2007), compareceram 
aos postos, para serem imunizadas, 158 dessas crianças. Todas foram avaliadas nutricionalmente. Qual a cobertura obtida nesse evento?

$$
\text { Cobertura }=\frac{\begin{array}{c}
\mathrm{n} \text {. de crianças }<5 \text { anos } \\
\text { imunizadas/avaliadas }
\end{array}}{\begin{array}{c}
\text { população estimada de }<5 \text { anos } \\
\text { residentes na área }
\end{array}} \times 100=\frac{158}{179} \times 100=88,27 \%
$$

A cobertura de imunização/avaliação nutricional da campanha de vacinação nessa comunidade, em agosto de 2007, foi de $88,27 \%$.

2. Um pólo-base Cajueiro, do DSEI Rio Folha tem oito aldeias e quatro equipes de saúde. O Sisvan foi implantado em apenas cinco aldeias. Qual a cobertura do Sisvan nas aldeias desse pólo-base?

$$
\text { Cobertura }=\frac{n \cdot \text { de aldeias com Sisvan }}{n \cdot \text { total de aldeias }} \times 100=\frac{5}{8} \times 100=\frac{500}{8}=62,5 \%
$$

A cobertura do Sisvan nas aldeias do pólo-base Cajueiro é estimada em $62,5 \%$.

\section{Para refletir}

Qual a cobertura do Sisvan no monitoramento do estado nutricional de crianças menores de cinco anos na localidade em que você atua?

Desenvolver indicadores de cobertura é importante para a avaliação da assistência prestada e da qualidade do diagnóstico realizado. Para isso, é necessário conhecermos o melhor possível o total da população-alvo, que constitui o denominador da razão (VAUGHAN; MORRAN, 1997).

Em serviços de saúde que atuam com uma população de referência e/ ou adstrita e nos modelos de atenção comunitária como o PSF, caso haja uma boa cobertura na prestação de serviços, as taxas encontradas podem se aproximar da realidade populacional. Caso a cobertura seja pequena, é necessário que se desenvolvam estratégias para obtenção de dados populacionais em inquéritos ou levantamentos específicos. Assim,
Inquéritos ou estudos de prevalência ou seccionais medem a prevalência de um agravo em uma dada população, em um determinado período. Nesse tipo de estudo, tanto os dados sobre os agravos quanto as características das pessoas são coligidos simultaneamente. A população do estudo deve ser definida com o maior rigor possível, pois constituirá o denominador dos indicadores de prevalência.

Estudos baseados na clientela de um serviço de saúde são limitados, como fonte de informação sobre a população total, mas podem ser utilizados para o planejamento e a avaliação das ações voltadas para aquela população (PALMEIRA, 2000). 
O símbolo $\bar{X}$ é utilizado na matemática e estatística para representar a média aritmética. poderemos interpretar melhor as informações geradas como, por exemplo: comparar as taxas de distúrbios nutricionais de indivíduos avaliados pelo Sisvan nos serviços de saúde com as provenientes de estudos populacionais realizados.

Como afirmado anteriormente, apenas uma parcela da população é usuária dos serviços públicos de saúde. As razões estão relacionadas à oferta de serviços e à decisão de aderir aos programas ofertados. Na população indígena, o acesso aos serviços de saúde se constitui no principal problema na efetuação da cobertura. Sendo assim, as taxas de distúrbios nutricionais geradas são geralmente superiores às encontradas em estudos populacionais, que representam a população como um todo.

Outras ferramentas da estatística podem ser aplicadas como estratégia para refinar a consolidação (tratamento) de dados, obedecendo aos objetivos do Sisvan e ao conhecimento sobre sua adequação e efetuação. Elas visam descrever a distribuição de freqüência dos eventos avaliados, com o propósito de verificar seu comportamento. Destacamos, a seguir, algumas delas.

\section{- Média aritmética}

É a soma das observações individuais dividida pelo número total de observações efetuadas. Essa medida é a mais usada, mas pode levar a interpretações equivocadas. É uma medida útil, mas deve-se ter em conta que, caso haja valores extremos (muito afastados da média), ela poderá ser desviada para cima ou para baixo. O problema se torna mais intenso quanto menor for a amostra de observações efetuadas.

Vejamos um exemplo: na maternidade de Dourados, nasceram nove crianças no dia 29 de maio de 2007, com os seguintes pesos: 3.000g; $2.780 \mathrm{~g} ; 3.850 \mathrm{~g} ; 3.200 \mathrm{~g} ; 2.920 \mathrm{~g} ; 4.100 \mathrm{~g} ; 2.300 \mathrm{~g} ; 3.200 \mathrm{~g} ; 2.040 \mathrm{~g}$. Qual a média de peso dessas crianças?

\section{Exemplo 1}

$$
\bar{X}=\frac{3.000+2.780+3.850+3.200+2.920+4.100+2.300+3.200+2.040}{9}=\frac{27.390 \mathrm{~g}}{9}=3.043 \mathrm{~g}
$$


A média de peso das crianças foi de 3.043g.

Observe que os valores de peso variaram de $2.040 \mathrm{~g}$ (o menor) a $4.100 \mathrm{~g}$ (o maior). Temos aqui o valor mínimo e máximo (medidas extremas) do conjunto de valores de peso ao nascer. Se entre os recém-nascidos houvesse um com apenas $1.500 \mathrm{~g}$ ao invés de $4.100 \mathrm{~g}$, veja como mudaria o resultado:

Exemplo 2

$\bar{X}=\frac{3.000+2.780+3.850+3.200+2.920+1.500+2.300+3.200+2.040}{9}=\frac{24.790 \mathrm{~g}}{9}=2.754 \mathrm{~g}$

A média de peso das crianças passaria a ser de $2.754 \mathrm{~g}$.

A diferença entre os dois resultados foi de $289 \mathrm{~g}$, o que não aconteceria se fosse utilizada a mediana (tratada a seguir).

\section{$\checkmark$ Mediana}

Corresponde ao valor central de uma série ordenada de observações (crescente ou decrescente); é o valor que divide a distribuição ao meio.

Se as observações ordenadas forem constituídas por número ímpar de dados, a mediana é o valor que fica no centro. Vejamos o exemplo das crianças nascidas na maternidade de Dourados: $2.040 \mathrm{~g} ; 2.300 \mathrm{~g} ; 2.780 \mathrm{~g}$; $2.920 \mathrm{~g} ; 3.000 \mathrm{~g} ; 3.200 \mathrm{~g} ; 3.200 \mathrm{~g} ; 3.850 \mathrm{~g} ; 4.100 \mathrm{~g}$.

A mediana de peso foi $3.000 \mathrm{~g}$.

No caso de as observações serem em número par, a mediana é a média aritmética dos dois valores que ficam na posição central dos dados ordenados. Tomando o mesmo exemplo, retirando um dos pesos 3.200g, teríamos esta seqüência: $2.040 \mathrm{~g} ; 2.300 \mathrm{~g} ; 2.780 \mathrm{~g} ; 2.920 \mathrm{~g} ; 3.000 \mathrm{~g} ; 3.200 \mathrm{~g}$; 3.850g; 4.100g. Para o cálculo da mediana, utilizaríamos:

$$
\text { Mediana }=\frac{2.920+3.000}{2}=2.960 \mathrm{~g}
$$

As medidas extremas devem ser sempre observadas na análise de consistência, a fim de identificar possíveis erros ou os outliers (valores absurdos). Esse assunto foi discutido no Capítulo 4, "Construção do fluxo de dados", na Parte II deste livro.

Para avaliar o tempo de aleitamento materno a mediana é a medida mais utilizada porque a variabilidade de tempo de aleitamento é muito grande. Muitas mulheres amamentam por apenas alguns dias, enquanto outras amamentam por dois ou até três anos. A média de tais valores não seria representativa do grupo em estudo. 
A mediana, nesse caso, seria de $2.960 \mathrm{~g}$.

\section{$\checkmark$ Moda}

É o valor encontrado com maior freqüência no grupo observado.

Exemplificando: usando os pesos das crianças do exemplo anterior: 3.000g; 2.780g; 3.850g; 3.200g; 2.920g; 4.100g; 2.300g; 3.200g; 2.040g, a moda é $3.200 \mathrm{~g}$ (aparece duas vezes).

\section{- Separatrizes}

Divide um conjunto de observações em quatro, cinco, 10, 100 partes iguais, para facilitar a comparação de dados. Para o Sisvan, as de uso mais corrente são os quartis e os percentis.

Quartis - representam a divisão das observações em quatro partes iguais, cada uma delas correspondendo a um quartil. Por exemplo: distribuição da obesidade em adultos por quartis de renda (Tabela 1).

Tabela 1 - Prevalência (\%) de obesidade (IMC > 30) em adultos ( $\geq 20$ anos) em duas regiões brasileiras (Nordeste e Sudeste), segundo quartis de renda familiar per capita. Anos de 1975, 1989 e 1997

\begin{tabular}{l|c|c|c|c|c|c} 
Região e Quartis de renda & \multicolumn{5}{l}{ Homens } \\
Nordeste & 1975 & 1989 & 1997 & 1975 & 1989 & 1997 \\
\hline $1^{\circ}$ quartil & 0,7 & 0,8 & 1,7 & 3,0 & 5,2 & 8,0 \\
\hline $2^{\circ}$ quartil & 0,9 & 1,4 & 3,8 & 3,2 & 8,3 & 14,1 \\
\hline $3^{\circ}$ quartil & 1,1 & 3,0 & 4,1 & 4,5 & 7,8 & 13,3 \\
\hline $4^{\circ}$ quartil & 2,8 & 5,2 & 8,4 & 7,6 & 9,9 & 14,6 \\
\hline Total & 1,4 & 2,6 & 4,5 & 4,6 & 7,8 & 12,5 \\
\hline Sudeste & 1975 & 1989 & 1997 & 1975 & 1989 & 1997 \\
\hline $1^{\circ}$ quartil & 1,6 & 2,9 & 3,8 & 6,6 & 11,6 & 15,0 \\
\hline $2^{\circ}$ quartil & 2,2 & 4,2 & 9,7 & 8,0 & 16,5 & 12,1 \\
\hline $3^{\circ}$ quartil & 3,3 & 7,8 & 9,6 & 10,3 & 14,8 & 13,2 \\
\hline $4^{\circ}$ quartil & 5,3 & 8,1 & 9,5 & 9,1 & 13,2 & 8,2 \\
\hline Total & 3,1 & 5,8 & 8,1 & 8,5 & 14,0 & 12,1 \\
\hline
\end{tabular}

Fonte: Monteiro e Conde (2000). 
Percentis - representam a divisão das observações em 100 partes iguais, cada uma delas correspondendo a um percentil. Por exemplo: classificação do estado nutricional de crianças menores de cinco anos pelo índice P/I na Caderneta de Saúde da Criança (BRASIL, 2007).

\section{- Desvio-padrão}

É uma medida de variabilidade de valores em torno da média, que só deve ser aplicada quando a sua distribuição segue um padrão considerado "normal". Nessas situações, a média e a mediana são iguais.

O desvio-padrão mede o grau de dispersão de um conjunto de dados em relação à media, ou seja, a diferença entre cada dado e a média do conjunto (VIEIRA, 1980). Veja a Figura 1.

Figura 1 - Representação da curva normal com desvio-padrão, moda, média e mediana

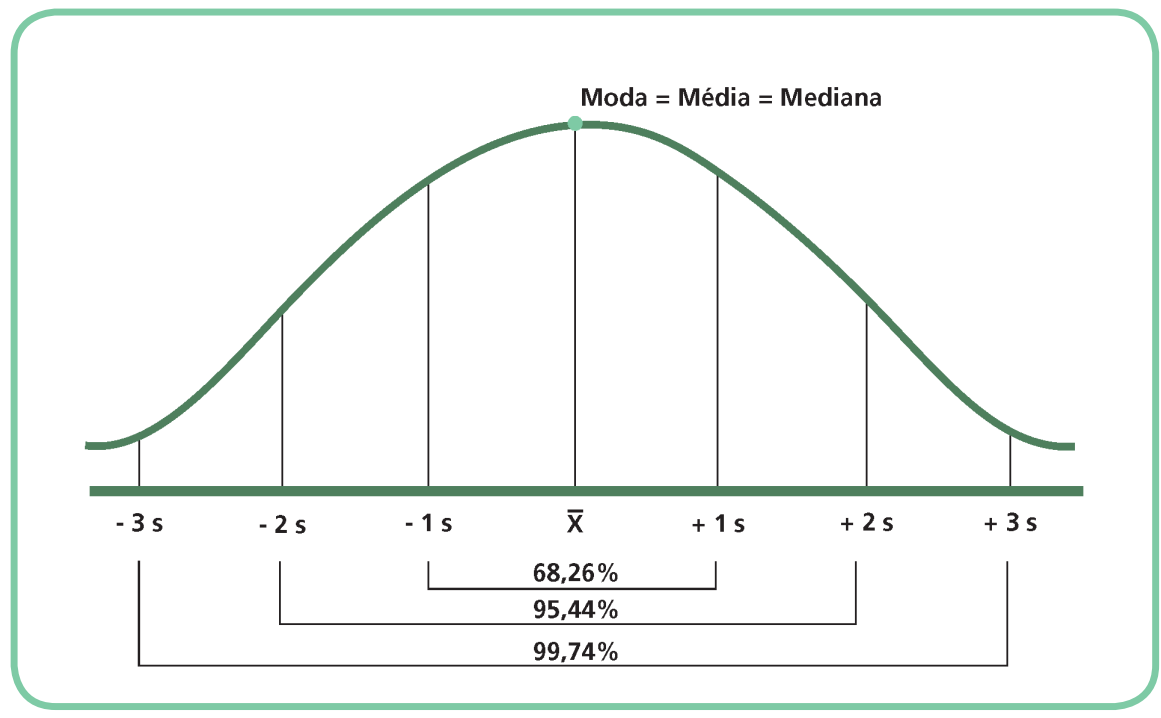

Fonte: Adaptado de Vasconcelos (2007).

Existe uma fórmula para o cálculo do desvio-padrão, e o resultado depende dos valores observados nas medições. Podem ser positivos (+ 1DP, + 2 DP) ou negativos (- 1DP, - 2 DP). É muito utilizada em pesquisas, sendo considerados limites de normalidade para os indicadores nutricionais os valores compreendidos entre $-2 \mathrm{DP}$ e $+2 \mathrm{DP}$.

Vejamos um exemplo: na medição do índice Estatura para Idade (E/I) em escolares, os situados abaixo de 2DP (-2DP) em relação à população de referência do NCHS são considerados de baixa estatura. 
Geoprocessamento é o conjunto de tecnologias que integram as fases de coleta, processamento e uso de informações relacionadas ao espaço físico. Utiliza técnicas matemáticas e computacionais para o tratamento de informações geográficas.

Importante: gerar dados de forma burocratizada não tem nenhum valor!
Para que e por que são usadas essas medidas?

As medidas são essenciais para sintetizar as informações e auxiliar na interpretação do perfil da população analisada, com o intuito de qualificar a assistência prestada e avaliar o grau de resolutividade das atividades de assistência e promoção da saúde.

\section{Recomendações para tratamento e análise dos dados}

As equipes envolvidas na implantação e execução do Sisvan nas aldeias, nos pólos-base e DSEI devem estar atentos às seguintes recomendações:

- avaliar a qualidade dos dados gerados;

- organizar esses dados;

- trabalhar ao máximo as informações decorrentes desses dados, ou seja:

- verificar se os resultados das análises foram influenciados por mudanças da demanda da assistência (férias de profissionais, campanhas, distribuição de alimentos);

- calcular a freqüência e a distribuição de freqüência dos distúrbios nutricionais no serviço;

- comparar esses resultados com os obtidos no mesmo local em outros períodos, avaliando se houve ou não variações, e se elas são decorrentes de ações empreendidas pelo serviço;

- comparar os resultados com os obtidos em outros serviços, programas comunitários e estudos de base populacional;

- lançar as informações em mapas da comunidade, se possível por meio de sistemas de geoprocessamento, para melhor visualizar a localização da população com problemas nutricionais, facilitando a divulgação dos resultados, o planejamento das intervenções e o mapeamento das freqüências.

Acreditamos que ter clareza das limitações impostas na construção dos indicadores é a forma mais prudente de superar alguns problemas de qualidade da informação. Com as informações, devemos entender a realidade local, avaliar e rever o planejamento de ações. Esse é o salto de qualidade que podemos dar nos serviços oferecidos à população. 
Além disso, quanto mais utilizarmos os dados produzidos, do nível local ao federal, estaremos contribuindo para a melhoria dos bancos de dados e, conseqüentemente, para a qualidade dos indicadores gerados por esses dados.

\section{PARA PRATICAR - ANÁLISE DE DADOS}

Observe a Tabela 2 - Consolidado mensal do DSEI para crianças menores de cinco anos. DSEI X, junho 2007 -, apresentada a seguir, e depois realize as atividades propostas.

1. Faça uma análise interna dos dados do consolidado do DSEI, considerando, especialmente, os seguintes pontos:

a) o universo a que ele se refere (local, período, população específica);

b) o(s) indicador(es) a ser(em) construído(s) e suas respectivas categorias;

c) o registro dos subtotais, que pode levar a considerações pormenorizadas;

d) a distribuição do estado nutricional nas diversas faixas etárias (seus percentuais e variações entre os percentuais observados);

e) a distribuição de atendimentos nas diferentes unidades.

2. Agora, faça uma análise mais abrangente (olhar externo), comparando os dados encontrados nessa população com os das pesquisas nacionais de crianças menores de cinco anos de idade.

3. É interessante ampliar sua visão e comparar os dados encontrados na sua área de atuação com os de outras fontes locais (outros períodos, serviços de saúde, municípios) e com outros estudos populacionais, complementar com dados de outros sistemas de informação e avaliar os possíveis determinantes da situação encontrada. 


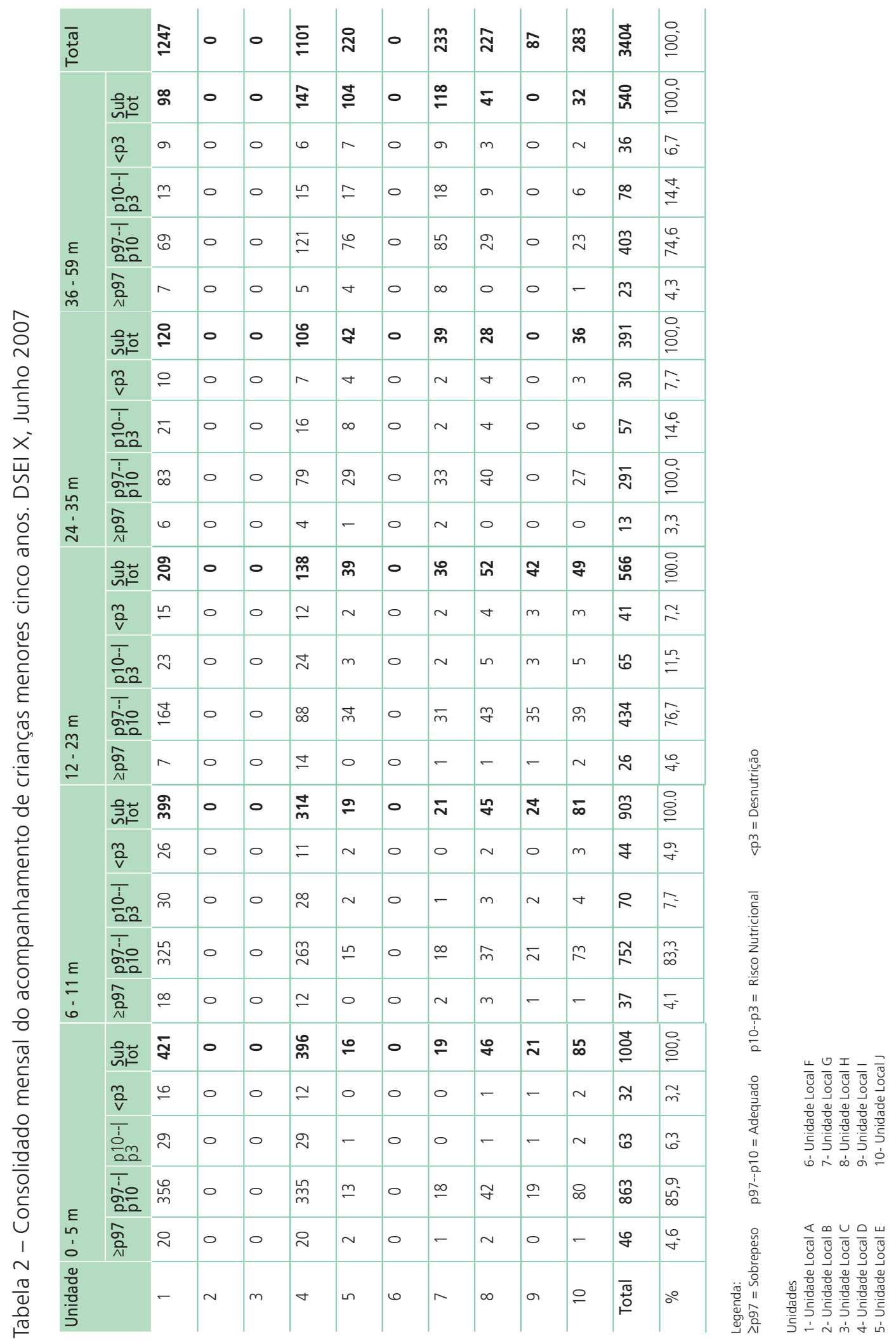




\section{Referências}

BRASIL. Ministério da Saúde. Secretaria de Atenção à Saúde. Caderneta de saúde da criança. Brasília, 2007.

MERCHÁN-HAMANN, E.; TAUIL, P. L.; COSTA, M. P. Terminologia das medidas e indicadores em epidemiologia: subsídios para uma possível padronização da nomenclatura. Informe Epidemiológico, v. 9, n. 4 , p. $273-284,2000$.

MONTEIRO, C. A.; CONDE, W. L. Evolução da obesidade nos anos 90: a trajetória da enfermidade segundo estratos sociais no Nordeste e Sudeste do Brasil. In: MONTEIRO, C. A. Velhos e novos males da saúde no Brasil: a evolução do país e de suas doenças. 2 ed. São Paulo: Hucitec; Nupens; USP, 2000.

PALMEIRA, G. A epidemiologia. In: ROZENFELD, S. (Org). Fundamentos da vigilância sanitária. Rio de Janeiro: Ed. Fiocruz, 2000. p. 137-194.

PEREIRA, M. G. Epidemiologia: teoria e prática. 4. reimpr. Rio de Janeiro: Guanabara Koogan, 2000.

SILVA, D. O.; ENGSTROM, E. M.; ZABOROWSKI, E. L. Sisvan: instrumento para o combate aos distúrbios nutricionais de saúde: diagnóstico coletivo. Rio de Janeiro: Fiocruz/Centro Colaborador em Alimentação e Nutrição, 2002.

SZKLO, M.; JAVIER NIETO, F. Epidemiology beyond the basics. Maryland: Aspen Publication, 2007.

VASCONCELOS, F. A. G. Avaliação nutricional de coletividades. 4. ed. Florianópolis: Ed. da UFSC, 2007.

VAUGHAN, J. P.; MORRROW, R. H. Epidemiologia para municípios: manual para gerenciamento dos distritos sanitários. 2. ed. São Paulo: Hucitec, 1997.

VIEIRA, S. Introdução à bioestatística. 3. ed. Rio de Janeiro: Campus, 1980. 


\section{Divulgação dos resultados}

Denise Oliveira e Silva

Denise Cavalcante Barros

Aqui abordaremos as principais formas e estratégias de divulgação dos resultados do Sisvan. A apresentação desse conteúdo parte da experiência dos autores na observação do desenvolvimento do Sisvan no país.

Uma das grandes dificuldades reveladas pelos profissionais acontece no momento de transformar as informações do Sisvan em ação. Para executar essa tarefa, o passo fundamental é divulgar os resultados do Sisvan! Existem várias formas, mas a principal é aquela que potencializa o protagonismo entre os profissionais e a população na construção de ações que contribuem para a melhoria das condições alimentares e nutricionais em sua área de atuação.

Nesse momento, podemos nos perguntar: será que apenas informar os resultados encontrados é um ato transformador da realidade? Como posso mudar um quadro de falta de comida, de acesso à educação e/ou de ausência de saneamento?

Esses questionamentos geram os debates que queremos estimular! O nosso papel como agente formador e transformador será o de contribuir para que sua atuação profissional junto à população seja responsável e efetiva, ajudando-o a mantê-lo em paz com sua consciência de cidadão e, também, contribuindo para que você tenha a perspicácia de saber transitar entre o tempo político e o técnico das ações de intervenção. 
Eqüidade é a possibilidade de acesso de todos à informação.

Globalidade considera que a comunicação não é uma ação isolada; ao contrário, leva em conta o contexto social, econômico e afetivo

Participação implica que todo processo de comunicação requer o envolvimento dos atores a eles relacionados.

Racionalidade supõe que a comunicação parte de uma diretriz metodológica baseada na razão e na experiência, para a solução dos problemas. Para isso é necessário que a informação seja traduzida com clareza.

\section{Para refletir}

Você já utilizou alguma forma ou estratégia de divulgação dos resultados de seus trabalhos? Em caso positivo, relate-as e procure lembrar de seus efeitos.

A divulgação dos resultados visa prover os setores de decisão política e a sociedade em geral com informações para o planejamento de intervenções. Está baseada num processo de comunicação dinâmico, no qual existem os emissores, a mensagem e os receptores. É como uma "orquestra", com uma multiplicidade de atores sociais que "tocam" diferentes instrumentos, isto é, atuam à luz de seus valores culturais e morais. Esse é um processo rico de interações, implicando alguns princípios, como eqüidade, globalidade, participação e racionalidade.

A construção do processo de comunicação requer a seleção das informações a serem divulgadas (mensagem) pelo seu emissor, considerando algumas características do público-alvo (receptores) e de fatores estratégicos. É importante definir, também, o momento certo de divulgação, nem sempre tão claro e evidente. Há cenários relacionados à conjuntura política, social e, às vezes, pessoal do público-alvo, que facilitam a divulgação de uma mensagem, permitindo que ela atinja seus receptores de forma favorável (SILVA; ENGSTROM; ZABOROWSKI, 2002).

Para o Sisvan, a divulgação das informações é um ponto-chave para o bom funcionamento do sistema, fortalecendo o processo de produção de dados e orientando o planejamento. O público-alvo, receptor das mensagens no Sisvan, é muito variado, incluindo gestores e técnicos governamentais, sociedade civil organizada e comunidade. As mensagens, portanto, devem estar voltadas para sensibilizar e subsidiar a decisão política de gestores locais e de outros níveis governamentais, assim como para alcançar a população, de modo que esta participe também das ações decorrentes.

Os gestores funcionam como os "porta-vozes" para os setores da macrodecisão política, que precisam de informações técnicas para conseguirem a melhoria de programas de ações locais. Com esse ideário, as informações do Sisvan devem ser relevantes para:

- os setores de decisão política;

- a reorganização da assistência local;

- a instrumentalização da comunidade na melhoria da sua situação de saúde, alimentação e nutrição. 
Uma vez selecionados o conteúdo, o público-alvo e o momento pertinente para a divulgação da mensagem (por exemplo, diagnóstico nutricional da clientela), a etapa técnica seguinte é a seleção da forma de apresentação das informações.

Essa é uma área de conhecimento ainda nova para os profissionais da saúde, e temos muito que aprender com profissionais de comunicação, estabelecendo parcerias para melhorar as estratégias de informação, educação e comunicação.

Dentre as estratégias de marketing utilizadas na área de comunicação, ressaltamos, como exemplo, aquela que considera que as mensagens veiculadas devem ter como princípios a AIDA (Atenção - Interesse - Desejo - Aquisição). Assim, inicialmente, as mensagens precisam despertar a Atenção no receptor; promovendo, a seguir, o Interesse, ou maior aproximação e reflexão sobre a mensagem; essa reflexão deve "tocar", sensibilizar ou produzir Desejo para uma mudança de atitude ou pensamento, para, finalmente, propiciar a Aquisição do conteúdo da mensagem (SANT'ANNA, 2001).

Sem dúvida, na área da saúde, muito temos que caminhar para apreender tais conhecimentos. Neste capítulo não pretendemos esgotar o conhecimento na área, mas podemos nos apropriar de alguns conceitos que nos ajudem na escolha dos instrumentos de informação e comunicação.

\section{Instrumentos de informação e comunicação}

A seleção de instrumentos a serem utilizados deve estar coerente com os objetivos da equipe, em relação a um ou mais resultados a serem divulgados. É necessário que essa seleção seja definida a partir de uma discussão dos responsáveis pelo Sisvan, que os jornalistas chamam de "discussão de pauta".

Nesse momento são discutidos:

- quais os assuntos/temas a serem divulgados;

- a quem a informação se destina;

- como deve ser feita a divulgação;

- a avaliação crítica sobre a disponibilidade operacional, técnica e financeira para o desenvolvimento da informação. 
Agora vamos conhecer alguns dos instrumentos que podemos utilizar para a comunicação. Eles podem estar na forma escrita ou gráfica.

Dentre os instrumentos escritos de divulgação no campo técnico, destacamos como os principais: o informe, o boletim e o relatório. Eles devem ter sempre especificado o local e a época a que se referem as informações.

Informe é um instrumento que trata as informações dentro de uma periodicidade definida, sendo em geral composto de poucas laudas, ou seja, é conciso e próprio para as pessoas que têm pouco tempo de seu cotidiano para leitura. Podem ser mensais, trimestrais, quadrimestrais etc.

Boletim é um instrumento mais elaborado, que demonstra um nível maior de organização do Sisvan, na medida em que pressupõe um processo racional de divulgação de informações. Os boletins devem ser emitidos dentro de prazos predefinidos. Em geral, seu público-alvo são técnicos e gestores de programas e ações.

Relatório é um instrumento que usa uma linguagem discursiva mais minuciosa, descritiva, das situações/ações observadas. Seus elementos estruturais são: capa, folha de rosto, descrição da equipe técnica, sumário, listas, resumo executivo, texto, anexos, glossários, referências bibliográficas e índice. Seu público-alvo são técnicos responsáveis pela gestão de ações e programas.

Os instrumentos gráficos mais usados para a apresentação de dados do Sisvan são as tabelas e os gráficos e obedecem às normas e convenções estabelecidas pelo Instituto Brasileiro de Geografia e Estatística (1993).

Chamamos sua atenção para as definições adotadas pela ciência estatística dos dados que produzimos. Eles são denominados variáveis e classificados em: qualitativos, distribuídos em categorias; ordinais com uma ordenação; quantitativos, expressos em números (VIEIRA, 1980).

\section{Como construir tabelas e gráficos?}

Vamos conhecer agora como se constrói tabelas e gráficos.

Tabela é a "forma não discursiva de apresentar informações nas quais o dado numérico se destaca como informação central" (INSTITUTO BRASILEIRO 
DE GEOGRAFIA E ESTATÍSTICA, 1993, p. 9). É composta de título, moldura, cabeçalho, linhas e colunas.

Veja um exemplo de tabela construída com dados do Sisvan de um determinado DSEI.

Tabela 1 - Distribuição do estado nutricional (Peso/ldade expresso em percentis do NCHS) de crianças menores de cinco anos atendidas no DSEl Mangaba, segundo faixa etária. MS/Brasil, abril de 2007

\begin{tabular}{|c|c|c|c|c|c|c|c|c|c|c|c|c|}
\hline \multirow{3}{*}{$\begin{array}{l}\text { Estado } \\
\text { Nutricional } \\
(\mathrm{P} / \mathrm{I})\end{array}$} & \multicolumn{12}{|c|}{ Número e percentual de crianças atendidas por idade (em meses) } \\
\hline & \multicolumn{2}{|l|}{$0-5$} & \multicolumn{2}{|l|}{$6-11$} & \multicolumn{2}{|c|}{$12-23$} & \multicolumn{2}{|c|}{$24-35$} & \multicolumn{2}{|c|}{$36-59$} & \multicolumn{2}{|l|}{ Total } \\
\hline & $\mathrm{N}$ & $\%$ * & $\mathrm{N}$ & $\%$ * & $\mathrm{N}$ & $\%$ * & $\mathrm{N}$ & $\%$ * & $\mathrm{N}$ & $\%$ * & $\mathrm{N}$ & $\%$ * \\
\hline$>$ p97 & 11 & 3,7 & 13 & 4,1 & 8 & 2,1 & 2 & 1,4 & 5 & 2,3 & 40 & 2,9 \\
\hline p97-Ip10 & 270 & 91,2 & 269 & 85,8 & 308 & 77,5 & 122 & 83,0 & 191 & 88,4 & 1.160 & 84,6 \\
\hline p10-lp3 & 10 & 3,4 & 20 & 6,4 & 48 & 12,1 & 14 & 9,5 & 14 & 6,5 & 105 & 7,7 \\
\hline$<\mathrm{p} 3$ & 5 & 1,7 & 12 & 3,9 & 34 & 8,5 & 9 & 6,1 & 6 & 2,8 & 66 & 4,8 \\
\hline Total $(1)^{\star *}$ & 296 & 100,0 & 314 & 100,0 & 398 & 100,0 & 147 & 100,0 & 216 & 100,0 & 1.371 & 100,0 \\
\hline$S / /^{* * *}$ & 23 & 7,2 & 25 & 7,4 & 32 & 7,6 & 13 & 8,4 & 22 & 9,2 & 115 & 7,7 \\
\hline Total (2) ${ }^{* * * *}$ & 319 & 100,0 & 339 & 100,0 & 430 & 100,0 & 160 & 100,0 & 238 & 100,0 & 1.486 & 100,0 \\
\hline
\end{tabular}

Observe que o título da tabela é a descrição da temática. Nele deve estar indicada a natureza das informações a serem apresentadas, a abrangência temporal e geográfica, e os dados numéricos, descritos por extenso de maneira clara, concisa e sem abreviações. É importante apresentar a descrição da abrangência geográfica de maneira completa, para situar o leitor no espaço geográfico e nas unidades político-administrativas responsáveis pelas informações. Pode, por exemplo, ser referente à cidade, ao estado ou ao país, e ao período que as informações representam. No caso de tabelas com informações de serviços de saúde, é necessário citar o nome da unidade de saúde por extenso, o município, o estado e país, com o respectivo período (dia e/ou mês e/ou semestre e/ou ano). 
Toda tabela tem uma moldura, caracterizada pelo conjunto de linhas e colunas. Segundo o IBGE (INSTITUTO BRASILEIRO DE GEOGRAFIA E ESTATÍSTICA, 1993), é adequado haver no mínimo três traços horizontais paralelos (linhas), sendo o primeiro para separar o espaço do cabeçalho, o segundo para separar os dados descritos e o terceiro, o rodapé. Não estão previstos traços verticais de delimitação e as laterais devem ser abertas.

O cabeçallho é o espaço que descreve o conteúdo das linhas e colunas indicadoras. É separado do corpo da tabela por um traço horizontal

Toda tabela deve ter a indicação da fonte, na primeira linha depois do seu rodapé, para identificar a pessoa física ou jurídica responsável pelos dados. É importante não confundir fonte com nota geral, que visa esclarecer algum conteúdo que mereça destaque ou detalhamento, podendo essa última também ser escrita no rodapé.

Às vezes, para facilitar visualmente a apresentação de informações, optamos pelos quadros, com resultados quantitativos ou qualitativos. Eles são utilizados para apresentação esquemática de informações textuais e têm uma estrutura básica semelhante à das tabelas, mas não devem ser com elas confundidas, pois os quadros possuem uma delimitação externa. Veja as diferenças no exemplo a seguir.

Quadro 1 - Passos do diagnóstico coletivo nas áreas de planejamento (P), execução (E) e avaliação (A)

\begin{tabular}{|l|l|l|l|}
\hline Passos & Área & Objetivo & Ação \\
\hline $1^{\circ}$ & P & Planejar a investigação & $\begin{array}{l}\text { Seleção e organização dos procedimentos } \\
\text { diagnósticos }\end{array}$ \\
\hline $2^{\circ}$ & E & $\begin{array}{l}\text { Realizar o diagnóstico } \\
\text { nutricional }\end{array}$ & Traçar o perfil nutricional coletivo \\
\hline $3^{\circ}$ & A & Conhecer determinantes & $\begin{array}{l}\text { Identificar as causas prováveis do perfil } \\
\text { evidenciado }\end{array}$ \\
\hline $4^{\circ}$ & P & Planejar ação & $\begin{array}{l}\text { Estabelecer condutas individuais e } \\
\text { coletivas }\end{array}$ \\
\hline $5^{\circ}$ & E & Intervir & $\begin{array}{l}\text { Atuar para controle dos agravos e } \\
\text { promoção de saúde }\end{array}$ \\
\hline $6^{\circ}$ & A & Avaliar & $\begin{array}{l}\text { Avaliar o impacto das ações empreendidas } \\
\text { na melhoria do perfil }\end{array}$ \\
\hline
\end{tabular}

Quando os dados numéricos são descritos em classe de freqüência, existem convenções para apresentar os limites inferiores e superiores da 
classe, ou seja, os seus intervalos. A linha horizontal representa o intervalo entre os valores descritos; o traço vertical indica que o valor mais próximo está incluído no intervalo. Assim, podemos ter os seguintes tipos de intervalos:

- abertos ( - ) inclui todos os valores intermediários apresentados, excluindo os extremos;

- fechados $(|-|)$ inclui os extremos, além dos valores intermediários;

- semi-aberto à direita ( | - ) inclui todos os valores intermediários, inclusive o extremo à esquerda, mas exclui o extremo à direita;

- semi-aberto à esquerda $(-\mid)$ inclui todos os valores intermediários, inclusive o extremo à direita, mas exclui o extremo à esquerda.

Exemplo: Quando fazemos a descrição do estado nutricional de crianças, usamos intervalos para as faixas etárias e a classificação dos índices por percentis. Veja como representá-los:

\section{- Faixa etária}

0- 6 meses $=$ intervalo aberto, considera as crianças desde o nascimento até os 6 meses incompletos;

$6 \mid-12$ meses $=$ inclui as crianças de 6 meses completos até os 12 meses incompletos.

\section{$\checkmark$ Percentil}

$\geq$ p97 = inclui o p97,

p97-l10 = exclui o p97, mas inclui o p10,

p10 - 3 = não inclui o p10, mas inclui o p3,

$<$ p3 = não inclui o p3.

As normas do IBGE (INSTITUTO BRASILEIRO DE GEOGRAFIA E ESTATÍSTICA, 1993) recomendam que as classes inicial e final de uma distribuição de freqüência em uma tabela sejam fechadas. No caso de nossa classe de freqüência ser percentil, usamos o intervalo inicial e final “aparentemente abertos" (> p97 e < p3), mas, na realidade, eles estão limitados pelos percentis 100 e 1 , respectivamente. 
O gráfico é um instrumento de apresentação de resultados para ilustrar a distribuição de freqüências, sendo os dados registrados em eixos de abscissas e ordenadas. Deve ser de fácil compreensão, mostrando título, escala e legendas.

O título pode ser escrito tanto acima como abaixo do gráfico. As escalas devem apresentar valores crescentes, da esquerda para a direita e de baixo para cima. As legendas são colocadas, de preferência, ao lado direito.

Os gráficos podem ter vários formatos, como: de linhas, de barras, setores, diagramas, polígonos, dentre outros. Descreveremos, a seguir, os mais utilizados para o Sisvan.

Gráfico de linhas é uma representação largamente utilizada quando se pretende observar a variação de uma variável em relação a outra. Colocamos os valores das variáveis nos respectivos eixos e marcamos um ponto para cada par de valores; a seguir, unimos esses pontos.

Veja um exemplo de gráfico de linha, construído para divulgar as informações sobre o percentual de crianças com baixo peso no DSEI Rio Folha, nos anos de 2002 e 2006.

Gráfico 1 - Percentual de baixo peso (peso/idade $<$ p10 e p $<3$ ) em menores de 5 anos atendidas no DSEI Rio Folha/ Brasil, em 2002 e 2006

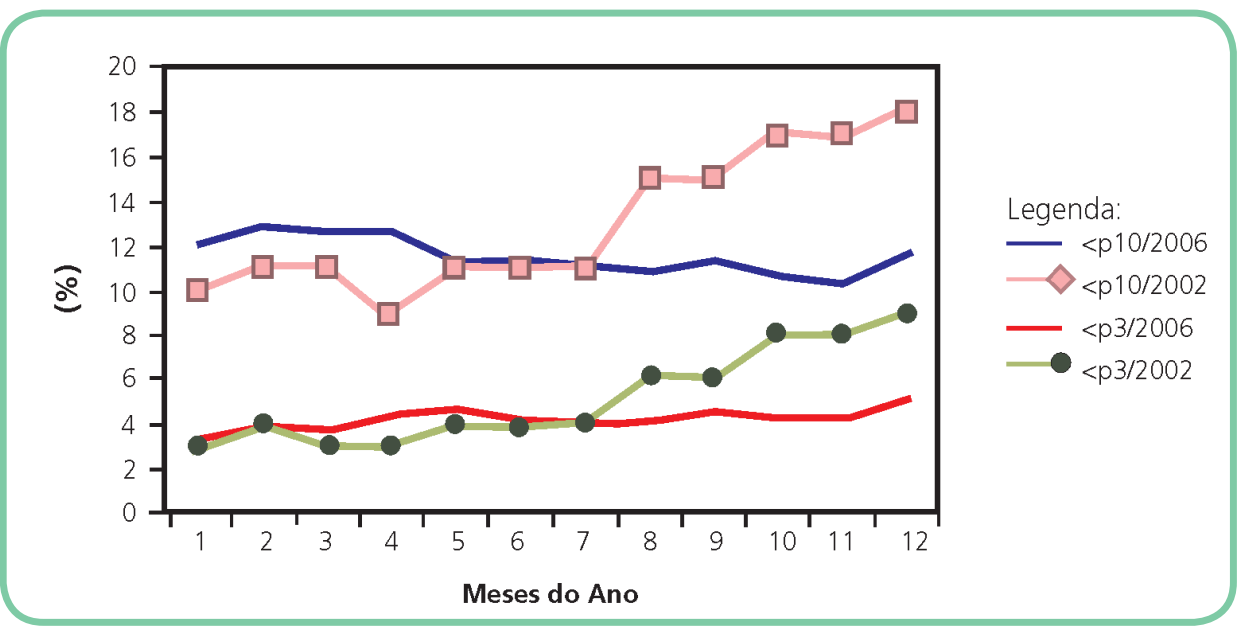

Nele podemos observar a variação da freqüência de baixo peso $(<$ pl0 e $<$ p3) durante os anos de 2002 e 2006 e ao longo de cada ano. Notamos claramente que no ano de 2002 a freqüência de baixo peso apresentou 
um aumento a partir de julho (mês 7) e que em 2006 esse percentual se manteve estável. É importante buscar as possíveis respostas para o aumento de casos a partir de julho de 2002 .

Uma outra opção é usar o gráfico de barras. O formato mais comum é o de barras verticais, desenhadas separadamente. Nesse caso, as freqüências devem estar representadas no eixo vertical e as variáveis, no eixo horizontal. Podemos usar, excepcionalmente, barras justapostas, quando elas representarem uma mesma variável em momentos distintos.

Veja um exemplo de gráfico de barras.

Gráfico 2 - Percentual de crianças menores de 5 anos atendidas no pólo-base Santa Madalena segundo faixa de percentil selecionada (peso/idade). DSEI Rio Folha/Brasil. 2002 e 2006

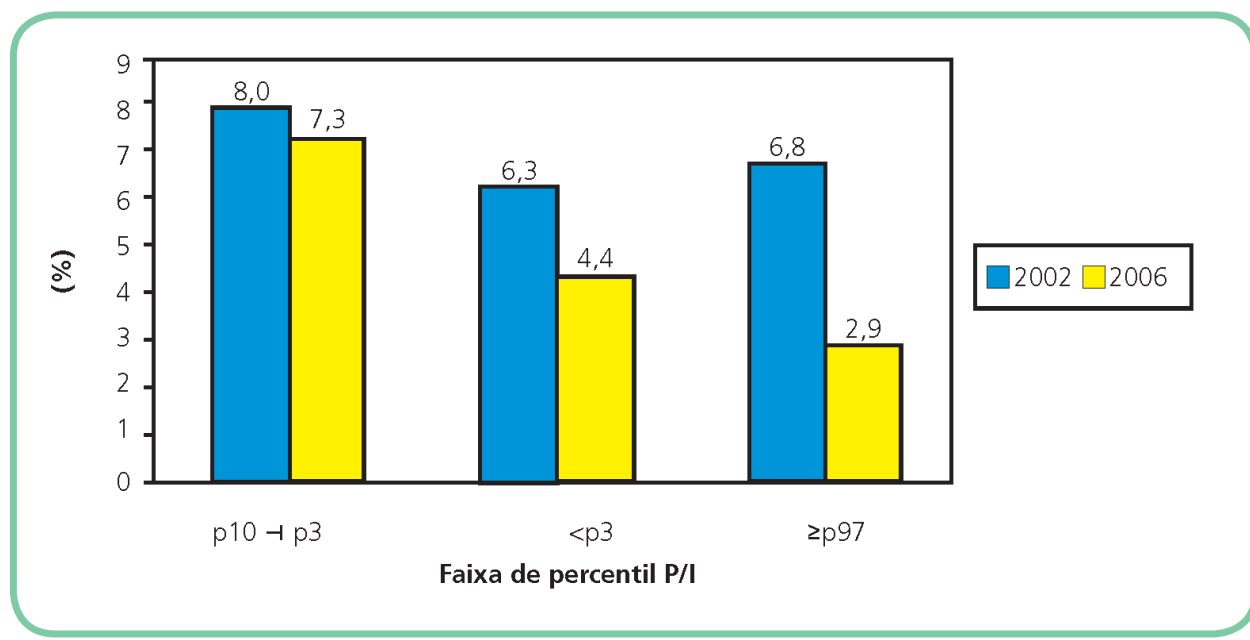

Veja que, nesse caso, fica fácil visualizar que o percentual de crianças em risco nutricional (p10 - l p3) é a alteração mais encontrada; que as freqüências das alterações nutricionais diminuíram no ano de 2006 em relação a 2002; e que a maior queda foi a observada entre as crianças com $\geq$ p97.

Outra forma de apresentação de informações é usando o gráfico em setores, mais conhecido como "gráfico de pizza". É muito útil para comparar valores apresentados em percentuais; a soma desses valores sempre totaliza $100 \%$. É importante que os valores a serem representados façam parte de um todo, ou seja, estejam sempre relacionados a uma mesma variável com poucas categorias. Para construí-lo, desenhamos uma circunferência em cujo interior estão representadas as categorias da variável selecionada. 
No exemplo apresentado no próximo gráfico, observamos que o percentual de crianças com estado nutricional adequado (p97 -l p10) é de $85,3 \%$; que $7,3 \%$ estão em risco nutricional (p10 - l p3); 4,4\% são desnutridas $(<\mathrm{p} 3) ; 2,9 \%$ têm sobrepeso $(\geq \mathrm{p} 97)$. A diferença entre os percentuais registrados aparece claramente nessa representação, de fácil compreensão. Veja o exemplo.

Gráfico 3 - Distribuição percentual do estado nutricional de crianças menores de 5 anos, segundo o percentil peso/idade, referência NCHS, do pólo-base Santa Madalena. DSEI Rio Folha/Brasil, 2006

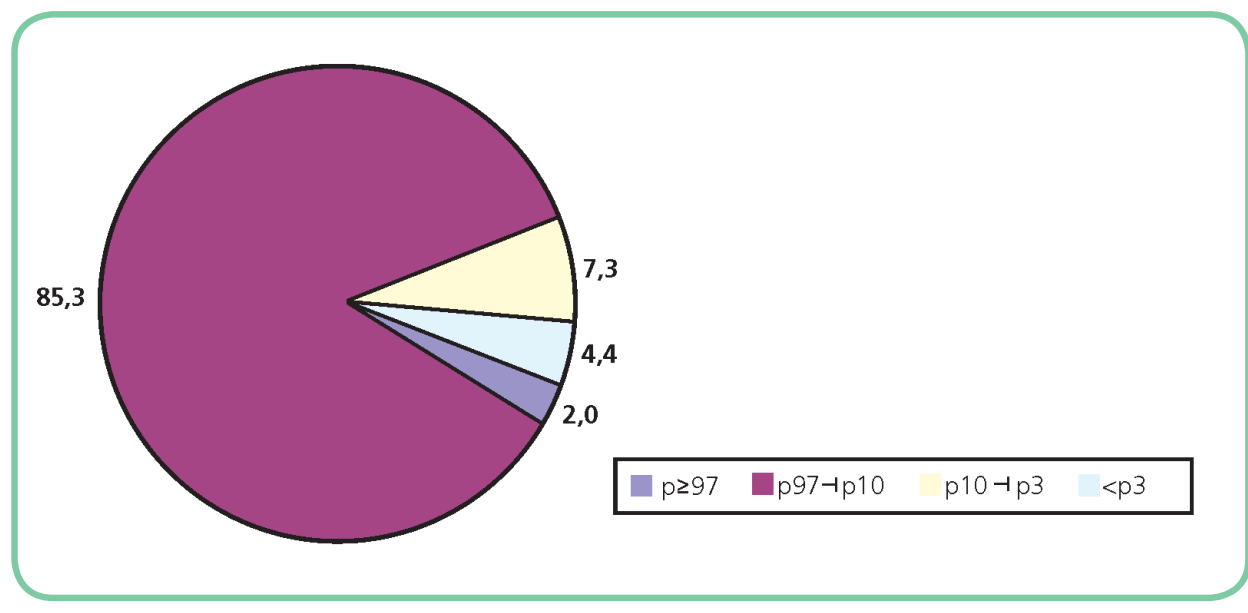

Para Refletir

Será que informar apenas os resultados encontrados, utilizando os instrumentos apresentados neste Capítulo, é um ato transformador da realidade?

Os instrumentos apresentados são formas de comunicação que dependem daqueles fatores que citamos sobre o processo de comunicação social.

Ao optar por um deles, é necessário conhecer o público-alvo e os objetivos da mensagem. A escolha do formato será orientada pela busca da clareza da informação a ser oferecida, isto é, pelo grau de entendimento do público-alvo sobre o que se quer comunicar.

Uma vez disponíveis, as informações devem ser discutidas com todos os usuários do sistema que possam vir a utilizá-las para alguma ação. Como dissemos anteriormente, a melhor forma para a sua construção é a participativa, com adesão de todos os atores. 
Os produtos finais resultantes desse processo de divulgação servirão de base para a elaboração de estratégias de intervenção. Todos os instrumentos descritos visam a divulgação para os usuários e comunidade, e devem estar baseados na discussão crítica dos resultados do Sisvan por meio da participação popular.

Esse processo é um ato de reciprocidade com dupla função - cognitiva e comunicativa -, que não pode ser rompido. Assim, informar e comunicar em prol da melhoria das condições de saúde é compartilhar a experiência e a cidadania vividas pelos atores.

O pressuposto do Sisvan é produzir informação para ação. Isso significa que as informações geradas devem ser usadas em prol da melhoria das condições de saúde, alimentação e nutrição. É importante lembrar que o estado nutricional, além de retratar o equilíbrio entre o consumo de alimentos e a utilização biológica, expressa a relação do indivíduo com o meio ambiente (BARROS, 2008). Entender essa dimensão é importante para pensar os modos de informar e comunicar os resultados do Sisvan. Para isso é fundamental entender que a divulgação da informação é resultado da análise epidemiológica da situação nutricional da clientela usuária do serviço de saúde.

Divulgar as informações gera reações. Podemos destacar que a maioria delas é expressa por dúvidas e pelo descrédito das informações disponibilizadas. Às vezes, essa reação é decorrente da falta de conhecimento técnico sobre o fenômeno observado, de manipulação política e de erros cometidos pela equipe técnica na interpretação dos resultados. Não importa quantos são os motivos; importa, sim, estarmos consciente que esse processo precisa ser acompanhado e avaliado.

No próximo Capítulo, vamos trabalhar o uso de dados-informações como estratégia para o planejamento de ações e intervenções. A apresentação desse conteúdo também parte da experiência dos autores na observação do desenvolvimento do Sisvan no país.

\section{PARA PRATICAR - DIVULGAÇÃO DOS DADOS}

De acordo com a análise e interpretação dos resultados apresentados na atividade do Capítulo 5, tendo como base a sua realidade, proponha uma estratégia de divulgação dos mesmos.
A função do Sisvan é discutida no Capítulo 6, volume 1 do livro Vigilância Alimentar e Nutricional para a Saúde Indígena, de Denise Cavalcante Barros, Denise Oliveira e Silva e Silvia Ângela Gugelmin (2007). 


\section{Referências}

BARROS, D. C. Bases para o diagnóstico nutricional. In: BARROS, D.C.; SILVA, D. O.; GUGELMIN, S. A. Vigilância alimentar e nutricional para a saúde indígena. Rio de Janeiro: Fiocruz, 2008. v. 2.

INSTITUTO BRASILEIRO DE GEOGRAFIA E ESTATISTICA. Normas de apresentação tabular. 3. ed. Rio de Janeiro, 1993.

PEREIRA, M. G. Usos da epidemiologia. In: Epidemiologia: teoria e prática. 4. ed. Rio de Janeiro: Guanabara Koogan, 2000. p. 17-29.

SANT'ANNA, A. Propaganda, teoria, técnica e prática. 7. ed. São Paulo: Pioneira Thomson Learning, 2001.

SILVA, D. O.; ENGSTROM, E. M.; ZABOROWSKI, E. L. Sisvan: instrumento para o combate aos distúrbios nutricionais de saúde: diagnóstico coletivo. Rio de Janeiro: Fiocruz/Centro Colaborador em Alimentação e Nutrição, 2002.

VIEIRA, S. Noções básicas. In: Introdução à bioestatística. 3. ed. Rio de Janeiro: Campus, 1980. 


\section{Uso dos dados e informações para o planejamento de ações e intervenções}

Denise Oliveira e Silva

Uma das grandes dificuldades para os profissionais é transformar as informações geradas pelo Sisvan em ação. A equipe responsável precisa saber como fazer para que os resultados do Sisvan sejam divulgados e possibilitem a retroalimentação do sistema.

A nossa contribuição como agentes formadores é para que sua atuação profissional junto à população seja responsável e efetiva. Você precisa compreender que o Sisvan é um sistema abrangente que incorpora informações de diversos setores, como agricultura, economia e saúde.

No Brasil, o seu desenvolvimento ocorreu prioritariamente no setor saúde, propiciando subsídios para outros setores. Atualmente, a experiência acumulada do Sisvan no setor saúde tem uma contribuição importante para a consolidação do Sistema de Segurança Alimentar e Nutricional no país, a partir da promulgação da Lei de Segurança Alimentar (LOSAN BRASIL, 2006).

Uma informação, quando gerada, deve ter como desfecho a sua divulgação, fechando um ciclo de comunicação. O uso das informações orienta as ações a serem desencadeadas. Portanto, é importante que a visão do Sisvan como apenas um banco de dados seja superada. Todos os mecanismos devem ser potencializados para que as informações geradas nesse sistema sejam usadas para desencadear ações e retroalimentar o sistema.

Todo o conjunto de informações que já foram produzidas deve estar sempre disponível. A equipe de profissionais responsável deve ter habilidade
O histórico do Sisvan e seus percursos na saúde indígena são discutidos no Capítulo 6, Parte II, volume 1, do livro Vigilância Alimentar e Nutricional para a Saúde Indígena, de Denise Cavalcante Barros, Denise Oliveira e Silva e Silvia Ângela Gugelmin (2007). 
O tema invisibilidade epidemiológica e demográfica dos povos indígenas brasileiros é discutido no Capítulo 2, Parte I do livro Vigilância Alimentar e Nutricional para a Saúde Indígena, volume 1, de Denise Cavalcante Barros, Denise Oliveira e Silva e Silvia Ângela Gugelmin (2007).

Diversas recomendações a respeito do tratamento e análise dos dados foram apresentadas no Capítulo 5, da Parte II deste livro, "Análise e interpretação dos dados". para traduzir os resultados obtidos e divulgá-los com clareza, orientando a tomada de decisões. A divulgação das informações é um ponto-chave para o bom funcionamento do Sisvan, fortalecendo o processo de produção de dados e possibilitando reavaliação de ações.

O Sisvan pode então ser um instrumento para a superação da invisibilidade do perfil epidemiológico da população indígena brasileira. Mas como?

A equipe de gerenciamento do Sisvan deve, obrigatoriamente, auferir confiabilidade aos dados e às informações geradas. O primeiro passo é saber realizar uma boa interpretação dos resultados. Não é possível desenvolver e/ou apresentar uma proposta de ação de intervenção sem confiança nos resultados que temos em nossas mãos. Avaliar a qualidade dos dados gerados, organizá-los e trabalhar ao máximo as informações decorrentes são os procedimentos de preparação que proporcionarão credibilidade ao Sisvan junto aos gestores, usuários e à comunidade.

Antes de iniciar a discussão sobre a forma como serão usados os dados para o planejamento de ações, temos que exercitar a interpretar os resultados. Para isso é necessário realizar todas as etapas do processo de análise das informações, conforme discutido anteriormente.

\section{Para refletir}

Em seu serviço, de que modo é realizada a análise dos dados antropométricos de crianças? Identifique os pontos que se aproximam e aqueles que se distanciam das recomendações para a interpretação dos resultados, descritas no Capítulo 5, deste livro.

Na interpretação do perfil nutricional, é necessário ter o cuidado de avaliar as vantagens e limitações dos indicadores usados e o diagnóstico coletivo resultante. Esse perfil é como um retrato da situação nutricional da população que está sendo acompanhada por você e sua equipe, em sua área de atuação. Ele sozinho não representa um perfil populacional e não pode ser generalizado, devendo ser utilizado no âmbito da clientela assistida (serviço).

Os resultados do diagnóstico nutricional da coletividade devem ser cuidadosamente analisados com o intuito de responder aos objetivos previamente estabelecidos. As informações geradas vão representar o perfil nutricional da clientela assistida, nos DSEI, pólos-base e aldeias.

Nessa análise, precisamos saber: 
- o que esse percentual significa? É um valor alto, baixo ou está dentro do esperado?

- essas informações têm consistência para o conjunto do universo estudado?

- o número de indivíduos avaliados foi adequado, ou o percentual de "casos sem informação" nutricional foi expressivo?

Podemos também ampliar o olhar e buscar entender:

- se houve uma tendência de variação de freqüência ao longo do tempo, isto é, se nos meses anteriores o percentual foi semelhante ou não;

- se as informações dessa clientela são similares às encontradas no cenário nacional, evidenciadas nas pesquisas nutricionais;

- quais fatores poderiam estar influenciando no perfil nutricional dessa clientela.

As informações devem ser descritas com o máximo de confiabilidade, visando tirar conclusões (hipóteses) com uma boa margem de acerto (probabilidade), em função dos dados (variáveis) coletados e dos grupos (toda a população ou segmentos) a que pertencem, para realizarmos interpretações fidedignas.

Acreditamos que ter clareza nas limitações impostas na construção dos indicadores é a forma mais prudente de superar alguns problemas de qualidade da informação. Com as informações devemos entender a realidade local, avaliar e rever o serviço prestado e o planejamento de ações. Esse é o salto de qualidade que podemos dar nos serviços oferecidos à população. Com os dados interpretados de forma correta, atingimos a confiabilidade para começar a iluminar as discussões para o planejamento de ações e informações.

\section{Para refletir}

Você participou de algum diagnóstico nutricional coletivo?

De que forma ele foi realizado? O que foi feito com os resultados?

Que ações puderam ser geradas com base nesses resultados?

Para orientar o desenvolvimento dessas ações, optamos por utilizar as recomendações do Guia de Projetos Participativos de Nutrição, da Organização das Nações Unidas para Agricultura e Alimentação (1997). Esse
Toda informação é importante! É preciso, no entanto, ter a clara dimensão do que elas expressam (as potencialidades) e perceber as respostas que não podem ser obtidas a partir de tais dados (as limitações). Assim não extrairemos conclusões inadequadas e distantes da realidade.

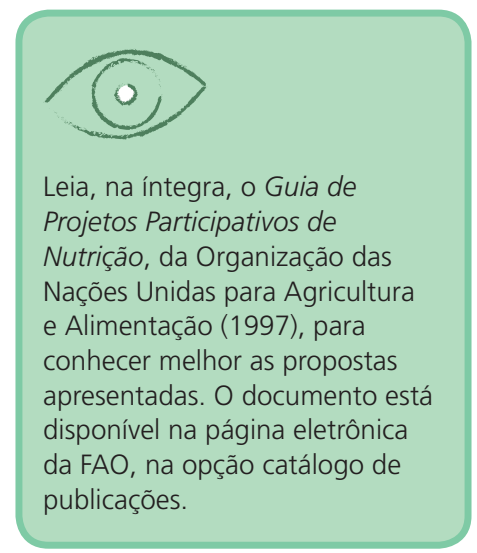


No Capítulo 4 deste volume, "Construção do fluxo de dados", são apresentados os modelos de Mapas de Acompanhamento do Estado Nutricional e os procedimentos para consolidação e interpretação dos dados, que resultam em informações importantes para o serviço. documento visa recolocar as informações do Sisvan como estratégia de planejamento para o desenvolvimento de ações e intervenções.

O Guia propõe algumas etapas para construção de ações e projetos participativos de nutrição. Neste livro, escolhemos trabalhar com algumas delas, que consideramos fundamentais para este processo. São elas:

- Identificação e definição de prioridades

- Mobilização de recursos institucionais e comunitários

- Seleção de intervenções

\section{Identificação e definição de prioridades}

Com os dados dos mapas elaborados por você, conforme já demonstrado no Capítulo 4, será possível, agora, conhecer o perfil nutricional de crianças, gestantes, adultos, idosos e, quem sabe, muitas outras coisas. Nesse momento, quando vamos levantar os problemas que devem ser priorizados, surgem algumas dúvidas e nos defrontamos com limites de atuação. Quem dera pudéssemos atender a tudo! Mas, temos que decidir o que fazer e de forma rápida, precisa e adequada às oportunidades políticas, financeiras, técnicas e operacionais que envolvem o nosso serviço. Para isso, precisamos selecionar quais atividades vamos desenvolver.

Para identificar e selecionar as atividades, é necessário sistematizar e hierarquizar as prioridades. Essa etapa concretiza a transformação dos dados em informação, isto é, a geração de indicadores, que devem ser agrupados em categorias de informações, baseadas nos objetivos institucionais e nas demandas da rede Sisvan. Esses indicadores são, em geral, selecionados de forma pactuada entre os atores envolvidos no sistema, tanto do setor saúde como da comunidade.

Se você tiver dúvidas em relação à geração de indicadores, releia o primeiro Capítulo da Parte II que aborda essa questão com detalhes.

Vale relembrar, aqui, que é preciso termos clareza do que pretendemos saber com as informações do Sisvan, ou seja, para que servem?

Vamos destacar alguns objetivos básicos das informações geradas pelo Sisvan: 
- apoiar a assistência direta e melhorar a assistência local e a promoção à saúde;

- monitorar a situação nutricional de grupos específicos, segundo características dos sistemas de informação e vigilância em saúde. No caso dos DSEI, "alimentar" o sistema de informações da Funasa;

- subsidiar políticas e ações para promoção de saúde, prevenção e controle de agravos nutricionais.

Dessa forma, as informações têm utilidade para tomada de decisões dos gestores.

As informações geradas na atenção básica à saúde devem ser norteadas pelos princípios da Norma Operacional Básica (NOB) (BRASIL, 1996) e da Norma Operacional da Assistência à Saúde (NOAS), do SUS (BRASIL, 2001), além dos contidos na Norma Técnica Vigilância Alimentar e Nutricional para os Distritos Sanitários Especiais Indígenas (FUNDAÇÃO NACIONAL DE SAÚ$D E$, 2006b). Destacamos, ainda, que a Vigilância Alimentar e Nutricional integra a terceira diretriz da Política Nacional de Alimentação e Nutrição (BRASIL, 1999) e as recomendações das Conferências de Segurança Alimentar e Nutricional (CONFERÊNCIA NACIONAL DE SEGURANÇA ALIMENTAR E NUTRICIONAL, 2004) e de Saúde Indígena (FUNDAÇÃO NACIONAL DE SAÚDE, 2006a).

No âmbito local, para melhorar a assistência prestada aos usuários, é necessário pensar na implementação do conceito da atitude de vigilância. Nesta fase, os dados que vamos discutir têm que expressar a valorização do estado nutricional, como componente fundamental para a saúde e atenção prioritária a grupos mais vulneráveis.

Como identificar as prioridades?

Você tem o retrato da sua população. Nele apareceram muitas informações e você deve selecionar aquelas que são prioritárias. O primeiro passo é pensar que esse processo é coletivo.

Você é um dos atores desse processo, mas, quem são os outros atores?

Temos vários atores, tais como: profissionais de saúde, gestores, lideranças comunitárias, agentes financiadores do governo, instituições nãogovernamentais e a comunidade. Podemos assumir que todos eles têm
A vinculação das informações geradas na atenção básica à saúde, às normas e às políticas públicas é analisada nos Capítulos 3 e 5 do livro Vigilância Alimentar e Nutricional para a Saúde Indígena, volume 1, de Denise Cavalcante Barros, Denise Oliveira e Silva e Silvia Ângela Gugelmin (2007).

O mesmo volume, no Capítulo 6, reforça a importância das informações geradas na atenção básica à saúde serem usadas para repensar a rotina diária da assistência prestada. 
um papel no desenvolvimento das ações derivadas do Sisvan e podem ser considerados agentes de desenvolvimento. Esses são os atores que ajudam na identificação das prioridades.

Para definir prioridades, é necessário estabelecer os contatos iniciais entre os agentes de desenvolvimento. No Guia de Projetos Participativos de Nutrição, da Organização das Nações Unidas para Agricultura e Alimentação (1997), essa fase deve ser realizada por meio de dois processos:

- coletar, revisar e organizar a informação existente sobre os aspectos alimentares e nutricionais;

- identificar os agentes de desenvolvimento envolvidos em atividades relacionadas à alimentação e nutrição.

Tendo o Sisvan implantado em seu local de trabalho e seguindo as recomendações sugeridas para a análise e interpretação dos dados, o primeiro processo será relativamente fácil, visto que as informações sobre a situação nutricional estarão disponíveis. As informações mais freqüentes utilizadas nessa etapa são:

- comparação dos percentuais encontrados em cada categoria com os valores esperados na referência;

- comparação com outras fontes locais (serviços, dados de programas comunitários, municípios) e com dados de pesquisas populacionais locais ou nacionais;

- utilização de indicadores de outros sistemas de informação;

- avaliação de possíveis determinantes.

Nessa avaliação, agregamos o conhecimento da realidade local para interpretar os achados (perfis e tendências) do diagnóstico nutricional. Por exemplo, dados sobre prevalência de aleitamento materno, existência de ações de suplementação alimentar, morbidades, condições dos serviços de saúde e do ambiente podem auxiliar as interpretações.

Com os resultados organizados, vamos realizar o inventário de instituições que, localmente, trabalham em atividades relacionadas com alimentação e nutrição. É nesse momento que estabelecemos os contatos iniciais e identificamos os agentes técnicos de desenvolvimento (enfermeiras, agentes de saúde, médicos, nutricionistas etc.), gestores (coordenadores dos DSEI e pólos-base), lideranças políticas e comunitárias. Isso pode ser feito através de reuniões, oficinas e/ou outras formas de reflexão sobre esses resultados, em busca de soluções. 
Uma proposta interessante para realizar nessa etapa é construir um diagrama de causalidade, usando como técnica a construção de uma "árvore de problemas" (INSTITUTO NACIONAL DE ALIMENTAÇÃO E NUTRIÇÃO, 1994), que é um caminho largamente utilizado devido à sua facilidade de compreensão e construção. Entretanto, é importante destacar que existem várias técnicas; você poderá escolher aquela que seja mais adequada à sua realidade.

Após a leitura, observe que a lógica de criação de uma "árvore de problemas" prevê a necessidade de identificar as causas e conseqüências de um problema central. As raízes são as causas; os galhos e ramificações são as conseqüências, e a parte central - o tronco - é o problema que vamos enfrentar. E com base nas informações são identificadas as ações necessárias para superá-lo. A Figura 1 apresenta um exemplo de uma "árvore de problemas" sobre a fome.

Figura 1 - Árvore de problemas

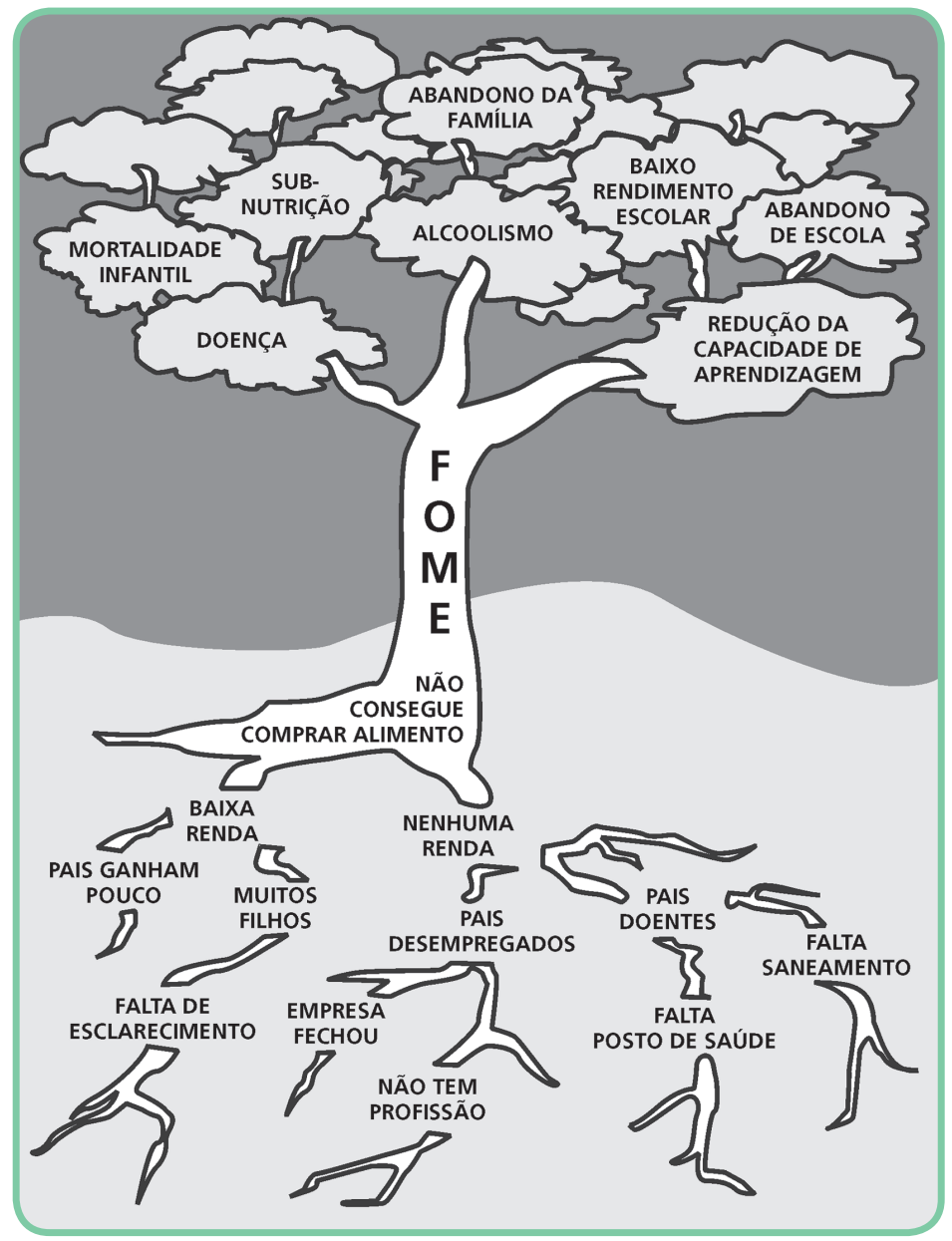

Fonte: Instituto Nacional de Alimentação e Nutrição (1994)

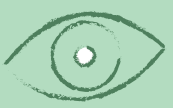

Sugerimos a leitura do documento Planejamento participativo: um instrumento de combate à fome (INSTITUTO NACIONAL DE ALIMENTAÇÃO E NUTRIÇÃO, 1994), antes de iniciarmos a criação da "árvore de problemas", para você se familiarizar um pouco mais com a técnica. Você pode entrar em contato com o Ministério da Saúde para solicitar informações sobre esse documento. 
Vamos praticar um pouco a construção de um diagrama de causalidade ou modelo causal, ou ainda, uma árvore de problemas. Com essa atividade você visualizará mais facilmente a situação e as possibilidades de intervenção.

\section{PARA PRATICAR - IDENTIFICAÇÃO DE PROBLEMAS}

A partir de agora você irá construir uma "árvore de problemas". Mas, antes, é preciso identificar um problema. Com esse objetivo, leia o caso proposto a seguir e depois realize as seguintes atividades:

a) liste, por ordem crescente de prioridade, os problemas identificados por você, e discuta com o seu grupo de trabalho;

b) selecione um dos problemas e desenhe uma árvore com as raízes (as causas do problema identificado no caso apresentado), tronco (a causa principal do problema), galhos e folhas (as conseqüências).

\section{Caso}

Eram mães com os filhos no colo! Outras com um prato de comida na mão para alimentar as crianças.

Nesse dia, nessa cidade distante 228 quilômetros de uma grande capital de um estado do centro do país, o que se via era a revolta da comunidade indígena! Todos se sentiam prejudicados pelas notícias veiculadas na imprensa de que os índios estariam deixando de alimentar os filhos por questões culturais, contribuindo para o aumento do índice de desnutrição.

Nesse DSEI tinha sido registrada, em poucas semanas, a morte de 15 crianças com idades entre dois meses e sete anos, em duas aldeias. 0 total de crianças menores de sete anos nas duas aldeias era de cerca de 330.0 pólo-base responsável pelo atendimento das duas aldeias encontrava-se sem coordenador técnico e profissional de nível superior havia quatro meses, apesar de o município receber recursos da Secretaria de Atenção à Saúde (SAS) para contratação de Equipes Multidisciplinares de Saúde Indígena (EMSI). 0 atendimento às aldeias estava sendo realizado por um auxiliar de enfermagem e três Agentes Indígenas de Saúde (AIS).

Segundo informações dos AIS, o quadro das crianças se iniciava com diarréia intensa e febre. As mães paravam de alimentar as crianças, cuja situação, em poucas semanas, evoluía para desnutrição grave e morte. A referência hospitalar só era aceita quando a desnutrição se mostrava mais grave para as famílias, como a prostração e a acentuada perda de peso. Segundo ainda os AIS, algumas das crianças não apresentavam diarréia, mas um quadro de febre alta e sinais 
de infecção respiratória. De acordo com o relato, as crianças que pioravam mais rapidamente eram as que já estavam "magrinhas". Não havia registro de dados do estado nutricional. Nem os AIS nem a auxiliar de enfermagem pesavam as crianças. As balanças do pólo-base eram usadas como suporte de material. A de adulto era usada pelos próprios indígenas, que se pesavam quando iam buscar medicamentos. A farmácia do pólo estava cheia de medicamentos para dor e febre, dois tipos de antibióticos, mas faltava soro de reidratação oral. Das 15 crianças que evoluíram para óbito, 12 tinham sido internadas no hospital do município mais próximo e três morreram na aldeia. Segundo dados colhidos na referência, as crianças evoluíram para óbito nos primeiros três dias de internação, apresentando quadro de hipotermia, hipoglicemia e choque séptico.

Havia ainda cinco crianças internadas cuja recuperação ocorria satisfatoriamente, sendo que três delas apresentavam baixo peso para a idade, e as demais estavam em risco nutricional.

A equipe de reportagem do jornal 0 Estado também estava na aldeia e observou o cuidado e a preocupação das mães com a saúde das crianças. Todas as semanas, as índias se reuniam para fazer um sopão para os filhos. A iniciativa dependia de doações; por isso, nem sempre era realizada. Nas casas, as crianças com menos de cinco anos eram alimentadas pela mãe. 0 problema era que o único alimento se constituía de um prato de arroz.

O chefe do DSEI, um médico que trabalhava há cinco anos na aldeia, desesperado com as notícias da imprensa local, pediu apoio à assessoria de comunicação da Funasa em Brasília, para explicar que estavam sendo tomadas medidas para resolver a situação. Providenciou a contratação de um responsável pelo Sisvan para organizar uma ação nas aldeias. Seriam contratados mais membros da equipe, como um médico, uma enfermeira e dois auxiliares de enfermagem. Estaria vindo outra equipe de outro DSEI próximo para investigar as causas das mortes, mas não havia tempo de esperar o resultado, pois outros casos de adoecimento já estavam sendo relatados pelos AIS. As balanças eletrônicas e dois antropômetros portáteis haviam acabado de chegar, além de três balanças para os AIS.

Para os indígenas, as providências anunciadas pelos representantes de órgãos públicos não serviam como justificativa para esconder a precariedade do atendimento de saúde oferecido nas aldeias. "Isso é um absurdo. Quantas vezes deixamos de comer para alimentar nossos filhos. As mães cuidam sim das crianças e a desnutrição não tem nada a ver com a nossa cultura", rebateu a agente de saúde, a índia Maria das Dores.

Um médico da Funasa, dr. Serafim Alves, contou que sua equipe enfrentava resistência das famílias indígenas para realizar o atendimento médico. A espiritualidade, 
vergonha e dúvida sobre os procedimentos adotados pelos agentes de saúde levavam os indígenas a desistirem do tratamento, avaliou o médico. "Eles acreditam que uma doença como a desnutrição, por exemplo, é um feitiço e somente o rezador pode fazer a cura", explicou Serafim Alves.

As aldeias não contavam com saneamento básico, nem com água tratada, pois a Coordenação Regional da Funasa (Core) não finalizou a obra, faltando uns poucos metros de encanamento para disponibilizar a água.

O índio Alberto dos Santos Silva, morador da aldeia, também contestou as informações veiculadas na imprensa. Ele disse que muitas lideranças indígenas contribuíam para que informações equivocadas fossem divulgadas. "As autoridades querem culpar os índios pelo problema da desnutrição", finalizou ele.

Havia disponibilidade de alimentos tradicionais, por meio de algumas roças comunitárias e familiares, mas as fontes de proteína eram sazonais. Nessa época do ano não havia peixe, a maior fonte de proteína das famílias. Algumas tinham aposentadoria dos idosos e adquiriam alimentos de baixa qualidade nos mercados regionais, como refrigerantes e alimentos industrializados. 0 município não havia cadastrado nenhuma família no Programa Bolsa-Família, e a ação de distribuição de alimentos solicitada ao Ministério do Desenvolvimento Social e Combate à Fome (MDS) estava atrasada há três meses.

O Conselho Distrital de Saúde Indígena (Condisi) foi convocado em caráter de urgência e propôs a criação de um comitê específico para analisar e mapear a situação. Ao final foi realizado um ritual ancestral para pedir ajuda para a aldeia superar a tragédia.

Dentre as propostas debatidas para driblar a resistência estava a realização de um ritual, pelos pajés, antes de qualquer tratamento médico, ganhando a confiança das famílias com rezas e ritos tradicionais. No entanto, havia falta de preparo das equipes da Funasa para tratar das questões culturais das comunidades. "É preciso conversar com eles para ultrapassar a barreira cultural". Para um AIS, o caminho para superar a desnutrição virá quando houver distribuição de terras e a recuperação ambiental das áreas já habitadas pela população de índios.

Embora a fome esteja matando crianças indígenas, as ações de combate à desnutrição e a questão fundiária vêm sendo ignoradas pelas autoridades, e o assistencialismo é a única medida colocada em prática pelo governo federal. Uma Organização Não-Governamental (ONG) local entendeu que a criação de um programa integrado entre os Ministérios do Desenvolvimento Agrário e da Agricultura e Pecuária deveria ser iniciado. "O assunto nem é colocado em discussão. 0 governo só toma medidas imediatas, mas é preciso tratar o problema pela raiz", afirmou o coordenador da ONG. 
Uma semana após a tragédia, o governo do Estado entregou 31,2 toneladas de alimentos na aldeia, por meio do Programa Fome Zero. A ação foi necessária para minimizar a carência da comunidade, mas não é suficiente para tirar as famílias da miséria.

O capitão da aldeia pediu ajuda de técnicos agrícolas para fazer roças nas aldeias. "Não temos maquinário para tirar esse matagal e as famílias precisam de auxílio na plantação. Não estamos conseguindo plantar nem mandioca e batata", frisou o capitão.

Um membro do Condisi também defendeu a mesma opinião. Segundo ele, a distribuição de cesta básica ameniza, mas não resolve o problema. "Paralelamente a isso, são necessárias ações estruturais. Chega desse jogo de empurra-empurra, ninguém quer assumir a responsabilidade", ressaltou o índio.

O coordenador da ONG acredita que essa avalanche de alimentos entregue nas aldeias, de forma desordenada, contribuiu para o aumento do preconceito contra a comunidade indígena. "As pessoas vão questionar: esses índios recebem um monte de comida e continuam passando fome?"

Além disso, o assistencialismo é um atrativo para os índios desaldeados, que só retornam às aldeias para receber cesta básica. 0 problema, segundo ele, é que daqui a alguns anos, quando a aldeia for esquecida novamente, a fome volta a castigar as famílias, dessa vez em número ainda maior. Atualmente, os índios dependem de maquinário para conseguir plantar nas aldeias. A terra está tomada pelo matagal e a comunidade não tem mais condições de limpar a terra com enxada. Os três tratores da aldeia estão parados desde o ano passado, em uma oficina mecânica do município.

Caso adaptado pelos autores com base no relato de uma situação real, sendo fictícios os nomes dos envolvidos.

Observe que na construção da "árvore de problemas" e da lista de prioridades surgem muitas indagações, como: quais são as nossas prioridades; como vamos selecioná-las; por onde começar; quais instituições devem ser contatadas.

Para dar maior eficiência a esse processo, a sua construção deve contar com a participação de todos os atores envolvidos, ou seja, profissionais da saúde, representantes comunitários e gestores. 
Os determinantes do estado nutricional e a construção de modelos causais são discutidos no Capítulo 4, Parte II, volume 1 do livro Vigilância Alimentar e Nutricional para a Saúde Indígena, de Denise Cavalcante Barros, Denise Oliveira e Silva e Silvia Ângela Gugelmin (2007).
A Organização das Nações Unidas para Agricultura e Alimentação (1997) recomenda: o diálogo entre os atores (profissionais, instituições, comunidade) é a base de um projeto participativo de nutrição. Mediante o diálogo, cada um contribuirá para melhor compreensão dos problemas alimentares e nutricionais. Com o avanço do projeto, tanto a compreensão dos problemas como a perspectiva que se tem deles evoluem e amadurecem.

\section{Mobilização de recursos institucionais e comunitários}

Uma vez que os problemas nutricionais apresentam uma rede complexa de determinantes, a solução requer a participação de diversos atores. Os parceiros do DSEI, incluindo setores como da agricultura, saúde, educação, desenvolvimento social, sociedade civil, estão todos os envolvidos na solução dos problemas identificados. É nesse momento que é discutida a rede causal do problema nutricional que está sendo analisado e suas possíveis soluções, segundo as características dos agentes de desenvolvimento, especialmente da comunidade. O tempo de realização pode ser longo, se os resultados não estiverem claramente descritos e apresentados pela equipe responsável pelo Sisvan.

Neste processo de trabalho, é importante abrir espaço para a participação efetiva da população, identificando pessoas-chave na comunidade. Elas fariam a comunicação com outros membros da comunidade, trazendo informações e sugestões úteis. Ao mesmo tempo, o apoio dessas pessoas (lideranças, agentes indígenas de saúde, agentes de saneamento, professores, pajés/xamãs) facilitaria a mobilização de maior número de pessoas, proporcionaria maior credibilidade à proposta e ajudaria a obter êxito e sustentação. Quando as comunidades e os serviços iniciam as atividades com seus próprios meios, há maior participação e compromisso com a proposta, diminuindo o grau de dependência de recursos externos.

Outra etapa a ser cumprida na mobilização é o levantamento dos recursos disponíveis na comunidade, no distrito e/ou pólo, bem como um inventário das instituições locais que desenvolvem ou prestam apoio às atividades relacionadas à alimentação e nutrição. Nesse inventário podem-se incluir os serviços oferecidos, o nome da instituição que os presta, sua localização e distância da comunidade, assim como os recursos que pode colocar à disposição para a execução das ações.

Com essas informações, é possível preparar um mapa, indicando a interação entre cada instituição/parceiro e sua importância na resolução dos problemas identificados, ou no desenvolvimento das intervenções. A construção coletiva do mapa permite discutir os problemas e visualizar as oportunidades para proporcionar melhor assistência à comunidade. 


\section{PARA PRATICAR - ATITUDE DE VIGILÂNCIA}

Assista novamente ao vídeo Atitude de vigilância, mas, agora, em conjunto com o seu grupo de trabalho, para, juntos, refletirem sob uma nova perspectiva, isto é, à luz das indagações a seguir:

1. Quais os limites de atuação sobre os problemas apontados no vídeo?

2. Que recursos institucionais e comunitários precisam ser mobilizados para a busca de soluções?

\section{Seleção de intervenções}

Uma vez identificados os problemas alimentares e nutricionais, o passo seguinte consiste em buscar soluções, elegendo ações que possam melhorar a situação. Essa etapa precisa ser desenvolvida com base em um quadro de ações, metas, atividades, cronograma, e na identificação dos recursos institucionais e comunitários possíveis de serem mobilizados.

Cabe lembrar que, para alguns problemas essenciais, como acesso a terra, educação e/ou saúde não existem soluções a curto prazo. No entanto, a mobilização da comunidade, dos profissionais, dos representantes do controle social e até mesmo do governo local pode resultar na apresentação de soluções aos responsáveis pela elaboração de políticas e programas na área.

Vamos praticar um pouco? Propomos, a seguir, uma atividade para você construir um quadro com ações, metas e prazos.

\section{PARA PRATICAR - SELEÇÃO DE INTERVENÇÕES}

Em continuidade ao exercício de construção da "árvore de problemas", que você desenvolveu com seu grupo de trabalho, dê o passo seguinte:

1. Selecione um problema e descreva, no mínimo, quatro ações/intervenções, com as respectivas metas e cronogramas, que devem ser implementas para solucioná-lo.

2. Para sistematizar suas idéias, você pode utilizar o modelo de quadro a seguir.

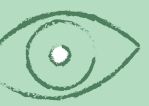

O vídeo Atitude de vigilância foi produzido pelo Inan/MS e CPCE/UnB (Centro de Produção Cultural e Educativa/Universidade de Brasília, coleção Vídeos em Saúde), em junho de 1997. Ele faz parte do acervo da Coordenação Geral das Políticas de Alimentação e Nutrição (CGPAN), do Ministério da Saúde, e da videoteca do Departamento de Comunicação em Saúde (DCS), do Instituto de Comunicação Científica e Tecnológica em Saúde (ICICT) da Fiocruz, que pode ser acessada por meio da página eletrônica da Fiocruz. Para qualquer informação sobre a reprodução, contatar a videoteca. 


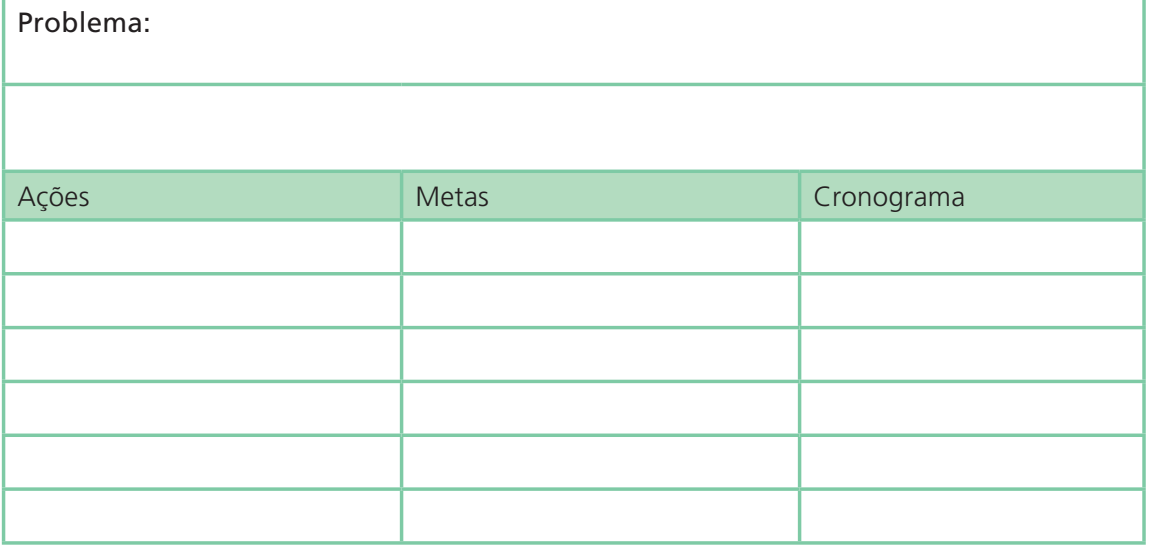

A construção do quadro nos oferece como resultado as ações e intervenções a serem executadas. Em geral, é um elenco grande e extenso e, conseqüentemente, de difícil seleção. Para isso, é importante definir, previamente, os critérios de seleção de intervenções.

Beghin, Cap e Dujardin (1988) propuseram uma forma esquemática e bem útil para definir critérios e selecionar intervenções. A partir das ações e intervenções que iremos desenvolver, identificadas na etapa anterior, vamos discutir os critérios para selecionar aquelas mais importantes para a nossa atuação. Lembre-se de que todo esse processo é coletivo e precisa ser debatido e pactuado entre todos os agentes de desenvolvimento.

A técnica proposta pelos autores é a da construção de um quadro com a descrição das ações/intervenções e a lista de critérios através de uma escala numérica de pontuação. Pode-se incorporar critérios qualitativos que vão aumentar ainda mais o poder de escolha da intervenção.

Os critérios mais utilizados para selecionar uma intervenção são: (1) baixo custo, (2) boa exeqüibilidade técnica e operacional; (3) adesão da comunidade; (4) adesão do profissional da saúde; e (5) existência de apoio institucional. No entanto você e/ou seu grupo de trabalho poderão definir outros critérios que atendam a sua realidade. 


\section{PARA PRATICAR - ESTABELECIMENTO DE CRITÉRIOS DE SELEÇÃO}

1. Reveja o quadro do exercício anterior, com seu grupo de trabalho, e proponha quatro critérios para selecionar a intervenção que será implementada. Comente as razões de escolha de cada critério, sinalizando aquele que tem maior importância na definição de prioridades de ação.

2. Selecione quatro ações/intervenções do quadro referido no item anterior, e faça outro quadro com a descrição dos critérios e das ações/intervenções, conforme o modelo a seguir.

Critérios de seleção das ações/intervenções

\begin{tabular}{|l|l|l|l|l|l|}
\hline \multirow{2}{*}{ Ações/Intervenções } & \multicolumn{5}{c|}{ Critérios } \\
\cline { 2 - 7 } & 1 & 2 & 3 & 4 & Total \\
\hline & & & & & \\
\hline & & & & & \\
\hline & & & & & \\
\hline & & & & & \\
\hline & & & & & \\
\hline & & & & & \\
\hline & & & & & \\
\hline
\end{tabular}

1.Estabeleça as notas dos critérios, com variação de 0 a 10, para classificar as ações/intervenções. A nota 0 será para o critério mais fraco e 10, para o mais forte em relação à ação/intervenção que está sendo avaliada.

2.Some, na linha de ações/intervenções, o valor de pontos para todos os critérios, sinalizando aquela que recebeu maior pontuação.

Importante: se ao final houver empate entre algumas das intervenções, deverá prevalecer aquela intervenção que tiver a nota mais alta para um dos critérios que você e/ou seu grupo estabeleceu como o mais importante. Por exemplo, você e/ou seu grupo podem ter definido que baixo custo é o critério mais importante; logo, a ação que tiver maior nota neste critério é aquela que irá prevalecer. 
Reconhecemos que o processo de construção do Sisvan pode ser desenvolvido de várias formas, mas a principal é aquela que potencializa o protagonismo entre os profissionais e a população, possibilitando a construção de ações que contribuam para a melhoria das condições alimentares e nutricionais da população indígena. Podemos nos indagar agora: será que apenas informar os resultados encontrados é um ato transformador da realidade? Será que as informações que divulguei são suficientes para alterar um quadro de falta de comida, de falta de acesso à educação e ao saneamento? Não podemos afirmar a você se isso é suficiente. Podemos, sim, dividir com você que, com o uso desses dados e sua transformação em informações, você pode exercitar a advocacia política desses problemas junto à sociedade, à comunidade e aos setores de decisão política. Esses questionamentos nos acompanharão por nossa vida profissional. E quem sabe serão nossos estimuladores!

Estaremos à disposição para compartilhar com você os momentos difíceis e de dúvidas, ajudando-o em seu cotidiano de atuação. A perspicácia de saber transitar entre o tempo político e técnico das ações de intervenção é um dos principais desafios a serem superados por todos nós. Enfim, o que desejamos é contribuir para a melhoria da situação alimentar e nutricional da população brasileira, na qual os povos indígenas têm um papel histórico e digno.

\section{Referências}

BARROS, D. C. (Org.); SILVA, D. O. e (Org.); GUGELMIN, S. A. (Org.). Vigilância alimentar e nutricional para a saúde indígena, 1. Rio de Janeiro: Fiocruz/ENSP/Educação a Distância, 2007.

BEGHIN, I.; CAP, M.; DUJARDIN, B. A guide to nutritional assessment. Geneva: WHO, 1988.

BRASIL. Lei n. 11.346, de 15 de setembro de 2006. Cria o Sistema Nacional de Segurança Alimentar e Nutricional - SISAN com vistas em assegurar o direito humano à alimentação adequada e dá outras providências. Diário Oficial da União, Brasília, 18 set. 2006. Disponível em: <http://www.abrandh. org.br/downloads/losanfinal15092006.pdf>. Acesso em: 23 fev. 2007.

Ministério da Saúde. Norma operacional básica do Sistema Único de Saúde: NOB-SUS 96. Brasília, 1997. 34 p.

Portaria MS/GM n. 95, de 26 de janeiro de 2001. Dispõe sobre a Norma Operacional da Assistência à Saúde - NOAS-SUS 01/01. Brasília, 2001.

Portaria MS n. 710, de 10 de junho de 1999. Dispõe sobre a Política Nacional de Alimentação e Nutrição. Diário Oficial da União, Brasília, v. 110, 11 jun. 1999. Seção 1, p. 14. 
CONFERÊNCIA NACIONAL DE SEGURANÇA ALIMENTAR E NUTRICIONAL, 2., 2004, Olinda. Relatório final. Brasília: CONSEA, 2004.

FUNDAÇÃO NACIONAL DE SAÚDE. Conferências Nacionais de Saúde Indígena: relatórios finais. Brasília, 2006a.

Norma técnica do Sistema de Vigilância Alimentar e Nutricional para os Distritos Sanitários Especiais Indígenas. Brasília, 2006b.

INSTITUTO NACIONAL DE ALIMENTAÇÃO E NUTRIÇÃO (Brasil). Planejamento participativo: um instrumento de combate a fome. Brasília: Ministério da Saúde; Instituto de Pesquisa Econômica Aplicada; Organização das Nações Unidas para Agricultura e Alimentação, 1994. 43 p.

ORGANIZAÇÃO DAS NAÇÕES UNIDAS PARA A AGRICULTURA E A ALIMENTAÇÃO. Guia para projetos participativos de nutrição. Roma, 1997. Disponível em: < http://www.fao.org/DOCREP/003/ V1490PN1490P00.htm\#TOC> Acesso em: 23 fev. 2007. 


\section{Siglas}

Abrasco

Associação Brasileira de Pós-Graduação em Saúde Coletiva

A

Adequado

AJ

Altura do Joelho

A/l

Altura para Idade

AIDPI

Atenção Integrada às Doenças Prevalentes na Infância

AIS

Agente Indígena de Saúde

BP

Baixo peso

BPN

Baixo Peso ao Nascer

$\mathrm{CB}$

Circunferência do Braço

$\mathrm{CDC}$

Center Disease Control and Prevention

CGPAN

Coordenação Geral das Políticas de Alimentação e Nutrição

Clap

Centro Latino-Americano de Perinatologia e Desenvolvimento Humano

\section{$\mathrm{CPO}$}

Índice de dentes cariados, perdidos e obturados

Condisi

Conselho Distrital de Saúde Indígena

Core

Coordenação Regional da Funasa

CPCE

Centro de Produção Cultural e Educativa

DCS

Departamento de Comunicação em Saúde da Fiocruz

DCSE

Dobra Cutânea Subescapular

Desai

Departamento de Saúde Indígena

Dimea

Divisão de Metrologia na Saúde e Meio Ambiente

DN

Diagnóstico Nutricional

DP

Desvio-Padrão
DPC

Desnutrição Protéico-Calórica

DSEI

Distrito Sanitário Especial Indígena

DUM

Data da Última Menstruação

E/I

Estatura para Idade

EMSI

Equipes Multidiscipinares de Saúde Indígena

EN

Estado Nutricional

ENSP

Escola Nacional de Saúde Pública

ESF

Estratégia Saúde da Família

FAO

Organização das Nações Unidas para Agricultura e Alimentação

Funasa

Fundação Nacional de Saúde

ICICT

Instituto de Comunicação Científica e Tecnológica em Saúde da Fiocruz

IG

Idade Gestacional

IMC

Índice de Massa Corporal

Inan

Instituto Nacional de Alimentação e Nutrição

IOM

Institute of Medicine

IRA

Infecções Respiratórias Agudas

Inmetro

Instituto Nacional de Metrologia, Normalização e

Qualidade Industrial

Ipem

Instituto de Pesos e Medidas

MDS

Ministério do Desenvolvimento Social e Combate à Fome

MS

Ministério da Saúde

NCHS

National Center for Health Statistics 
NOAS

Norma Operacional de Assistência à Saúde

$\mathrm{NOB}$

Norma Operacional Básica

○

Obesidade

OMS

Organização Mundial da Saúde

ONG

Organização Não-Governamental

PA

Peso atual

P/A

Peso para Altura

PB

Perímetro Braquial

PC

Perímetro Cefálico

P/E

Peso para Estatura

$\mathrm{P} / \mathrm{I}$

Peso para Idade

PIG

Pequenas para Idade Gestacional

PPG

Peso pré-gestacional

PT

Perímetro Torácico

$\mathrm{RCIU}$

Retardo do Crescimento Intra-Uterino

SAS

Secretaria de Atenção à Saúde

Siab

Sistema de Informação da Atenção Básica

Siasi

Sistema de Informação da Atenção à Saúde Indígena

$\mathrm{SIH}$

Sistema de Informação Hospitalar

Sim

Sistema de Informação de Mortalidade

Sinan

Sistema de Informação de Agravos de Notificação

Sinasc

Sistema de Informação de Nascidos Vivos

Sisvan

Sistema de Vigilância Alimentar e Nutricional

Sobrepeso

SUS

Sistema Único de Saúde
TFT

Taxa de Fecundidade Total

TM

Taxa de Mortalidade Infanti

TRO

Terapia de Reidratação Oral

UnB

Universidade de Brasília

WHO

World Health Organization 
Formato: $210 \times 260 \mathrm{~mm}$

Tipologias: Meridien LT Std e Frutiger Lt Std.

Papel: Printmax $90 \mathrm{~g} / \mathrm{m}^{2}$

Capa: Cartão supremo $250 \mathrm{~g} / \mathrm{m}^{2}$

Impressão e Acabamento: Ctp Digital, Ediouro Gráfica e Editora Ltda.

Rio de Janeiro, junho de 2008

Não encontrando nossos títulos em livrarias,

contactar a EDITORA FIOCRUZ:

Av. Brasil, $4036-1^{\circ}$ andar - Sala 112

Manguinhos - Rio de Janeiro - RJ 21040-361

Tel.: (21) 3882-9039 e 3882-9041

Telefax: (21) 3882-9006

e-mail: editora@fiocruz.br

http://www.fiocruz.br/editora 